\title{
Sorption of lead and arsenic on soil components and effectiveness of phosphates for remediating lead and arsenic contaminated soils
}

\author{
Harjinder Sandhu \\ West Virginia University
}

Follow this and additional works at: https://researchrepository.wvu.edu/etd

\author{
Recommended Citation \\ Sandhu, Harjinder, "Sorption of lead and arsenic on soil components and effectiveness of phosphates for \\ remediating lead and arsenic contaminated soils" (2001). Graduate Theses, Dissertations, and Problem \\ Reports. 1376. \\ https://researchrepository.wvu.edu/etd/1376
}

This Dissertation is protected by copyright and/or related rights. It has been brought to you by the The Research Repository @ WVU with permission from the rights-holder(s). You are free to use this Dissertation in any way that is permitted by the copyright and related rights legislation that applies to your use. For other uses you must obtain permission from the rights-holder(s) directly, unless additional rights are indicated by a Creative Commons license in the record and/ or on the work itself. This Dissertation has been accepted for inclusion in WVU Graduate Theses, Dissertations, and Problem Reports collection by an authorized administrator of The Research Repository @ WVU.

For more information, please contact researchrepository@mail.wvu.edu. 


\title{
Sorption of Lead and Arsenic on Soil Components and Effectiveness of Phosphates for Remediating Lead and Arsenic Contaminated Soils
}

\section{Harjinder Sandhu}

\author{
Dissertation submitted to the \\ College of Agriculture, Forestry and Consumer Sciences \\ at West Virginia University \\ in partial fulfillment of the requirements \\ for the degree of \\ Doctor of Philosophy \\ in \\ Plant and Soil Sciences
}

Devinder K. Bhumbla, Ph. D., Chair

Bradford C Bearce, Ph.D.

Joginder Nath, Ph.D.

John Renton,Ph.D.

John Sencindiver, Ph.D.

Jeffery G. Skousen, Ph.D.

Division of Plant and Soil Sciences

Morgantown, West Virginia

2001

Keywords: Iron Coatings, Aluminum Coatings, Lead and Arsenic Sorption, Lead Pyromorphite, Heavy Metal Remediation, Phosphates 


\title{
ABSTRACT \\ Sorption of Lead and Arsenic on Soil Components and Effectiveness of Phosphates for Remediating Lead and Arsenic Contaminated Soils
}

\author{
Harjinder Sandhu
}

High concentration of trace elements such as arsenic (As) and lead $(\mathrm{Pb})$ represents one of the potentially costly threats to water and soil resources as well as serious threats to humans. Clay minerals are potential binding agents for pollutants due to their high cation exchange capacity and large surface area. Laboratory investigations were undertaken to evaluate the effect of $\mathrm{Fe}$ and $\mathrm{Al}$ hydrous oxide coatings on the sorption of $\mathrm{Pb}$ and As. Four clay minerals attapulgite, illite, kaolinite and montmorillonite with a range of surface characteristics were selected to investigate the $\mathrm{Pb}$ and As sorption. The minerals were coated with three different levels of each of $\mathrm{Fe}$ and $\mathrm{Al}$ hydrous oxides. Adsorption and desorption studies were performed for each of these heavy metals at seven different $\mathrm{pH}$ levels. Coating with both $\mathrm{Fe}$ and $\mathrm{Al}$ hydrous oxide increased the retention of $\mathrm{Pb}$ and As. Lead desorption was decreased when minerals were coated with highest levels of $\mathrm{Fe}$ and $\mathrm{Al}$. In order to fully understand the fate and transport of metal in the environment, there is a need to accurately describe and model the complex natural system. The ability of surface complexation models (SCMs) to fit sets of titration data as a function of changes in model parameters was evaluated using FITEQL and acid base titration of clays coated with $\mathrm{Fe}$ and $\mathrm{Al}$ hydrous oxide. Three SCMs were evaluated: the constant capacitance model, the diffuse-double layer and triple layer model. For all the models evaluated, increasing the value of total number of sites resulted in a decrease in the FITEQL best fit equilibrium log K value. Generally better $F$ value fits were obtained when the site density $\left(\mathrm{N}_{\mathrm{s}}\right)$ value was between 1 to 10 sites $/ \mathrm{nm}^{2}$.

Sequestering heavy metals in insoluble phosphate minerals has been suggested as an in situ remediation technique for $\mathrm{Pb}$ contaminated soils. Lead sequestered in apatite minerals has great durability and leaching resistance, significantly exceeding other chemically stabilized forms. Sequential extractions of $\mathrm{Pb}$ have been used to determine the suitability of phosphates to immobilize $\mathrm{Pb}$. Laboratory studies were conducted to investigate whether the lead pyromorphite formation is the artifact of the sequential extraction or it is actually formed. It was found that formation of pyromorphite might be due to the artifact of extraction process. There are concerns about the use of phosphate in soils contaminated with both $\mathrm{Pb}$ and As because As and phosphate compete for the same sorption sites. Greenhouse experiments were conducted on soils contaminated with both $\mathrm{Pb}$ and As. These soils were treated with four rates of phosphates and seeded with Japanese millet (Echinochloa crusgalli) and red clover (Trifolium pratense). Results showed that when soils were contaminated with arsenic (As) only, application of phosphates resulted in increased concentrations of As in soil solution, however when soils were contaminated with both $\mathrm{Pb}$ and $\mathrm{As}$, application of phosphorus did not increase As concentration in soil solution. Laboratory investigations were conducted to determine the mechanism responsible for reduced As mobility in soils that are co-contaminating with $\mathrm{Pb}$. The results suggested that $\mathrm{As}$ in $\mathrm{Pb}$ contaminated soils coprecipitates with lead phosphates. 


\title{
TO MY PARENTS
}

\section{WHOSE BLESSINGS AND INSPIRATIONS}

\author{
BROUGHT ME THIS FAR
}




\section{TABLE OF CONTENTS}

ACKNOWLEDGMENTS .......................................................................

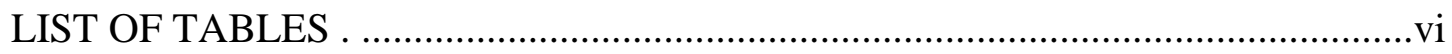

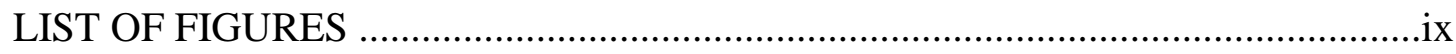

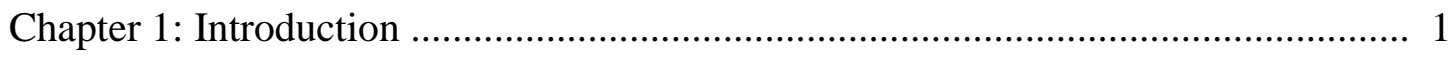

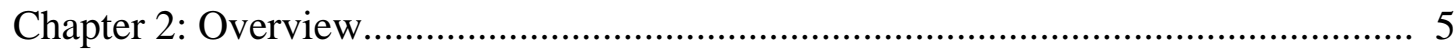

Chapter 3: Sorption of Lead and Arsenic on Iron and Aluminum Coated Clays .........25

Chapter 4: Surface Complexation Modeling ......................................................63

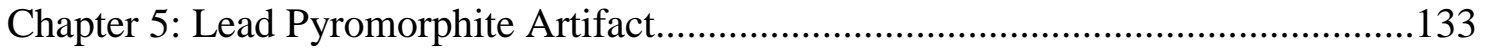

Chapter 6: Use of Phosphates for Remediating Lead and Arsenic Contaminated

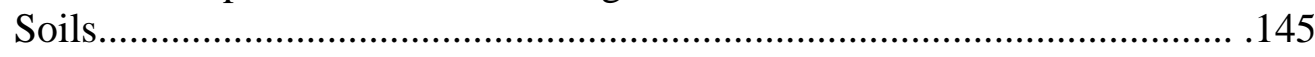




\section{ACKNOWLGEMENTS}

I wish to express my sincere gratitude to Dr. Devinder Bhumbla for all his support, motivation, guidance, incessant encouragement, moral support and time so generously given during the course of investigation. His indefatigable professional interests, ever willingness to help have had a profound influence on my thinking. I learnt great deal of things from him and he will always be a source of inspiration to me. This manuscript would not have been possible without his help.

I also wish to extend my appreciation to members of my advisory committee- Drs., B. C. Bearce, John Sencindiver, Jeff Skousen, Joginder Nath and J. J. Renton for their valuable suggestions, critical review and constructive criticism of the manuscript. I also wish to thank Dr. Louis McDonald for his ever-willingness to provide technical guidance and scientific literature whenever I approached him .

Appreciation is also extended to E. J.Wright and my fellow graduate students for their help in the laboratory experiments. I am sincerely thankful to my friends Bharpoor, Vinod, Jandeep for their help during the preparation of this manuscript. Much appreciation is extended to Amandeep, Swarn and Ramkumar for their brotherly moral support.

With great pleasure, I acknowledge the vital role my family. I am both extremely lucky and thankful for their continual love, encouragement, and support . My parents (Mrs. Harpal kaur and Mr. Jarnail singh), brothers (Devinder and Bhagwant), sister (Jasbir), sister-in law ( Ramneek), provided me with much needed determination and means to carry out this study. Finally I wish to extend my deepest love to my marvelous wife, Deepak, without whom I would have never reached this far, and my thanks to her for knowing me so well 


\section{LIST OF TABLES}

3.1 Important physico-chemical characteristics of clay minerals .................... 27

4.1 Surface chemical reaction and model parameter .................................... 66

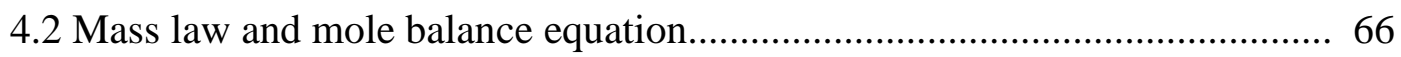

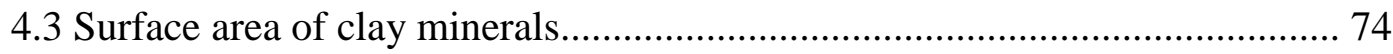

4.4 Point of zero salt effect (PZSE) of different clay minerals .......................... 76

4.5 Sensitivity of DLM to variation in total site density for pure clay minerals .. 80

4.6 Sensitivity of DLM to variation in total site density for $4 \%$ iron coated clay

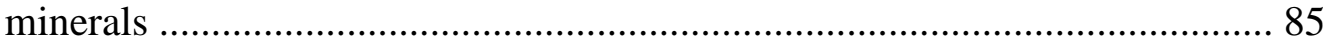

4.7 Sensitivity of DLM to variation in total site density for $4 \%$ aluminum coated

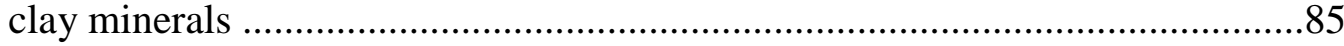

4.8 Effect of coatings on the DLM best fit value of protolysis constant for

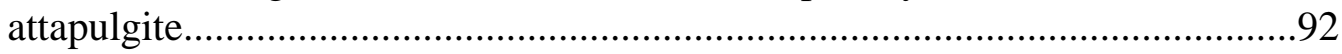

4.9 Effect of coatings on the DLM best fit value of protolysis constant for illite....92

4.10 Effect of coatings on the DLM best fit value of protolysis constant for kaolinite

4.11 Effect of coatings on the DLM best fit value of protolysis constant for montmorillonite

4.12 Sensitivity of CCM to variation in total site density, ionic strength and capacitance for titration data for pure clay minerals

4.13 Sensitivity of CCM to variation in total site density, ionic strength and capacitance for titration data for $4 \%$ Iron coated clay minerals.

4.14 Sensitivity of CCM to variation in total site density, ionic strength and capacitance for titration data of $4 \%$ aluminum coated clay minerals.

4.15 Effect of coatings on sensitivity of CCM to variation in total site density, ionic strength and capacitance for attapulgite titration data..... 
4.16 Effect of coatings on sensitivity of CCM to variation in total site density, ionic strength and capacitance for illite titration data.

4.17 Effect of coatings on sensitivity of CCM to variation in total site density, ionic strength and capacitance for kaolinite titration data

4.18 Effect of coatings on sensitivity of CCM to variation in total site density, ionic strength and capacitance for montmorillonite titration data.

4.19 Representative sensitivity of TLM to variation in total site density and ionic strength using pure clay titration data.

4.20 Representative sensitivity of TLM to variation in total site density and ionic strength using $4 \%$ iron coated clay titration data.

4.21 Representative sensitivity of TLM to variation in total site density and ionic strength using $4 \%$ aluminum coated clay titration data...

4.22 Effect of coatings on the sensitivity of TLM for attapulgite.

4.23 Effect of coatings on the sensitivity of TLM for illite 126

4.24 Effect of coatings on the sensitivity of TLM for kaolinite......

4.25 Effect of coatings on the sensitivity of TLM for montmorillonite.

5.1 Lead Concentration $(\mu \mathrm{g} / \mathrm{g})$ in different fractions of the original soils 138

5.2 Lead Concentration $(\mu \mathrm{g} / \mathrm{g})$ in different fractions of the soils treated with $(11,550(\mu \mathrm{g} / \mathrm{g})) \mathrm{P}$ 138

5.3 Lead Concentration $(\mu \mathrm{g} / \mathrm{g})$ in different fractions of the soils treated with $(23,110(\mu \mathrm{g} / \mathrm{g})) \mathrm{P}$.

6.1: Physico- chemical properties of the Soil-1 used in the greenhouse experiment -1 .

6.2: Physico- chemical properties of soils used in the greenhouse experiment-2

6.3: Effect of four rates of phosphate treatments on As concentrations $\left(\mathrm{mg} \mathrm{kg}^{-1}\right)$ in red clover plants grown on three soils that have been contaminated with 
$0,125,250 \mathrm{mg} \mathrm{kg}^{-1} \mathrm{As}$

6.4 : Effect of phosphate concentrations in extracting solutions on As extractions from three soils contaminated with three levels of As...................161

6.5: Effect of application rate of phosphates on $\mathrm{Pb}$ and As concentrations in Japenese millet grown on three soils contaminated with both $\mathrm{Pb}$ and $\mathrm{As} . . . . . . .163$

6.6: Effect of application rate of phosphates on $\mathrm{Pb}$ and $\mathrm{As}$ concentrations in red clover grown on three soils contaminated with both $\mathrm{Pb}$ and $\mathrm{As} . . . \ldots \ldots \ldots \ldots \ldots . . . . . .165$

6.7: Lead and As concentrations in equilibrum solutions when $0.1 \mathrm{M} \mathrm{Pb}\left(\mathrm{NO}_{3}\right)_{2}$ were reacted with $0.1 \mathrm{M}$ phosphate solution that contained 0.0001 to $0.01 \mathrm{M}$ $\mathrm{Na}\left(\mathrm{AsO}_{4}\right)_{2}$. 166 


\section{List of Figures}

3.1 Effect of different levels of iron coatings on the adsorption of lead by montmorillonite.

3.2 Effect of different levels of aluminum coatings on the adsorption of lead by montmorillonite.

3.3 Effect of different levels of iron coatings on the adsorption of arsenic by montmorillonite.

3.4 Effect of different levels of aluminum coatings on the adsorption of arsenic by montmorillonite

3.5 Effect of different levels of iron coatings on the adsorption of lead by illite 33

3.6 Effect of different levels of aluminum coatings on the adsorption of lead by illite 34

3.7 Effect of different levels of iron coatings on the adsorption of arsenic by illite 36

3.8 Effect of different levels of aluminum coatings on the adsorption of arsenic by illite. .37

3.9 Effect of different levels of iron coatings on the adsorption of lead by kaolinite ....38

3.10 Effect of different levels of aluminum coatings on the adsorption of lead by kaolinite

3.11 Effect of different levels of iron coatings on the adsorption of arsenic by kaolinite.

3.12 Effect of different levels of aluminum coatings on the adsorption of arsenic by kaolinite.

3.13 Effect of different levels of iron coatings on the adsorption of lead by attapulgite 42

3.14 Effect of different levels of aluminum coatings on the adsorption of lead by attapulgite.

3.15 Effect of different levels of iron coatings on the adsorption of arsenic by attapulgite

3.16 Effect of different levels of aluminum coatings on the adsorption of arsenic by 
attapulgite.

3.17 Effect of different levels of iron coatings on the desorption of lead by montmorillonite.

3.18 Effect of different levels of aluminum coatings on the desorption of lead by montmorillonite

3.19 Effect of different levels of iron coatings on the desorption of lead by illite.

3.20 Effect of different levels of aluminum coatings on the desorption of lead by illite.

3.21 Effect of different levels of iron coatings on the desorption of lead by kaolinite .50

3.22 Effect of different levels of aluminum coatings on the desorption of lead by kaolinite.

3.23 Effect of different levels of iron coatings on the desorption of lead by attapulgite

3.24 Effect of different levels of aluminum coatings on the desorption of lead by attapulgite.

3.25 Lead adsorption on pure and iron coated clay minerals. .57

3.26 Lead adsorption on pure and aluminum coated clay minerals.............................58

3.27 Arsenic adsorption on pure and iron coated clay minerals................................. 59

3.28 Arsenic adsorption on pure and aluminum coated clay minerals..........................60

4.1 Diffuse double layer model fit of titration data for pure attapulgite.........................81

4.2 Diffuse double layer model fit of titration data for pure illite................................82

4.3 Diffuse double layer model fit of titration data for pure kaolinite ............................83

4.4 Diffuse double layer model fit of titration data for $4 \%$ iron coated attapulgite 
4.5 Diffuse double layer model fit of titration data for $4 \%$ aluminum coated attapulgite

4.6 Diffuse double layer model fit of titration data for $4 \%$ iron coated illite .88

4.7 Diffuse double layer model fit of titration data for $4 \%$ iron coated kaolinite

4.8 Diffuse double layer model fit of titration data for $4 \%$ aluminum coated kaolinite. 90

4.9 Diffuse double layer model fit of titration data for $4 \%$ aluminum coated illite.........91

4.10 Constant capacitance model fit of titration data for pure attapulgite.......................96

4.11 Constant capacitance model fit of titration data for pure illite..............................97

4.12 Constant capacitance model fit of titration data for pure kaolinite.........................98

4.13 Constant capacitance model fit of titration data for $4 \%$ iron coated attapulgite .....102

4.14 Constant capacitance model fit of titration data for $4 \%$ aluminum coated attapulgite 103

4.15 Constant capacitance model fit of titration data for $4 \%$ iron coated illite 104

4.16 Constant capacitance model fit of titration data for $4 \%$ iron coated kaolinite 105

4.17 Constant capacitance model fit of titration data for $4 \%$ aluminum coated kaolinite...... 106

4.18 Constant capacitance model fit of titration data for $4 \%$ aluminum coated illite ...107

4.19 Triple layer model fit of titration data for pure attapulgite. 113

4.20 Triple layer model fit of titration data for pure illite. .114

4.21 Triple layer model fit of titration data for pure kaolinite..... .115

4.22 Triple layer model fit of titration data for $4 \%$ iron coated attapulgite.

4.23 Triple layer model fit of titration data for $4 \%$ aluminum coated attapulgite 120 4.24 Triple layer model fit of titration data for $4 \%$ iron coated illite. .121 
4.25 Triple layer model fit of titration data for $4 \%$ aluminum coated illite...................122

4.26 Triple layer model fit of titration data for $4 \%$ iron coated kaolinite......................123

4.27 Triple layer model fit of titration data for $4 \%$ aluminum coated kaolinite...............124

5.1 Extractable lead without phosphorus from iron-oxides......................................140

$5.2 \mathrm{X}$ - ray diffraction of iron oxides sorbed with lead and phosphates......................141

5.3 Extractable lead with phosprous from the iron-oxides.....................................142

6.1: Effect of mole fraction of As in $\mathrm{P}$ solution on $113 \mathrm{~d}$ spacing of a pyromorphite crystal................................................... 168 


\section{Chapter 1}

\section{Introduction}

\section{Rationale and Scope of Research}

Pollution of the biosphere with toxic elements has accelerated dramatically since the beginning of the industrial revolution. As a result of accumulation in the biosphere, lead $(\mathrm{Pb})$ and arsenic(As) pose more serious worldwide environmental and health hazards than any other elements (Jaworski, 1987; Huang Yan-Chu, 1997).

Lead concentration in agricultural soils of the US ranges from $<1$ to $135 \mathrm{mg} / \mathrm{kg}$ with an average of $12.3 \mathrm{mg} / \mathrm{kg}$ (Holmgren et al., 1993). However, the number of soils containing elevated $\mathrm{Pb}$ concentration has increased during the past half century due to anthropogenic contamination resulting from leaded paints, leaded gasoline, and $\mathrm{Pb}$ emission and waste from industries (Mielke, 1994). Lead contamination can cause a variety of environmental problems including Pb toxicity to plants, animals, and humans (Buchauer, 1973; Johnson and Eaten, 1980). Ingestion of contaminated soil is the most common pathway for lead poisoning in children (Chaney, 1989; EPA, 1993). Lead can enter the food chain through contaminated vegetation; however, $\mathrm{Pb}$ concentration of plants is generally less than $1 \mathrm{mg} / \mathrm{kg}$ in fruits and seeds, and 1 to 3 $\mathrm{mg} / \mathrm{kg}$ in leaves.

Arsenic is a commonly occurring toxic element in natural ecosystems. The natural concentration of As in soil is 5-6 mg/kg (Vinogrador, 1959; Backer and Chesnin, 1975; Bowen, 1979). The total amount of As in soil and its chemical form have an important influence on plant growth, and animal and human health. The sources of As in soils are the parent rock and human activities. Human activities may result in an accumulation of As in soil through use of arsenical pesticides, application of $\mathrm{P}$ fertilizer, irrigation, dust from burning of fossil fuels, and 
disposal of industrial and animal wastes (Sandberg and Allen, 1975). The anthropogenic influence on the level of As in soils depends on the intensity of human activity, the distance from the pollution sources, and the pollutant dispersion pattern.

Soil serves as an important medium for accumulation, transformation, and migration of the toxic chemicals. Sources of $\mathrm{Pb}$ and As contamination can be agricultural activities such as application of insecticides $\left(\mathrm{PbHAsO}_{4}\right)$ and industrial activities such as mining and smelting. Existing and abandoned disposal sites of $\mathrm{As}$ and $\mathrm{Pb}$ are potential sources of soil, and ground and surface water pollution. There is a need for remediation methods that do not destroy soil structure or fertility and are cheap and suitable for application on arable land (David et al., 1995).

Amorphous oxides of $\mathrm{Fe}$ and $\mathrm{Al}$ are known to adsorb $\mathrm{Pb}$ and $\mathrm{As}$ (Mckenzie, 1980; Bhumbla and Keefer, 1997). These oxides may occur as discrete particles, having little contact with clay surfaces or coating on clays, or as interlayers between clay mineral surfaces. Heavy metal adsorption characteristics of hydrous oxide coated clay may differ from either the hydrous oxides alone or clay minerals occurring as individual phases. Heavy metal adsorption on hydroxy-coated mineral surfaces may be affected by such factors as type of clay mineral and extent of surface coating with oxides/hydroxides. The type of clay mineral should influence the heavy metal adsorption because of variable particle sizes and different surface areas available for adsorption. The extent of surface coating should determine the extent of heavy metal adsorption because the cation adsorption characteristics of hydrous oxides and silicate clays differ markedly. Most soils are heterogeneous media that contain a host of different minerals, solids and oxides. As a result exploring the effect of coatings on adsorption/desorption of $\mathrm{Pb}$ and $\mathrm{As}$ is worthy of investigation. 
Soil may act as a reservoir and can become an environmental pathway or carrier of $\mathrm{Pb}$ and As to biota. Thus, it is important to develop methods to minimize $\mathrm{Pb}$ and $\mathrm{As}$ bio-availability. Phosphate minerals have been used to immobilize $\mathrm{Pb}$ in situ from aqueous solutions and in $\mathrm{Pb}$ contaminated soils (Chowdhury et al., 1994; Ma et al., 1995,1993, Mench, 1994). The primary mechanism of $\mathrm{Pb}$ immobilization appears to be phosphate mineral dissolution and subsequent precipitation of pyromorphite like

$\left(\mathrm{Pb}_{10}\left(\mathrm{PO}_{4}\right)_{6}(\mathrm{OH})_{2}\right)$ minerals through such mechanisms as cation substitution. Adsorption and precipitation as other minerals are also possible (Ma et al., 1993). Phosphate minerals with moderate solubility supply sufficient $\mathrm{P}$ to precipitate $\mathrm{Pb}$, while causing minimum $\mathrm{P}$ contamination to the environment (Ma, 1996).

The effect of $\mathrm{P}$ on As phytotoxicity is unpredictable. Tsutsumi (1983) found that phosphate fertilizer additions to soils having lead arsenate pesticide residue can increase As availability. This increase of As availability may be due to: 1) competition between As and P fixation sites on soil (Woolson et al., 1973); 2) displacement of As ions by $\mathrm{P}$ ions from adsorption sites, rendering more As available; and 3) antagonism between $\mathrm{P}$ and As on plant roots and within the plant system.

The toxicity from $\mathrm{Pb}$ and $\mathrm{As}$ and their presence in the environment at dangerous levels are well established facts; however, the questions remain: what will be the impacts of using phosphate to remediate $\mathrm{Pb}$ and $\mathrm{As}$ contaminated soils, and how can significant risks be accurately evaluated? Finding effective answers to these questions hinges on a clear understanding of the mechanisms of $\mathrm{Pb} / \mathrm{As}$ - phosphate interactions. This will provide scientists and engineers information to implement better strategies for dealing with $\mathrm{Pb}$ and $\mathrm{As}$ 
contaminated soils, and will allow for better decisions on $\mathrm{Pb}$ and $\mathrm{As}$ disposal that will not cause further threats to society and the environment. 


\section{Chapter 2}

\section{Overview}

\subsection{Lead}

The contamination of soil by $\mathrm{Pb}$ from anthropogenic activities such as mining, use of leaded gasoline and the manufacture and testing of $\mathrm{Pb}$ based explosives is a worldwide environmental concern. Soils polluted with $\mathrm{Pb}$ pose health threats to humans as well as plants and animals, often necessitating extensive remediation practices. Various biological and chemical processes are already being used to remediate contaminated soil and water. These processes include the following

1) Phytoremediation

2) Application of soil amendments, and

3) Fixation

\subsubsection{Phytoremediation}

Remediation of metal contaminated soils using plants that accumulate heavy metal is currently being studied throughout the world (Wu et al., 1999; Cunningham et al., 1995; Schnoor et al., 1995). This remediation strategy, termed phytoremediation and defined as the use of plants for environmental clean up, may provide a more economical and aesthetically pleasing alternative to conventional remediation options.

Most plants are highly sensitive to heavy metals and cannot endure even low concentrations in soils (Larcher,1980), but there exists some plants that are metal resistant (Shaw,1990). Metal resistance can be achieved through a variety of mechanisms that can be 
defined as either a mechanism of avoidance or mechanism of tolerance. Levitt (1980) defines avoidance as the ability to prevent excessive metal uptake, and tolerance as the ability to cope with metals that are excessively accumulated in some part of the plant. Plants that use mechanisms of avoidance are often called as metal excluders and metal tolerant plants are called metal accumulators.

The initial emphasis in phytoremediation research has been on a small number of wild plants termed hyper-accumulators that are able to accumulate high concentrations of specific metals in aboveground tissues (Baker et al., 1988; 1994; Chaney et al,. 1995).Therefore, current efforts have emphasized use of agricultural species such as Brassica spp., Zea mays L., and Nicotiana spp., that could be grown efficently following established agricultural practices (Wu et al., 1999; Huang and Cunningham, 1996; Kumar et al., 1995; Mench and Martin, 1991). Advantages of using metal accumulator plants are low costs, generation of recyclable metal-rich plant residues containing a range of toxic metals, minimal environmental disturbance, elimination of secondary air or water borne wastes, and public acceptance.

This research is promising since a variety of species have been identified that can accumulate high concentrations of certain metals. Such species generally require significant maintenance in the form of irrigation, fertilization, and use of herbicides, insecticides and other soil amendments. Thus the use of these species is restricted to arable lands and would not be applicable to more highly disturbed and remote areas such as abandoned mine sites (Klassen et al., 2000).

Approaches to enhance the effectiveness of phytoremediation will likely include manipulating agronomic practices (e.g. cropping, fertilizing) to optimize plant growth and 
biomass using plant breeding and genetic engineering to develop high biomass metal accumulation and using chemical amendments to increase soil $\mathrm{Pb}$ availability.

Recent research has shown that chemical amendments such as synthetic organic chelates may enhance phytoextraction by increasing $\mathrm{Pb}$ availability, plant uptake and translocation of $\mathrm{Pb}$. Huang et al. (1997) conducted greenhouse studies on the effect of EDTA, HEDTA, CDTA, DTPA and EDDHA on soil solution and Pb uptake by corn (Zea mays), pea (Pisum aestivum), ragweed (Ambrosia artemissifolia), sunflower (Helianthus annus). They found EDTA to be the most effective chelate for enhancing $\mathrm{Pb}$ uptake and $\mathrm{Pb}$ solubility in soil. Research by Blaylock et al. (1997) evaluated the potential of CDTA, DTPA, EDTA and EGTA to enhance Pb uptake by Indian mustard (Brassica juncea). They also found EDTA to be the most effective chelate in increasing the availability of $\mathrm{Pb}$ to the plants. Despite the impact of chelates on $\mathrm{Pb}$ availability and solubility, Copper et al.(1999) reported that research is still needed to determine the most successful combination of plants, soil management practices, and type, rates and method of application of chelates for successful remediation of $\mathrm{Pb}$-contaminated soils. The other issue that needs to be considered in chelate-assisted phytoextraction is that the potential environmental impact associated with increased $\mathrm{Pb}$ solubility (i.e. leaching and runoff of $\mathrm{Pb}$ ).

\subsubsection{Application of Soil Amendments}

Soil amendments can be used to alter soil chemistry and sequester the metal contaminants, thus having a dramatic effect on presumed environmental hazards (Mench et al., 1984). Cox and Rains (1972) reported that raising the $\mathrm{pH}$ of acid soils by liming, combined with a suitable choice of plant species and proper grazing management, could substantially 
reduce the entry of $\mathrm{Pb}$ into the food chain. Maclean et al. (1969) suggested that lime repressed the solubility of $\mathrm{Pb}$ because of the greater capacity of organic matter to complex lead at increased pH. Berti and Cunningham (1997) used various types of organic materials such as ground alfalfa (Medicago sativa), sphagnum peat moss and composted leaves. They concluded that these organic materials reduced the bioavailability of $\mathrm{Pb}$ as measured with PBET (physiologically based extraction test). Pearson et al. (2000) investigated the effectiveness of organic matter as possible in situ remediation technique for metal contaminated soils. Their study was designed to determine the bioavaliability of $\mathrm{Pb}$ to the earthworm (Eisenia fetida) in an artifical soil amended with varying levels of organic matter. They reported that organic soil amendments increased the bioavailabitity of $\mathrm{Pb}$ to the earthworm. Zimdahl and Foster (1976) reported that organic matter addition offers some promise for reduction of $\mathrm{Pb}$ uptake by plants. The mechanism involved has not been described, but it is probably related to sorptive capacity of organic matter. They further reported that there is more $\mathrm{Pb}$ immobilization at higher $\mathrm{pH}$.

\subsubsection{Fixation}

\subsubsection{Effect of metallic oxides and hydroxide}

Lead has been shown to accumulate in $\mathrm{MnO}_{2}$ in soils (Taylor and Mckenzie, 1966; Norrish, 1975) and the addition of $\mathrm{MnO}_{2}$ to soils contaminated with $\mathrm{Pb}$ reduces the uptake of $\mathrm{Pb}$ by plants (Mckenzie 1978). Mckenzie (1980) reported that possible mechanisms to account for the binding of $\mathrm{Pb}$ by oxides of $\mathrm{Mn}$ are: strong specific adsorption of $\mathrm{Pb}$, a strong affinity of $\mathrm{Pb}$ for oxides of $\mathrm{Mn}$, oxidation of $\mathrm{Pb}$ on $\mathrm{Mn}$ oxide surfaces, and formation of some specific $\mathrm{Pb}-\mathrm{Mn}$ mineral such as coronadite $\left(\mathrm{Pb}_{2} \mathrm{Mn}_{8} \mathrm{O}_{16}\right)$. Mckenzie (1980) further reported that a significant 
amount of $\mathrm{Pb}$ entered the interlayer spaces of fine grained birnessites $\left(\left(\mathrm{Na}_{0.7} \mathrm{Ca}_{0.3}\right) \mathrm{Mn}_{7} \mathrm{O}_{14} \cdot 2.8 \mathrm{H}_{2} \mathrm{O}\right)$ resulting in an uptake of $\mathrm{Pb}$ in excess of the amount required for a monolayer on the surface. Stumm and Morgan (1996) also reported that iron (hydr)oxides are known to bind heavy metals through adsorption or co-precipitation. Due to these mechanisms, iron oxides can control the distribution and concentration of heavy metals in aqueous systems and have been utilized in environmental technologies to remove metals from waste water and liquid hazardous waste (Benjamin et al., 1996). Postma and Jakobsen (1996) reported that freshly precipitated iron oxides are amorphous or poorly crystallized, and although their large surface area is advantageous for metal retention, but they are metastable and can, over time, undergo transformation into crystalline compounds such as hematite or goethite. The solubility of the latter crystalline phases is orders of magnitude lower than that of the amorphous solids, and the vulnerability of these compounds to microbial iron reduction is also considerably reduced.

Sorensen et al. (2000) heated iron oxides containing heavy metals (e.g. $\mathrm{Pb}, \mathrm{Hg}, \mathrm{Cr}$ and $\mathrm{Cd}$ ) and 50,600 and $900^{\circ} \mathrm{C}$ to simulate their transformations caused by heat treatment prior to disposal or aging at a proper disposal site. They found that heat treatment at 600 and $900^{\circ} \mathrm{C}$ and aging resulted the in transformation of amorphous iron oxide to hematite, which has less surface area, and less retaining power for the $\mathrm{Pb}$. At low concentration, the affinity of $\mathrm{Pb}$ for hematite $\left(\mathrm{Fe}_{2} \mathrm{O}_{3}\right)$ surfaces was greater than that for goethite $(\mathrm{FeOOH})$ surfaces, although the surface area of the hematite was much smaller than that of goethite. Coupled with greater difficulty in extracting adsorbed $\mathrm{Pb}$ from hematite, this suggests that hematite is likely to be an important sink for $\mathrm{Pb}$ in soils. Sposito (1984) reported that Fe oxide and hydroxide could specifically 
adsorb $\mathrm{Pb}$ and, the adsorption increased at high $\mathrm{pH}$ (7-9). McBride (1994) reported that Fe and $\mathrm{Al}$ oxides as well as silica adsorb $\mathrm{Pb}$ and $\mathrm{Cu}$ more strongly than any other divalent metals.

Ponder et al. (2000) reported the use of nanoscale zero valent iron for remediation of $\mathrm{Pb}$. They reported that the zero valent iron removes aqueous contaminants by reductive dechlorination, in the case of chlorinated solvents or by reduction to an insoluble form in the case of aqueous metal ions. One important parameter in the rate at which remediation occurs is the surface area of the zero valent iron particles. They also reported that rates of remediation of $\mathrm{Pb}$ are up to 30 times higher for zero valent iron nanoparticles than for iron powder on a $(\mathrm{Fe})$ molar basis.

\subsubsection{Inorganic Material}

Cost effectiveness and environmental friendliness have made the addition of phosphate minerals a promising technology to remediate $\mathrm{Pb}$ contaminated soil (Zhang and Ryan, 1999). Nriagu (1984) suggested that phosphate minerals should have potential to immobilize $\mathrm{Pb}$ in lead contaminated sites and wastes due to low solubility of $\mathrm{Pb}$ orthophosphates. Recent research results have demonstrated the reduction in soluble $\mathrm{Pb}$ levels of soil solutions by mixing phosphate minerals with $\mathrm{Pb}$ - contaminated soils and the formation of pyromorphite (Ma, 1996). Experiments have been carried out using highly soluble forms of phosphate, e.g. $\mathrm{K}_{2} \mathrm{HPO}_{4}$, but due to the soluble nature of the $\mathrm{P}$ source there would be eutrophication risk associated with such kind of treatment. 
Ma et al. (1994) successfully used hydroxyapatite as a Pb-immobilization material. They reported : 1) hydroxyapatite had the ability to immobilize $\mathrm{Pb}^{2+}$ in the presence of interfering cations, anions and dissolved organic matter; 2) the reaction product was stable in the contaminated environment, and 3) the reaction was very rapid. The primary mechanism of $\mathrm{Pb}$ immobilization appears to be through phosphate mineral dissolution, and subsequent precipitation of a pyromorphite $\left(\mathrm{Pb}_{10}\left(\mathrm{PO}_{4}\right)_{6}(\mathrm{OH})_{2}\right)$. Mechanisms such as cation substitution, adsorption and precipitation as other $\mathrm{Pb}$ minerals are also possible (Ma et al., 1996). The formation of pyromorphite from soluble phosphate and $\mathrm{Pb}$ has been found to be a rapid process; soluble $\mathrm{Pb}$ can be depleted from solution within a few seconds if a stoichiometric amount of phosphate is provided and the system is well mixed. Thus the soluble $\mathrm{Pb}$ concentration in the aqueous system containing apatite and $\mathrm{Pb}$-bearing solids will be determined by the dissolution rate of apatite and overall $\mathrm{Pb}$ release rate (desorption, dissociation and dissolution) of the $\mathrm{Pb}$ species (Zhang and Ryan, 1999). Ma et al. (1995) reported that rock phosphate is also effective in immobilizing $\mathrm{Pb}$ in contaminated soils. Preliminary experiments (Hodsen et al., 2000) using a moderately contaminated soil indicated that bonemeal treatment could be a useful remediation method. Hodson et al. (2000) reported that poorly crystallized apatite e.g. bone apatite (in the form of bonemeal-finely crushed bone), might represent a low cost, readily available phosphate source that could be used to remediate metal contaminated land without causing excessive runoff. Phosphate is effective only when $\mathrm{Pb}$ is the sole contaminant, i.e. without As at the same soil/site. 


\subsection{Arsenic}

Arsenic is of environmental concern due to its toxicity to plants, animals and human beings. It occurs naturally in about 245 minerals, which when subjected to weathering can release soluble As into natural waters. Arsenic can also be found in waste streams from a variety of industrial processes. For example, As waste can be generated from petroleum refining, glass, melting and smelting of ores that are mined for their $\mathrm{Pb}$, $\mathrm{Cu}, \mathrm{Zn}, \mathrm{Au}$ and $\mathrm{Ag}$. Arsenic is also released into the environment by the dispersion of arsenic containing fertilizers, pesticides, and wood preservatives (Smith et al.,1998). The availability, physiological and toxicological effects of arsenic depend on its chemical form. Arsenate $(+5)$ and arsenite $(+3)$ are the primary forms of inorganic As in soils and natural waters. Of these forms, $\mathrm{As}(+3)$ is the most toxic, soluble, and mobile (Duele and Swoboda, 1972) species found in the environment. The concentrations of these species in soil solution depend on a number of soil parameters, including redox potential (Eh) (Masschelyn et al., 1991), pH (Pierce and Moore, 1980), Fe and Al hydroxides (Livesely and Huang, 1981), and clay content ( Frost and Griffin, 1977).

Lime additions to As containing wastes have been proven to be beneficial in reducing the mobility of dissolved As, presumably through the formation of low solubility calcium arsenates (Bothe and Brown,1999). Arsenic from the aqueous waste streams also can be removed by precipitation as arsenic sulfides and iron arsenates. These precipitates reactions have limited $\mathrm{pH}$ ranges within which they exhibit solubility maxima (Bothe and Brown, 1999). Robins (1992) reported that calcium arsenate exhibits the lowest equilibrium concentrations of arsenate ion and are stable at high $\mathrm{pH}$, whereas ferric arsenates (i.e. scorodite) are stable only at low $\mathrm{pH}$. 
The adsorption and retention of As by soils control its persistence, activity, movement, transformation, and ecological effects (Luo et al., 1991). Arsenic adsorption on a wide variety of adsorbents, including phyllosilicates (Manning and Goldberg, 1997), aluminum oxides (Gupta and Chen, 1978), and iron oxides (Raven et al., 1998) has been studied.

\subsubsection{Role of Oxides of Aluminum and Iron In Arsenic Adsorption}

Arsenic availability to plants is controlled by adsorption- desorption reactions (Bhumbla and Keefer, 1997). The clay fraction and Fe oxides have frequently been implicated in the sorption of As by soils. Arsenic toxicity to plants decreases as the clay and Fe oxide concentrations increase (Crafts and Rosenfels, 1939), presumably due to lower level of As maintained in the soil solution. Several investigators (Keaton and Kardos, 1940; Misra and Tiwari, 1963) have shown that similar textured soils are high in reactive Fe compounds (either native or added) sorb larger amounts of As than soils low in Fe. Mica minerals strongly sorb arsenate as they weather (Stewart et al., 1975) and this seems to be a function of the spacing in the clay lattice and the amount of hydroxyaluminum present on the clay surface.

Retention of As has been shown to be proportional to sesquioxide concentration of soils and this retention decreased as the amorphous $\mathrm{Al}$ and $\mathrm{Fe}$ compounds were removed (Holm et al., 1979; Gulens et al., 1979). The adsorption of As depended on the oxidation state; generally As(+5) was adsorbed more strongly than As (+3) . Raven et al.(1998) reported that iron oxides, including the poorly crystalline iron oxides, e.g. ferrihydrite, have a strong affinity for both arsenite and arsenate. The retention of arsenite and arsenate 
is predominantly by ligand exchange with surface structural $\mathrm{OH}_{2}$ and /or $\mathrm{OH}^{-}$at surface adsorption sites. The retention of arsenite and arsenate is strongly $\mathrm{pH}$-dependent, but with the opposite trends. At low to moderate As adsorption levels, the adsorption envelopes of arsenite and arsenate usually cross within the $\mathrm{pH}$ range of 6-7.5 i.e. ferrihydrite exhibits a relatively greater retention of arsenate at lower $\mathrm{pH}$ values, whereas arsenite is more strongly retained at higher $\mathrm{pH}$ values (Ravin et al., 1998) Arsenite adsorption maximized between pH 7 and 9 (Pierce and Moore, 1980; Gupta and Chen, 1978). Wanen and Jones (1984) found that As was effectively removed from acidic solutions by adsorption onto soil minerals, indicating that As oxyanions were naturally retained in the presence of oxides and clay minerals (Holm et al., 1979; Frost and Griffin, 1977), and strongly adsorbed by Fe (Leckie et al., 1980), $\mathrm{Al}$ (Gupta and Chen, 1978; Anderson et al., 1976) and Mn oxides (Oscarson et al., 1983). Only a few studies have investigated the adsorption of $\mathrm{As}(+3)$ on aluminum oxides or aluminosilicate minerals despite the abundance of these materials in the terrestrial environment. One reason is the relatively weak affinity of aluminum oxides for As( +3$)$ when compared with iron oxides. Activated alumina has a 2-fold higher affinity for arsenate than arsenite at $\mathrm{pH}$ 7. Kaolinite and montmorilloinite were investigated as sorbents of $\operatorname{As}(+3)$ and $A s(+5)$ from landfill leachate and exhibited higher affinites for $\mathrm{As}(+5)$ than $\mathrm{As}(+3)$. Though phyllosilicates exhibit a lower affinity for anions than iron and aluminum oxides, they can be abundant mineral components in soil and sediments.

\subsubsection{Effects of $P$ on As availability and uptake}


Arsenic is toxic to biota, and $\mathrm{P}$ has been found to enhance its mobility in wellaerated soils by competing for sorption sites (Woolsen et al.,1973). Arsenic, like P is strongly adsorbed by amorphous Fe oxide (Jacob et al., 1970) and is released under anaerobic conditions (Fordham and Norrish, 1979). Phosphate is adsorbed by both soil colloidal Fe and Al oxides, whereas As is adsorbed by soil colloidal Fe oxide. Arsenic and phosphate in soil exhibit similar behavior (Fassbender, 1975; Johnston and Barard, 1979), but the amount of phosphate sorbed is greater than that of As (Dean and Rubins, 1947).

The adsorption of phosphates and arsenates indicates an analogous sorption behavior. Under comparable conditions, a larger quantity of phosphates is sorbed presumably due to different ionic radii of anions in question (Holobrady et al., 1969). Phosphate substantially suppresses As adsorption by soils and the extent of suppression varies from soil to soil (Livesey and Huang, 1981). Johnson and Hiltbold (1969) showed that the arsenates in soils were more soluble than phosphates.

There are conflicting reports in the literature as to the effect of phosphate on availability and uptake of As. Toxicity of As in nutrient solution was reduced by increasing phosphate concentration (Hurd-karrer, 1939). Benson (1953) reported that As toxicity to barley was overcome by phosphate in pot culture, but there was little or no response to phosphate application to the field. Jacobs et al. (1970) reported that increasing the level of $\mathrm{P}$ in the spoil increased As in the plant at $80 \mathrm{mg}$ of $\mathrm{As} \mathrm{kg}^{-1}$, but the increase was greater in sandy soil than in silty soil. The sandy soil was relatively low in As or P retention capacity. Addition of $\mathrm{P}$ to the soil resulted in enhanced As toxicity from displacement of As by P. The inconsistency in the literature can be reconciled if the effect of $\mathrm{P}$ on As uptake is considered as two separate factors: plant and soil. The plant factor 
considers an antagonism between $\mathrm{P}$ and $\mathrm{As}$ at the root surface. When phosphatic fertilizers were applied to As contaminated soils, As toxicity was increased by As being displaced from the soil surfaces to the soil solution. Bhumbla (1991) reported that application of rock phosphate had no effect on amounts of available As in soils as rock phosphate did not supply sufficient $\mathrm{P}$ to mobilize As from sorption sites in soil. Benson (1953) suggested that As may substitute for $\mathrm{P}$ in calcium phosphate minerals. This substitution can potentially reduce the availability of As to plants.

Schwiezer (1967) noted that addition of P may enhance As phytotoxicity. This is because $\mathrm{P}$ and As have similar chemical and physical properties. Phosphorus competes for As fixation sites in soil and thus may affect As availability. Several investigators noted reduction in phytotoxicity of $\mathrm{As}$ as $\mathrm{P}$ level increased in a wide variety of crops (Rumburg et al.,1980). Peryea (1991) and Creger and Peryea (1994) reported that phosphate fertilizer addition to soils containing $\mathrm{Pb}$ - $\mathrm{As}$ pesticide residues increase As solubility because of $\mathrm{PO}_{4}{ }^{3-}-\mathrm{AsO}_{4}{ }^{3-}$ exchange. Woolsen and Kearney (1973) further reported that As release was positively related to added phosphate source. Arsenic solubility was consistent with a mechanism of specific $\mathrm{PO}_{4}{ }^{3-}-\mathrm{AsO}_{4}{ }^{3-}$ exchange while $\mathrm{PO}_{4}{ }^{3-}$ solubility was consistent with control by metastable $\mathrm{PO}_{4}{ }^{3-}$ Minerals. As a result, the effects of $\mathrm{P}$ on As phytotoxicity are unpredictable.

In nature, $\mathrm{Pb}$ and $\mathrm{As}$ are often present together. The most important commercial compound of As, arsenic oxide, is produced as a by-product in smelting of $\mathrm{Pb}$ ores. It has been also introduced into the biosphere via the use of $\mathrm{Pb}$-As pesticides in agriculture and forestry. Before the wide spread use of organic pesticides lead arsenate was the most common pesticide used in orchards. 
Unlike the layer silicates, oxides and hydroxides of $\mathrm{Fe}$ and $\mathrm{Al}$ retain $\mathrm{Pb}$ and $\mathrm{As}$ by direct co-ordination to the surface oxygen anions by the process of chemisorption ( Mckenzie 1980;Sposito 1990;Manning and Goldberg, 1997). Jenne (1968) suggested that the reactivity of hydroxide coating on clay would be considerably higher than reactivity of free hydroxides especially with respect to heavy metal adsorption. Cavalloro and McBride (1984) observed a pronounced decrease in the adsorption of heavy metal ions after removing the Fe hydroxide and Al hydroxide from a soil clay. The chemical, physical, and mineralogical characteristics of natural and laboratory synthesized clay-Al hydroxide and clay-Fe hydroxide complexes are well documented (Rich, 1968; Barnhisel, 1977), whereas information about the adsorption of $\mathrm{Pb}$ and $\mathrm{As}$ by synthesized clay-hydroxide mixture is scarce.

Therefore, adsorption of $\mathrm{Pb}$ and $\mathrm{As}$ on hydrous oxide coated clay surface is important in governing $\mathrm{Pb}$ and $\mathrm{As}$ related pollution. Information available in the literature is too limited to draw a meaningful conclusion about the adsorption chemistry of $\mathrm{Pb}$ and As in hydrous oxide coated clay and the fate of applied $\mathrm{P}$ fertilizer in $\mathrm{Pb}$ and $\mathrm{As}$ contaminated sites. In order to fully understand the fate and transport of metal in the environment, we need to be able to accurately describe and model complex natural systems. Surface complexation models (SCMs) are capable of simulating the experimentally observed acid-base titration properties of metal oxide and pure clay minerals (Schindler and Stumn, 1987). However, no study has been conducted to simulate acid-base titration on $\mathrm{Fe}$ and $\mathrm{Al}$ coated clays. Data from experimental studies of $\mathrm{Pb}$ and $\mathrm{As}$ co-precipitation with $\mathrm{Fe}$ and $\mathrm{Al}$ coated clay, insight gained from modeling complex 
natural systems by using SCMs and the effect of $\mathrm{P}$ fertilizer on As solubility or $\mathrm{Pb}$ immobilization could be vital in remediating $\mathrm{Pb}$ and $\mathrm{As}$ contaminated sites.

The objectives of the present investigation are:

1) To determine the effect of hydrous oxide coating on adsorption of $\mathrm{Pb}$ and $\mathrm{As}$ by clays.

2) To describe a methodology for determining a unique set of model parameters for SCMs from titration data for iron and aluminum coated clay minerals.

3) To explore the effectiveness of the $\mathrm{P}$ fertilizer on $\mathrm{Pb}$ immobilization and/or $\mathrm{As}$ immobilization/ release in $\mathrm{Pb}$ and As contaminated sites.

\section{References}

Abernathy,C.O.1993. Inorganic arsenic. An overview. In C.R. Cothen(ed.) Trace substances, environment and health. Science reviews, London, England.

Anderson, M.A., J.F. Ferguson, and J. Avis. 1976. Arsenate adsorption on amorphous aluminum hydroxide. J. Colloid Interface Sci. 54:335-337.

Backer, D.E., and Chesnin, L. 1975. Chemical monitoring of soils for environment quality and animal and human health. Adv. Agron. 27:305-374.

Baker, A., R.Brooks, and R. Reeves.1988. Growing for gold, copper and zinc. New Scientist 10:44-48.

Baker, A., R.D. Reeves, and A.S.M. Hajar.1994. Heavy Metal accumulation and tolerance in British populations of the metallophyte Thalaspi caerulescens J. \& C. Presl (Brassicaceae). New Phytol. 127:61-68.

Barnhisel, R.I. 1977. Chlorites and hydroxy-interlayered vermiculite and smectite. In J.B. Dixon and S.B. Weed (eds) Minerals in Soil Environments. Soil Science Society of America, Madison, Wisconsin, pp.331-356.

Benjamin, M.M ., R.S.Sletten, R.P. Bailey and T.Benett.1996.Sorption and filtration of metal using iron oxide coated sand. Water Res. 30:2609-2914.

Benson. N.R. 1953. Effect of season, phosphate, and acidity on plant growth in arsenic toxic soils. Soil Sci. 76:215-224. 
Berti, W.R., and S.D. Cunningham.1997. In place inactivation of $\mathrm{Pb}$ in $\mathrm{Pb}$-contaminated soils. Environ. Sci. Technol. 31: 1359-1364.

Bhumbla, D.K. and R.F. Keefer. 1997. Arsenic mobilization and bioavailability in soils. Adv. Environ. Sci. Technol. 26:51-81.

Bhumbla, D.K. 1991. Ameliorative effect on fly ashes. Ph.D. Dissertation.West Virginia Univ., Morgantown, WV.

Blaylock, M.J., D.E.Salt, S.Dushenkov, O. Zakharova, C.Gussman, Y.Kapulnik, B.D. Ensely, and I.Rakskin.1997. Enhanced accumulation of $\mathrm{Pb}$ in Indian mustard by soil-applying chelating agents. Environ. Sci. Technol. 31: 860-865.

Bothe J.V and P.W.Brown.1999. Arsenic immobilization by calcium arsenate formation. Environ. Sci. Technol. 33: 3806-3811.

Cavalloro. N. and M.B. McBride. Zinc and copper sorption and fixation by acid soil clay. Effect of selective dissolutions. Soil Sci. Soc. Am. J. 48:1050-1054.

Chaney, R., S. Brown, Y. Ming Li, J.S.Angle, F.Homer, and C. Green.1995. Potential use of metal hyperaccumulators. Mining Environ. Manage. 9:9-11.

Chowdhury, L.C., R.R. Standforth, and R.S. Warren. 1994. In situ remediation of contaminated soil at a lead-acid battery cracking site using phosphate. pp.12261229. In The 6th international special symp. emerging technologies for hazardous waste management, Atlanta,Ga.19-21 Sept. 1994. ACS. Atlanta, GA.

Cooper, E.M., J.T.Sims, S.D.Cunningham, J.W. Huang, and W.R. Berti.1999. Chelateassisted phytoextraction of lead from contaminated soils. Environ. Sci. Technol 28: $1709-1719$.

Cox W.J., Rain D.W. 1972. Effect of lime on lead uptake by five plant species. J. Environ. Qual. 1:167-169.

Crafts, A.S., and R.S. Rosenfels. 1939. Toxicity studies with arsenic in eighty California soils. Hilgardia. 12:177-200.

Creger, T.L., and P.J. Perya. 1994. Phosphate fertilizer enhances arsenic uptake by apricot liners grown in lead-arsenate enriched soil. The Am. Soc. Hort. Sci. 29(2):88-92.

Cunningham, S.D., W.R. Berti and T.W. Huang. 1995. Phytoremediation of contaminated soils. Trends Biotechnol. 13:393-397. 
Dean, L.A. and E.J. Rubins. 1947. Anion exchange in soils. 1. Exchangeable phosphorus and the anion exchange capacity. Soil. Sci. 63:377-387.

Duel, L.E.and A.R. Swoboda.1972. Arsenic solubility in a reduced environment. Soil Sci Soc. Am. J. 48:1025-1030.

EPA. 1993. Federal register.(1993). Prot. Agen. Standards for use or disposal of sewage sludge; Final rules. pp 9248-9415.

Fassbender, H.W. 1975. Solubility and fractionation criteria for evaluating arsenic phosphorus relations in soils. Ambio. 4(3):134-135.

Foredham, A.W., and K. Norrish. 1979. Arsenate-74 uptake by components of several acidic soils and its implications for phosphate retention. Aust. J. Soil Res. 17:307-316.

Frost, R.R., and R.A. Griffin. 1977. Effect of $\mathrm{pH}$ on adsorption of arsenic and selenium from landfill leachate by clay mineral. Soil Sci. Soc. Am. J. 41:53-57.

Gulen, J., D.R. Champ and R.E. Jackson. 1979. Influence of redox environment on the mobility of As in ground water. Am. Chem. Soc. Symp. Sea. 81-85.

Gupta, S.K., and K.Y. Chen. 1978. Arsenic removal by adsorption. J. Water Pollut. Control Fed.50:493-506.

Hodson, M.E., E.J.Valsami, J.Cotter-Howells. 2000. Bonemeal additions as a remediation treatment for metal contaminated soil.Environ Sci Technol. 34: 35013507.

Hodson, M.E., E.J.Valsami, J.Cotter-Howells, W.E. Dubbin, A.J.Kemp, I.Thornton and A. Warren.2001.Effect of bonemeal(calcium phosphate) on metal release from contaminated soils- a leaching column study. Environ. Poll. 112:233-243.

Holm, T.R., M.A. Anderson, D.A. Iverson and R.S. Stanforth.1979. Heterogenous interactions of arsenic in aquatic systems. ACS Symp. Sea. pp. 710-739.

Holobrady, K., J. Galba and E. Chrenekova. 1969. Adsorption of arsenates in soils. Pol'nohospodarstvo 15(11):956-963.

Huang, J.W., J.Chen, W.R. Berti and S.D.Cunningham.1997. Phytoremediation of lead contaminated soils: Role of synthetic chelates in lead phytoextraction. Environ. Sci. Technol. 31: 800-805.

Huang, J.W., and S.D.Cunningham.1996. Lead phytoextraction: Species variation in lead uptake and translocation. New Phytol. 134: 1-10. 
Hurd-Karrer, A.M. 1939. Antagonism of certain elements essential to plants toward chemically related toxic elements. Plant Physiol. 14:9-29.

Jacobs, L.W., J.K. Syers and D.R. Keeney. 1970. Arsenic sorption by soils. Soil Sci. Soc. Am. Proc. 34:750-754.

Johnson. L.R., and A.E. Hiltbold. 1969. Arsenic content of soil and crops following use of methanearsenate herbicides. Soil Sci. Soc. Am. Proc. 33(2):279-282.

Johnston, S.E., and W.M. Barnard. 1979. Comparative effectiveness of fourteen solutions for extracting arsenic from four western New York soils. Soil Sci. Soc. Am. Proc. 43(2):304-308.

Keaton, C.M., and L.T. Kardos. 1940. Oxidation-reduction potentials of arsenatearsenite systems in sand and soil medium. Soil Sci. 50:189-207.

Kumar, P.B., A.N., V Dushenkov, H. Motto and I. Raskin. 1995. Phytoextraction the use of plants to remove heavy metals from soils. Environ. Sci. Technol. 29:12321238.

Larcher,W.1980. Physiological plant ecology. Springer-Verlag, Berlin.

Leckie, J.O., M.M. Benjamin, K. Hayes, A. Kaufman and S.Atman. 1980. Adsorption /co-precipitation of Trace Elements from water with iron oxyhydroxide. Electric Power Research Institute, Palo Alto, CA.

Levitt, J.1980. Responses of plants to environmental stresses. Academy Press, New York.

Livesey, N.T., and P.M. Huang. 1981. Adsorption of arsenate by soil and its relation to selected chemical properties and anions. Soil Sci. 131(2):88-94.

Luo, J.F., Xia, Z.L., and Li, S.Z. 1991. Chemical behavior of As in purple soils and their effects on crop. Acta Sci. Circumstantiae. 11(3):269-275.

Ma, O.Y., T.J. Logan, S.J. Triana, and J.A. Ryan. 1994. Effects of $\mathrm{NO}_{3}{ }^{-}, \mathrm{Cl}^{-}, \mathrm{F}^{-}, \mathrm{SO}_{4}{ }^{2-}$ and $\mathrm{CO}_{3}{ }^{2-}$ on $\mathrm{Pb}$ immobilization by hydroxyapatite. Environ. Sci. Technol. 28:408-418.

Ma, O.Y. 1996. Factor influencing the effectiveness and stability of Aqueous lead immobilization by Hydroxyapatite. J. Environ. Qual. 25:1420-1429.

Ma, O.Y., T.J. Logan and S.J. Traina. 1995. Lead immobilization from aqueous solution and contaminated soils using phosphate rock. Environ. Sci. Technol. 29:1118-1126. 
Ma, O.Y., S.J. Triana, T.J. Logan, J.A. Ryan. 1993. In situ Pb immobilization by apatite. Environ. Sci. Technol. 27:1803-1810.

Maclean, A.J., P.L. Halstead, and B.J. Finn. 1969. Extractability of added lead in soils and its concentration in plants. Can. J. Soil Sci. 49:327-334.

Manning, B.A., and S. Goldberg. 1997. Adsorption and stability of Arsenic (III) at the clay mineral-water interface. Environ. Sci.Technol. 31:2005-2011.

Masscheleyn, P.H., R.D.Delanue and W.H.Patrick.1991. Effect of redox potential and pH on arsenic speciation and solubility in a contaminated soil. Environ. Sci. Technol. 25:1414-1418.

McBride, M.B.1994. Environmental chemistry of soils. Oxford Univ. Press, Oxford.

Mckenzie, R.M. 1978. The effect of two manganese dioxide on the uptake of lead, cobalt, nickel, copper and zinc by subterranean clover. Aust. J. Soil. Res. 16:209214.

Mckenzie, R.M. 1980. The adsorption of lead and other heavy metals on oxides of manganese and iron. Aust. J. Soil Res. 18:61-73.

Mench, M.J. 1984. A mimicked in situ remediation study of metal contaminated soils with emphasis on cadmium and lead. J. Environ. Qual. 23:58-63.

Mench, M., and E.Martin.1991. Mobilization of cadmium and other metals from two soils by root exudates of Zea mays L., Nicotiana tabacum L., and Nicotiana rustica L . Plant Soil 132: 187-196.

Mirsa, S.G., and R.C. Tiwari. 1963. Arsenate-arsenite adsorption in soils. Indian J. App. Chem. 26:117-126.

Norrish, K.1975.Geochemistry and mineralogy of trace elements. In Trace Elements in Soil-plant-Animal Systems. D.J. D. Nicholas and A.R. Egan (eds.), pp. 55-81. Press, New York.

Nriagu, J.O.1984.Phosphate minerals: Their properties and general modes of occurrence. pp.1-136.In J. O. Nriagu and P.B. Moore (ed.) Phosphate minerals. Springer Verlag, Munich.

Osrcarson, D.W., P.M. Huang, P.W. Liaw and U.T. Hammer. 1983. Kinetics of oxidation of arsenite by various manganese dioxide. Soil Sci. Soc Am. J. 47:644-648.

Peryea. F.J. 1991. Phosphate induced release of arsenic from soils contaminated with lead arsenate. Soil Sci. Soc. Am. J. 55:1301-1306. 
Pierce, M.L. and C.B. Moore. 1980. Adsorption of arsenite on amorphous iron hydroxide from dilute aqueous solution. Environ. Sci. Technol. 14:214-216.

Pignatello, J.J. 1989. In Reaction and movement of organic chemical in soils. Sawhney, B.L. and Brown, K.ed. pp. 45-80. Soil Sci. Soc. Am. Madison, WI.

Pearson, M.S, K. Maenpaa, G.M.Pierzynski and M.J.Lydy. 2000:Effects of soil amendments on the bioavailability of Lead, Zinc, and Cadmium to Earthworms. J Environ Qual. 29:1611-1617.

Pierce, M.L and C.B.Moore.1980. Adsorption of arsenite and arsenate on amorphous iron hydroxide from dilute aqueous solutions. Environ. Sci. Technol.14:214-216.

Ponder, M.S., J.G.Darab and T.E. Mallouk.2000. Remediation of $\mathrm{Cr}$ and Pb aqueous solutions using supported nanoscale zero valent iron.34:2564-2569.

Postma, D., and R. Jakobsen.1996.Redox zonation: equilibrium constraints on the Fe(III)/ $\mathrm{SO}_{4}$-reduction interface.Geochim.et. Cosmochim. Acta. 60:3169.-3175.

Raven, K.P., A. Jain and R.H.Loeppert.1998.Arsenite and arsenate adsorption on ferrihydrite: Kinetics, equilibrium and adsorption envelopes. Environ. Sci. Technol. 32.344-349.

Rich, C.I. 1968. Hydroxy interlayers in expansible layer silicates. Clays Clay Miner. 16:157-163.

Robins, R.G. 1992. Mercury and arsenic wastes: removal, recovery, treatment and disposal. U.S. Environmental Protection Agency Pollution Technology Review; Noyes Data Corporation: New Jersey.

Schnoor, J.L., L.A, Licht, S.C McCutcheon, N.L. Wolfe, and L.H Carreira. 1995. Phytoremediation of organic and nutrient contaminants. Environ. Sci. Technol. 29: 318-323.

Shaw, A.J.(ed) 1990. Heavy metal tolerance in plants. Evolutionary aspects. CRC Press, Boca Raton,FL.

Smith, E., R.Naidu and A.M.Alston. 1998. Arsenic in soil environment: review. In Advances in Agronomy, Sparks, D.L., Ed. Academic New York. vol 64, pp. 149195.

Soresen, M.A., M.M. Stackpoole, A.I. Frenkel, R.K.Bordia, G.V. Korshin and T.H. Christensen.2000.Aging of iron (hydr)oxides by heat treatment and effects on metal binding. Environ. Sci. Technol. 34:3991-4000. 
Stumm, W., J.J.Morgan.1996. Aquatic Chemistry, John Wiley and Sons, New York.

Sposito, G. 1984. The surface chemistry of soils. Oxford Univ. Pres, New York.

Stewart, J.W.B., J.R. Bettang, D.A. Rennie, P.M. Huang and R.B. Mckercher. 1975. Trace metal aided studies of the movement of toxic elements in plant-soil-water systems under controlled conditions. FAO/IARA Div., Atomic Energy Food Agriculture, Washington D.C.

Taylor, R.M. and R.M. Mckenzie. 1966. The association of trace elements with manganese mineral in Australian soils. Aust. J. Soil. Res. 4:29-39.

Wangen, L.E., and M.M. Jones. 1984. The attenuation of chemical elements in acid leachates from coal mineral wastes by soils. Environ. Geol. Water Sci. 6:161-170.

Woolson, E.A., and P.C. Kearney. 1973. Persistence and reactions of ${ }^{14} \mathrm{C}$-Cacodylic acid in soils. Environ. Sci. Techno. 17:47-50.

Wu, J., F.C.Hsu, and S.D.Cunningham.1999. Chelate assisted $\mathrm{Pb}$ phytoextraction: $\mathrm{Pb}$ availability, uptake and translocation constraints. Environ. Sci. Technol. 33: 18981904.

Zhang, P. and J.A.Ryan.1999.Transformation of $\mathrm{Pb}$ from cerrusite to chloropyromorphite in the presence of hydroxyapatite under varying conditions of $\mathrm{pH}$. Environ. Sci. Technol. 33:625-630.

Zimdahl R.L. and J.M. Foster. 1976. The Influence of applied phosphorous, manure or lime on uptake of lead from soil. J. Environ. Qual. 5:31-33. 


\section{Chapter 3}

\section{Sorption of Lead and Arsenic by Iron and Aluminum Coated Clays}

\subsection{Introduction}

Pollution of the biosphere with toxic elements has accelerated dramatically since the beginning of industrial revolution. Soils serve as an important medium for accumulation, transformation and migration of the toxic chemicals. As a result of their accumulation in the biosphere, Lead and As pose more serious worldwide environment and health hazards than any other elements (Jaworski, 1987; Huang Yan-Chu, 1997). Sources of $\mathrm{Pb}$ and $\mathrm{As}$ contamination can be agricultural activities such as application of lead arsenate $\left(\mathrm{PbHAsO}_{4}\right)$ insecticides and industrial activities such as mining and smelting. Existing and abandoned disposal sites of $\mathrm{Pb}$ and $\mathrm{As}$ are potential sources of soil, and ground and surface water pollution.

Clay minerals are potential harborers of pollutants as they have a large specific area and high cation exchange capacity. Clays exhibit two kinds of charge : permanent negative surface charge and $\mathrm{pH}$-dependent charge. Permanent charge, which is caused by isomorphic substitution, for the most part is compensated by cation intercalated in the interstitial space (McBride, 1994). The binding mechanism of cation on permanent charged sites is mainly characterized by electrostatic interactions, which are reversible in nature. The $\mathrm{pH}$ dependent charge is located at edge sites, where the surface hydroxyl can be protonated or deprotonated depending on the solution $\mathrm{pH}$. The adsorption of heavy metal cation by hydroxyl groups is governed by covalent binding and therefore is chemically specific.

In addition to the clay minerals, the finer inorganic soil fractions contains poorly crystallized phases which usually are very intimately associated with the clay surface

(Sposito, 1989). The crystalline form of these solids, the most common being goethite $(\mathrm{FeOOH})$ and gibbsite $\left(\mathrm{Al}(\mathrm{OH})_{3}\right)(\mathrm{Hsu}, 1977$; Schwetman and Taylor, 1977) exhibit variable ( $\mathrm{pH}$ dependent) charge surfaces when suspended in aqueous system (Barrow, 1985). The occurrence of hydrous oxides as discrete crystalline phases, although found in 
some natural soils, is not a common phenomenon (Hsu, 1977; Schwertmann and Taylor, 1977; Sposito, 1989). The most common mode of their natural occurrence in natural soil is either as poorly crystallized phases or two dimensional amorphous phases both of which are intimately associated with clay surfaces (Hendershot and Lavkulich, 1983). Heavy metal retention by pure oxides of Fe and Al ( Mckenize, 1980; Bhumbla and Keefer, 1997) and pure clay minerals (Frost and Griffins, 1976) has been experimentally demonstrated. The pure form of clay minerals and hydrous oxides have fundamentally different surface charge characteristics (Barrow, 1985). The solid phases resulting from intimate association between the two should have surface charge characteristics that are different from either of them which, eventually affect the heavy metal adsorption characteristics on them. Heavy metal adsorption on hydroxy coated mineral surfaces may be affected by such factors as type of clay minerals, type of hydrous oxide and extent of surface coating with oxides/hydroxides. The type of clay mineral should influence the heavy metal adsorption because of variable particle sizes and different surface area available for adsorption. The extent of surface coating should determine the extent of heavy metal adsorption because the cation adsorption characteristics of hydrous oxides and silicate clays differ markedly.

Therefore, adsorption of As and As on hydrous-coated clay surface is important in governing $\mathrm{Pb}$ and $\mathrm{As}$ related pollution. Information available in the literature is too limited to draw a meaningful conclusion about the adsorption chemistry of $\mathrm{Pb}$ and $\mathrm{As}$ in hydrous oxide coated clay in $\mathrm{Pb}$ and $\mathrm{As}$ contaminated sites. The information gained from the experimental studies of $\mathrm{Pb}$ and $\mathrm{As}$ adsorption with $\mathrm{Fe}$ and $\mathrm{Al}$ coated clay could be vital in remediating $\mathrm{Pb}$ and $\mathrm{As}$ contaminated sites. So the objective of this paper is to determine the effect of hydrous oxide coating on the adsorption of $\mathrm{Pb}$ and $\mathrm{As}$ by clays.

\subsection{Materials and Methods}

Clay mineral samples of pure attapulgite, illite, kaolinite and montmorillonite obtained from the Source Clay Mineral Repository of the Clay Mineral Society were used for this investigation. Important physico chemical characteristics are given in Table 3.1. 
Table 3.1: Important physico-chemical characteristics of clay minerals

\begin{tabular}{|l|l|l|l|l|}
\hline \multirow{2}{*}{ Characteristics } & \multicolumn{5}{|c|}{ Minerals } \\
\cline { 2 - 5 } & Attapulgite & Illite & Kaolinite & Montmorillonite \\
\hline $\begin{array}{l}\mathrm{N}_{2} \text { Surface } \\
\mathrm{Area}\left(\mathrm{m}^{2} \mathrm{~g}^{-1}\right)\end{array}$ & $136.35 \pm 0.31$ & - & $23.50 \pm 0.06$ & $83.79 \pm 0.22$ \\
\hline $\begin{array}{l}\text { Cation } \\
\text { Exchange } \\
\text { Capacity(c mol } \\
\mathrm{kg}^{-1}\end{array}$ & 19.5 & 15.0 & 3.3 & 84.4 \\
\hline $\mathrm{SiO}_{2}(\%)$ & 60.9 & 55.1 & 43.9 & 70.1 \\
\hline $\mathrm{Al}_{2} \mathrm{O}_{3}(\%)$ & 10.4 & 22.0 & 38.5 & 16.0 \\
\hline $\mathrm{Fe}_{2} \mathrm{O}_{3}(\%)$ & 2.98 & 5.28 & 0.98 & 0.65 \\
\hline $\mathrm{MgO}(\%)$ & 10.2 & 2.80 & 0.03 & 3.69 \\
\hline
\end{tabular}

Source: Hower and Mowatt(1965) and van Olpen and Fridiat(1979)

All the clay samples were separated into $<2 \mathrm{~m}$ (Stokes' diameter) fraction by sedimentation technique. The $<2 \mathrm{~m}$ fraction of clay samples obtained after separation was coated with $\mathrm{Fe}$ and $\mathrm{Al}$ coatings by the following procedure. The obtained samples $(<2$ $\mathrm{m}$ ) of clay were washed three times with $0.1 \mathrm{M} \mathrm{HCl}$. The solution obtained after washing was analyzed for $\mathrm{Fe}$ and $\mathrm{Al}$ concentration which was found to be very low $(<100$ ppb). The sample was redried at $40{ }^{\circ} \mathrm{C}$ and 20 grams of clay samples were weighed into each of a series of four $250 \mathrm{ml}$ centrifuge bottles containing $60 \mathrm{ml}$ of $0.1 \mathrm{M} \mathrm{HCl}$. Concentrated solution of $\mathrm{Fe}$ and $\mathrm{Al}$ were prepared by dissolving ferric chloride $\left(\mathrm{FeCl}_{3} \cdot 6 \mathrm{H}_{2} \mathrm{O}\right)$ and aluminum chloride $\left(\mathrm{AlCl}_{3}\right)$ in reagent grade water. Appropriate volumes of these $\mathrm{Fe}^{3+}$ and $\mathrm{Al}^{3+}$ solution were added to centrifuge bottles containing clay to give 0 , 0.5, 2.00 and 4.00 per cent by weight of $\mathrm{Fe}(\mathrm{OH})_{3}$ and $\mathrm{Al}(\mathrm{OH})_{3}$. After shaking the samples for 2 hours, the $\mathrm{pH}$ of each sample was adjusted to 7.00 with $\mathrm{NaOH}$. The samples were again put on a shaker for overnight shaking and $\mathrm{pH}$ was adjusted to 7.00 , if necessary. This process continued until the $\mathrm{pH}$ of samples remained constant. Then, samples were centrifuged and the supernatant was collected to analyze for $\mathrm{Fe}^{3+}$ and $\mathrm{Al}^{3+}$ by PerkinElmer Inductively Coupled Plasma (ICP) spectrophotometer. The solid obtained after 
centrifuging was put in to a dialysis tube and suspended in reagent grade water until the samples were free of chloride. $\mathrm{AgNO}_{3}$ test was used to check that samples were free of chloride. The salt free samples were transferred to a plastic beaker and dried at $40^{\circ} \mathrm{C}$. Aging of samples was done by six wetting and drying cycles. After the last dry cycle, samples were crushed and stored in tightly capped plastic bottles.

3.2.1 Adsorption and desorption experiment: Lead and As adsorption on iron oxide/hydrous oxide clays was studied in batch experiments. An array of $\mathrm{pH}$ values with fixed metal concentration was used to obtain adsorption edges. Volume of acid and base required to achieve a particular $\mathrm{pH}$ was determined by using a kinetic program in the autotitrator. To obtain adsorption edges, 50-mg solid samples were shaken with $0.1 \mathrm{M}$ $\mathrm{NaClO}_{4}$ solution containing $(100 \mu \mathrm{M} \mathrm{Pb}$ and $100 \mathrm{M} \mathrm{As})$ at room temperature in $50-\mathrm{ml}$ centrifuge tubes. The centrifuge tubes were purged with Argon to reduce $\mathrm{CO}_{2}$ partial pressure. The reaction bottles were shaken for 24 hours. After this, tubes were centrifuged at $3000 \mathrm{rpm}$ for 15 minutes and supernatants were filtered through Whatman No. 42 filter paper. Filtrates were analyzed for $\mathrm{Pb}$ and $\mathrm{As}$ using either an ICP spectrophotometer (for samples having $\mathrm{Pb}$ and $\mathrm{As}(>100 \mu \mathrm{g} / \mathrm{g}$ ) and graphite furnace atomizer (for samples having $\mathrm{Pb}$ and $\mathrm{As} \leq 100 \mu \mathrm{g} / \mathrm{g})$.

To quantify the exchangeable fraction of adsorbed $\mathrm{Pb}, 9 \mathrm{ml}$ of $37 \mathrm{mM} \mathrm{Mg}\left(\mathrm{NO}_{3}\right)_{2}$ solution were added to the remaining $1 \mathrm{ml}$ of wet sediment. The samples were shaken for $2 \mathrm{hrs}$ and analyzed for dissolved $\mathrm{Pb}$ concentration. Statistical analysis was done on all the samples and standard error values are shown in the all the figures.

\subsection{Results}

3.3.1 Adsorption of $\mathbf{P b}$ and $\mathrm{As}$ by clay minerals: Compared to pure montmorillonite, the presence of $0.5 \%$ and $4 \%$ coatings of $\mathrm{Fe}$ and $\mathrm{Al}$ led to a decrease in the dissolved $\mathrm{Pb}$ and As concentration (Figures 3.1-3.4). The effect was more pronounced for As as compared to $\mathrm{Pb}$ (Figures 3.3-3.4). Moreover, in the case of As, the effect was more pronounced at $4 \%$ Fe coatings (Figure 3.3). For Illite, there was not much difference in the 
dissolved concentration of $\mathrm{Pb}$ on $\mathrm{Fe}$ and $\mathrm{Al}$-coated as compared to pure illite (Figures 3.5-

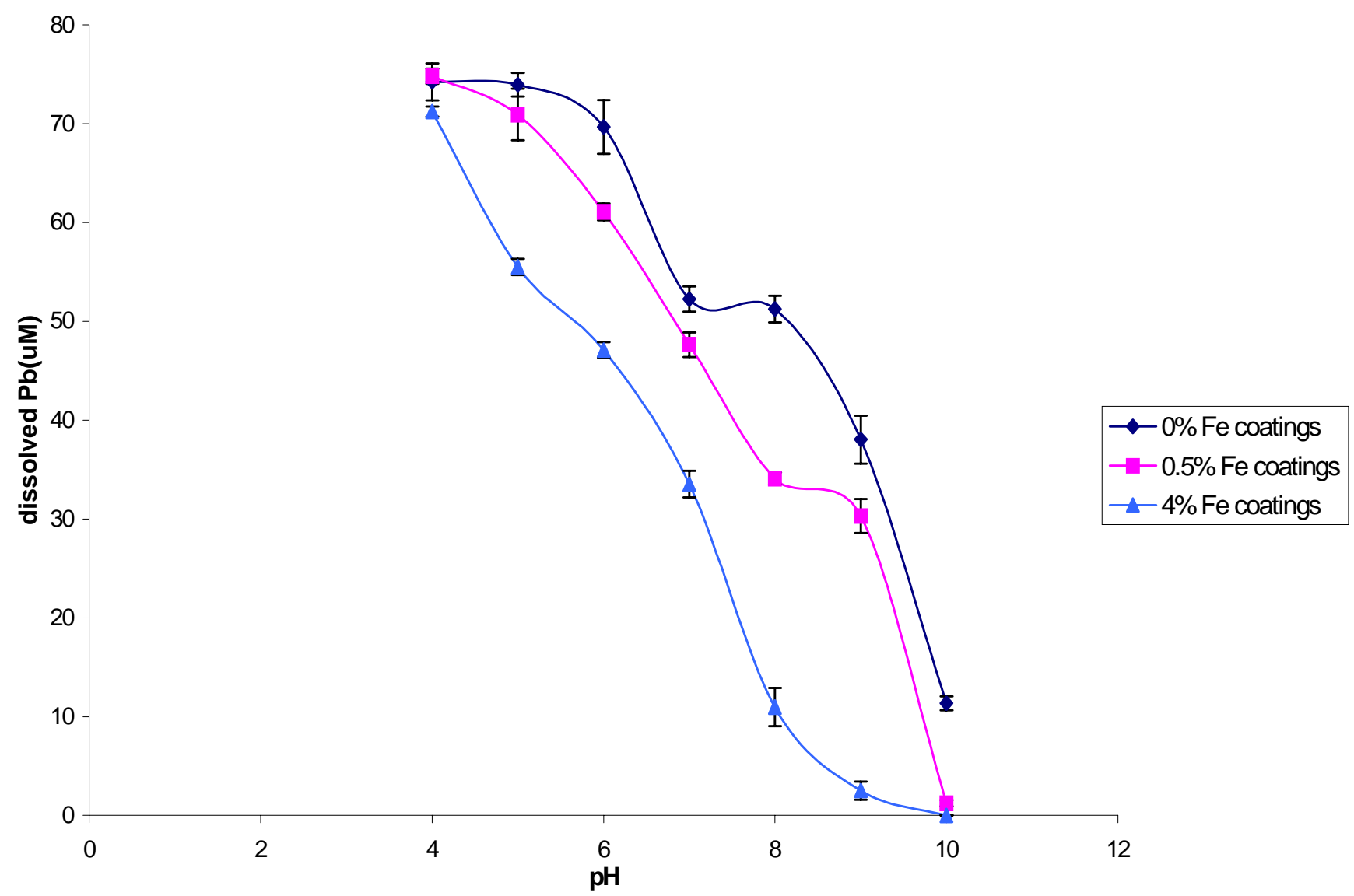

Figure 3.1: Effect of different levels of iron coatings on the adsorption of lead by montmorillonite

3.6). But there was drastic reduction in the dissolved concentration of As by both $4 \% \mathrm{Fe}$ 


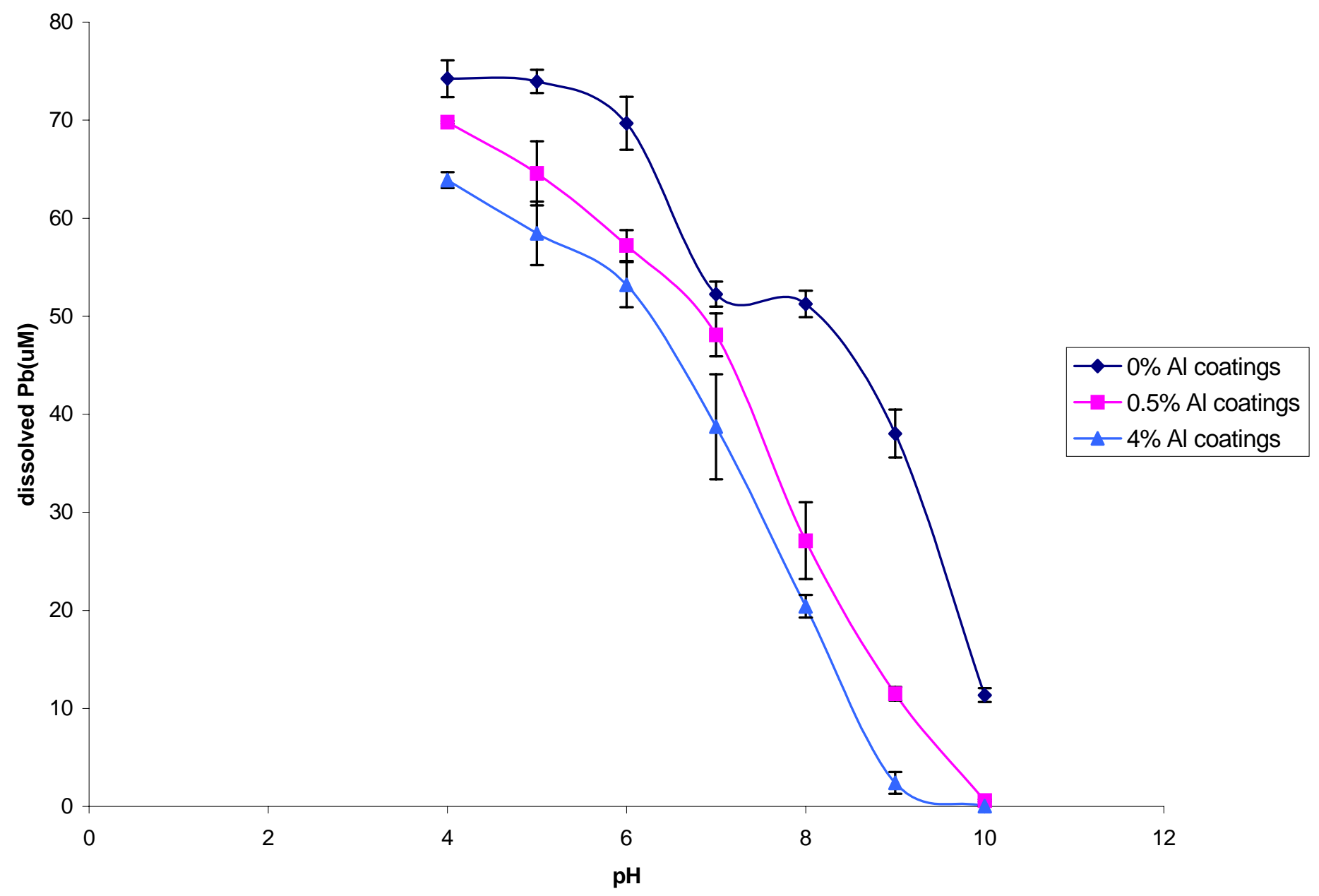

Figure 3.2: Effect of different levels of aluminum coatings on the adsorption of lead by montmorillonite 


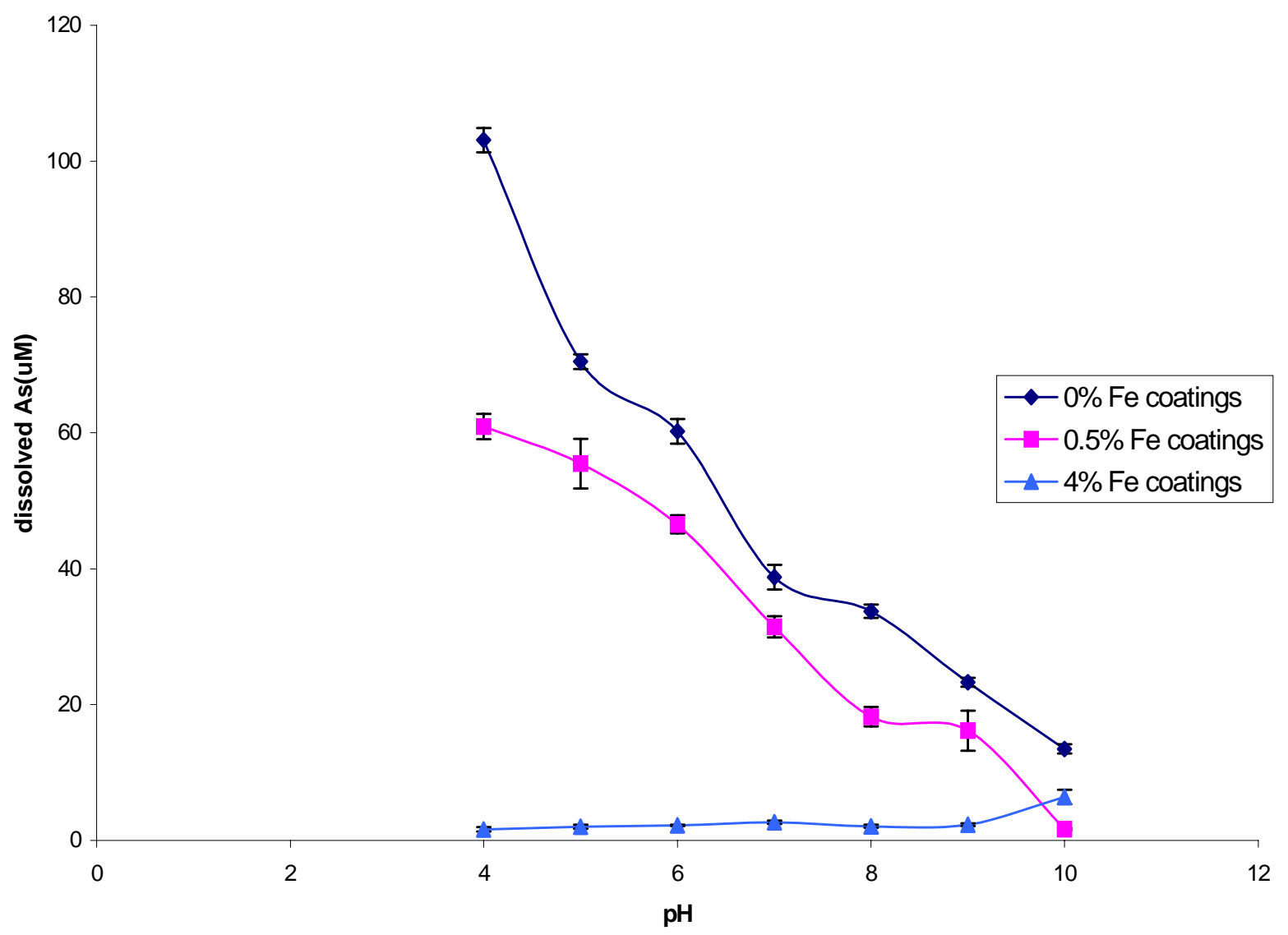

Figure 3.3: Effect of different levels of iron coatings on the adsorption of arsenic by montmorillonite 


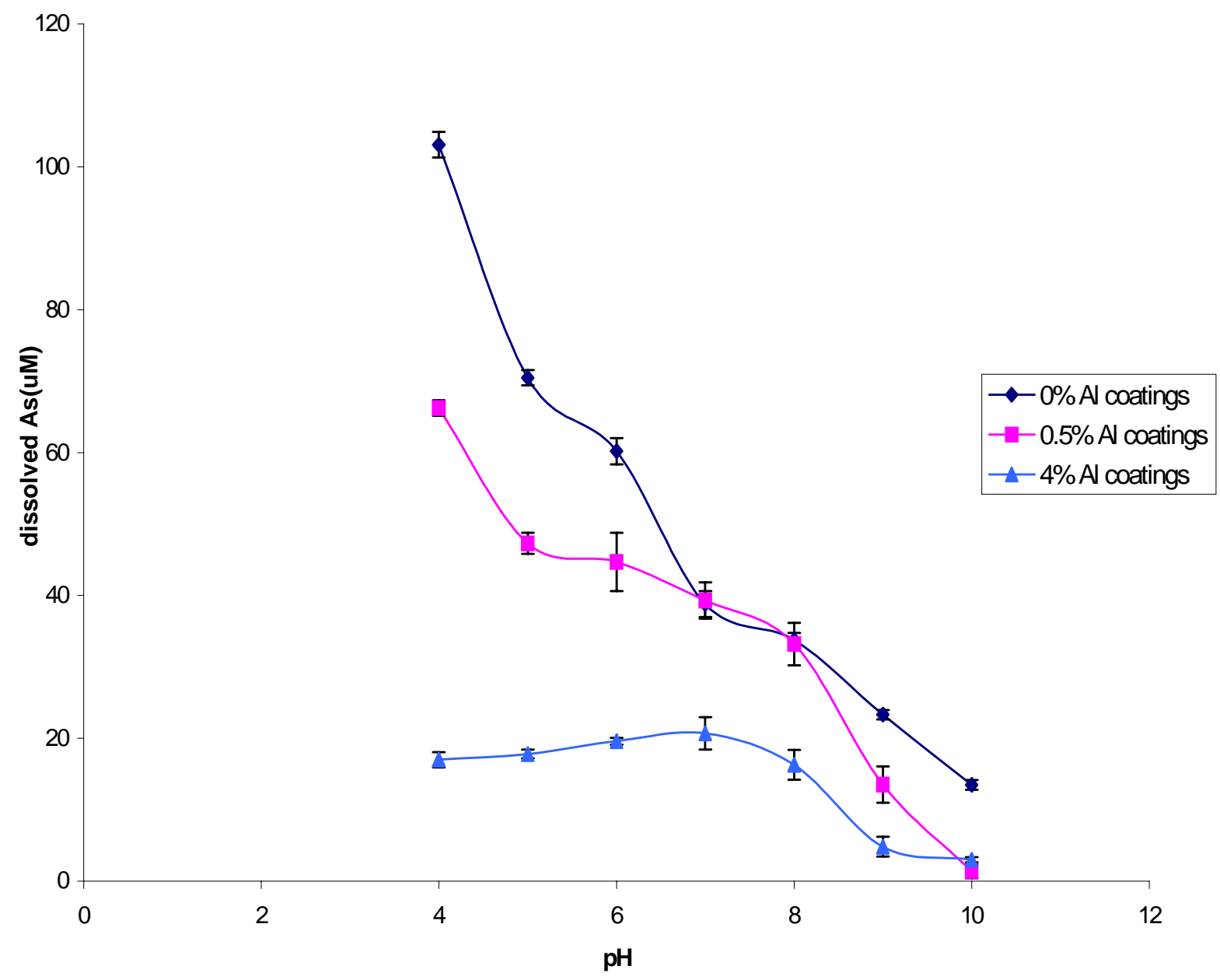

Figure 3.4: Effect of different levels of aluminum coatings on the adsorption of arsenic by montmorillonite 


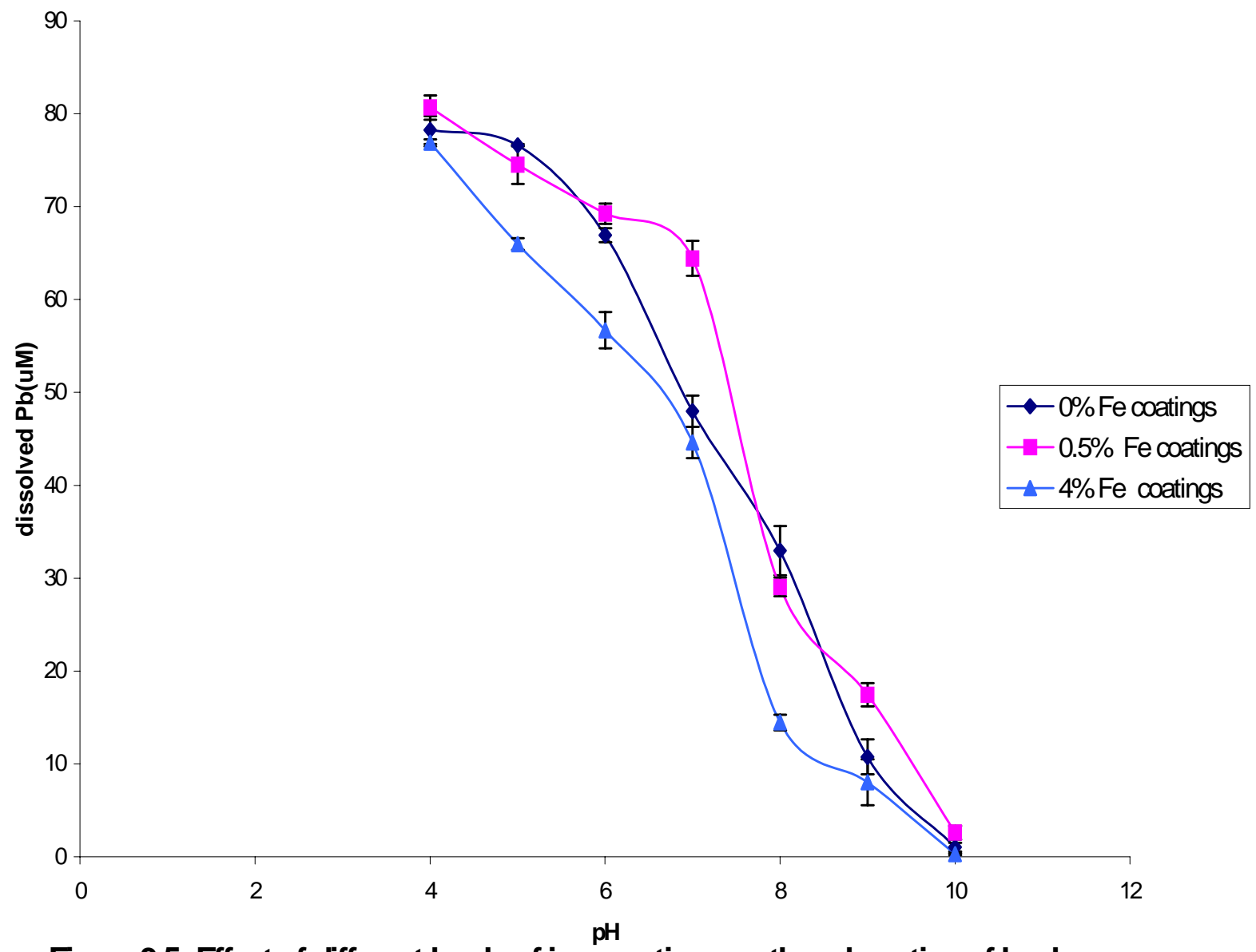

Figure 3.5: Effect of different levels of iron coatings on the adsorption of lead by Illite 


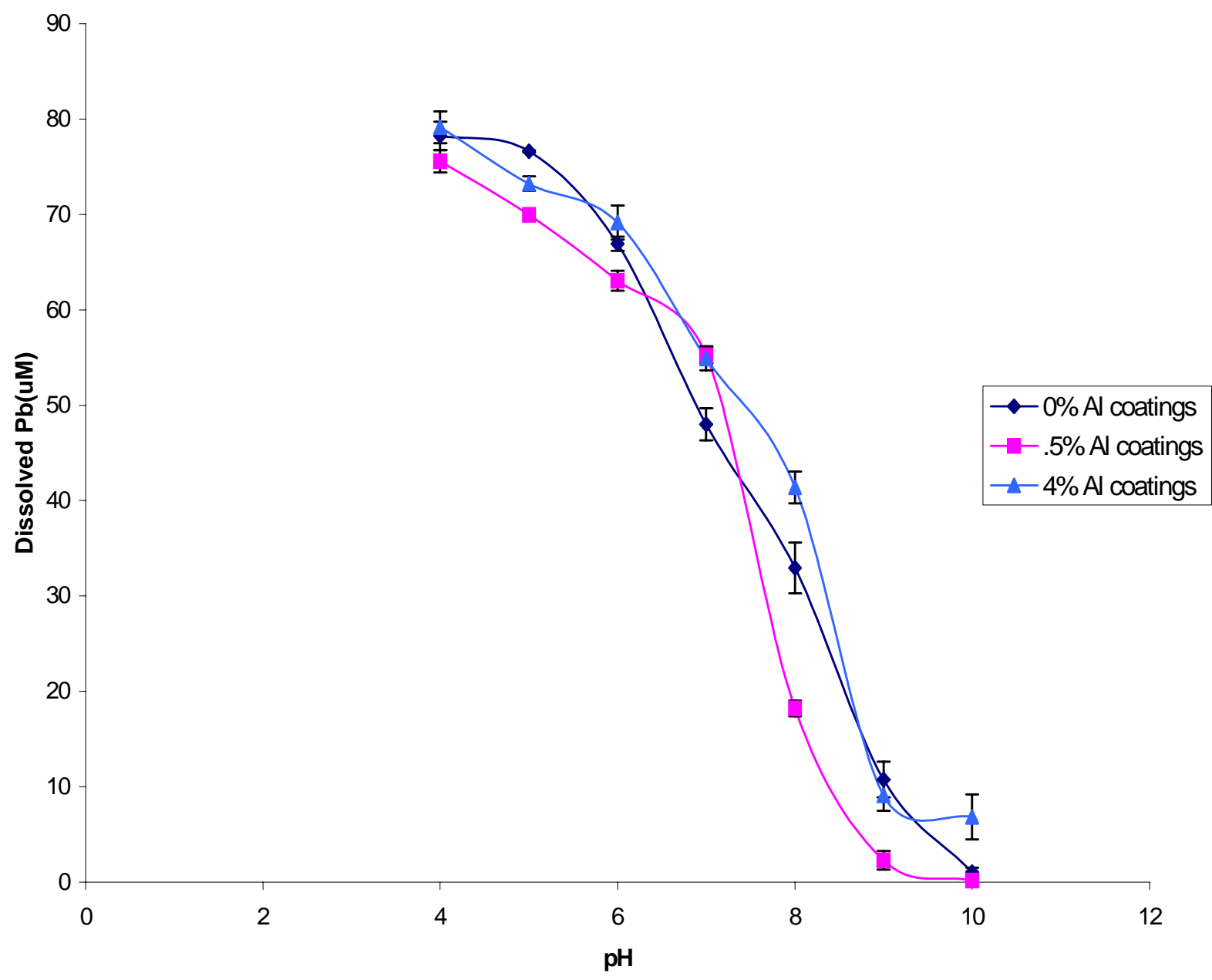

Figure 3.6: Effect of different levels of aluminum coatings on the adsorption of lead by Illite 
and 4\% Al coated illite as compared to pure illite (Figures 3.7-3.8). Dissolved As concentration was less at all the $\mathrm{pH}$ values for $4 \%$ Fe coatings on illite as compared to $4 \%$ Al coatings. Pure kaolinite showed more dissolved concentration of $\mathrm{Pb}$ and $\mathrm{As}$ as compared to $\mathrm{Fe}$ and $\mathrm{Al}$ coated kaolinite at all the $\mathrm{pH}$ values (Figures 3.9-3.12). The dissolved concentration of As was much less at all pH's (4-10) for $4 \%$ Fe coated illite as compared to $0.5 \%$ Fe coated and pure kaolinite (Figure 3.11). Dissolved Pb and As concentration at different levels of $\mathrm{Al}$ and Fe hydrous oxide coated attapulgite exhibited similar trends to those of kaolinite and illite (Figures 3.13-3.16). There was a decrease in the dissolved concentration of $\mathrm{As}$ and $\mathrm{Pb}$ with the increase in $\mathrm{Fe}$ as well as the $\mathrm{Al}$ hydrous oxide coatings. Amount of $\mathrm{As}$ and $\mathrm{Pb}$ present in the solution was lower in the case of $\mathrm{Fe}$ hydrous-coated samples than Al hydrous coated samples.

3.3.2 Exchange of $\mathbf{P b}$ by Magnesium: $\mathrm{Pb}$ adsorbed on all the pure clay minerals in this study was considerably remobilized after the addition of $37 \mathrm{mM} \mathrm{Mg}\left(\mathrm{NO}_{3}\right)_{2}$. This indicates that the $\mathrm{Pb}$ was nonspecifically adsorbed on pure clays. This is shown by significant desorption of $\mathrm{Pb}$ generally by all the clay minerals. Coatings with both $\mathrm{Al}$ as well as $\mathrm{Fe}$ hydrous oxides on all the clay minerals results in lower desorption of $\mathrm{Pb}$ in the soil solution (Figures 3.17-3.24).

\subsection{Discussion}

3.4.1 Adsorption of $\mathrm{Pb}$ and $\mathrm{As}$ on pure and coated clay minerals: Significant immobilization of $\mathrm{Pb}$ was observed on pure and coated montmorillonite. About $25 \mathrm{M} \mathrm{Pb}$ was adsorbed without $\mathrm{pH}$ limitation down to 4 (Figure 3.1). On the other hand, $\mathrm{Pb}$ adsorption on all the clay minerals gradually increased with increasing amount of both Fe and $\mathrm{Al}$ coatings. This is due to the fact that low affinity sites on permanently charged clay surfaces were replaced by high affinity aluminum and iron hydroxyl functional groups with variable charge (Lothenbach et al., 1997). 


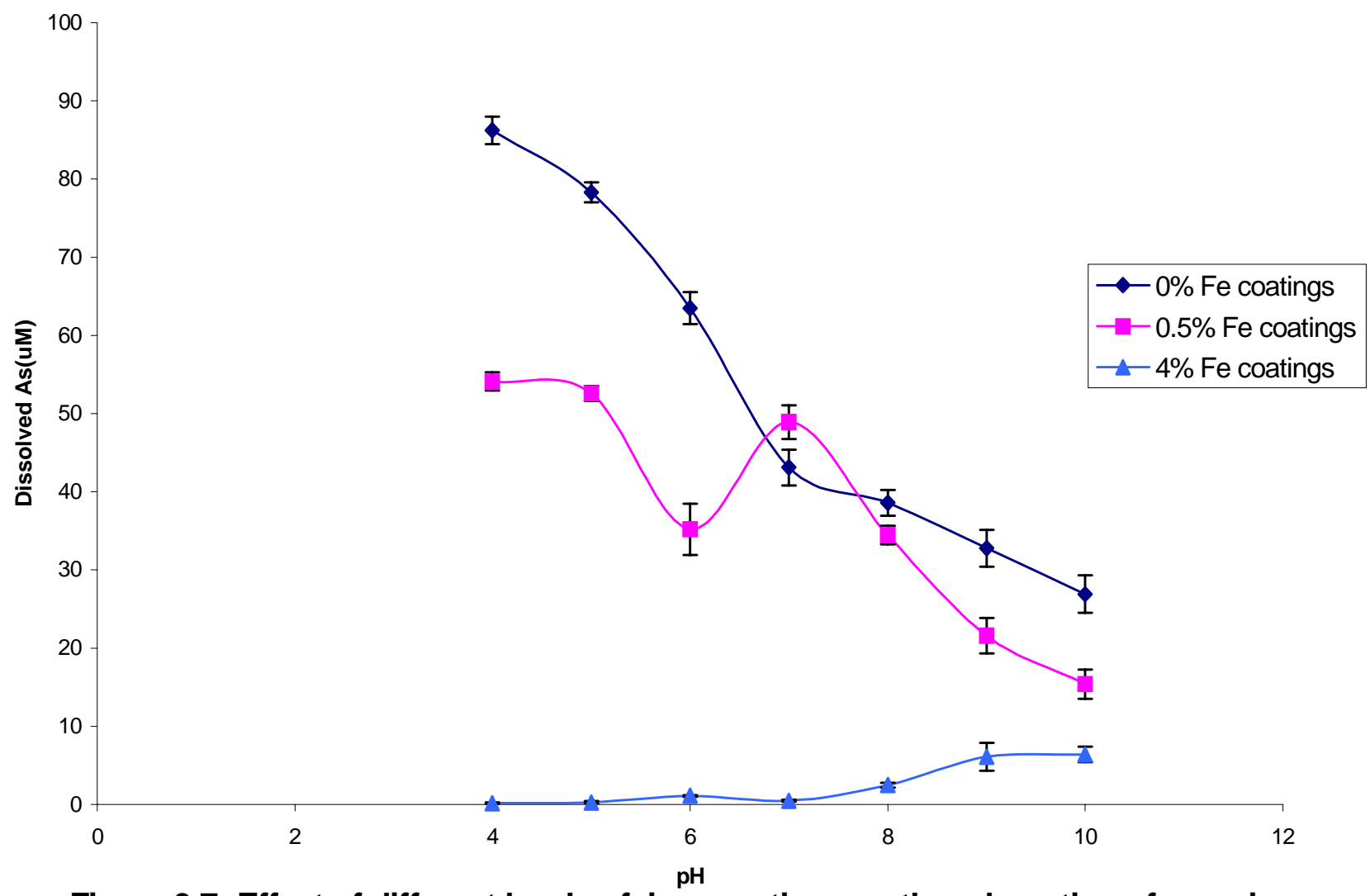

Figure 3.7: Effect of different levels of iron coatings on the adsorption of arsenic by Illite 


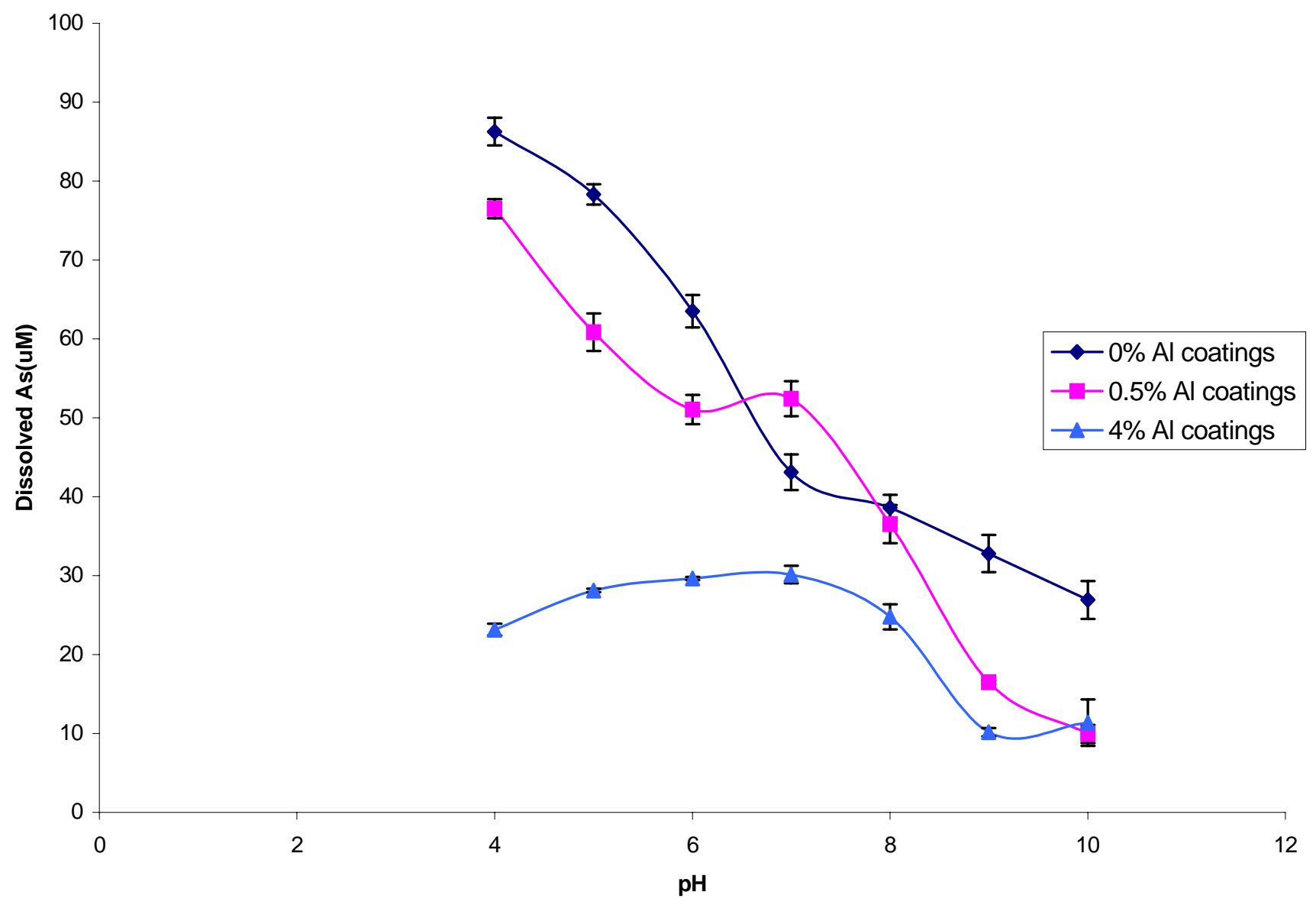

Figure 3.8: Effect of different levels of aluminum coatings on the adsorption of arsenic by illite 


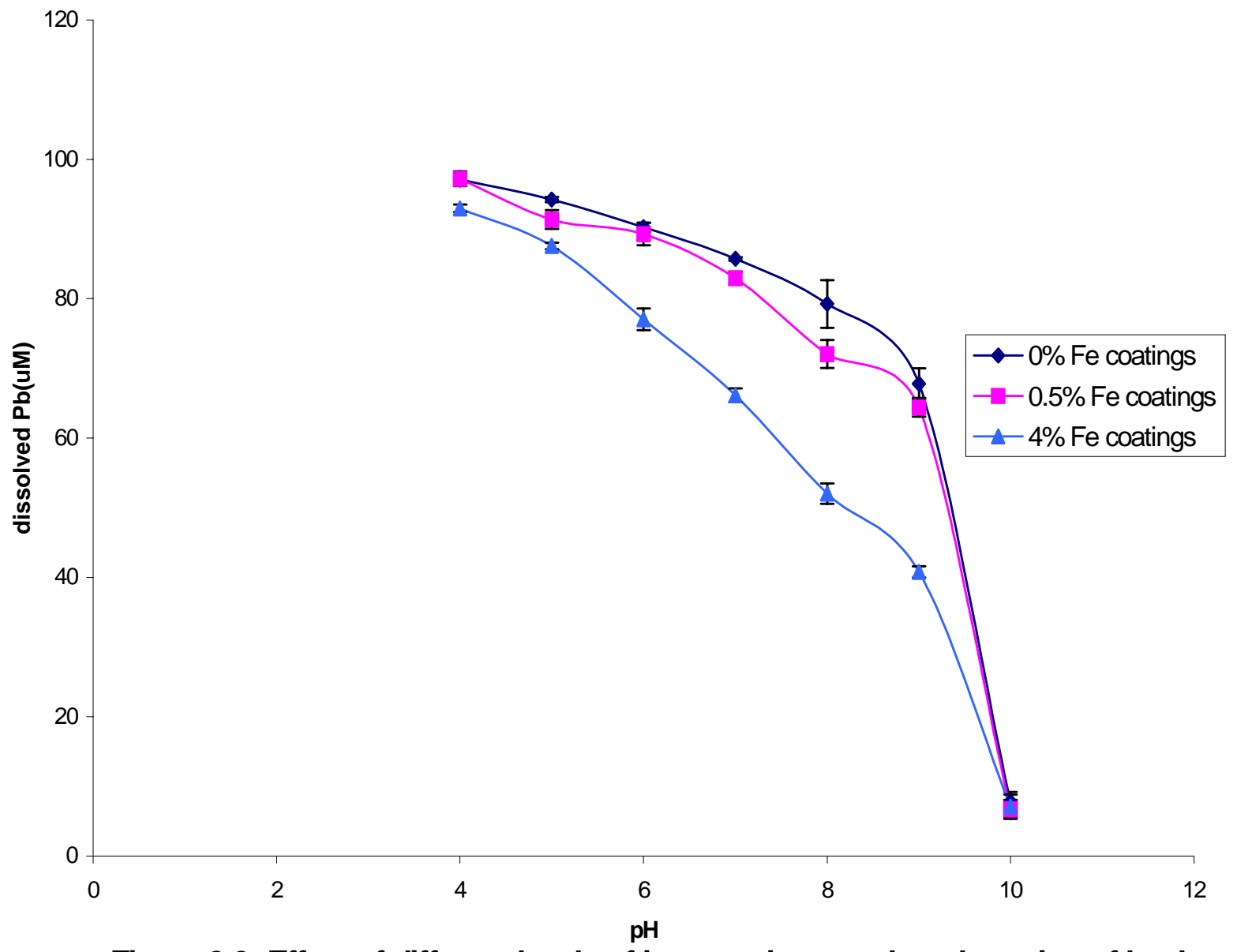

Figure 3.9: Effect of different levels of iron coatings on the adsorption of lead by kaolinite 


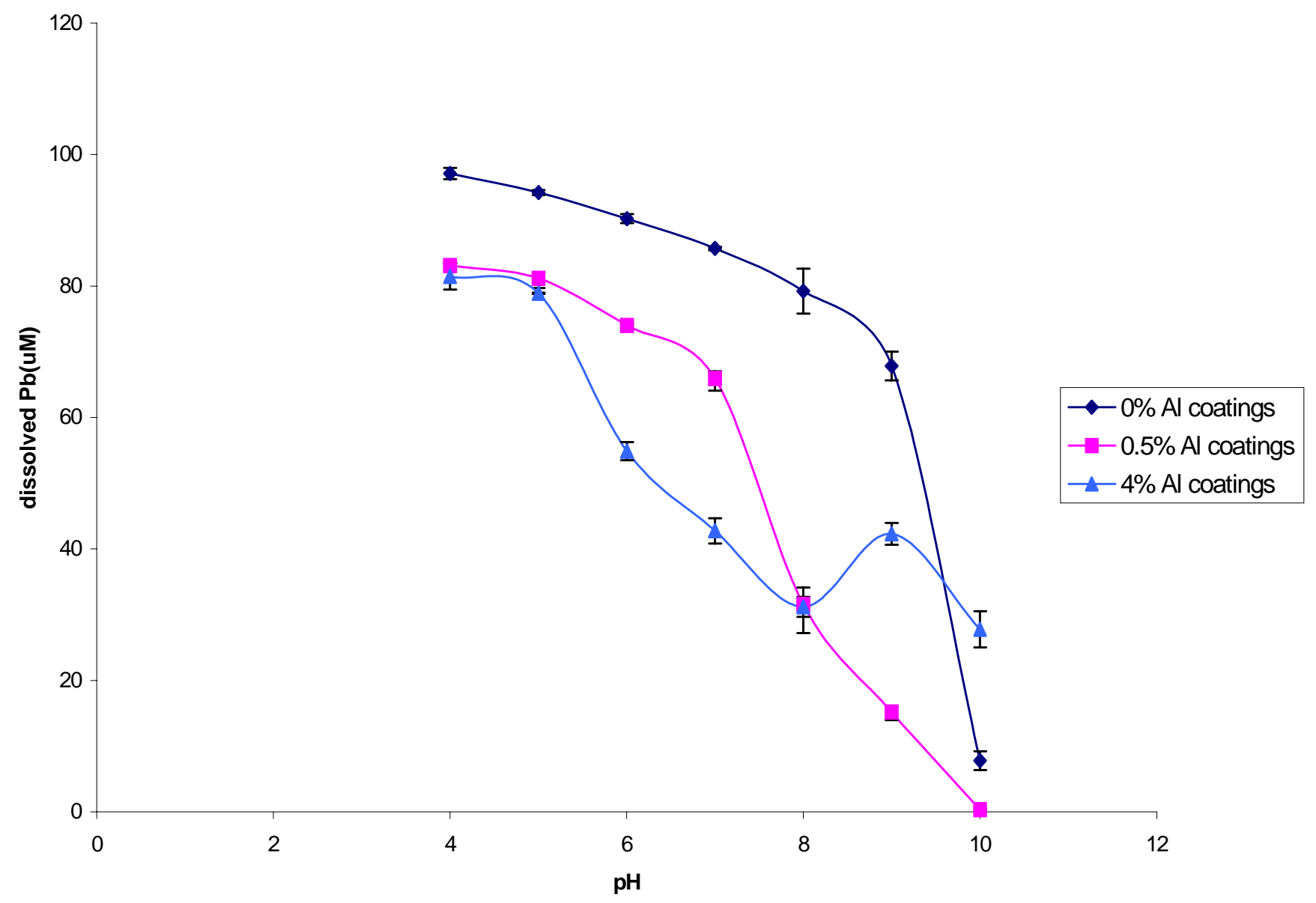

Figure 3.10: Effect of different levels of aluminum coatings on the adsorption of lead by kaolinite 


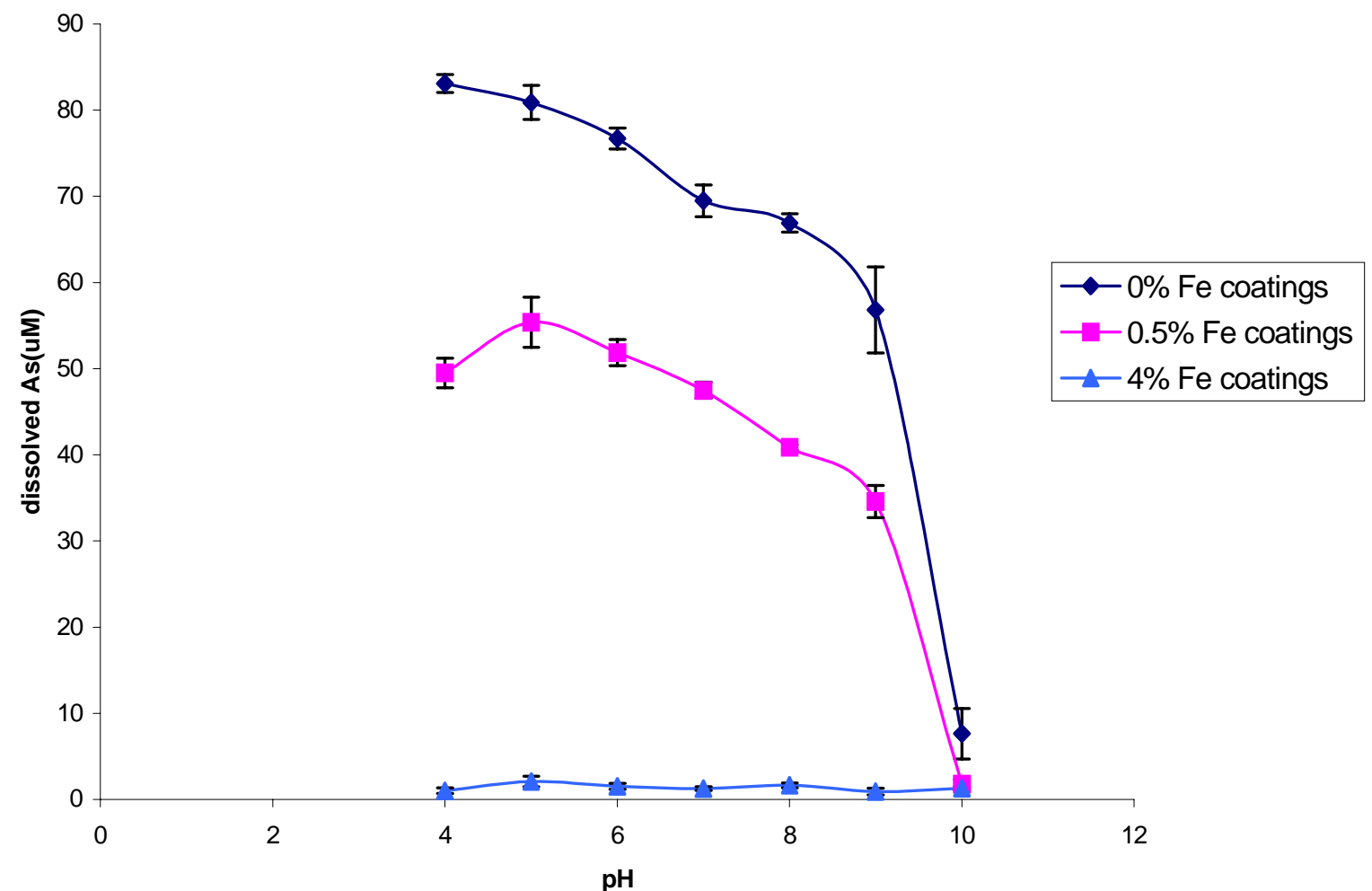

Figure 3.11: Effect of different levels of iron coatings on the adsorption of arsenic by kaolinite 


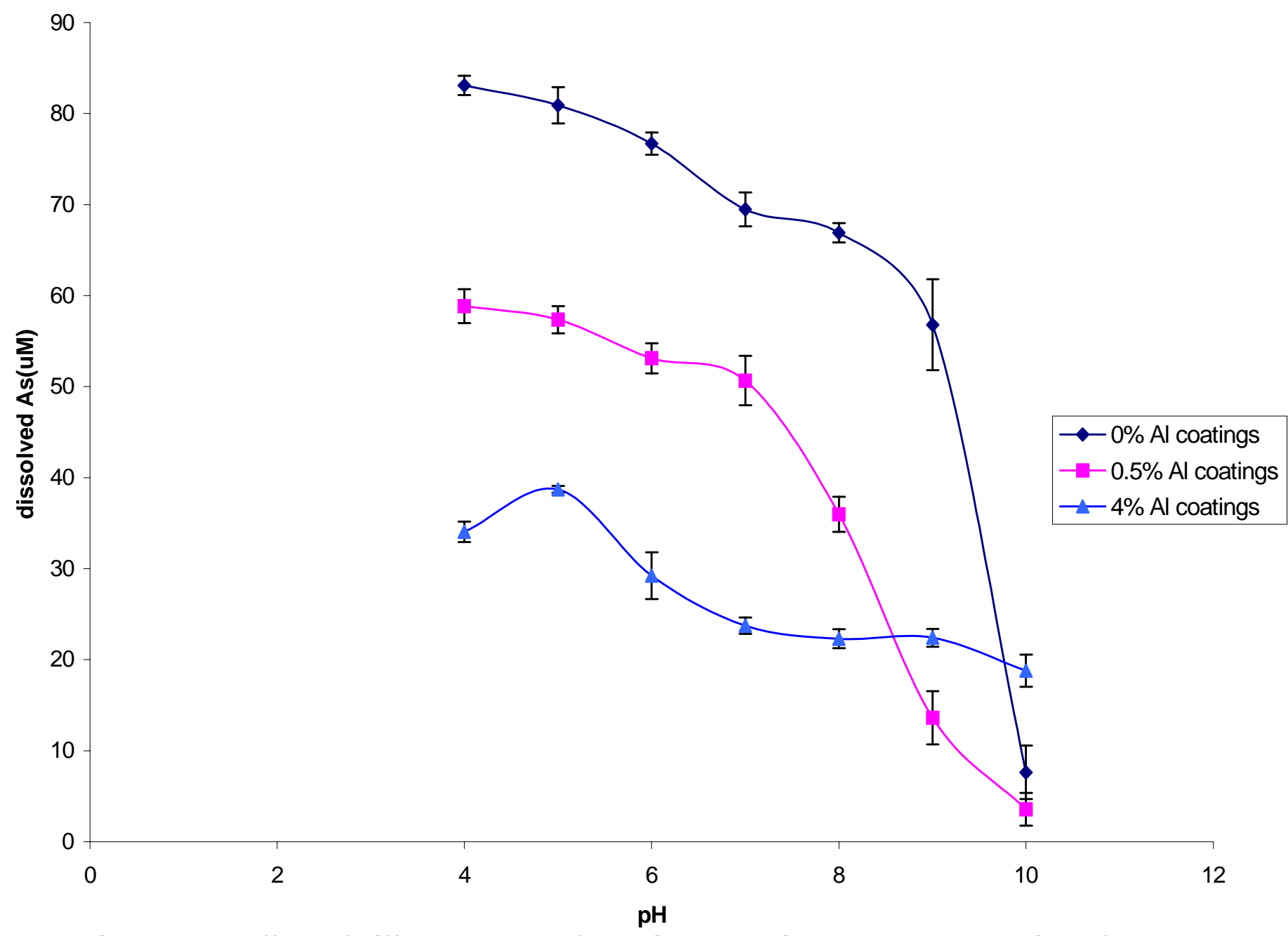

Figure 3.12: Effect of different levels of aluminum coatings on the adsorption of arsenic by kaolinite 


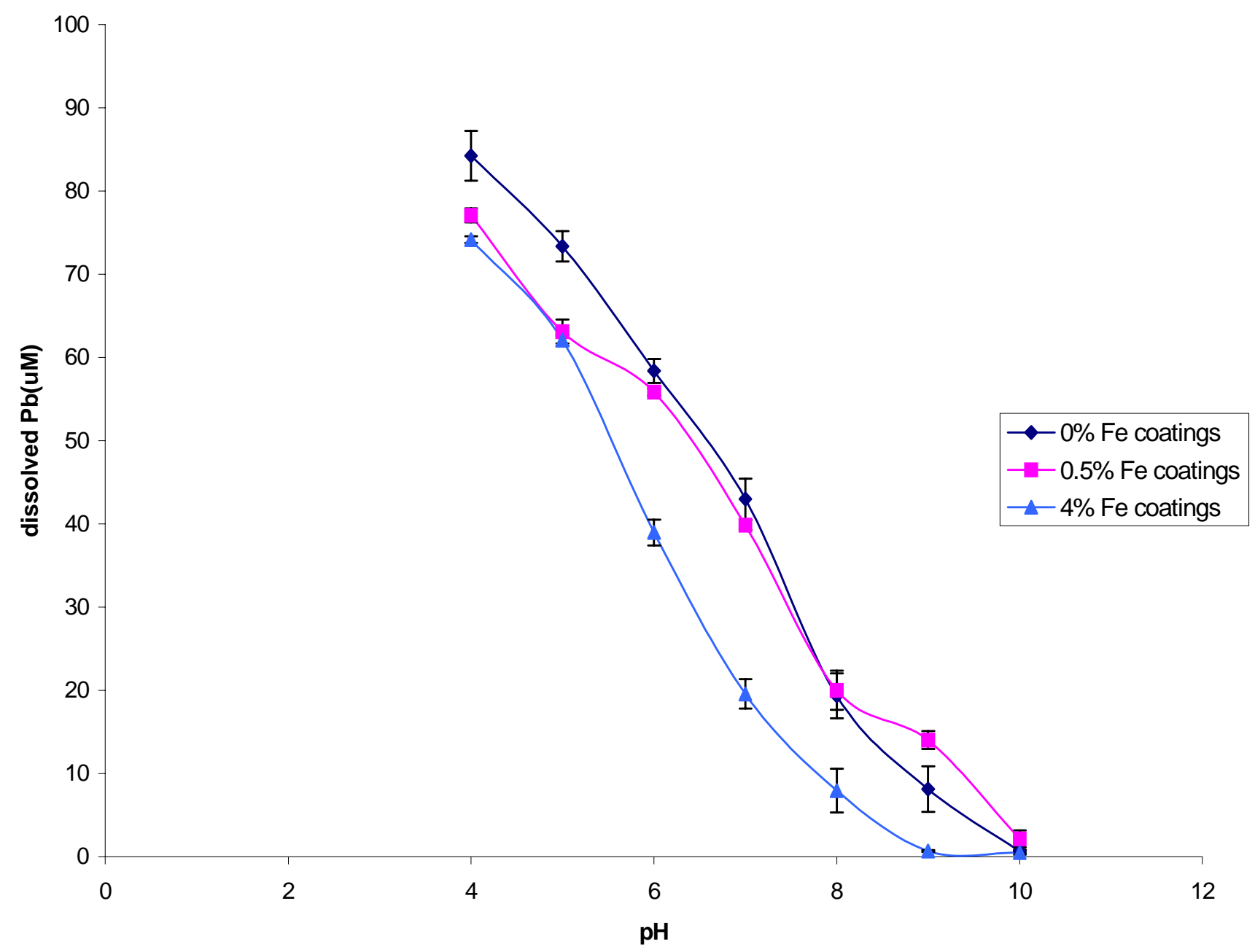

Figure 3.13: Effect of different levels of iron coatings on the adsorption of lead by attapulgite 


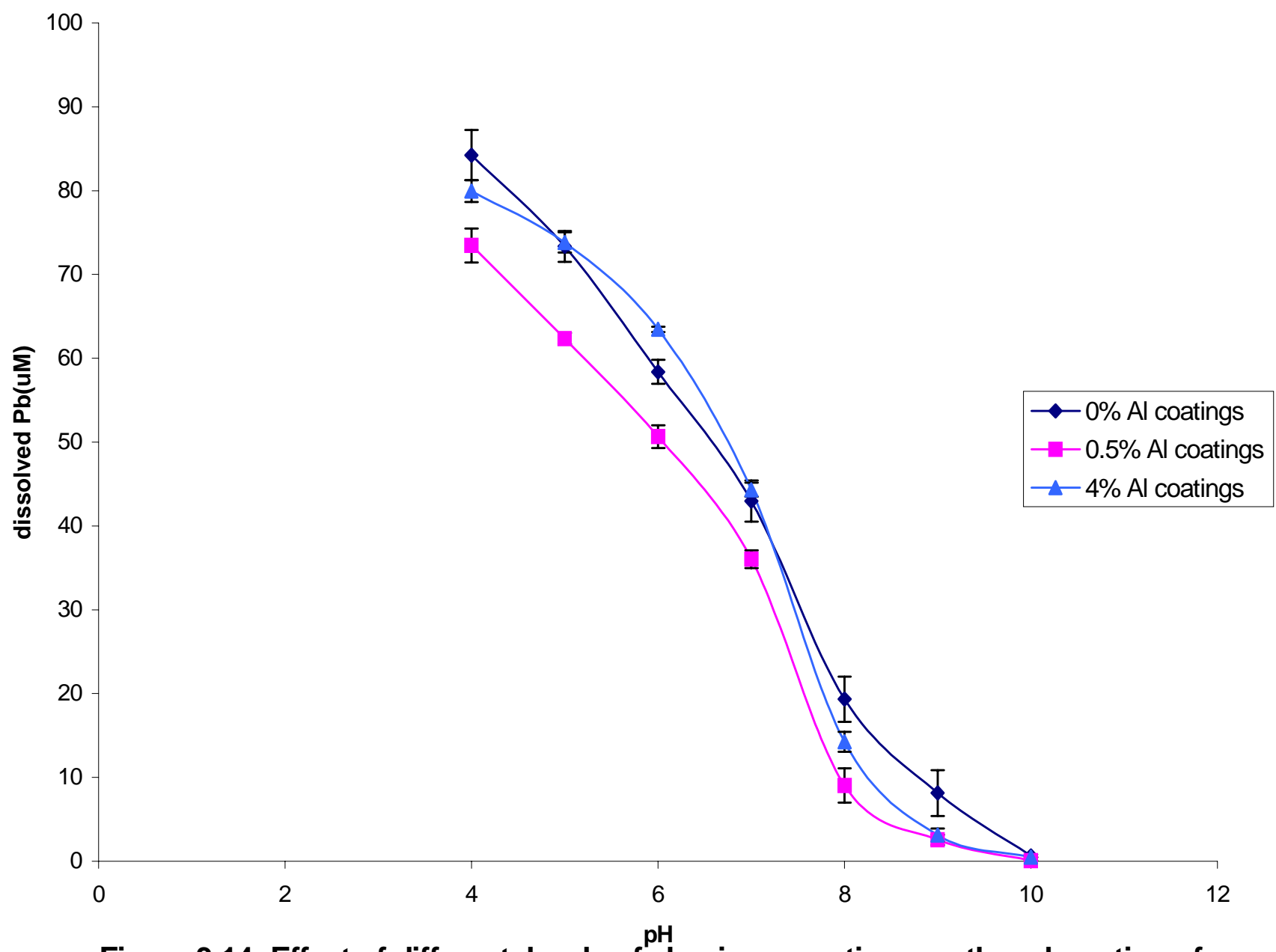

Figure 3.14: Effect of different levels of aluminum coatings on the adsorption of lead by attapulgite 


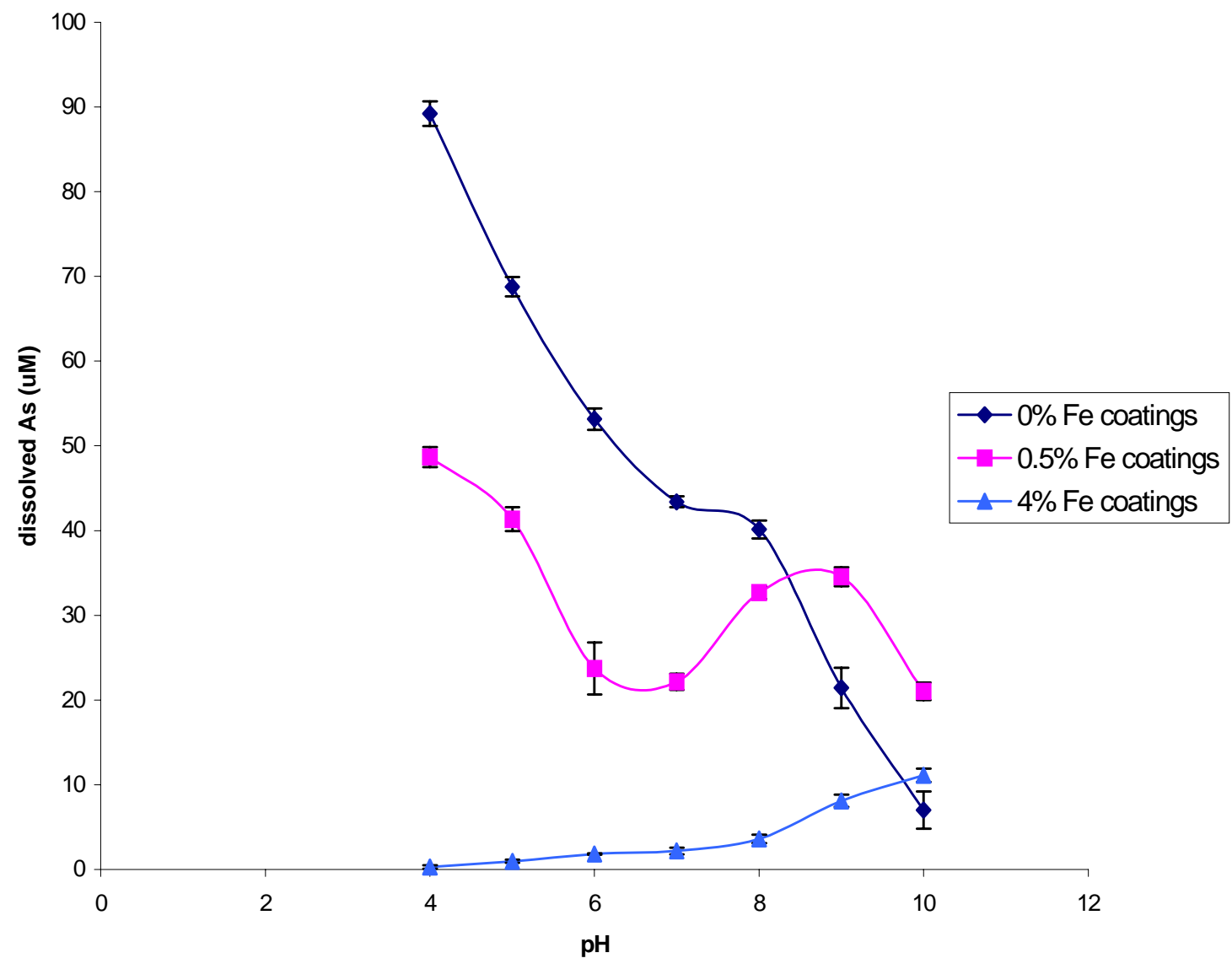

Figure 3.15: Effect of different levels of iron coatings on the adsorption of arsenic by attapulgite 


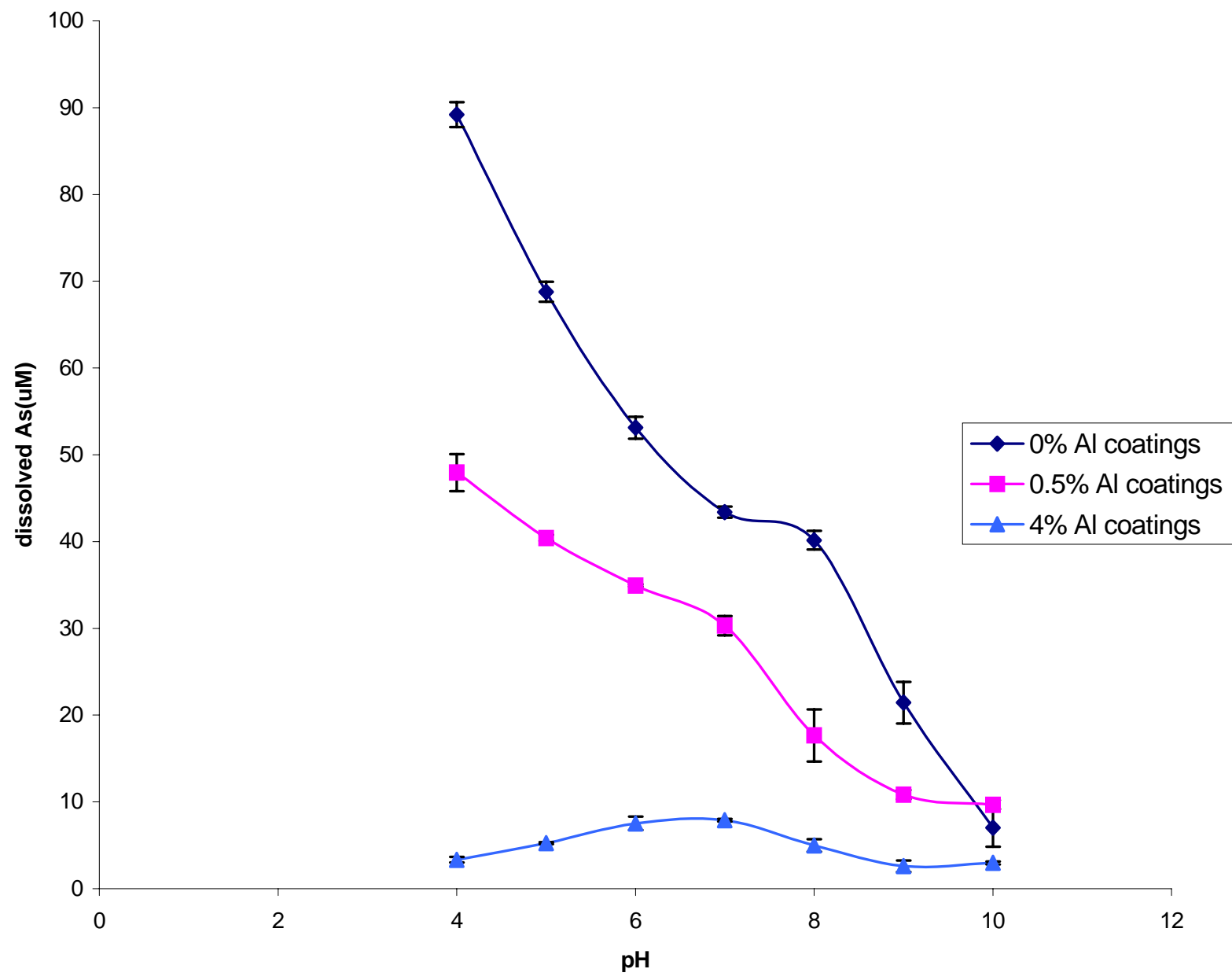

Figure 3.16: Effect of different levels of aluminum coatings on the adsorption of arsenic by attapulgite 


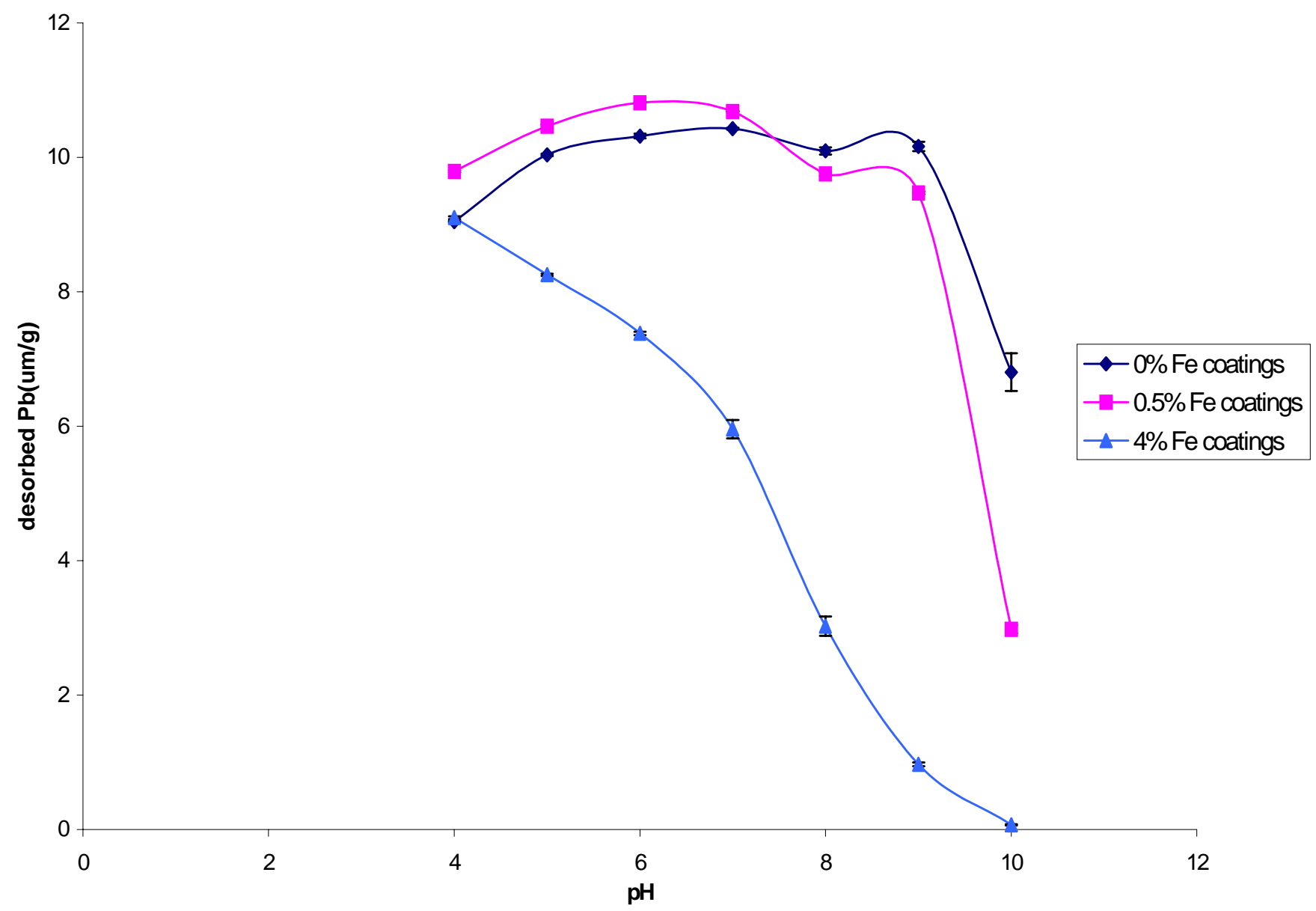

Figure 3.17: Effect of different levels iron coatings on the desorption of lead by montmorillonite 


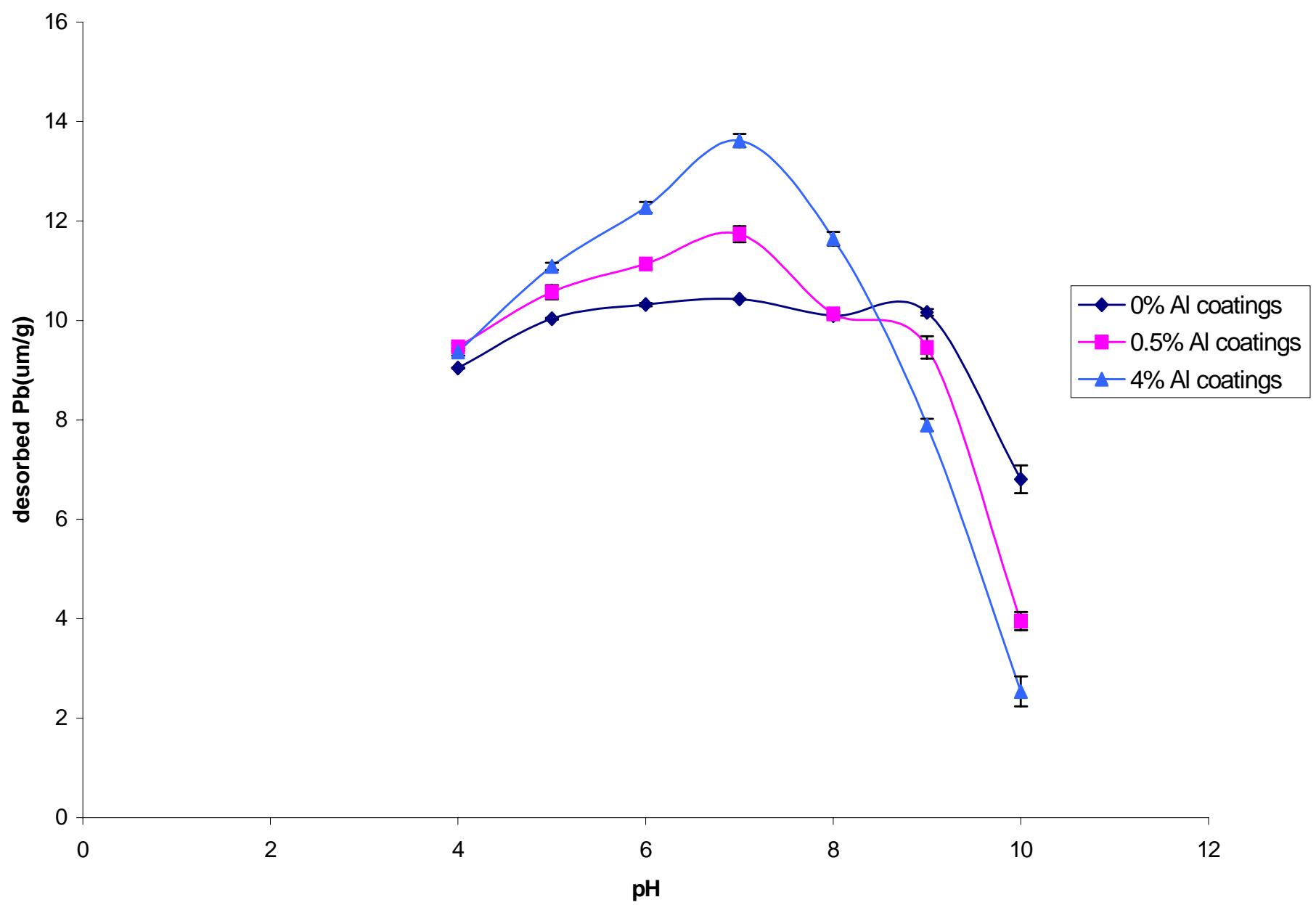

Figure 3.18: Effect of different levels of aluminum coatings on the desorption of lead by montmorillonite 


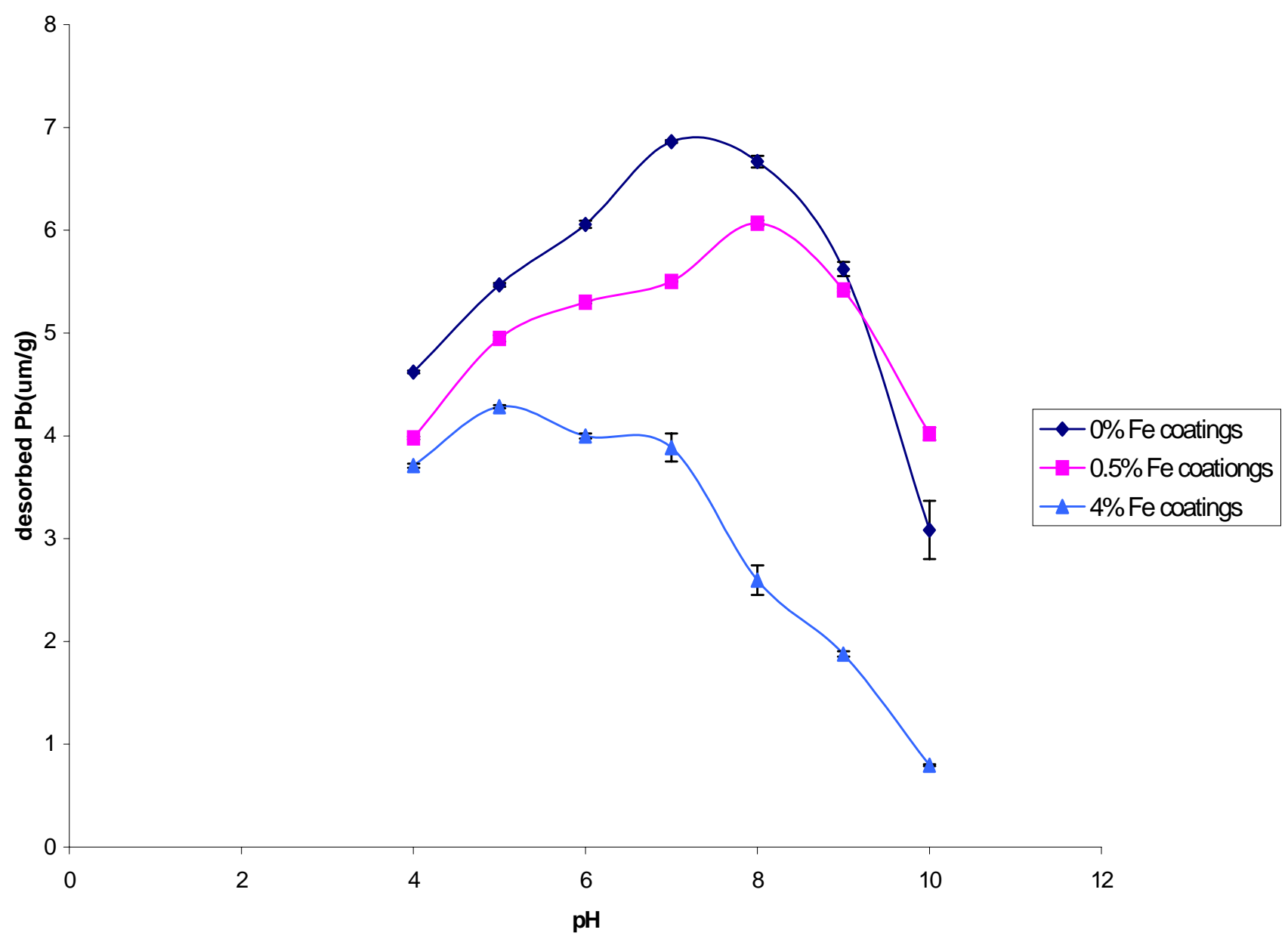

Figure 3.19: Effect of different levels of iron coatings on the desorption of lead by illite 


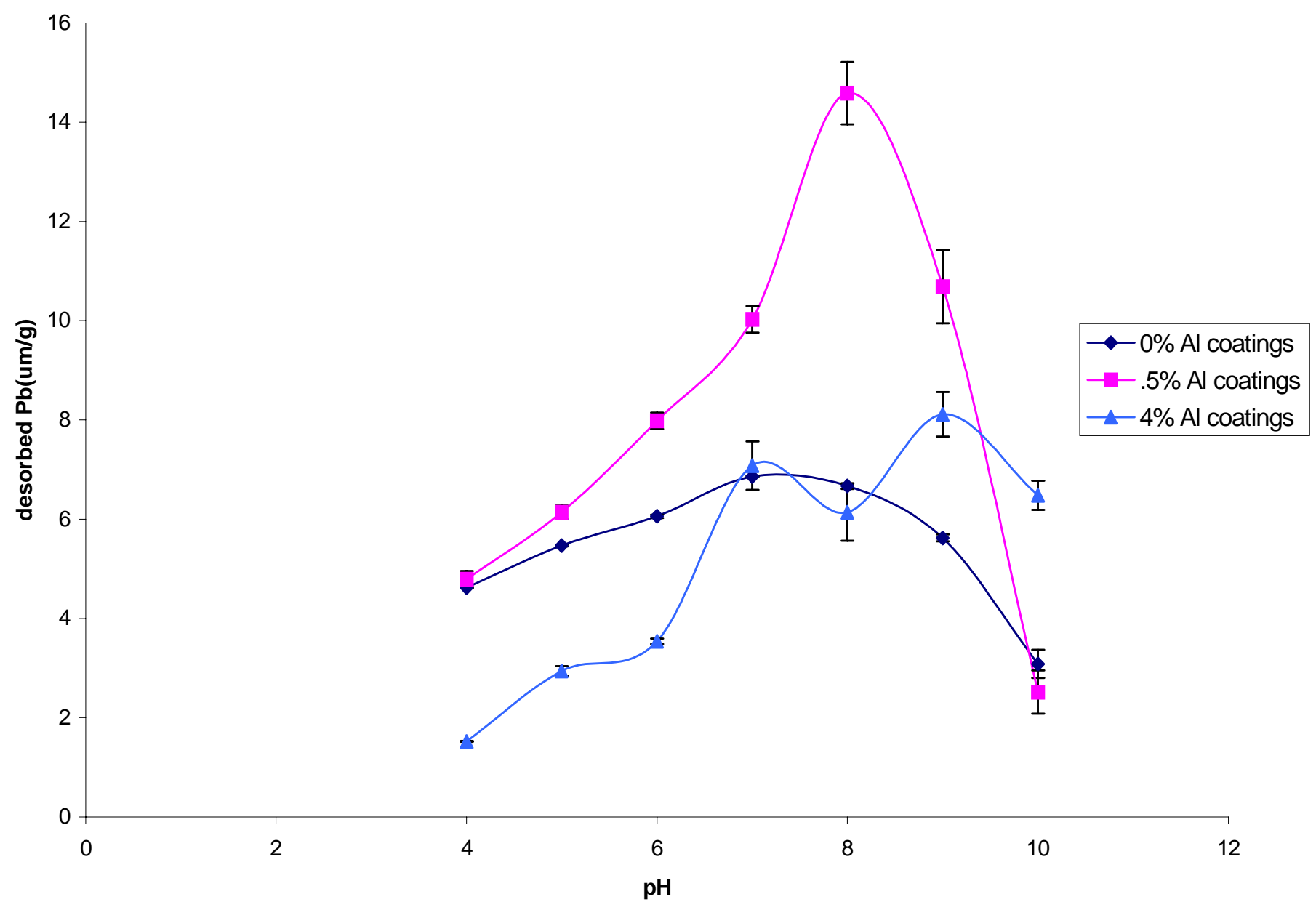

Figure 3.20: Effect of different levels of aluminum coatings on the desorption of lead by Illite 


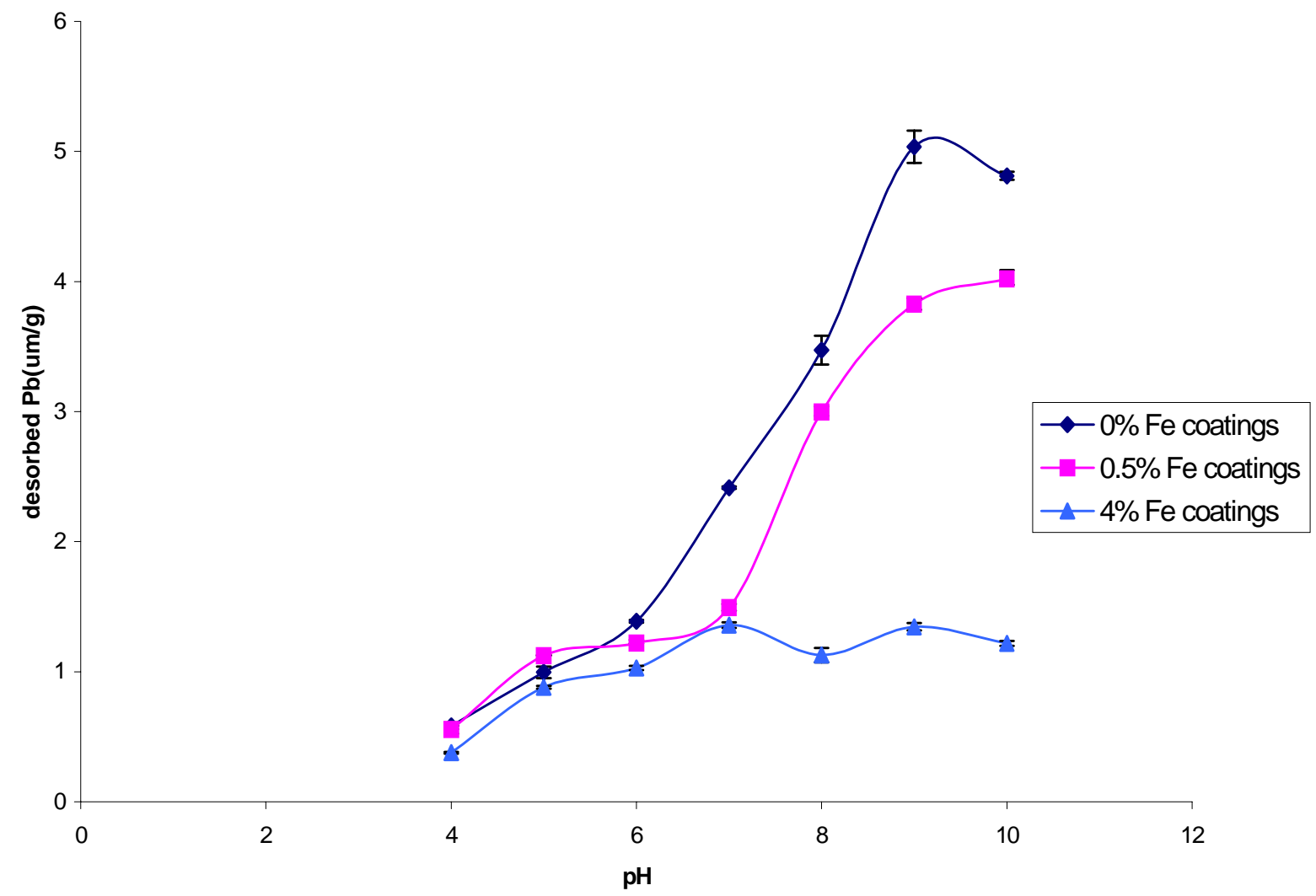

Figure 3.21: Effect of different levels of iron coatings on the desorption of lead by kaolinite 


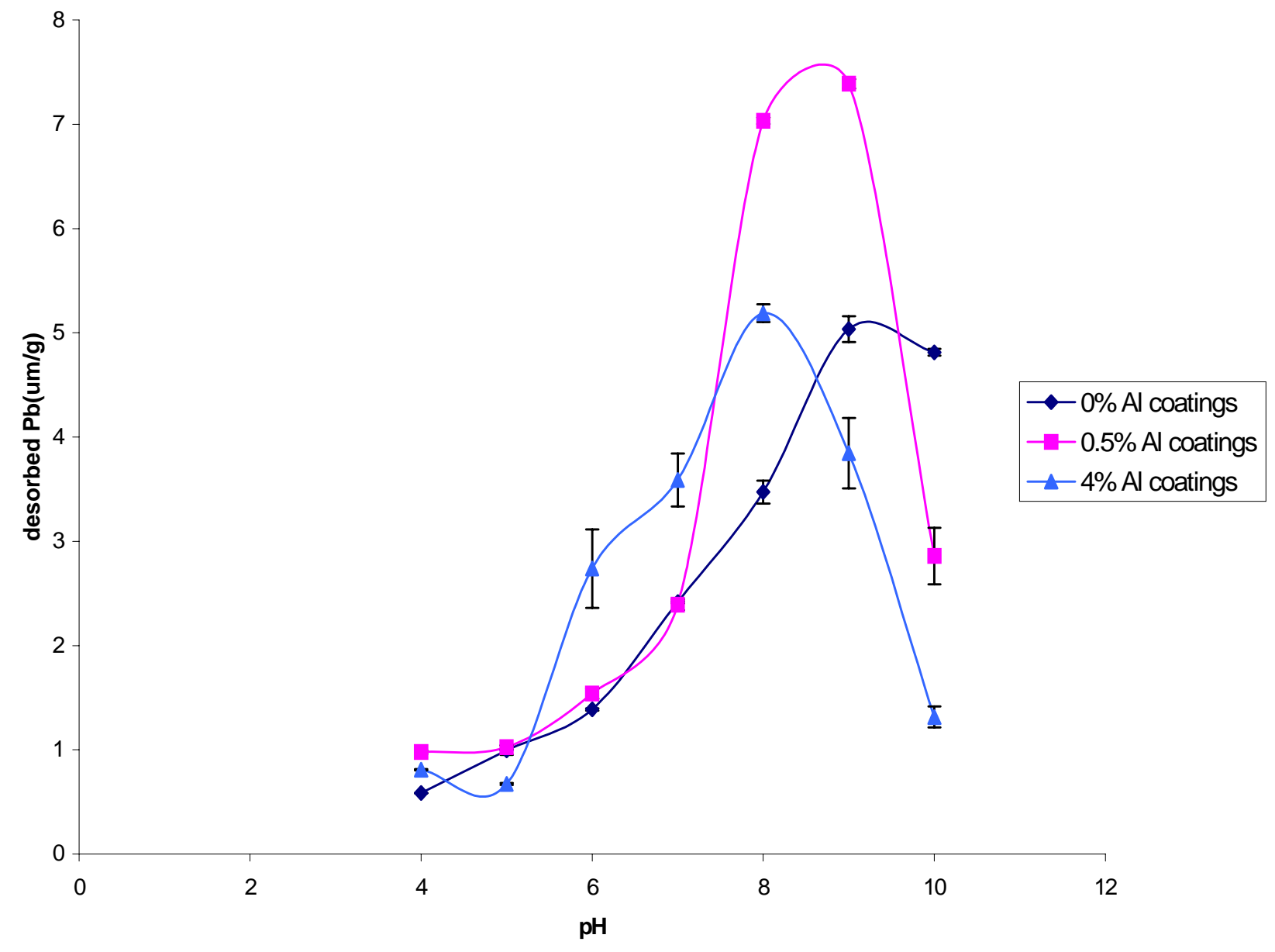

Figure 3.22: Effect of different levels of aluminum coatings on the desorption of lead by kaolinite 


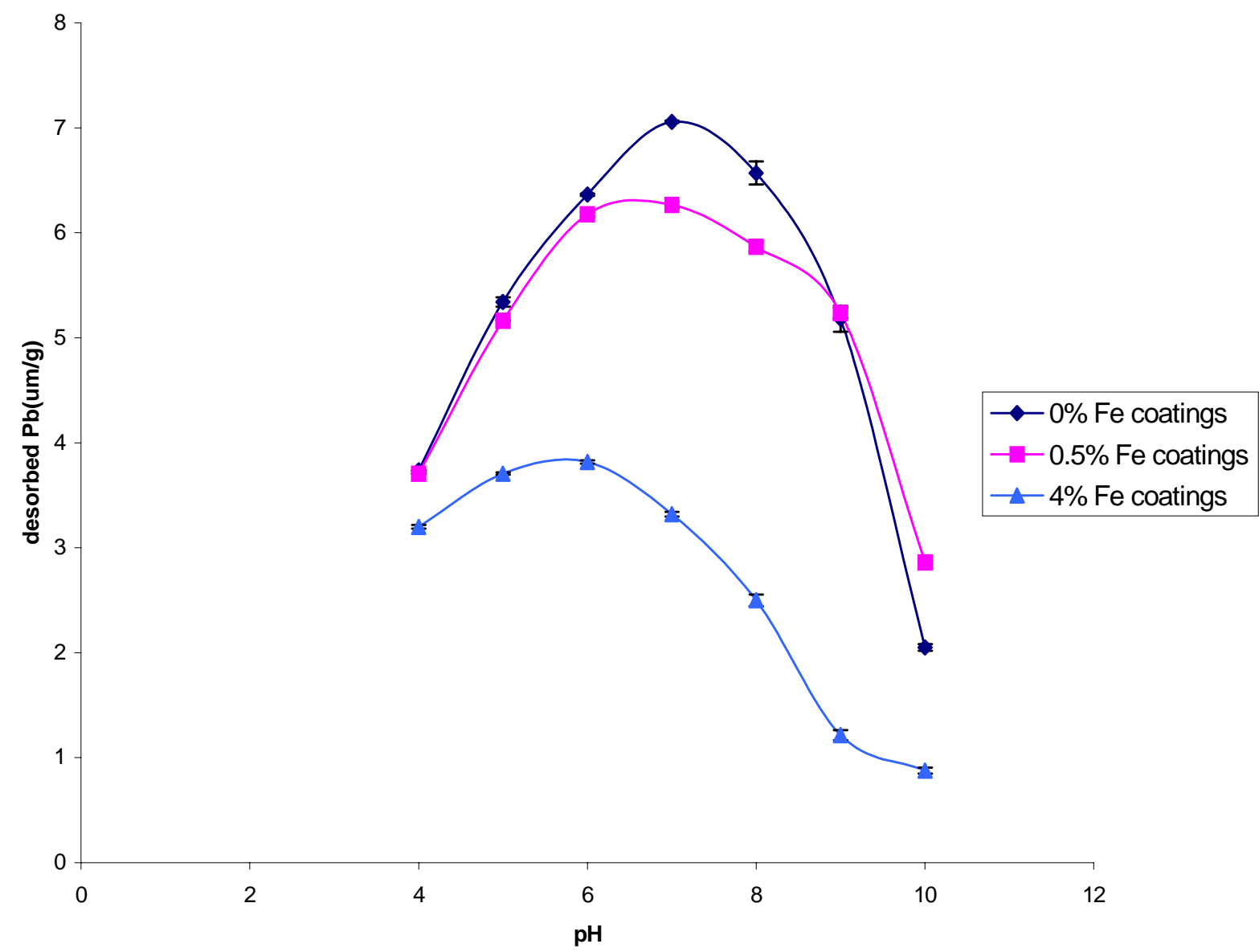

Figure 3.23: Effect of different levels of iron coatings on the desorption of lead by attapulgite 


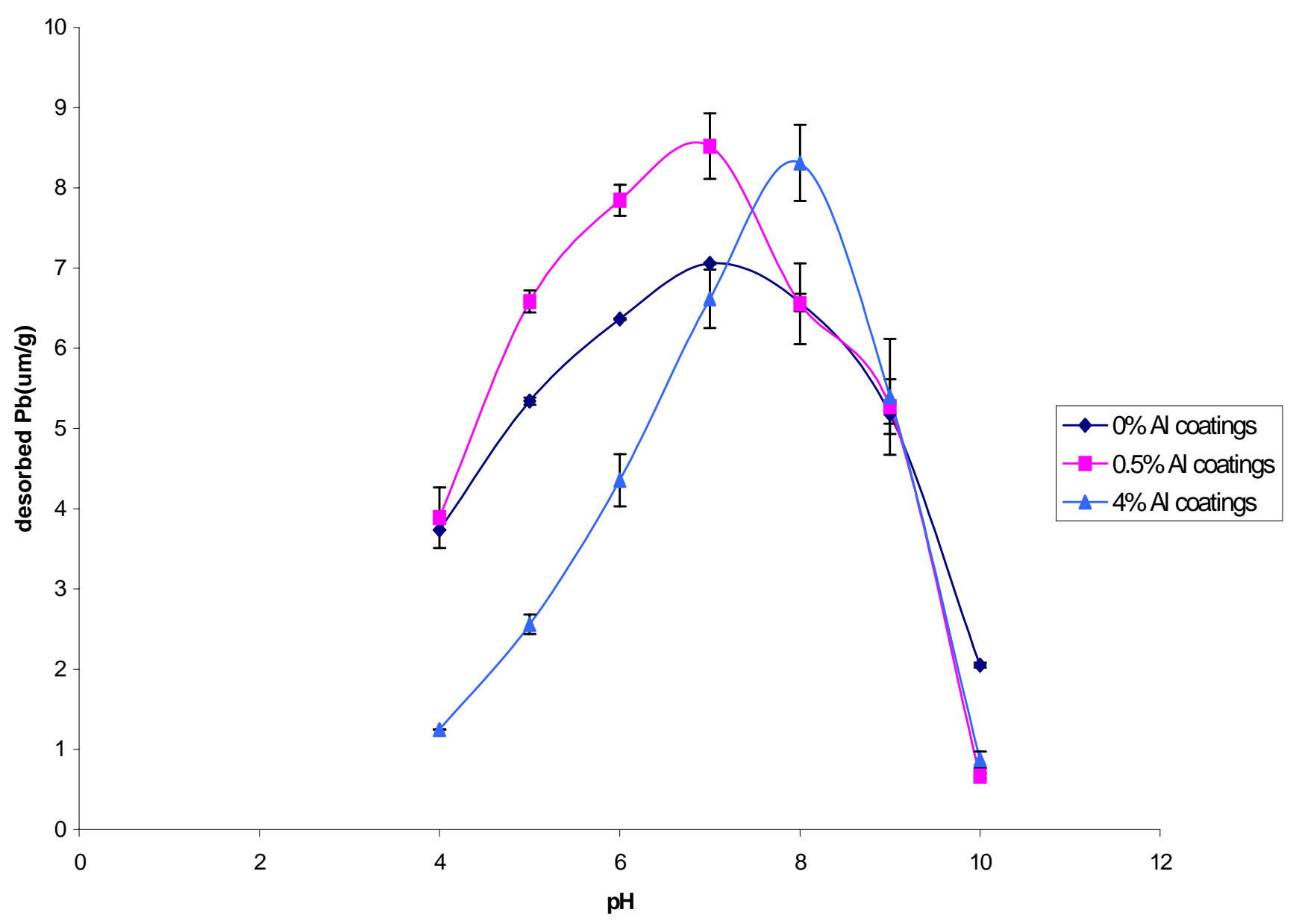

Figure 3.24: Effect of different levels of aluminum coatings on the desorption of lead by attapulgite 
After the addition of $\mathrm{Mg}$ there was relatively more desorption of $\mathrm{Pb}$ into solution from the pure minerals. More desorption of $\mathrm{Pb}$ into the soil is mainly due to non-specific adsorption of $\mathrm{Pb}$ on pure minerals. But in the case of $\mathrm{Al}$ and $\mathrm{Fe}$ coated clay minerals, the desorption was relatively low. This effect was observed by Schulthess and Huang ( 1990),

Zachara et al. (1992), and Bradbury and Baeyens (1995), who postulated that the metal cations are specifically adsorbed on hydroxyl sites located on the mineral edge surfaces $\left(\mathrm{S}^{\mathrm{w}} \mathrm{OH}\right)$. Specific adsorption of $\mathrm{Pb}$ on $\mathrm{\Upsilon}^{-}-\mathrm{Al}_{2} \mathrm{O}_{3}$ as already proposed by Hohl and Stumn (1976) and Chisholm-Brause et al. (1989) observed the specific binding of $\mathrm{Pb}$ on $\Upsilon-\mathrm{Al}_{2} \mathrm{O}_{3}$ by $\mathrm{X}$-ray absorption spectroscopy .

Dissolved As concentrations at various $\mathrm{pH}$ values and various levels of $\mathrm{Fe}$ and $\mathrm{Al}$ hydrous oxide coatings for all the minerals are given in Figures 3.3, 3.4, 3.7, 3.8, 3.11, 3.12, 3.15, and 3.16. The concentration of dissolved As in the presence of uncoated clay minerals was relatively high as compared to that in the presence of $\mathrm{Al}$ and Fe coated clay minerals. The results indicate that uncoated minerals have a limited number of anion adsorption sites. For example, the variable charge sites responsible for chemical interactions with anions dominantly consist of $\mathrm{Si}-\mathrm{O}$ groups located on edge surface of montmorillonite. Montmorillonite does have Al-O sites but the percentage compared with $\mathrm{Si}-\mathrm{O}$ sites is low. By coating the montmorillonite and other clay minerals, there is increase in the Al-O and Fe-O sites, which should definitely chemisorb anions involved in inner sphere complex formation with hydroxylated surface.

Results of this investigation also indicate that in all four clay minerals, Al hydrous oxide created a lower number of adsorption sites than those created by equivalent amounts of $\mathrm{Fe}$ hydrous oxide coatings. The number of sites eventually affect the $\mathrm{Pb}$ and $\mathrm{As}$ adsorption. The effect was more pronounced in case of As adsorption. The disparity between $\mathrm{Al}$ and $\mathrm{Fe}$ hydrous coatings can be ascribed to many factors. First, $\mathrm{Al}$ is known to 
polymerize in solution before complete precipitation (Hsu, 1977), and precipitation of polymeric species of $\mathrm{Al}$ produces a three dimensional order on the surface of clay minerals reducing the number of $\mathrm{Al}$ atoms exposed on the surface. This would in turn reduce the number of single co-ordinated $\mathrm{OH}$ groups involved (Prafitt and Russel, 1977). Second, there could be greater chemical affinity between arsenate and $\mathrm{Fe}-\mathrm{O}$ sites than between arsenate and Al-O sites. Third, Fe hydrous oxide coated clay samples have been shown to have higher surface area compared to Al hydrous oxide coated clay samples (Hendeshot and Lavkulich, 1983). Therefore, Fe hydrous oxide coated samples may have higher number of adsorption sites as well.

\subsubsection{Amount of adsorption- Comparisons of different minerals : Adsorption of $\mathrm{Pb}$} was the highest for pure montmorillonite and lowest for pure kaolinite. The reason for this is the high surface area and cation exchange capacity of montmorillonite compared to all other minerals. With the increase in $\mathrm{Fe}$ and $\mathrm{Al}$ coatings, montmorillonite consistently adsorbed higher amounts of $\mathrm{Pb}$ than all the other clay minerals ( Figures 3.25-3.26).

Among the pure minerals, higher As adsorption was observed for montmorillonite and attapulgite and lower was observed for kaolinite (Figure 3.27). This may be due to higher external surface area of montmorillonite and attapulgite that in turn results in higher edge area and higher adsorption of As (Frost and Griffin,1977). Moreover, attapulgite contains higher proportion of octahedrally co-ordinated cations ( $\mathrm{Al}$, $\mathrm{Fe}$, and $\mathrm{Mg}$ ) that give rise to anion adsorption sites. With the increase in $\mathrm{Fe}$ and $\mathrm{Al}$ coatings to $4 \%$, adsorption of As was greater for illite compared to that for attapulgite (Figure 3.28). Coating material probably covers the sites arising from both octahedrally (Al, Fe and $\mathrm{Mg}$ ) and tetrahedrally ( $\mathrm{Si}$ ) co-ordinated cations. Since uncoated attapulgite has a higher proportion of octahedrally coordinated sites (Table 3.1) a higher proportion of those sites could be covered by the coating material compared with that in illite (Dhaliwal, 1996). This is reflected by adsorption of lower amount of As by coated samples of attapulgite than coated samples of illite (Figures 3.27-3.28).

3.5 Relevance to Soils: Adsorption/desorption reactions may be important in controlling the aqueous concentration of $\mathrm{As}$ and $\mathrm{Pb}$ which eventually determine their bioavailability 
and toxicity. In this adsorption study, $\mathrm{Fe}$ and $\mathrm{Al}$ coatings on the different minerals were able to immobilize $\mathrm{As}$ and $\mathrm{Pb}$ specifically. This property of $\mathrm{Fe}$ and $\mathrm{Al}$ coatings can be potentially used for the gentle immobilization of heavy metals in polluted agricultural soils. 


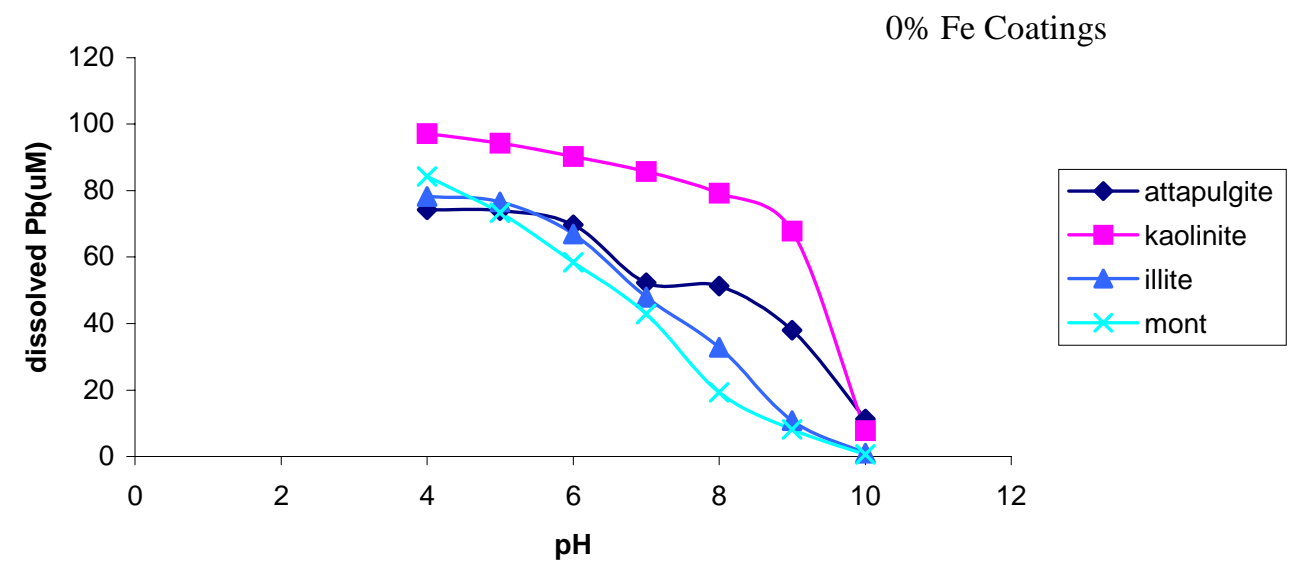

$0.5 \%$ Fe coatings
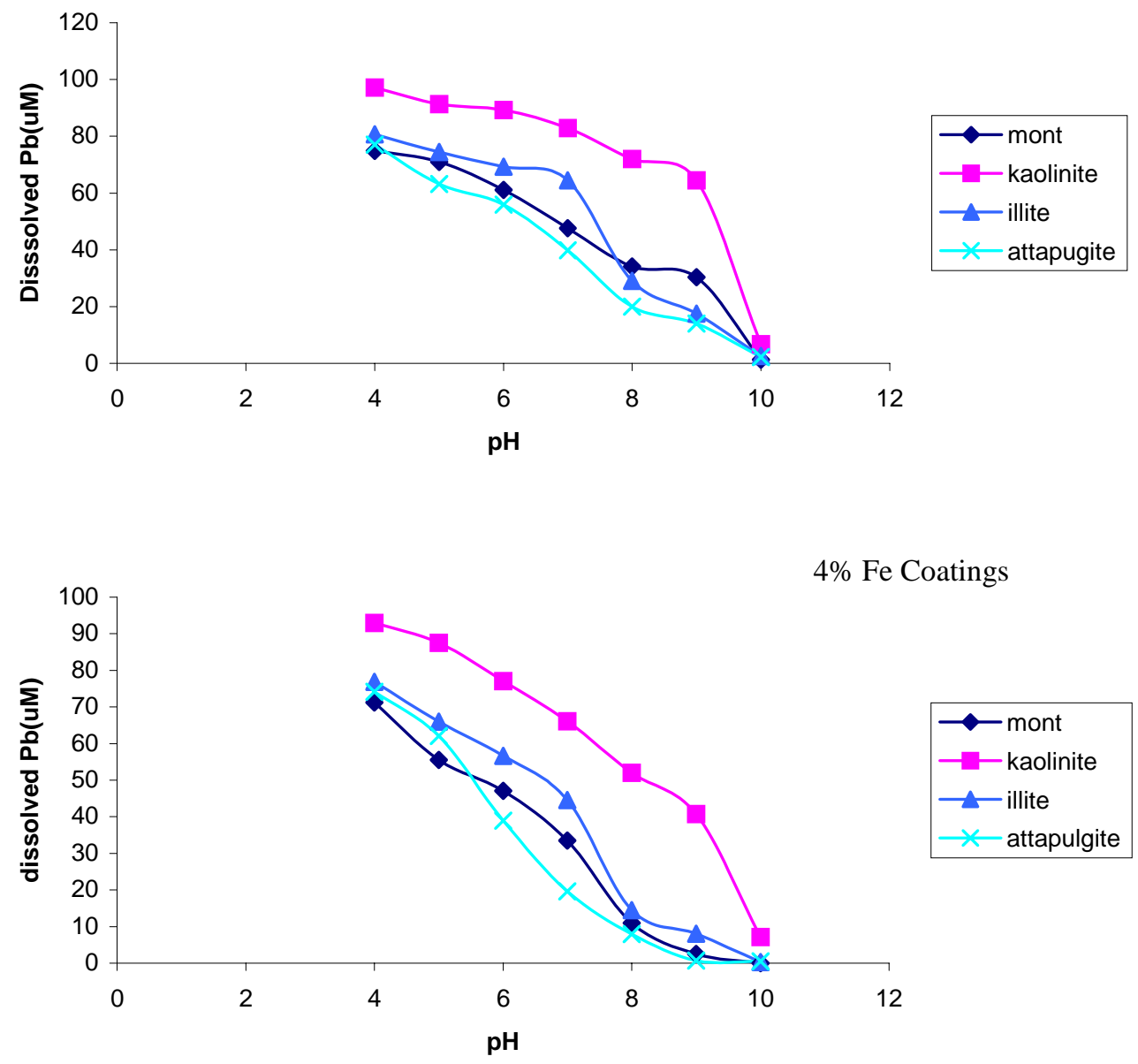

Figure 3.25: Lead adsorption on pure and Fe coated clay minerals 

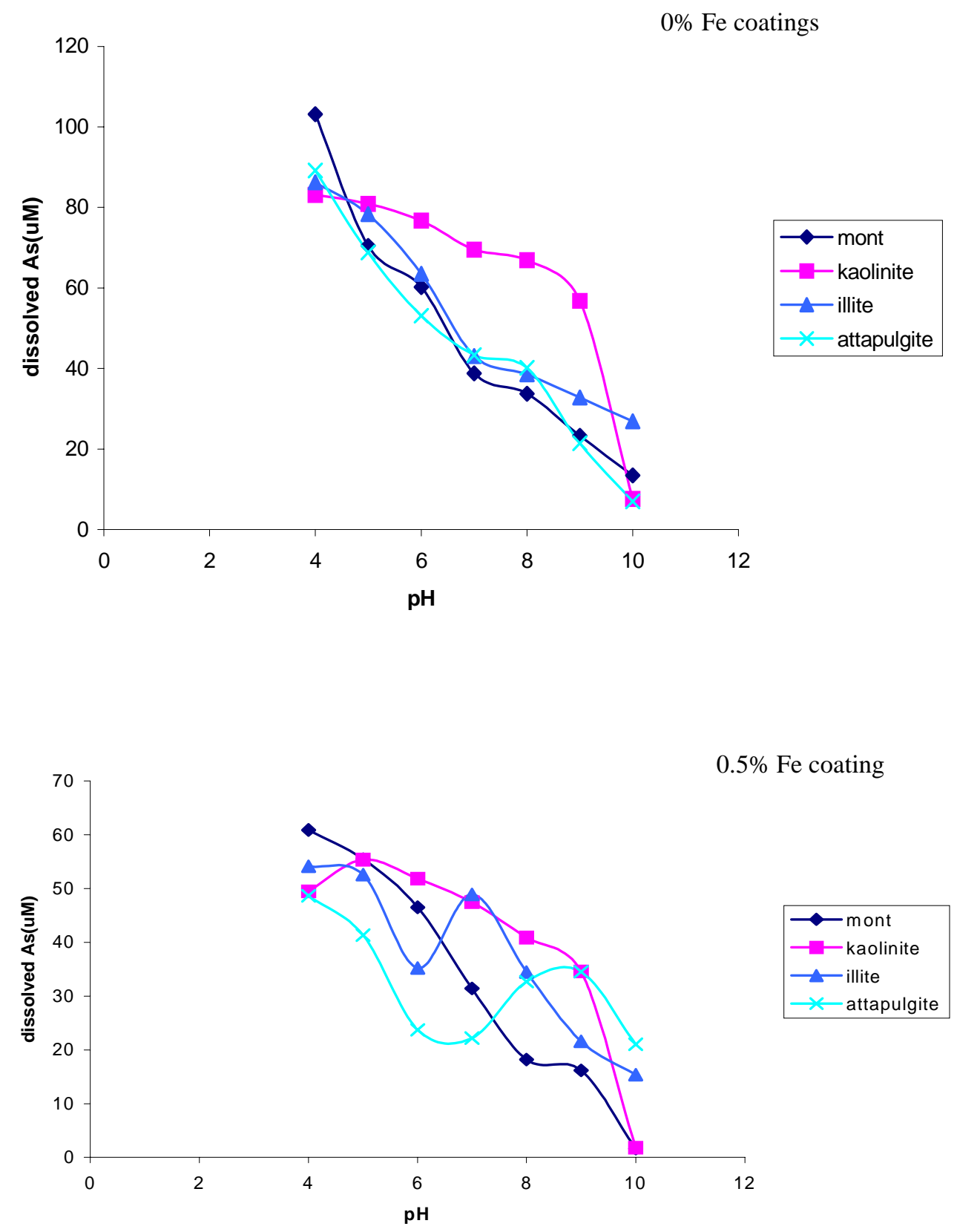

$4 \% \mathrm{Fe}$ coatings

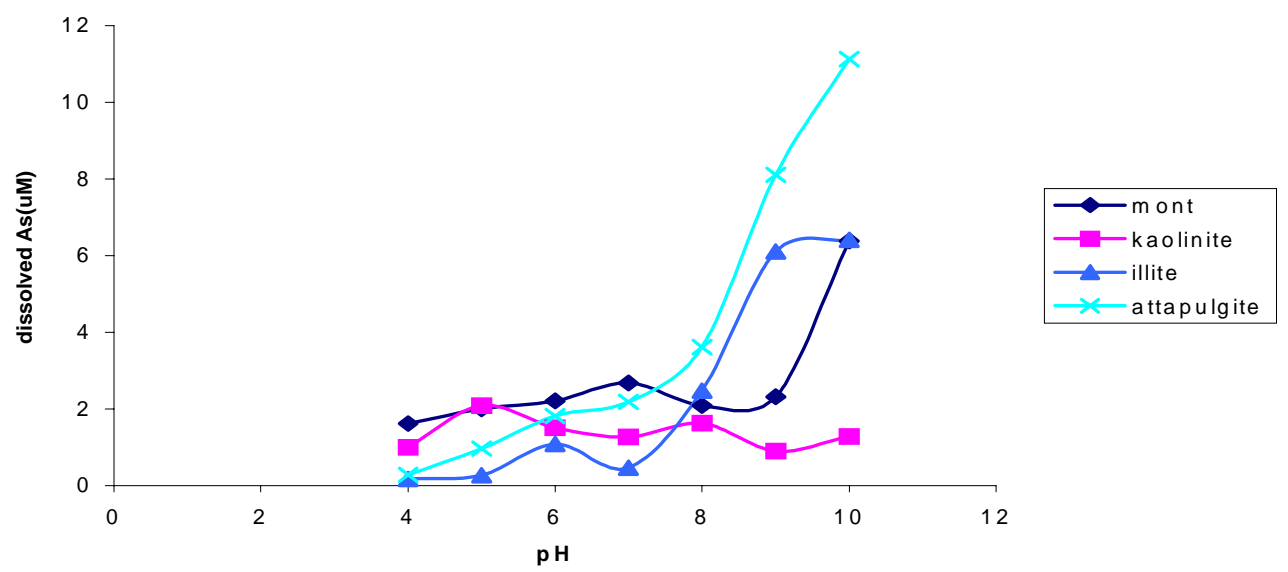



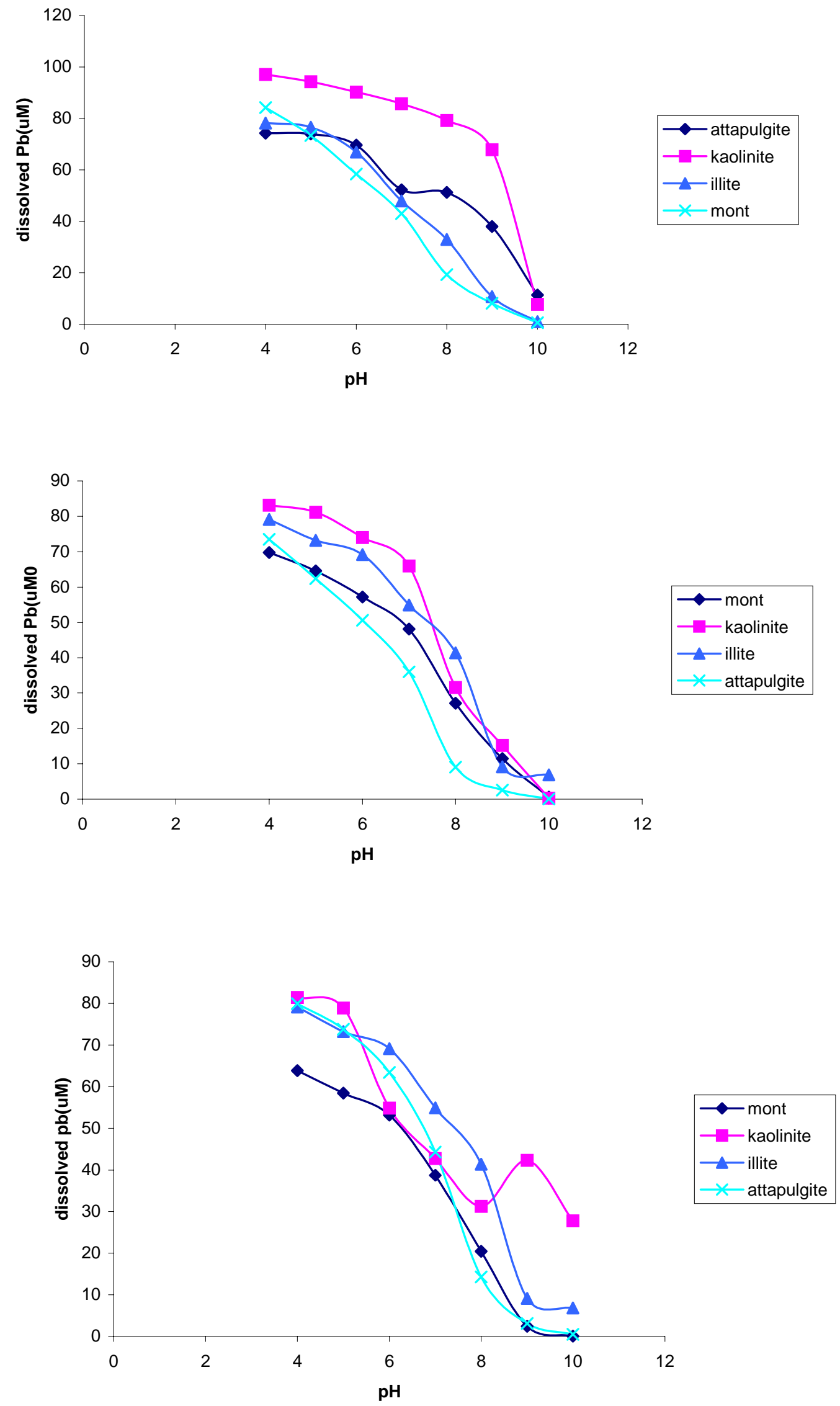

Figure 27: $\mathrm{Pb}$ adsorption on pure and $\mathrm{Al}$ coated clay minerals 

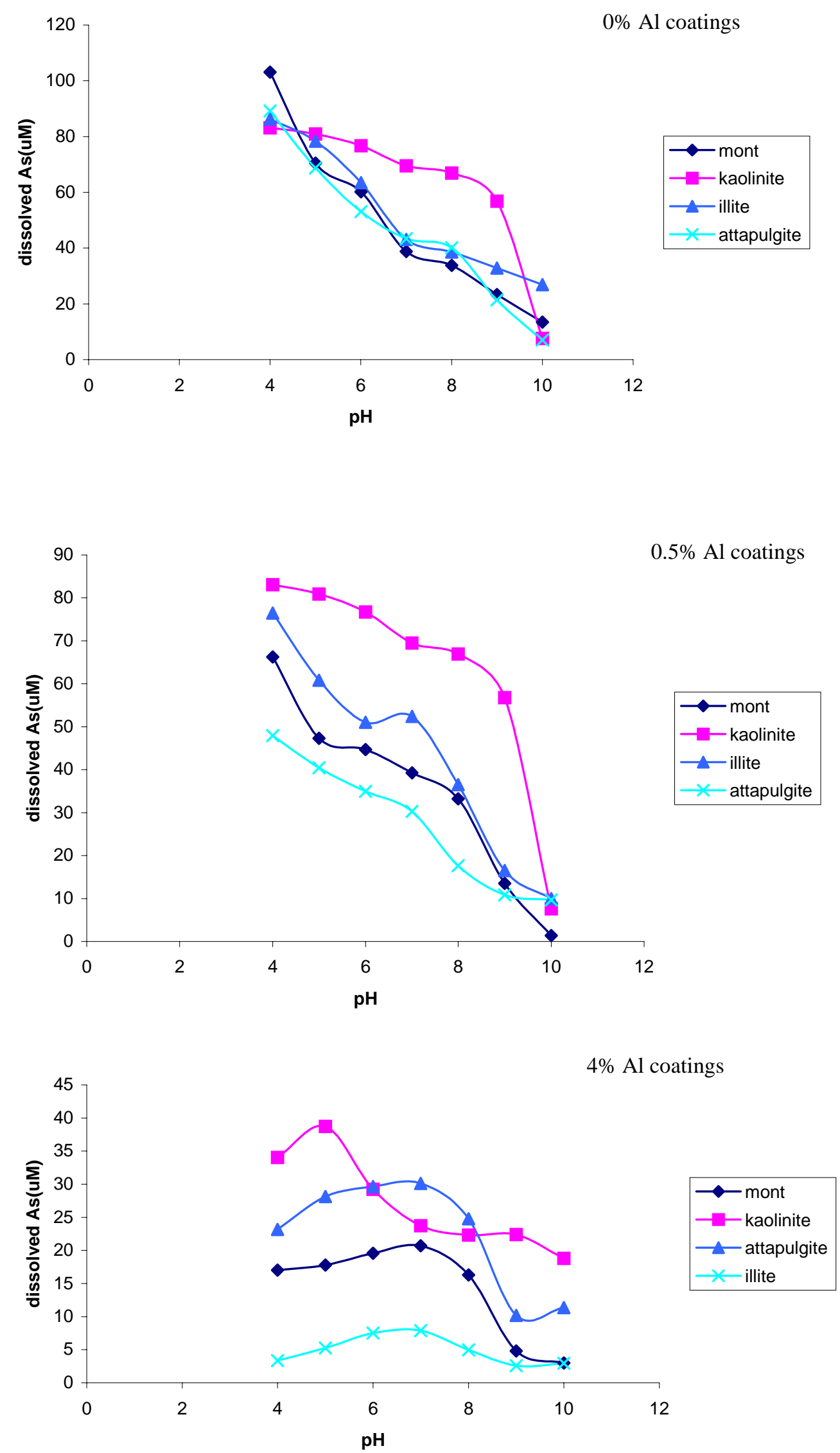

Figure 3.28: As adsorption on pure and Al coated clay 


\section{References}

Barrow, N.J.1985. Reaction of anion and cation with variable charge soils. Adv. Agron 38:183-230.

Bhumbla ,D.K and R.F.Keefer.1997.Arsenic mobilization and bioavaliability in soils.Adv. Environ. Sci. Technol. 26.51-81.

Bradbury, M.H and B.Baeyens.1995. A quantitative mechanistic description of Ni, Zn and Ca sorption on Na-Montmorillonite. Part III : Modelling: PSI Bericht No 9512. Paul Scherrer Institut: Villigen, Switzerland,1995.

Chisholm-Brause, C.J , A.L.Roe, K.F.Hayes, G.E.Brown, G.A. Parks and J.O.Leckie. 1989. X-ray absorption spectroscopy of $\mathrm{Co}(\mathrm{II})$ sorption complex on quartz $\left(\mathrm{SiO}_{2}\right)$ and rutile( $\left.\mathrm{TiO}_{2}\right)$.Phys. Bulletin.158:674-675.

Dhaliwal, S.S.1996. Effect of hydrous oxide coatings on adsorption of oxyanions by clay minerals. Ph. D. Dissertation, West Virginia University, Morgantown .

Frost,R.R and R.A.Griffin.1977. Effect of pH on adsorption of Arsenic and Selenium from landfill leachate by clay minerals.Soil Sci. Soc. Am. J. 41:53-57

Haung Yan-Chu.1997. Arsenic distribution in soils. Advances Environ. Sci. Technol. 26:17-49

Hendershot, W.H., L.M.lavkulich.1983.Effect of sesquioxide coatings on the surface charge of standard and soil samples. Soil Sci. Soc. Am. J. 47:1252-1260.

Hohl,H and W.J.Stumn.1976.Interaction of $\mathrm{Pb}^{2+}$ with hydrous $\mathrm{Al}_{2} \mathrm{O}_{3}$.J.Colloid Interface Sci.55:281-288.

Hower, J., and T.C. Mowatt.1966. The mineralogy of illites and mixed layers illite/ montmorillonite. Am. Minerals.51:825-854.

Hsu, P.H.1977. Aluminum hydroxides and oxyhydroxides. pp. 99-144. In J.B.Dixon and S.B.Weed(ed.) Minerals in Soil Environment. Soil Sci. Soc. Am., Madison, WI.

Jaworski, J.F.1987. Routes of exposure to human and bioavailability. In Lead, mercury, cadmium and arsenic in the environment, Hutchinson, T.C.,Meema, K.M eds, John Wiley and Sons. New York pp.3-16.

Lothenbach, B.,G.Furrer and R.Schulin.1997. Immobilization of heavy metals by polynuclear aluminum and montmorillontic compounds. Environ. Sci. Technol. 31:1452-1462. 
McBride, M.B.1994. Environmental chemistry of soils. Oxford Univ Press, Oxford.

Mckenzie, R.M.1980. The adsorption of lead and other heavy metals on the oxides of manganese and iron. Aust. J.Soil Res.18:61-73.

Parafitt, R.L and J.D.Russel.1977. Adsorption on hydrous oxides. IV. Mechanism of adsorption of various ions on goethite. J.Soil Sci. 28:297-305

Schulthess, C.P and C.P Haung.1990.Cadmium sorption to soil separates containing layer silicate and iron and aluminum oxides.Soil Sci. Soc. Am. J. 54:679-688.

Schwertmann, U., and R.M. Taylor.1977. Iron Oxides.pp.145-176.In J.B.Dixon and S.B.Weed(ed.) Minerals in Soil Environment. Soil Sci. Soc. Am., Madison, WI.

Sposito,G. 1989. The chemistry of soils. Oxford Univ Press New York and Oxford.

van Olphen, H., and J.J.Fripiat. 1979. Data handbook for clay minerals and other nonmetallic minerals. Pergamon Press, New York .pp 346.

Zachara,J.M, S.C.Smith, Ch. T.Resch and Ch. E.Cowan.1992. Adsorption of heavy metals by silicon and aluminum oxide surfaces on clay minerals.Soil Sci. Soc. Am. J 56.1074-1084. 


\section{Chapter 4}

\section{Surface Complexation Modeling}

\subsection{Introduction}

Iron and $\mathrm{Al}$ (hydr)oxides are common in the clay fraction of soils. They may occur as discrete particles having hardly any contact with clay or coatings on clays or as interlayer between clay mineral surfaces. Surface complexation models (SCMs) have the capability to simulate the adsorption of cations and anions as a function of $\mathrm{pH}$, solute concentration and ionic strength (Hayes \& Leckie, 1987; Hayes et al., 1988). Unlike empirical models, surface complexation models are chemical models that provide a description of a chemical system consistent with its chemical properties, and they give a general molecular description of adsorption phenomena using an equilibrium approach .

Parameters which adequately account for acid-base protolysis reactions of the surface must be determined in order to use surface complexation models to model the sorption processes. All models contain equilibrium constants $\left(\mathrm{K}_{\mathrm{i}}\right)$, the capacitance density for $\mathrm{i}^{\text {th }}$ surface plan $\left(\mathrm{C}_{\mathrm{i}}\right)$ and the total number of reactive surfaces with the hydroxyl group as the adjustable parameter ([ $\mathrm{SOH}]$ ). Different methods have been used for the parameter estimation. However depending on the method chosen, different values of model parameters for a given SCM and titration data may be obtained.

In order to fully understand the fate and transport of metal in the environment, we need to be able to accurately describe and model complex natural systems. Surface complexation models are capable of simulating the experimentally observed acid-base titration properties of metal oxide and pure clay minerals (Schindler and Stumn, 1987). However, no study has been done to simulate acid-base titration on iron and aluminum 
coated clays. The objective of this paper is to describe a methodology for determining a unique set of model parameters from titration data for iron and aluminum coated clay minerals.

\subsubsection{Surface Complexation Models}

The SCMs chosen for evaluating the sensitivity of model simulation to changes in parameter values were diffuse layer model (DLM) (Hayes \& Leckie, 1987; Hayes, 1987; Westall \& Hohl, 1980; Huang and Stumn, 1973), the constant-capacitance model (CCM) (Dzombak and Morel, 1990; Hohl \& Stumn, 1976) and the triple layer model (TLM) (Hayes \& Leckie, 1987; Hayes et al., 1988; Davis et al., 1978 and James \& Parks, 1982). Each model treats surface as if it were composed of amphoteric hydroxide functional groups which are capable of reacting with sorbing cationic or anionic species to form surface complexes. These models differ in their description of the diffuse double layer and the manner in which changes in the background electrolyte concentration are incorporated in model computations. These models require a different numbers of adjustable parameters. The most simple, DLM, requires three adjustable parameters and the most complex, TLM, requires seven adjustable parameters.

In the DLM, the three adjustable parameters required for simulating titration behavior are two surface protolysis constants, $\mathrm{K}^{+}$and $\mathrm{K}^{-}$and the total number of sites, $\mathrm{N}_{\mathrm{T}}$. The four adjustable parameters in the CCM are two surface protolysis constants, $\mathrm{K}^{+}$, and $\mathrm{K}^{-}$, the total number of surface sites, $\mathrm{N}_{\mathrm{T}}$ and an inner layer capacitance term, $\mathrm{C}_{\mathrm{i}}$. The more complex TLM has seven adjustable parameters including two surface protolysis constants, $\mathrm{K}^{+}$and $\mathrm{K}^{-}$, two capacitance, $\mathrm{C}_{1}$ and $\mathrm{C}_{2}$, total site concentration, $\mathrm{N}_{\mathrm{T}}$, and two 
electrolyte surface-binding constants, $\mathrm{K}_{\mathrm{an}}$ and $\mathrm{K}_{\mathrm{cat}}$. Table 4.1 summaries the three SCM' $\mathrm{s}$ in terms of protolysis reactions, surface complexation reactions, ion pair complexes, charge-potential relationships, and adjustable model parameter. Table 4.2 shows the placement of ions, potential, charge, and capacitance for CCM, DDM, \& TLM.

Modeling Titration Behavior: Surface change characteristics were determined from acidbase titration data. For the DLM \& CCM:

$[\mathrm{H}]-\left[\mathrm{OH}+[\mathrm{SO} H]-\left[\mathrm{S} \Phi=\mathrm{C}_{-} \mathrm{C}_{\mathrm{B}}\right.\right.$

The protolysis reactions are given by

$$
\begin{array}{cc}
\mathrm{SOH}+\mathrm{H}^{+} \leftrightarrow \mathrm{SOH}_{2}^{+} & \mathrm{K}_{\mathrm{a} 1}^{\mathrm{app}} \\
\mathrm{SOH} \leftrightarrow \mathrm{SO}^{-}+\mathrm{H}^{+} & \mathrm{K}^{\mathrm{app}}{ }_{\mathrm{a} 2} \\
\mathrm{H}_{2} \mathrm{O} \leftrightarrow \mathrm{H}^{+}+\mathrm{OH}^{-} & \mathrm{K}_{\mathrm{w}}
\end{array}
$$

With thermodynamic equilibrium constants

$$
\mathrm{K}_{\text {int }}^{+}=\frac{\left[\mathrm{SOH}^{+}\right]}{\left.[\overline{\mathrm{SOH}}]{ }^{+}\right] \mathrm{H}}
$$

$$
\mathrm{K}_{\mathrm{int}}^{-}=\frac{\left[\mathrm { SO } \left[{ }^{\mathrm{H}} \mathrm{H}\right.\right.}{[\mathrm{SOH} / \mathrm{RT}} \mathrm{e}
$$

$\left.\mathrm{K}_{\mathrm{w}}=\left[\mathrm{H} \chi_{\mathrm{H}+}\right)[\mathrm{OH}] \chi_{\mathrm{OH}-}\right)$

Where $\mathrm{e}^{-\mathrm{F \Psi} / \mathrm{RT}}$ is a electrostatic potential term. The electrostatic potential term should simply be considered as a solid phase activity coefficient correcting for the charge on surface complexes. 
Table 4.1: Surface Chemical Reaction and Model Parameters

\begin{tabular}{|c|c|c|}
\hline DLM & CCM & TLM \\
\hline & Protolysis Reaction & \\
\hline $\begin{array}{l}\mathrm{SOH}+\mathrm{H}^{+} \leftrightarrow \mathrm{SOH}_{2}^{+} \mathrm{K}^{+} \\
\mathrm{SOH} \leftrightarrow \mathrm{SO}^{-}+\mathrm{H}^{+}\end{array}$ & $\begin{array}{l}\mathrm{SOH}+\mathrm{H}^{+} \leftrightarrow \mathrm{SOH}_{2}^{+} \mathrm{K}^{+} \\
\mathrm{SOH} \leftrightarrow \mathrm{SO}^{-}+\mathrm{H}^{+}\end{array}$ & $\begin{array}{ll}\mathrm{SOH}+\mathrm{H}^{+} \leftrightarrow \mathrm{SOH}_{2}^{+} & \mathrm{K}^{+} \\
\mathrm{SOH} \leftrightarrow \mathrm{SO}^{-}+\mathrm{H}^{+} & \mathrm{K}^{-}\end{array}$ \\
\hline & $\begin{array}{l}\text { Surface Complexation } \\
\text { Reactions }\end{array}$ & \\
\hline $\begin{array}{l}\mathrm{SOH}+\mathrm{M}_{\mathrm{e}}^{2+} \leftrightarrow \mathrm{SOH}^{(\mathrm{m}-1)+}+\mathrm{H}^{+} \mathrm{K}_{\mathrm{m}} \\
\quad \mathrm{SOH}+\mathbf{L}^{1} \leftrightarrow \mathrm{SL}^{(1-1)-}+\mathbf{O H}^{-} \\
\quad \mathbf{K}_{\mathbf{m}}\end{array}$ & Same as DLM & Same as DLM \\
\hline & Ion Pairs & \\
\hline Not allowed & Not allowed & $\begin{aligned} \mathrm{SOH}+\mathrm{M}^{\mathrm{m}+} \leftrightarrow \mathrm{SO}^{-}-\mathrm{M}^{\mathrm{m}+}+\mathrm{H}^{+} \\
\mathbf{S O H}+\mathbf{L}^{1-} \leftrightarrow \text { SOH }_{2^{-}} \mathbf{L}^{1-}\end{aligned}$ \\
\hline & Charge Potential Relation & \\
\hline $\begin{array}{l}\sigma_{\mathrm{d}}+\sigma_{0}=0 \\
\sigma=2.51^{1 / 2} \psi\end{array}$ & $\sigma_{0}=\mathrm{C}_{1} \psi_{\mathrm{o}}$ & $\begin{array}{l}\psi_{\mathrm{o}}-\psi_{\mathrm{b}}=\sigma_{\mathrm{o}} / \mathrm{C}_{1} \\
\psi_{\mathrm{b}}-\psi_{\mathrm{d}}=\sigma_{\mathrm{d}} / \mathrm{C}_{2} \\
\sigma_{\mathrm{d}}=-(8 \mathrm{RTCED})^{1 / 2} \sinh \left(\mathrm{F} \psi_{\mathrm{d}} / 2 \mathrm{RT}\right)\end{array}$ \\
\hline & $\begin{array}{c}\text { Adjustable Model } \\
\text { Parameters }\end{array}$ & \\
\hline $\mathrm{K}^{+}, \mathrm{K}^{-}, \mathrm{N}_{\mathrm{S}}$ & $\mathrm{K}^{+}, \mathrm{K}^{-}, \mathrm{N}_{\mathrm{S}}, \mathrm{C}_{1}$ & $\mathrm{~K}^{+}, \mathrm{K}^{-}, \mathrm{K}_{\mathrm{Ca}}, \mathrm{K}_{\mathrm{An}}, \mathrm{C}_{1}, \mathrm{C}_{2}, \mathrm{~N}_{\mathrm{S}}$ \\
\hline
\end{tabular}

Table 4.2: Mass Law and Mole Balance Equation

\begin{tabular}{|c|c|c|}
\hline Model & Surface mole balance equations & Surface Mass Balance equation \\
\hline DLM & $\begin{array}{l}\sigma=[\mathrm{SOH}]-[\mathrm{SQ} \\
+(\mathrm{m}-1) \mathrm{SOH}^{(\mathrm{m}-1)}-(\mathrm{l}-1)\left[\mathrm{SL}^{(1-1)}\right]\end{array}$ & 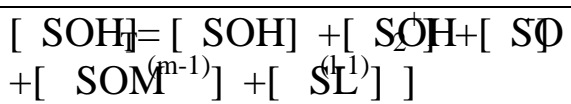 \\
\hline $\mathrm{CCM}$ & Same as for DLM & Same as for DLM \\
\hline TLM & $\begin{array}{l}\sigma_{0}=\mathrm{F} / \mathrm{S}_{\mathrm{d}}\left\{\left[\begin{array}{ll}\mathrm{SOH} \\
-[\end{array}\right]+\left[\begin{array}{ll}\mathrm{SO} & \left.\mathrm{SO}-\mathrm{An}^{1-}\right]-[\mathrm{SOM}] \\
\sigma_{\mathrm{d}}=\mathrm{S} / \mathrm{Sa}\left[\mathrm{SOCa}^{+}\right]\end{array}\right]-\left[\mathrm{SO}_{2} \mathrm{SAn}^{1-}\right]\right.\end{array}$ & $\begin{array}{l}\mathrm{S}_{\mathrm{T}}=[\mathrm{SOH}]+[\mathrm{SOH}+[\mathrm{S} \Phi \\
+\left[\mathrm{SOH}^{+}-\mathrm{A}^{-} \mathrm{n}^{(1-1)}\right]+ \\
{[\mathrm{SO}-\mathrm{C}]+[\mathrm{SL}]+} \\
{\left[\mathrm{SOM}^{\mathrm{n}-1)}\right]}\end{array}$ \\
\hline
\end{tabular}


For TLM surface charge characteristics were determined from the following relation:

[ H] $-\left[\mathrm{OH}+\left[\mathrm{SO}_{2} \mathrm{H}\right]-\left[\mathrm{S} \Phi+\left[\mathrm{SO}_{2}+\mathrm{An}^{-}\right]-\left[\mathrm{SOC}_{\mathrm{at}}^{+}\right]=\left(\mathrm{C}^{-} \mathrm{C}_{\mathrm{B}}\right)\right.\right.$

The protonation and dissociation constants remain as written in eq. (2)-(4) for TLM. The other intrinsic conditional equilibrium constants are (Davis et al., 1978; Davis and Leckie, 1978,1980):

$$
\begin{aligned}
& \mathrm{SOH}+\mathrm{C}^{+} \leftrightarrow \mathrm{SO}^{-}-\mathrm{C}^{+}+\mathrm{H}^{+} \\
& \mathrm{SOH}+\mathrm{H}^{+}+\mathrm{A}^{-} \leftrightarrow \mathrm{SOH}_{2}^{+}-\mathrm{A}^{-}
\end{aligned}
$$

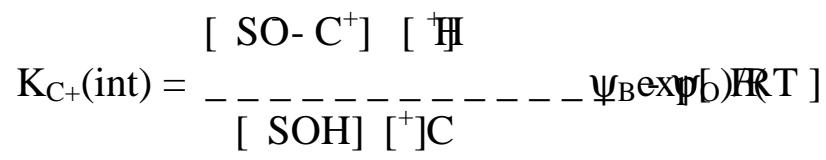

$$
\begin{aligned}
& \mathrm{K}_{\mathrm{A}-}(\mathrm{int})=\left[\begin{array}{c}
\left.\mathrm{SOH}^{+}-\mathrm{A}^{-}\right] \\
\left.------------\Psi_{\mathrm{O}} \exp [\mathrm{B}) \mathrm{HRT}\right]
\end{array}\right. \\
& {[\mathrm{SOH}]\left[^{+}\right] \mathrm{H}}
\end{aligned}
$$

\subsubsection{Ionic strength effects:}

CCM: In this model the constant ionic medium reference state determines the activity coefficients of the aqueous species in the conditional equilibrium constants and therefore no complexes are formed with ions in the background electrolyte. The relationship between surface charge and surface potential is given by

$$
\sigma=(\mathrm{Csa} / \mathrm{F}) \Psi
$$


According to this equation, interfacial potential is independent of ionic strength.

Therefore, a different set of CCM surface constants is required for each set of ionic strength conditions to be modeled.

DDL: Because a diffuse layer of counter ion charges is assumed for the solution side of the interface, the relationship between surface charge and potential is fixed by electrical double-layer theory. In the DLM, ionic strength effects on protolysis equilibrium are accounted explicitly through the Gouy-Chapman-Stern Grahame (GCSG) charge-potential for a symmetrical electrolyte and is given by :

$\sigma=0.1174 \sqrt{\mathrm{I}} \sinh (\mathrm{Z} \psi \times 19.46)$

According to the above equation, the effects of ionic strength on interfacial potential can be taken into account and only one set of DLM surface constants should be necessary to model sorption over a range of ionic strength conditions.

TLM: Like DLM, TLM can be used to model surface reaction over a range of ionic strength conditions with one set of surface equilibrium constants. It accounts for ionic strength by considering equation (14) and by considering the formation of ion-pair complexes with the background electrolytes.

\subsubsection{Model Parameter Estimations}

Studies have used surface complexation models to describe ion sorption onto natural particles (Goldberg and Glaubig, 1988; Sposito et al., 1988; Davis, 1998). To use SCM' s for model sorption processes, experimental or theoretical methods are required to 
determine the values for various model parameters. All models contain $\mathrm{K}_{\mathrm{i}}$, equilibrium constants; $\mathrm{C}_{1}$, the capacitance density for ith surface plane and [ $\left.\mathrm{SOH}\right]$, the total number of reactive surface hydroxyl groups. For any of these, the preferred method of obtaining the parameter value is to measure it directly. But in some cases it is not possible to calculate the value of the parameter. In those cases, the best set of values is typically based on a goodness of fit criterion.

For minerals, the total site concentration $\mathrm{N}_{\mathrm{T}}$ (moles/liter) can be calculated from measured values for surface area, $\mathrm{S}_{\mathrm{A}}$, site density, $\mathrm{N}_{\mathrm{S}}$ and solid concentration $\mathrm{C}_{\mathrm{S}}$ (with units of $\mathrm{m}^{2} / \mathrm{g}$, sites $/ \mathrm{m}^{2}, \mathrm{~g} /$ liter, respectively) measurements (Hayes et al., 1991).

$$
\mathrm{N}_{\mathrm{T}}=\mathrm{N}_{\mathrm{S}} * \mathrm{~S}_{\mathrm{A}} * \mathrm{C}_{\mathrm{S}} * 1.66 \times 10^{-6}
$$

The most popular method of measuring specific surface area is the gas sorption and data analysis method proposed by Brunauer, Emmett and Teller(1938). Their technique is known as BET method. While the BET method of measuring surface area is reproducible and easy to perform, it does have some limitations, particularly when results are to be applied to a solid suspended in water. The structure and surface characteristics of solids that interact strongly with water, such as metal oxides, can significantly change during the drying step required in BET method. Another method of determining surface area is by the retention of a polar liquid. Carter et al.(1965) introduced the use of ethylene glycol monethyl ether (EGME) as a polar molecule for determining the surface area of layer silicate minerals and soils. The convenient and rapid EGME method for estimation of surface area of soils and clays also involves assumptions and has limitations. One assumption is that EGME covered all interlayer and external surfaces. This 
assumption is difficult to prove. Because the experimental techniques employed to measure the specific surface area of finely divided solids vary so widely, the results vary significantly as well. For metal oxides, surface area measurements made with various methods typically differ by factor of 2 to 4 (Dzombak and Morel, 1990).

The value of site density has been determined either experimentally by tritium exchange (Davis and Leekie, 1978,1980), potentiometric titration (Balisterieri and Murray, 1981; Hohl and Stumn, 1976) fluoride adsorption (Sigg, 1979), maximum adsorption (Goldberg and Sposito, 1984a; Goldberg, 1985,1986a), calculated from crystal dimensions, or optimized to fit experimental adsorption data (Hayes et al., 1988). Site density estimates obtained for different methods typically differ by factor of 2 to 3 and sometimes more. Hayes et al. (1991) after doing sensitivity analysis for acid-base titration data on goethite, aluminum oxide and titanium oxide showed the models to be relatively insensitive to surface site density in the range $2-20$ sites $/ \mathrm{nm}^{2}$.

To date, no method exists for independently measuring electrical double-layer capacitance parameters for oxide water systems (Hayes et al., 1991). CCM model required the value of $C_{1}$ and TLM required the value of inner capacitance $\left(C_{1}\right)$ and outer capacitance $\left(\mathrm{C}_{2}\right)$. Goldberg (1992), pointed out that value of $\mathrm{C}_{1}$ can be obtained from titration data. Based on direct measurements of the capacitance of AgI-electrolyte interface assumed the value of $\mathrm{C}_{1}$ as $0.2 \mathrm{~F} / \mathrm{m}^{2}$ for TLM. However the applicability of these direct measurement to oxide surface is uncertain. Bousse and Bergveld (1983), made impedance measurements on $\mathrm{SiO}_{2}$ coated, ion-sensitive field effect transistors and supported the $\mathrm{C}_{2}$ value of $0.2 \mathrm{~F} / \mathrm{m}^{2}$ for oxides. Israelachvilli (1985) pointed out that 
theoretically range of capacitance value for various models can be calculated from the definition of integral capacitance.

$\in_{\mathrm{T}} \in_{\mathrm{D}}$
$\mathrm{C}_{1}=--\frac{\mathrm{B}}{-----}$

Given that range of reasonable values for $\epsilon_{\mathrm{T}}$ in the double -layer region is form 6 to 50 and that the distance of closest approach of a hydrated radius of a univalent ion is the range of 2.3 to $4.9 \mathrm{~A}^{\circ}$, if the capacitance values are required to fit the titration data, the value of $\mathrm{C}_{1}$ should be in the range of 0.1 to $2.0 \mathrm{~F} / \mathrm{m}^{2}$.

In general, values of intrinsic protonation and dissociation constants can be obtained for alkimetric or acidimetric titration curves carried out in the absence of specially adsorbing metal or ligand ions (Stumm et al., 1980). The two most common methods for determining surface equilibrium constants from titration data are by using objective curve fitting routines (Westall, 1982) or by graphical extrapolation methods(Davis and Hayes, 1986; James et al., 1978 and Kent et al., 1986). Graphical extrapolation technique involve plotting an approximation for conditional protolysis equilibrium constants given by

$\mathrm{PO}^{*}=-\log \left[\mathbf{H} \pm \log \left(\frac{\alpha}{1-\alpha}\right)\right.$

versus the fractional ionization (Hayes et al., 1991).

where

$$
\alpha=\frac{\alpha_{\mathrm{O}}}{\mathrm{N}_{\mathrm{S}}} \times\left[\frac{\mathrm{N}_{\mathrm{A}}}{\mathrm{F}}\right]
$$


Where $\left(\mathrm{N}_{\mathrm{A}} / \mathrm{F}\right)$ converts $\sigma_{\mathrm{O}}$ to net number of charged sites $/ \mathrm{m}^{2}$ to give the dimensionless fractional ionization. By plotting this graph according to these equations, the value of $\mathrm{K}^{+}$ $\mathrm{K}^{-}$are obtained by $\mathrm{y}$-intercept. Graphical methods are tedious, less precise, difficult to apply to complex systems and often applicable only to limited experimental ranges. Also graphical methods may yield biased results due to approximations required to implement them (Dzombak and Morel, 1987; Westall, 1986) In contrast, non-linear optimization programs are fast, reproducible, bias-free and applicable to complex systems over extended ranges. Other advantages of non-linear optimization are that the same best fit criterion can be applied to all data set and error bars associated with parameter can readily be obtained. (Dzombak \& Morel, 1990);

For this study, we have used FITEQL(Westall and Morel,1977;Westall, 1982). FITEQL is an iterative, gradient-directed non-linear least square optimization program based on the Gauss method (Bard, 1974; Gans, 1976) for unconstrained problems. The program is designed to determine the optimal valued of equilibrium constants or total component concentrations in a chemical adjustable parameters by changing their values until the sum of the squares of the residuals between the measured titration data and FITEQL calculated value is minimized. In general FITEQL convergence is most likely to occur when fitting data using only two adjustable parameters.

\subsection{Materials and Methods}

Clay mineral (attapulgite, illite, kaolinite \& montmorillonite) samples used in this investigation were obtained from the Source Clay Mineral Repository of the Clay Minerals Society. Then these clay mineral were separated for the particle size $<2 \mu \mathrm{m}$ 
fraction. Characterized samples of pure attapulgite, illite, kaolinite \& montmorillonite were coated with hydrous oxides of Fe using the method of Chao et al. (1964). The coated material was characterized with respect to surface characteristics. Surface area was determined by ethylene glycol monoethyl ether (EGME) method (Carter et al., 1986). Values for surface area are given in the Table 4.3. The surface areas reported here along with assumed value of site density were used to calculate total number of sites.

4.2.1 Titration data: For obtaining potentiometric titration curves, $0.200 \mathrm{~g}$ of sample were weighed into each of a series of $60 \mathrm{ml}$ plastic bottles. Each bottle contained $25 \mathrm{ml}$ of solution consisting of $0.001 \mathrm{M} \mathrm{NaClO}_{4}$ solution and a known concentration of acid and base. Samples were analyzed for $\mathrm{pH}$ and more $\mathrm{NaClO}_{4}$ was added in each sample to increase the ionic strength to $0.01 \mathrm{M}$. The samples were shaken for 30 minutes and $\mathrm{pH}$ values determined again. This process was repeated again so that there was a total of three $\mathrm{pH}$ values for each sample representing ionic strengths of $0.001,0.01$, and $0.1 \mathrm{M} \mathrm{NaClO}_{4}$. At all times samples were stirred to prevent settling and maintained under argon atmosphere. Whenever a bottle was opened, it was refilled with argon. Acid/alkali was added using $100 \& 1000 \mu \mathrm{l}$ Eppendorf pipettes. After $\mathrm{pH}$ measurements, the samples were individually centrifuged and filtered. Each of the supernatants was weighed and back titrated to original $\mathrm{pH}$ to determine amount of $\mathrm{H}^{+} / \mathrm{OH}^{-}$adsorbed by the mineral species. The back titrations were done with an auto titrating system. The same procedure was used for obtaining potentiometric titration data for all the samples. 
Table 4.3: Surface area $(\mathrm{m} 2 / \mathrm{g})$ of clay minerals

\begin{tabular}{cccc}
\hline Solid & \multicolumn{3}{c}{ Amount of coatings } \\
& $0 \%$ & $4 \% \mathrm{Fe}$ & $4 \% \mathrm{Al}$ \\
Attapulgite & 306.7 & 171.1 & 249.6 \\
Illite & 113.2 & 74.5 & 65.5 \\
Kaolinite & 40.2 & 29.7 & 25.2 \\
Montmorillonite & 589.5 & 533 & 536.2 \\
\hline
\end{tabular}




\subsubsection{Sensitivity Analysis}

Each Surface Complexation has a different number of adjustable parameter, so different sensitivity analysis strategies were implemented.

DLM Sensitivity Analysis: DLM has three adjustable parameters $\log \mathrm{K}^{+}, \log \mathrm{K}^{-}$, and $\mathrm{N}_{\mathrm{T}}$. So sensitivity analysis was done varying the value of $\mathrm{N}_{\mathrm{T}}$ in the FITEQL input file and observing the effect on the optimized values of $\log \mathrm{K}^{+}$and $\log \mathrm{K}^{-1}$.

CCM Sensitivity Analysis: CCM has four adjustable parameters $\log \mathrm{K}^{+}, \log \mathrm{K}^{-}, \mathrm{C}_{1}$, and $\mathrm{N}_{\mathrm{T}} \log \mathrm{K}^{+}, \log \mathrm{K}^{-}$are optimized by varying the value of $\mathrm{C}_{1}$ and $\mathrm{N}_{\mathrm{T}}$.

TLM Sensitivity Analysis: In the case of TLM, there are six adjustable parameter $\log \mathrm{K}^{+}$, $\log \mathrm{K}^{-}, \mathrm{C}_{1}, \mathrm{~N}_{\mathrm{T}}, \log \mathrm{K}_{\mathrm{an}}$ and $\log \mathrm{K}_{\mathrm{ca}} . \mathrm{C}_{1}$ value of $0.2 \mathrm{~F} / \mathrm{m}^{2}$ has been used as reported by Westall and Hohl (1980) and Davis et al. (1978). Another constraint which was used is the relationship

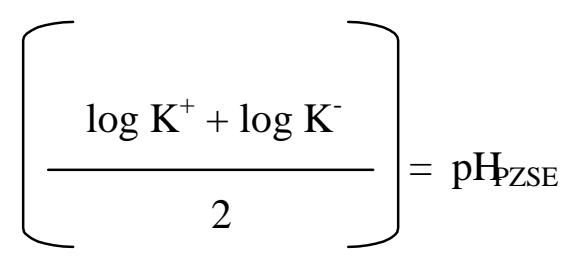

This was used to reduce the degree of freedom by one. The value of $\mathrm{pH}_{\mathrm{PZSE}}$ for all the clay minerals is given in Table 4.4. This relationship was used to estimate the value of $\log \mathrm{K}^{+}$and $\log \mathrm{K}^{-}$for TLM sensitivity analysis,. FITEQL will never converge if the protolysis constants and electrolyte binding constants are simultaneously declared as adjustable parameters, a consequence of interdependence of surface reactions. The values of $\mathrm{N}_{\mathrm{T}}$ and $\mathrm{C}_{1}$ were systematically varied, one variable at a time in the input file and best fit values of equation were obtained by FITEQL. 
Tabel 4.4: Point of zero salt effect (PZSE) of different clay minerals

\begin{tabular}{cccc}
\hline Solid & \multicolumn{3}{c}{ Amount of coatings } \\
\hline & $0 \%$ & $4 \% \mathrm{Fe}$ & $4 \% \mathrm{Al}$ \\
Attapulgite & 4.05 & 4.3 & 4.72 \\
Illite & 3.1 & 4.15 & 4.65 \\
Kaolinite & 4.35 & 6.02 & 5.41 \\
Montmorillonite & $<2.47$ & $<3.81$ & $<3.46$ \\
\hline
\end{tabular}


4.2.3 Estimation of Goodness of fit: This was done by overall variance, Vy, which is the weighted sum of squares of residuals divided by the degrees of freedom (SOS/DF)

$$
\mathrm{Vy}=\frac{\mathrm{SOS}}{\mathbf{D F}}=\frac{\Sigma\left[\mathrm{K}(\mathrm{m}) / \mathrm{S}_{\mathrm{R}}(\mathrm{m})\right]^{2}}{\mathbf{N}_{\mathbf{P}} \mathbf{N}_{\mathbf{R}}-\mathbf{N}_{\mathbf{u}}}
$$

where

$\mathbf{Y}_{\mathbf{R}}=$ TOTR(calc)-TOTR(expt) for all component (i.e. those for which both the total concentration and free concentration are known)

$\mathbf{S}_{\mathbf{R}}=$ is error calculated from the experimental error estimates. The value of experimental error $S_{R}$ is calculated form propagation of experimental error

$$
\mathrm{S}_{\mathrm{R}(\mathrm{m})}^{2}=\left.\left[\frac{\delta \mathrm{y}}{\delta \mathrm{T}_{\mathrm{I}, \mathrm{II}}}\right]\right|_{\mathrm{m}} ^{2} \mathrm{~S}_{\Gamma \mathrm{I}, \mathrm{II}(\mathrm{m})}^{2}+\left.\frac{\delta \mathrm{y}}{\delta \mathrm{x}_{\mathrm{II}, \mathrm{III}}}\right|_{\mathrm{m}} ^{2} \mathrm{~S}^{2} \mathrm{x}_{\mathrm{II}<\mathrm{III}(\mathrm{m})}
$$

Where $S_{T} \& S_{X}$ are estimated errors in the experimentally measured $T_{I, I I}$ and $X_{I I, I I I}$. It is assumed that errors in $T^{\prime}$ s and $X^{\prime}$ s are independent such that cross terms can be neglected.

$$
\left.\sum_{\mathrm{m}}\left[\frac{\delta \mathrm{y}}{\delta_{\mathrm{T}}}\right] \frac{\delta_{\mathrm{y}}}{\delta_{\mathrm{X}}}\right] \delta_{\mathrm{T}} \delta_{\mathrm{X}}=0
$$

The derivatives that appear in the error propagation equation are calculated from the chemical equilibrium equations. The value of $S_{T}(m)$ and $S_{X}(m)$ that are necessary to 
complete the error propagation should be supplied as input for all $\mathrm{m}$ titration points. It is more practical to calculate $S_{T}(m)$ and $S_{x}(m)$ from the following formulae:

$$
\begin{aligned}
& \mathrm{S}_{\mathrm{T}}(\mathrm{m})=\mathrm{S}_{\mathrm{T}}(\mathrm{abs})+\mathrm{S}_{\mathrm{T}}(\mathrm{rel}) * \mathrm{~T}(\mathrm{~m}) \\
& \mathrm{S}_{\mathrm{X}}(\mathrm{m})=\mathrm{S}_{\mathrm{X}}(\mathrm{abs})+\mathrm{S}_{\mathrm{X}}(\mathrm{rel}) * \mathrm{X}(\mathrm{m})
\end{aligned}
$$

Where $\mathrm{S}(\mathrm{abs})$ and $\mathrm{S}(\mathrm{rel})$ are estimates for the absolute and relative errors in experimental measurements. In all FITEQL runs reported, unless otherwise noted, the assumed absolute and relative errors of the titration data points were chosen to be representative of those errors expected in titration experiments. Typical values were 0.01 for relative error and $2.0 \times 10^{-6} \mathrm{M}$ absolute error (Hayes et al., 1990).

$\mathbf{N}_{\mathbf{P}}=$ number of data point

$\mathbf{N}_{\mathbf{R}}=$ the number of components for which both the total and the free concentrations are known.

$\mathbf{N}_{\mathbf{U}}=$ the number of adjustable parameters. The goodness of fit of the proposed model to the data is indicated by the proximity of $\mathrm{Vy}$ to 1 . The value of $\mathrm{Vy}$ depends on the experimental error estimates and Westall(1982) noted that values of Vy between 0.1 to 20 indicate a reasonable good fit values of Vy greatly in excess of 20 indicate that the model is inappropriate, while values significantly less than 0.1 generally indicate that the model has too many adjustable parameters. 


\subsection{Results and Discussions}

As the purpose of this work was to evaluate the merits of each model so the sensitivity analysis results for each model are discussed separately.

4.3.1 Diffuse double layer: The effects of different ionic strength $(0.001,0.01$, and $0.1 \mathrm{M})$ and $\mathrm{N}_{\mathrm{S}}$ (1 to 100 sites/nm2) on the best fit value of protolysis constants for all the clay minerals were evaluated .

Sensitivity analysis for pure clay minerals: For all pure clay minerals titration data set, FITEQL best fit values for $\log \mathrm{K}^{+}$and $\log \mathrm{K}^{-}$decreased with increasing value of $\mathrm{N}_{\mathrm{S}}$ (Table 4.5, Figures 4.1-4.3). The explanation for this trend is that in order for the computed number of protons released or consumed at a given $\mathrm{pH}$ to fit the titration data for different values of $\mathrm{N}_{S}$, it is necessary that the surface constants decrease as $\mathrm{N}_{\mathrm{S}}$ increases (Hayes et al., 1990) . For attapulgite, illite, kaolinte, and montmorillonite data set, based on F values, slightly better fits were obtained at all the three ionic strengths for $\mathrm{N}_{\mathrm{S}}$ less than 10 site $/ \mathrm{nm}^{2}$ compared to fit obtained for $\mathrm{N}_{\mathrm{S}}$ between 10 and 100 sites $/ \mathrm{nm}^{2}$. Generally better FITEQL fits were obtained at lower ionic strength as compared to higher ionic strength which is consistent with the findings of Hayes et al. (1990), who reported that based on the theoretical consideration, the DDL, are often limited to lower ionic strength conditions. Moreover, Dzombak and Morel (1990) also reported that DLMs usually over predict the diffuse layer potential at high ionic strength, so for modeling purpose it is restricted to low ionic strength conditions. DDL fits better for attapulgite and kaolnite as compared to illite and montmorillonite regardless of $\mathrm{N}_{\mathrm{S}}$ and ionic strength. 
Table 4.5: Sensitivity of DLM to variation in total site density for pure clay minerals.

\begin{tabular}{|c|c|c|c|c|c|c|c|c|c|}
\hline \multirow[b]{2}{*}{ IS } & \multirow[b]{2}{*}{$\mathbf{N}_{\mathbf{S}}$} & \multicolumn{2}{|c|}{ Attapulgite } & \multicolumn{4}{|c|}{ Illite } & \multicolumn{2}{|c|}{ Kaolinte } \\
\hline & & $\log K^{+}$ & $\log K^{-}$ & $F$ & $\log K^{+}$ & $\log K^{-}$ & $\mathbf{F}$ & $\log K^{+}$ & $\log K^{-}$ \\
\hline 0.001 & 1 & 5.43 & -8.712 & 12.8 & 5.55 & -6.76 & 53.6 & 6.64 & -5.96 \\
\hline 0.001 & 10 & 4.35 & 9.782 & 14.9 & 4.34 & -8.14 & 58.5 & 4.86 & -7.75 \\
\hline 0.001 & 100 & 3.35 & -10.78 & 15.1 & 3.32 & -9.17 & 58.8 & 3.82 & -8.79 \\
\hline 0.01 & 1 & 4.54 & -9.087 & 18.1 & 4.25 & -7.07 & 51.2 & 4.83 & -6.887 \\
\hline 0.01 & 10 & 3.49 & -10.185 & 22.8 & 2.998 & -8.732 & 78.9 & 3.64 & -8.407 \\
\hline 0.01 & 100 & 2.48 & -11.194 & 23.2 & 1.98 & -9.782 & 80.7 & 2.62 & -9.44 \\
\hline 0.1 & 1 & 3.85 & -9.505 & 50.5 & 3.23 & -7.22 & 55.8 & 4.13 & -7.383 \\
\hline 0.1 & 10 & 2.776 & -10.67 & 59.7 & 2.13 & -9.582 & 106.6 & & \\
\hline 0.1 & 100 & 1.79 & -11.69 & 60.6 & 1.12 & -10.05 & 108.6 & & \\
\hline
\end{tabular}

$\mathrm{IS}=$ ionic strength in $\mathrm{mol} / \mathrm{lit}, \mathrm{Ns}=$ site density in sites per $\mathrm{nm}, \mathrm{C}=$ capacitance, $\mathrm{NC}=$ no convergence in numeric scheme 


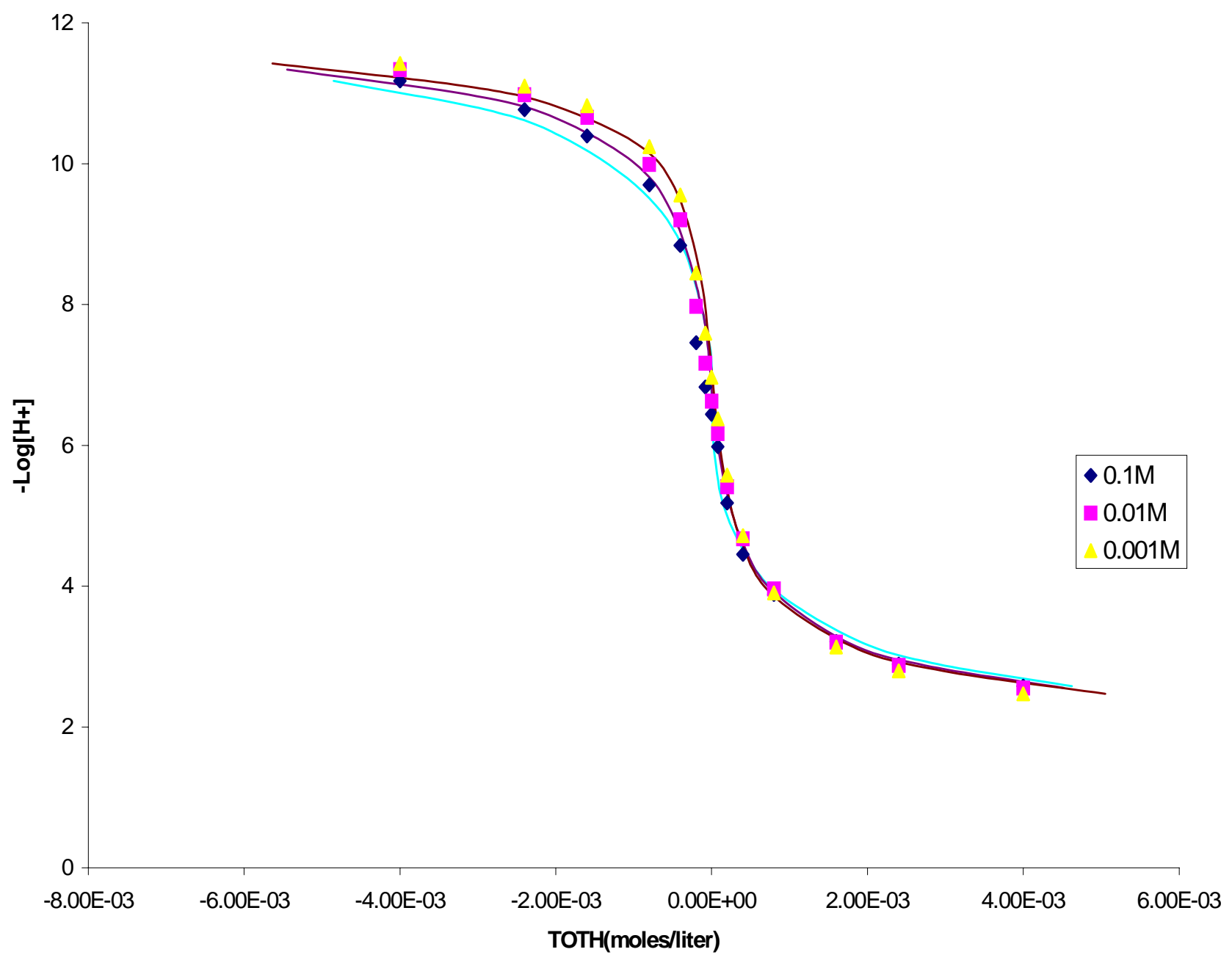

Figure 4.1 Diffuse double layer model fits of titration data for suspension of pure attapulgite 


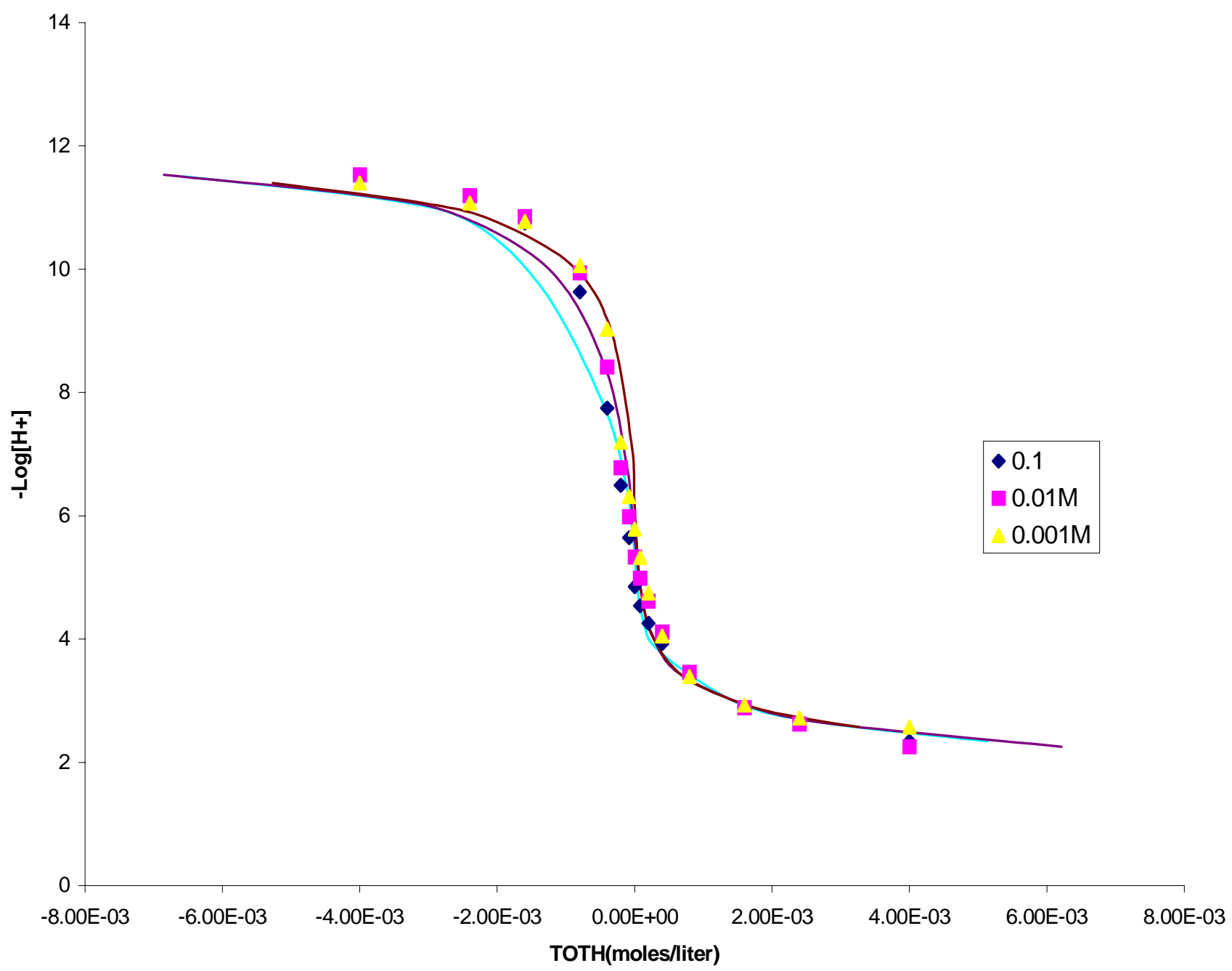

Figure 4.2: Diffuse layer model fit of titration data for suspension of pure illite 


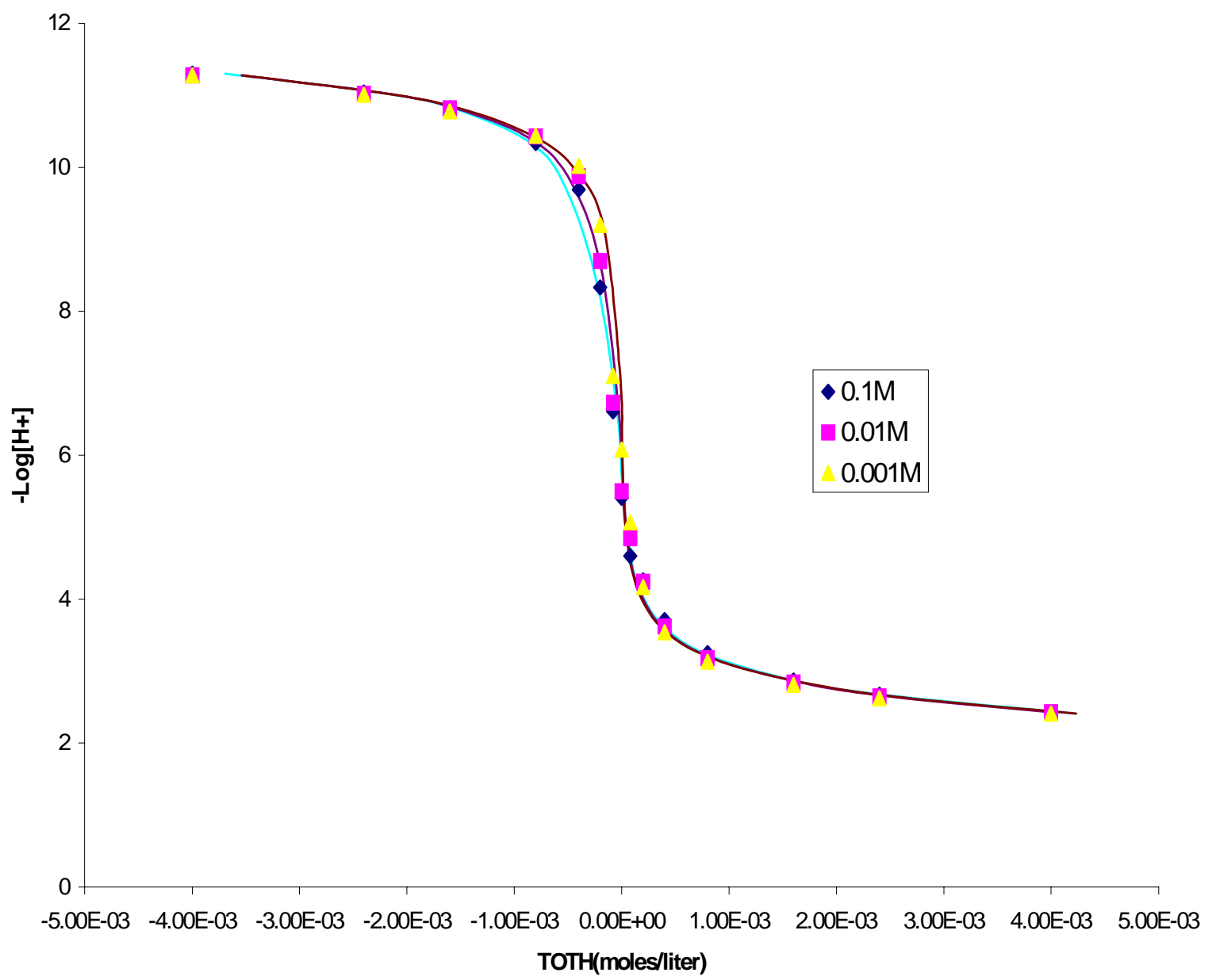

Figure 4.3: Diffuse -layer model fits of titration data for suspension of pure kaolinite 
Sensitivity analysis for coated clay minerals: Same trend of decreasing $\log \mathrm{K}+$ and $\log$ $\mathrm{K}$ - with increase in the value of $\mathrm{N}_{\mathrm{S}}$ was observed for both iron coated (4\%) and aluminum coated clay minerals (Tables 4.6, 4.7, Figures 4.4-4.9). For all the coated clay minerals data set (at all ionic strength) better $\mathrm{F}$ values were obtained for $\mathrm{N}_{\mathrm{S}}$ below 10 sites $/ \mathrm{nm}^{2}$ as compared to $\mathrm{F}$ value obtained for $\mathrm{N}_{\mathrm{S}}$ between 10 and 100 sites $/ \mathrm{nm}^{2}$. James and Parks (1982) reported that if the range of site density value is limited to value typical of nonporous microcrystalline oxides ( 2 to 20 sites $/ \mathrm{nm}^{2}$ ), one should be able to arrive at a unique set of surface constants for DLM using FITEQL and titration data. Based on F value, the iron coated clay titration data fitted better as compared to Al coated clay titration data. The reason for this is not very obvious but it may be that the complex surface chemistry of Al coated minerals cannot be represented by simple DLM. Among Fe coated clays, there is no data convergence for attapulgite and kaolinte at $0.001 \mathrm{M}$ ionic strength and best fit $\mathrm{F}$ values were obtained at $0.01 \mathrm{M}$ ionic strength. For iron coated illite there was data convergence at $0.001 \mathrm{M}$ ionic strength when the $\mathrm{N}_{\mathrm{S}}$ value was 10 and 100 . In illite good fit $\mathrm{F}$ value was obtained at ionic strength of $0.1 \mathrm{M}$ and $\mathrm{N}_{\mathrm{S}}$ of 1 . For montmorillonite best fit $\mathrm{F}$ values were obtained at $0.001 \mathrm{M}$ ionic strength.

Effect of Coatings on DLM best fit values: For kaolinite best fit $F$ values were obtained for $0 \%$ coating and not to $4 \%$ iron and aluminum coatings (Table 4.10 ). Generally for attapulgite, illite and montmorillionite, based on the $\mathrm{F}$ values better fits were obtained for the $4 \%$ iron coated clay minerals titration data compared to either pure and $4 \%$ aluminum coated clay minerals regardless of ionic strength and site density. (Tables 4.8, 4.9, 4.11). 
Table 4.6: Sensitivity of DLM to variation in total site density for $4 \%$ iron coated clay minerals

\begin{tabular}{|c|c|c|c|c|c|c|c|c|c|c|c|c|c|}
\hline & & \multicolumn{3}{|c|}{ Attapulgite } & \multicolumn{3}{|c|}{ Illite } & \multicolumn{3}{|c|}{ Kaolinte } & \multicolumn{3}{|c|}{ Montmorillonite } \\
\hline IS & $\mathbf{N}_{\mathrm{S}}$ & $\log K^{+}$ & $\log K^{-}$ & $\mathbf{F}$ & $\log K^{+}$ & $\log K^{-}$ & $\mathbf{F}$ & $\log K^{+}$ & $\log K^{-}$ & $F$ & $\log K^{+}$ & $\log K^{-}$ & $F$ \\
\hline 0.001 & 1 & 4.527 & -4.73 & 18.5 & & & $\mathrm{NC}$ & & & NC & 6.04 & -8.061 & 27.2 \\
\hline 0.001 & 10 & & & NC & 5.41 & -8.065 & 49.6 & & & NC & 4.91 & -9.196 & 28.6 \\
\hline 0.001 & 100 & & & NC & 4.37 & -9.109 & 49.7 & & & NC & 3.9012 & -10.207 & 28.7 \\
\hline 0.01 & 1 & 5.55 & -7.763 & 14.5 & 5.64 & -5.8 & 21.6 & & & NC & 4.32 & -8.841 & 49.6 \\
\hline 0.01 & 10 & 4.36 & -9.009 & 24.5 & 3.95 & -8.008 & 55.8 & 4.59 & -7.47 & 36.6 & 3.27 & -9.968 & 57.2 \\
\hline 0.01 & 100 & 3.34 & -10.027 & 25.3 & 2.93 & -9.075 & 58.3 & 3.56 & -8.57 & 38.2 & 2.26 & -10.97 & 57.9 \\
\hline 0.1 & 1 & 4.62 & -8.159 & 15.6 & 4.22 & -6.341 & 53.9 & & & NC & 3.36 & -8.676 & 71 \\
\hline 0.1 & 10 & 3.47 & -9.468 & 113.9 & 2.799 & -8.408 & 70.4 & 4.08 & -7.839 & 23.9 & 2.32 & -9.79 & 80.3 \\
\hline 0.1 & 100 & 2.45 & -10.495 & 45.5 & 1.779 & -9.532 & 76.9 & 3.02 & -8.98 & 29 & 1.32 & -10.8 & 81.1 \\
\hline
\end{tabular}

$\mathrm{IS}=$ ionic strength in $\mathrm{mol} / \mathrm{lit}, \mathrm{Ns}=$ site density in sites per $\mathrm{nm}, \mathrm{C}=$ capacitance, $\mathrm{NC}=$ no convergence in numeric scheme

Table 4.7: Sensitivity of DLM to variation in total site density for $4 \%$ aluminum coated clay minerals

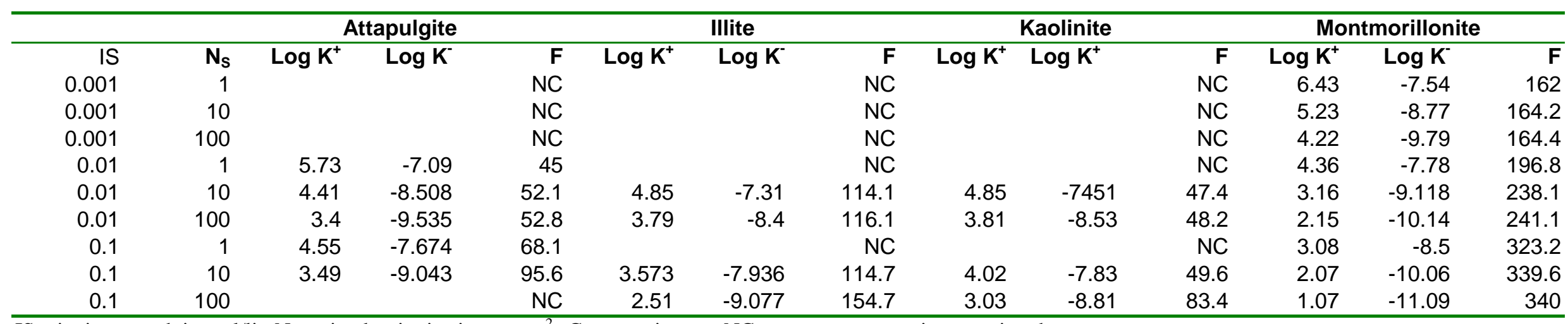

$\mathrm{IS}=$ ionic strength in $\mathrm{mol} / \mathrm{lit}, \mathrm{Ns}=$ site density in sites per $\mathrm{nm}^{2}, \mathrm{C}=$ capacitance, $\mathrm{NC}=$ no convergence in numeric scheme 


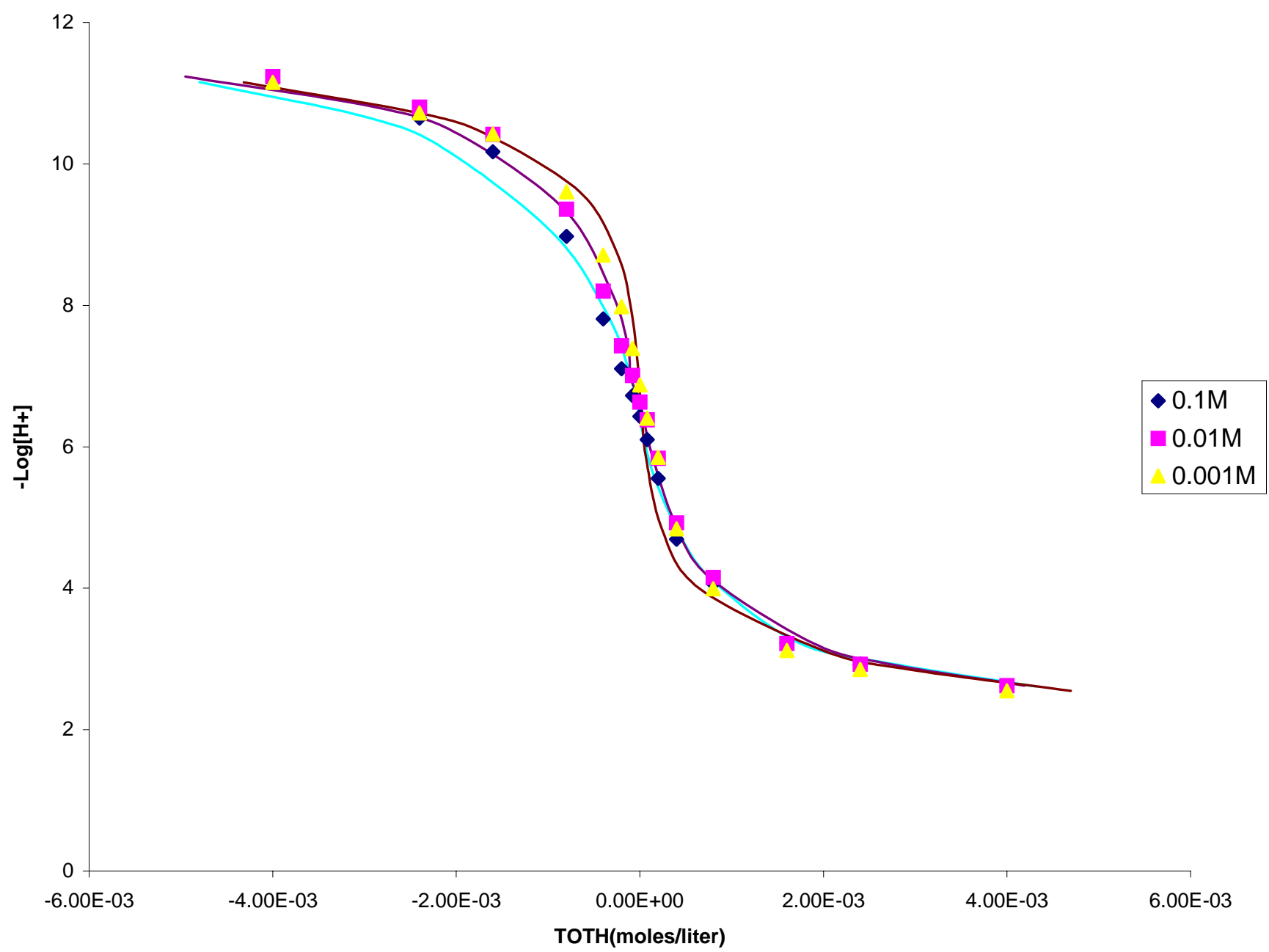

Figure 4.4 : Diffuse double layer model fit of titration data for suspension of $4 \%$ iron coated attapulgite 


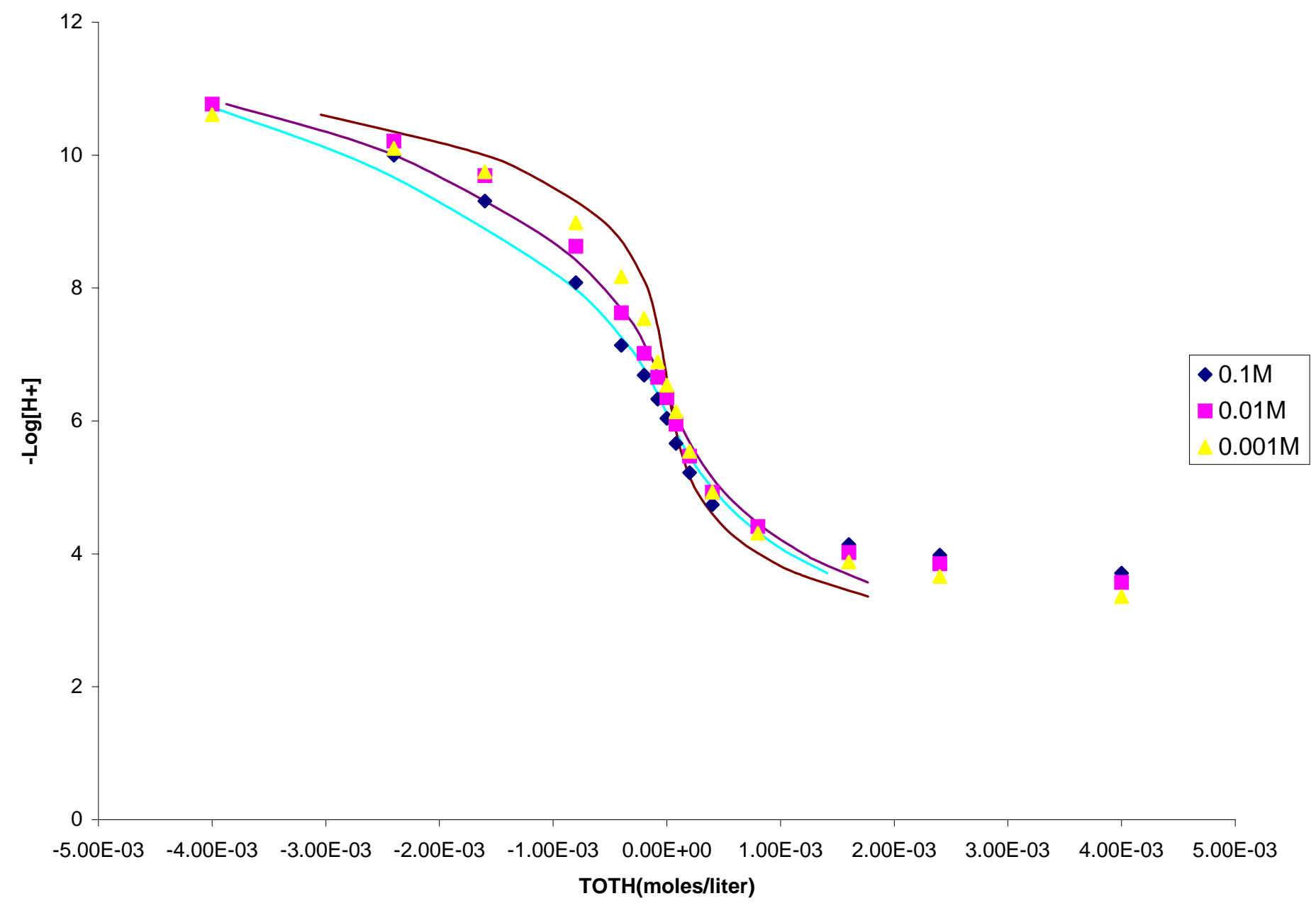

Figure 4.5: Diffuse-layer model fit of titration data for suspension of $4 \%$ aluminum coated attapulgite 


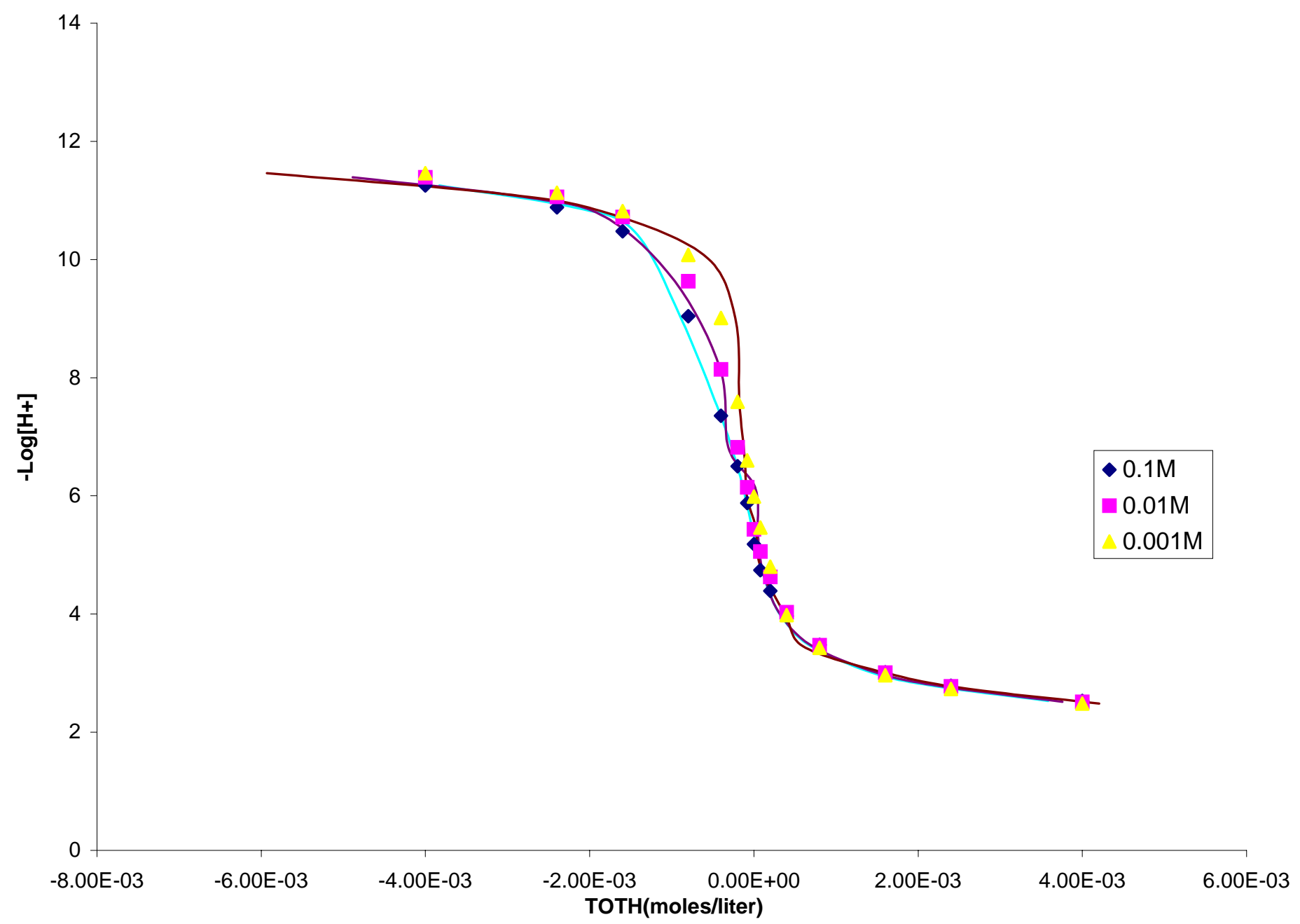

Figure 4.6: Diffuse-double layer model fit of titraiton data for suspension of $4 \% \mathrm{Fe}$ coated illite 


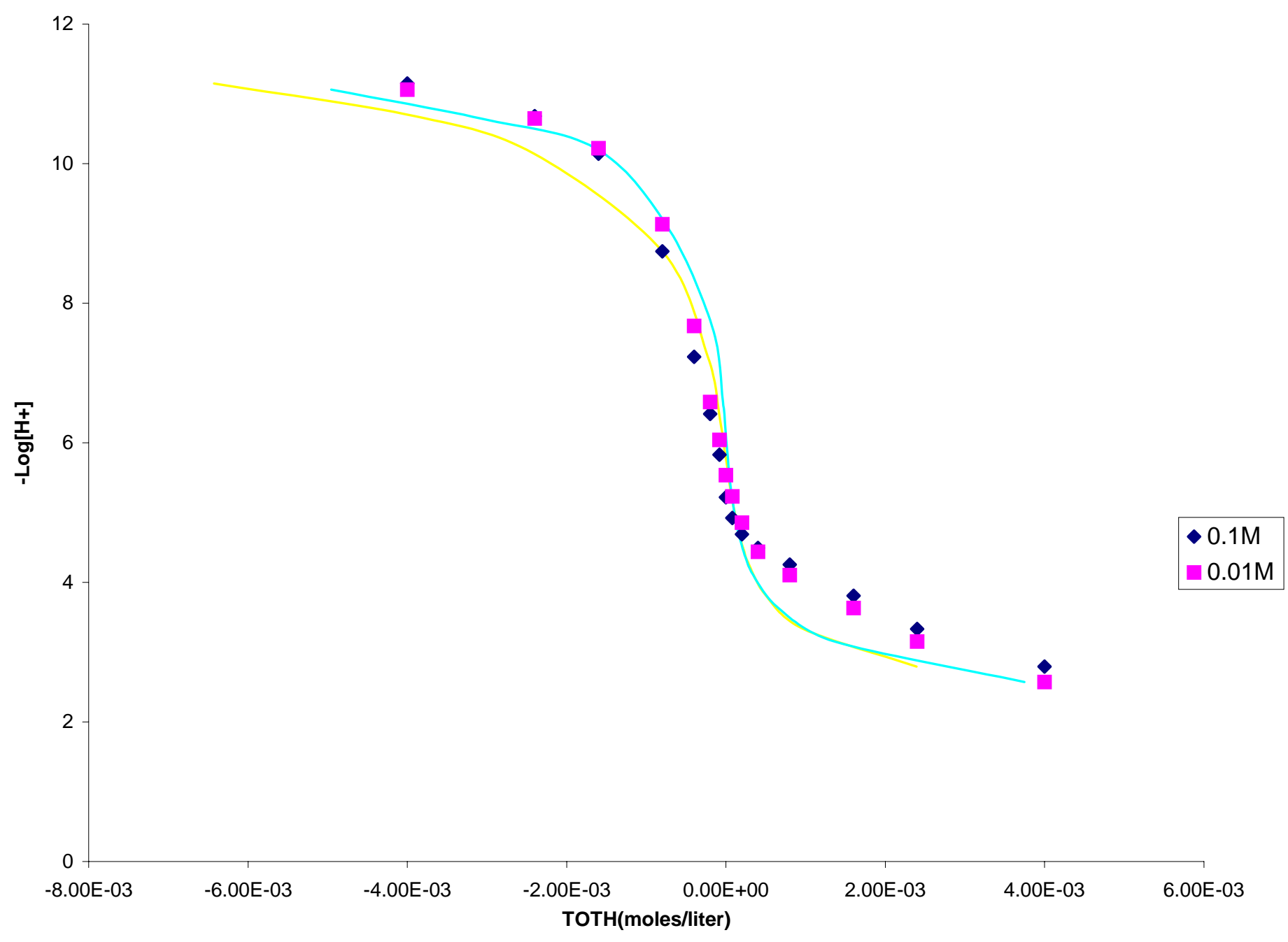

Figure 4.7: Diffuse-double layer model fit of titration data for suspension of $4 \%$ aluminum coated illite 


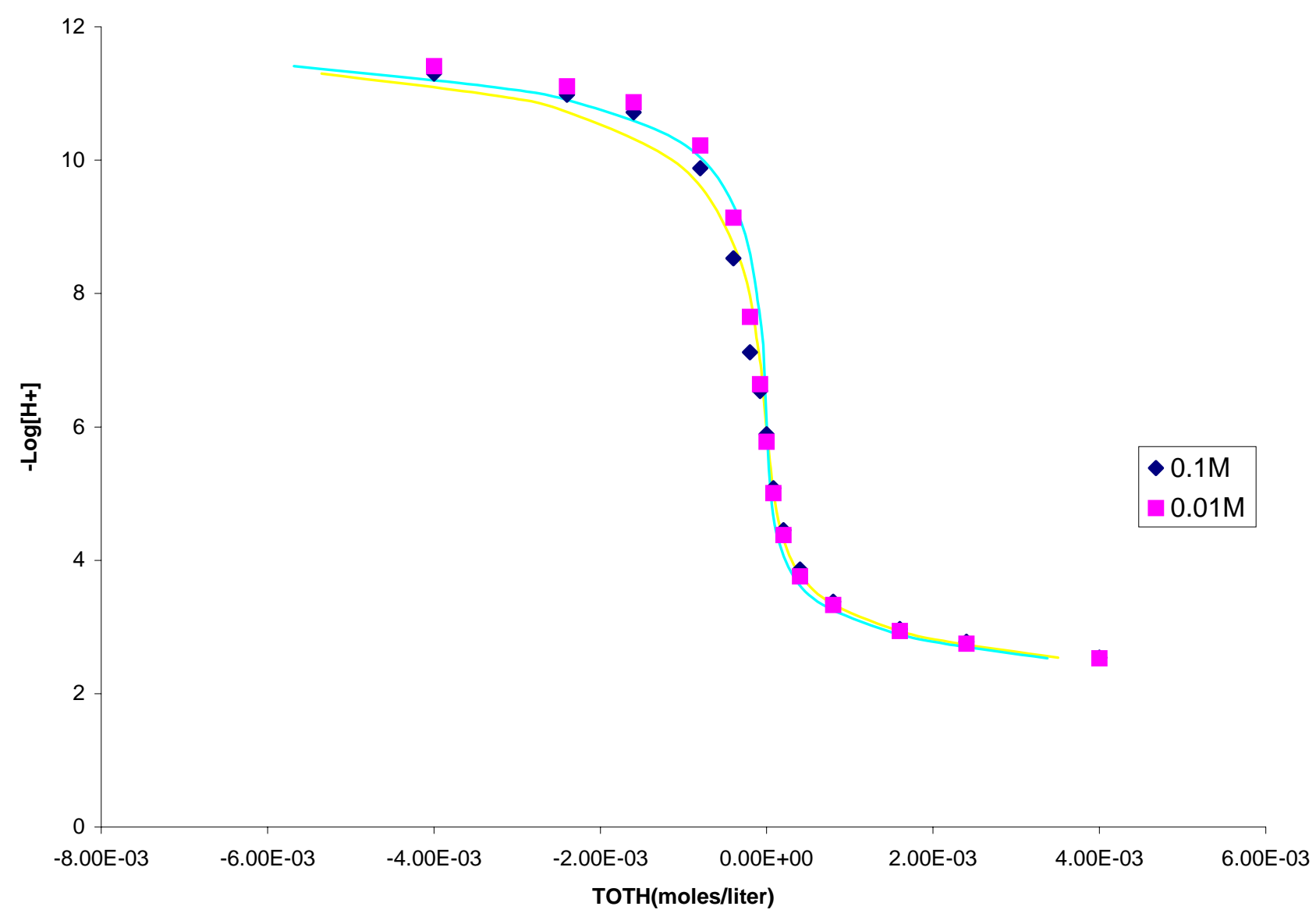

Figure 4.8: Diffuse double layer model fit of titration data for suspension of $4 \%$ iron coated kaolinite 


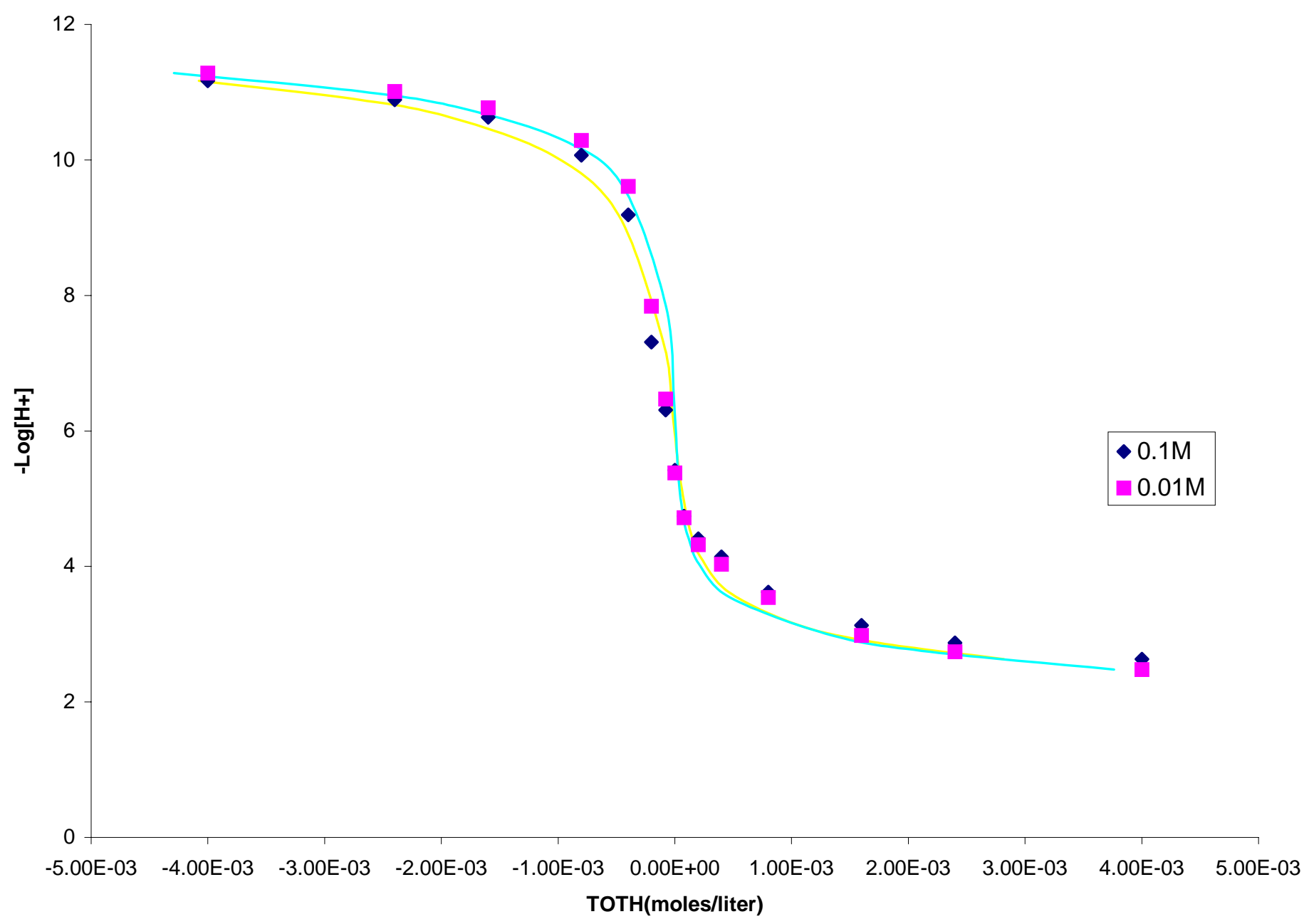

Figure 4.9: Diffuse layer model fit of titraion data for suspension of $4 \%$ aluminum coated kaolinite 
Table 4.8: Effect of coatings on DLM best fit value of protolysis constants for attapulgite.

\begin{tabular}{|c|c|c|c|c|c|c|c|c|c|c|}
\hline & & & $0 \%$ & & & $\mathrm{Fe} \mathrm{4 \%}$ & & & Al 4\% & \\
\hline IS & $\mathbf{N}_{\mathrm{S}}$ & $\log K^{+}$ & $\log K^{-}$ & $F$ & $\log K^{+}$ & $\log K^{-}$ & $F$ & $\log K^{+}$ & $\log K^{-}$ & $\bar{F}$ \\
\hline 0.001 & 1 & 5.43 & -8.712 & 12.8 & 4.527 & -4.73 & 18.5 & & & NC \\
\hline 0.001 & 10 & 4.35 & 9.782 & 14.9 & & & $\mathrm{NC}$ & & & NC \\
\hline 0.001 & 100 & 3.35 & -10.78 & 15.1 & & & $\mathrm{NC}$ & & & NC \\
\hline 0.01 & 1 & 4.54 & -9.087 & 18.1 & 5.55 & -7.763 & 14.5 & 5.73 & -7.09 & 45 \\
\hline 0.01 & 10 & 3.49 & -10.185 & 22.8 & 4.36 & -9.009 & 24.5 & 4.41 & -8.508 & 52.1 \\
\hline 0.01 & 100 & 2.48 & -11.194 & 23.2 & 3.34 & -10.027 & 25.3 & 3.4 & -9.535 & 52.8 \\
\hline 0.1 & 1 & 3.85 & -9.505 & 50.5 & 4.62 & -8.159 & 15.6 & 4.55 & -7.674 & 68.1 \\
\hline 0.1 & 10 & 2.776 & -10.67 & 59.7 & 3.47 & -9.468 & 113.9 & 3.49 & -9.043 & 95.6 \\
\hline 0.1 & 100 & 1.79 & -11.69 & 60.6 & 2.45 & -10.495 & 45.5 & & & NC \\
\hline
\end{tabular}

$\mathrm{IS}=$ ionic strength in $\mathrm{mol} / \mathrm{lit}, \mathrm{Ns}=$ site density in sites per $\mathrm{nm}, \mathrm{C}=$ capacitance, $\mathrm{NC}=$ no convergence in numeric scheme

Table 4.9: Effect of coatings on DLM best fit value of protolysis constants for illite.

\begin{tabular}{|c|c|c|c|c|c|c|c|c|c|c|}
\hline \multicolumn{5}{|c|}{$0 \%$} & \multicolumn{3}{|c|}{$\mathrm{Fe} 4 \%$} & \multicolumn{3}{|c|}{ Al 4\% } \\
\hline IS & $\mathbf{N}_{\mathrm{S}}$ & $\log ^{+}$ & $\log K^{-}$ & $F$ & $\log K^{+}$ & $\log K^{-}$ & $\mathbf{F}$ & $\log K^{+}$ & $\log K^{-}$ & $\bar{F}$ \\
\hline 0.001 & 1 & 5.55 & -6.76 & 53.6 & & & NC & & & NC \\
\hline 0.001 & 10 & 4.34 & -8.14 & 58.5 & 5.41 & -8.065 & 49.6 & & & NC \\
\hline 0.001 & 100 & 3.32 & -9.17 & 58.8 & 4.37 & -9.109 & 49.7 & & & NC \\
\hline 0.01 & 1 & 4.25 & -7.07 & 51.2 & 5.64 & -5.8 & 21.6 & & & NC \\
\hline 0.01 & 10 & 2.998 & -8.732 & 78.9 & 3.95 & -8.008 & 55.8 & 4.85 & -7.31 & 114.1 \\
\hline 0.01 & 100 & 1.98 & -9.782 & 80.7 & 2.93 & -9.075 & 58.3 & 3.79 & -8.4 & 116.1 \\
\hline 0.1 & 1 & 3.23 & -7.22 & 55.8 & 4.22 & -6.341 & 53.9 & & & NC \\
\hline 0.1 & 10 & 2.13 & -9.582 & 106.6 & 2.799 & -8.408 & 70.4 & 3.573 & -7.936 & 114.7 \\
\hline 0.1 & 100 & 1.12 & -10.05 & 108.6 & 1.779 & -9.532 & 76.9 & 2.51 & -9.077 & 154.7 \\
\hline
\end{tabular}

$\mathrm{IS}=$ ionic strength in $\mathrm{mol} / \mathrm{lit}, \mathrm{Ns}=$ site density in sites per $\mathrm{nm}^{2}, \mathrm{C}=$ capacitance, $\mathrm{NC}=$ no convergence in numeric scheme 
Table 4.10: Effect of coatings on DLM best fit value of protolysis constants for kaolinite.

\begin{tabular}{|c|c|c|c|c|c|c|c|c|c|c|}
\hline & & & $0 \%$ & & & e 4\% & & & Al 4\% & \\
\hline IS & $\mathbf{N}_{\mathrm{S}}$ & $\log K^{+}$ & $\log K^{-}$ & $F$ & $\log K^{+}$ & $\log K^{-}$ & $F$ & $\log K^{+}$ & $\log K^{-}$ & $F$ \\
\hline 0.001 & 1 & 6.64 & -5.96 & 20.5 & & & NC & & & NC \\
\hline 0.001 & 10 & 4.86 & -7.75 & 19.9 & & & NC & & & NC \\
\hline 0.001 & 100 & 3.82 & -8.79 & 19.9 & & & NC & & & NC \\
\hline 0.01 & 1 & 4.83 & -6.887 & 12.9 & & & $\mathrm{NC}$ & & & NC \\
\hline 0.01 & 10 & 3.64 & -8.407 & 10.3 & 4.59 & -7.47 & 36.6 & 4.85 & -7451 & 47.4 \\
\hline 0.01 & 100 & 2.62 & -9.44 & 18.7 & 3.56 & -8.57 & 38.2 & 3.81 & -8.53 & 48.2 \\
\hline 0.1 & 1 & 4.13 & -7.383 & 26.4 & & & NC & & & NC \\
\hline 0.1 & 10 & & & $\mathrm{NC}$ & 4.08 & -7.839 & 23.9 & 4.02 & -7836 & 49.6 \\
\hline 0.1 & 100 & & & $\mathrm{NC}$ & 3.02 & -8.98 & 29 & 3.03 & -8.81 & 83.4 \\
\hline
\end{tabular}

$\mathrm{IS}=$ ionic strength in $\mathrm{mol} / \mathrm{lit}, \mathrm{Ns}=$ site density in sites per $\mathrm{nm}^{2}, \mathrm{C}=$ capacitance, $\mathrm{NC}=$ no convergence in numeric scheme

Table 4.11:Effect of Coatings on DLM best fit value of protolysis constant for montmorillonite.

\begin{tabular}{|c|c|c|c|c|c|c|c|c|c|c|}
\hline \multirow[b]{2}{*}{ IS } & \multirow[b]{2}{*}{$\mathbf{N}_{\mathbf{S}}$} & \multicolumn{3}{|c|}{$0 \%$} & \multicolumn{3}{|c|}{ Fe $4 \%$} & \multicolumn{3}{|c|}{ Al $4 \%$} \\
\hline & & $\log K^{+}$ & $\log K^{-}$ & $\mathbf{F}$ & $\log K^{+}$ & $\log K^{-}$ & $\mathbf{F}$ & $\log K^{+}$ & $\log K^{-}$ & $\mathbf{F}$ \\
\hline 0.001 & 1 & 5.14 & -8.753 & 36.9 & 6.04 & -8.061 & 27.2 & 6.43 & -7.54 & 162 \\
\hline 0.001 & 10 & 4.099 & -9.814 & 38.5 & 4.91 & -9.196 & 28.6 & 5.23 & -8.77 & 164.2 \\
\hline 0.001 & 100 & 3.09 & -10.82 & 38.6 & 3.9012 & -10.207 & 28.7 & 4.22 & -9.79 & 164.4 \\
\hline 0.01 & 1 & 3.707 & -9.23 & 69.3 & 4.32 & -8.841 & 49.6 & 4.36 & -7.78 & 196.8 \\
\hline 0.01 & 10 & 2.69 & -10.34 & 72.8 & 3.27 & -9.968 & 57.2 & 3.16 & -9.118 & 238.1 \\
\hline 0.01 & 100 & 1.69 & -11.35 & 73.1 & 2.26 & -10.97 & 57.9 & 2.15 & -10.14 & 241.1 \\
\hline 0.1 & 1 & 1.583 & -8.91 & 14.15 & 3.36 & -8.676 & 71 & 3.08 & -8.5 & 323.2 \\
\hline 0.1 & 10 & 1.87 & -10.766 & 104 & 2.32 & -9.79 & 80.3 & 2.07 & -10.06 & 339.6 \\
\hline 0.1 & 100 & 0.813 & -11.77 & 105 & 1.32 & -10.8 & 81.1 & 1.07 & -11.09 & 340 \\
\hline
\end{tabular}

$\mathrm{IS}=$ ionic strength in $\mathrm{mol} / \mathrm{lit}, \mathrm{Ns}=$ site density in sites per $\mathrm{nm}^{2}, \mathrm{C}=$ capacitance, $\mathrm{NC}=$ no convergence in numeric scheme 
4.3.2 Constant Capacitance model: The effects of changes of $\mathrm{N}_{\mathrm{S}}$ and $\mathrm{C}_{1}$ on the best fit values of the surface hydrolysis constants were evaluated Sensitivity analysis for pure clay minerals: For a given value of $\mathrm{C}_{1}$ and ionic strength , the effect of site density $\left(\mathrm{N}_{\mathrm{S}}\right)$ on the best fit values of surface protolysis constants was to the DLM computations (Table 4.12, Figures 4.10-4.12) i.e. $\quad \log \mathrm{K}^{+}$and $\log \mathrm{K}^{-}$ decreased with increasing $\mathrm{N}_{\mathrm{S}}$. Similarly for given $\mathrm{N}_{\mathrm{S}}$ and ionic strength $\log \mathrm{K}^{+}$and $\log$ $\mathrm{K}^{-}$decreased with increasing $\mathrm{C}_{1}$. This can be explained (if the interfacial region is viewed as parallel- plate capacitor) by greater screening by counter ion charges as the value of $\mathrm{C}_{1}$ increases (Hayes et al., 1991). So in terms of fitting the titration data, the value of protolysis constants, have to decrease in order to compensate for effective increase in acidity (proton release) which results from enhanced charge screening on $\mathrm{C}_{1}$ increases. In general, for all the clay minerals, the $\mathrm{CCM}$ did not converge for $\mathrm{C}_{1}$ values below $0.6 \mathrm{~F} / \mathrm{m}^{2}$ and above $1.2 \mathrm{~F} / \mathrm{m}^{2}$. Generally, for all the clay minerals for a given value of $\mathrm{C}_{1}$ and $\mathrm{N}_{\mathrm{S}}$ as the ionic strength of the data set increased the optimized value of $\log \mathrm{K}^{+}$and $\log \mathrm{K}^{-}$decreased. Reasonable good fit $(\mathrm{F}<20)$ was observed for kaolinite at all ionic strength $(0.001,0.01$, and $0.1 \mathrm{M})$ and wide range of $\mathrm{N}_{\mathrm{S}}\left(1\right.$ to $\left.100 \mathrm{sites} / \mathrm{nm}^{2}\right)$ and $\mathrm{C}_{1}\left(0.2\right.$ to $\left.1.2 \mathrm{~F} / \mathrm{m}^{2}\right)$. For all the minerals at same ionic strength, as the value of $\mathrm{N}_{\mathrm{S}}$ increased (keeping the value of $\mathrm{C}_{1}$ constant) the $\mathrm{F}$ value also increased. Similarly for the same $\mathrm{N}_{\mathrm{S}}$, as $\mathrm{C}_{1}$ increased the value of $\mathrm{F}$ also increased. For illite and montmorillonite as the ionic strength increased for a given $\mathrm{C}_{1}$ and $\mathrm{N}_{\mathrm{S}}$, the $\mathrm{F}$ value also increased. For attapulgite relatively better fit was observed at $0.1 \mathrm{M}$ ionic strength. 
Table 4.12: Sensitivity of CCM to variation in total site density, ionic strength and capacitance for titration data of pure clay minerals

\begin{tabular}{|c|c|c|c|c|c|c|c|c|c|c|c|c|c|c|}
\hline \multirow[b]{2}{*}{ IS } & \multirow[b]{2}{*}{ C } & \multicolumn{4}{|c|}{ Attapulgite } & \multicolumn{3}{|c|}{ Illite } & \multicolumn{3}{|c|}{ Kaolnite } & \multicolumn{3}{|c|}{ Montmorillonite } \\
\hline & & & $\log ^{+}$ & $\log K^{-}$ & & $\log ^{+}$ & $\log K^{-}$ & $\mathbf{F}$ & $\log K^{+}$ & $\log K^{-}$ & $\mathbf{F}$ & $\log K^{+}$ & $\log K^{-}$ & $\mathbf{F}$ \\
\hline 0.001 & 1 & 0.8 & 4.1 & -10.16 & 55.1 & 4.08 & -7.98 & 30.2 & 4.46 & -7.83 & 9.8 & 4.12 & -10.35 & 76.7 \\
\hline 0.001 & 1 & 1 & 3.98 & -10.31 & 66.8 & 3.98 & -8.3 & 40.8 & 4.33 & -8.13 & 13.1 & 4.05 & -10.4 & 90.6 \\
\hline 0.001 & 1 & 1.2 & 3.88 & -10.42 & 75.7 & 3.92 & -8.6 & 48.9 & 4.24 & -8.41 & 15.9 & 3.99 & -10.54 & 102.3 \\
\hline 0.001 & 10 & 0.8 & 3.01 & -11.2 & 63.2 & 3 & -9.27 & 39.9 & 3.36 & -9.09 & 12.3 & 3.07 & -11.43 & 86.1 \\
\hline 0.001 & 10 & 1 & 2.87 & -11.4 & 76.6 & 2.92 & -975 & 52.1 & 3.22 & -9.51 & 16.4 & 2.98 & -11.54 & 103.4 \\
\hline 0.001 & 10 & 1.2 & 2.76 & -11.54 & 86.9 & 2.86 & -10.07 & 58.8 & 3.13 & -9.82 & 18.9 & 2.9 & -11.63 & 119.5 \\
\hline 0.001 & 100 & 0.8 & 2.01 & -12.27 & 63.9 & 2 & -10.29 & 40.6 & 2.35 & -10.11 & 12.6 & 2.07 & -12.44 & 87 \\
\hline 0.001 & 100 & 1 & 1.86 & -12.43 & 77.5 & 1.92 & -10.78 & 52.8 & 2.21 & -10.54 & 16.6 & 1.98 & -12.55 & 105.1 \\
\hline 0.001 & 100 & 1.2 & 1.75 & -12.55 & 87.9 & 1.85 & -11.09 & 59.4 & 2.12 & -10.85 & 19.1 & 1.89 & -12.64 & 121.1 \\
\hline 0.01 & 1 & 0.8 & 4.05 & -9.8 & 48.3 & 3.8 & -7.49 & 40.9 & 4.23 & -7.303 & 8.3 & 3.46 & -9.99 & 84.2 \\
\hline 0.01 & 1 & 1 & 3.96 & -9.972 & 58.9 & 3.72 & -7.75 & 52.6 & 4.11 & -7.59 & 10.8 & 3.42 & -10.14 & 93.1 \\
\hline 0.01 & 1 & 1.2 & 3.88 & -10 & 67 & 3.67 & -7.99 & 62.1 & 4.05 & -7.82 & 13.4 & 3.39 & -10.26 & 100.5 \\
\hline 0.01 & 10 & 0.8 & 2.99 & -10.92 & 55.7 & 2.74 & -8.78 & 53.7 & 3.14 & -8.582 & 10.7 & 2.44 & -11.09 & 90.2 \\
\hline 0.01 & 10 & 1 & 2.878 & -11.1 & 68 & 2.66 & -9.25 & 70.05 & 3.04 & -8.99 & 14.8 & 2.39 & -11.27 & 101 \\
\hline 0.01 & 10 & 1.2 & 2.78 & -11.8 & 77.9 & 2.611 & -9.62 & 80.14 & 2.98 & -9.31 & 17.8 & 2.35 & -11.39 & 109.6 \\
\hline 0.01 & 100 & 0.8 & 1.98 & -11.9 & 56.4 & 1.73 & -9.79 & 54.6 & 2.13 & -9.06 & 10.9 & 1.44 & -12.1 & 90.7 \\
\hline 0.01 & 100 & 1 & 1.87 & -12.11 & 66.8 & 1.65 & -10.28 & 71 & 2.03 & -10.01 & 15.1 & 1.39 & -12.28 & 101.7 \\
\hline 0.01 & 100 & 1.2 & 1.77 & -12.33 & 78.8 & 1.6 & -10.64 & 80.9 & 1.97 & -10.35 & 18.1 & 1.359 & -12.4 & 110.4 \\
\hline 0.1 & 1 & 0.8 & 3.86 & -9.42 & 46 & 3.27 & -7.02 & 32.4 & 4.17 & -6.99 & 5.44 & 2.88 & -9.54 & 94.6 \\
\hline 0.1 & 1 & 1 & 3.77 & -9.61 & 54.9 & 3.21 & -7.22 & 42.4 & 4.04 & -7.25 & 7.15 & 2.86 & -9.727 & 101 \\
\hline 0.1 & 1 & 1.2 & 3.71 & -9.76 & 61.5 & 3.17 & -7.36 & 50.8 & 3.97 & -7.44 & 8.96 & 2.83 & -9.86 & 105.1 \\
\hline 0.1 & 10 & 0.8 & 2.8 & -10.4 & 52.2 & 2.21 & -8.28 & 47 & 3.07 & -8.24 & 7.33 & 1.86 & -10.67 & 99.2 \\
\hline 0.1 & 10 & 1 & 2.71 & -10.74 & 62.3 & 2.14 & -8.63 & 65.5 & 2.96 & -8.59 & 10.96 & 1.84 & -10.86 & 105.6 \\
\hline 0.1 & 10 & 1.2 & 2.63 & -10.87 & 70.6 & 2.11 & -8.99 & 81.3 & 2.89 & -8.88 & 14.5 & 1.81 & -10.99 & 110.2 \\
\hline 0.1 & 100 & 0.8 & 1.8 & -11.56 & 52.8 & 1.2 & -9.29 & 47.9 & & & NC & 0.86 & -11.6 & 99.6 \\
\hline 0.1 & 100 & 1 & 1.7 & -11.75 & 63 & 1.14 & -9.66 & 66.8 & & & NC & 0.83 & -11.8 & 106 \\
\hline 0.1 & 100 & 1.2 & 1.62 & -11.88 & 71.5 & 1.1 & -10.02 & 82.8 & & & NC & 0.82 & -12 & 110.6 \\
\hline
\end{tabular}

$\mathrm{IS}=$ ionic strength in $\mathrm{mol} / \mathrm{lit}, \mathrm{Ns}=$ site density in sites per $\mathrm{nm}, \mathrm{C}=$ capacitance, $\mathrm{NC}=$ no convergence in numeric scheme 


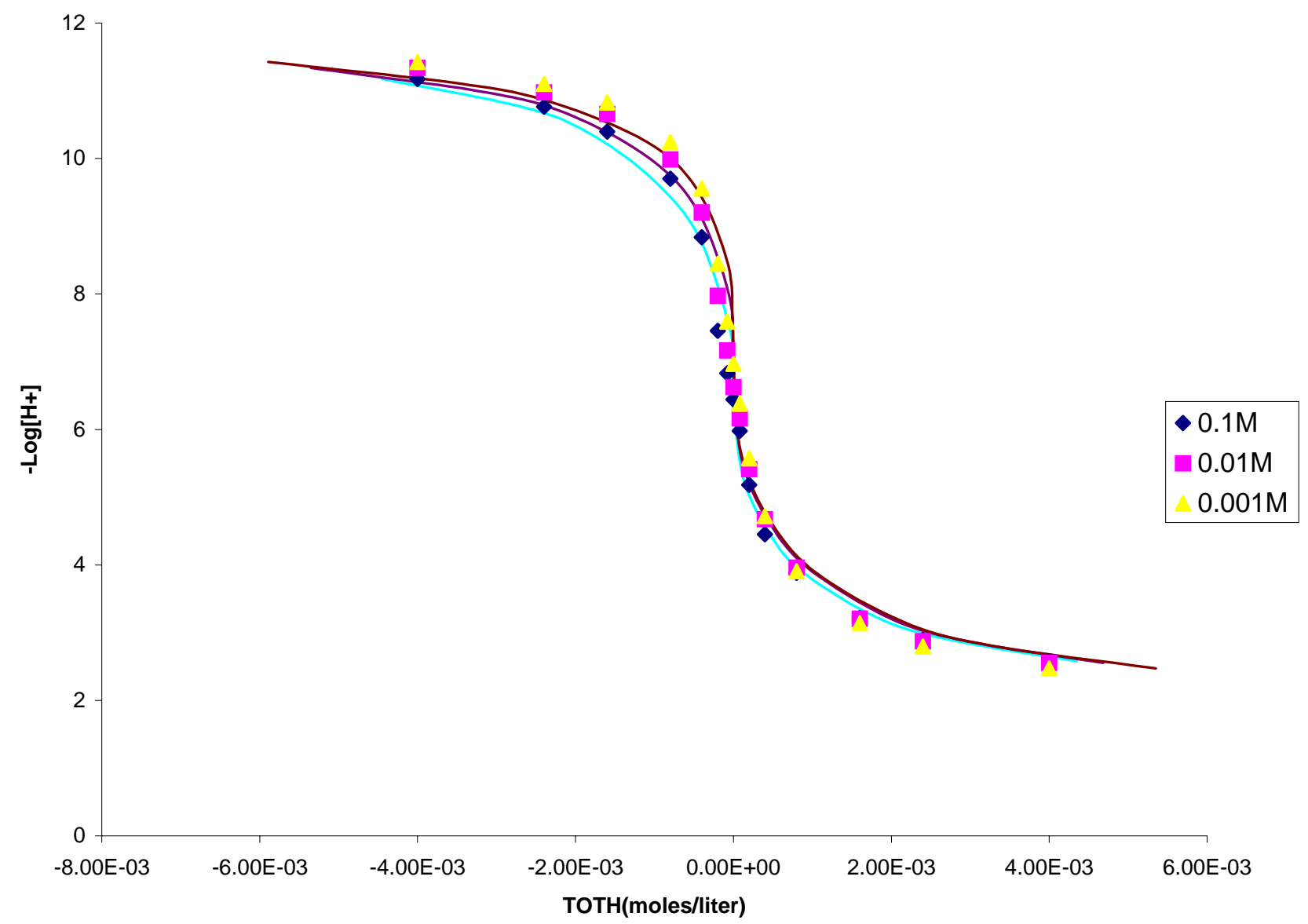

Figure 4.10:Constant capacitance model fit of titration data suspension of pure attapulgite 


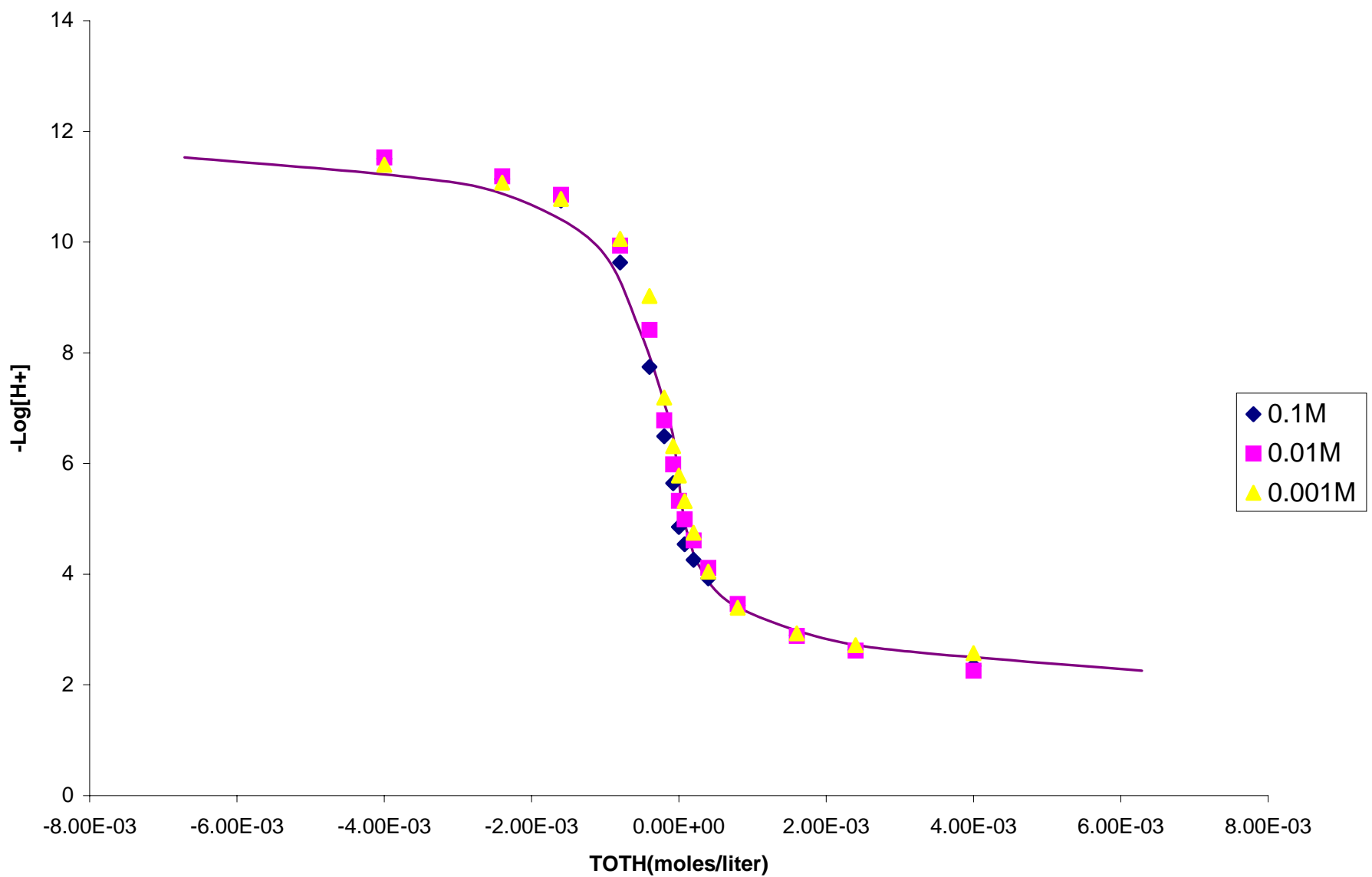

Figure 4.11: Constant capacitance model fit of titration data suspension of pure illite 


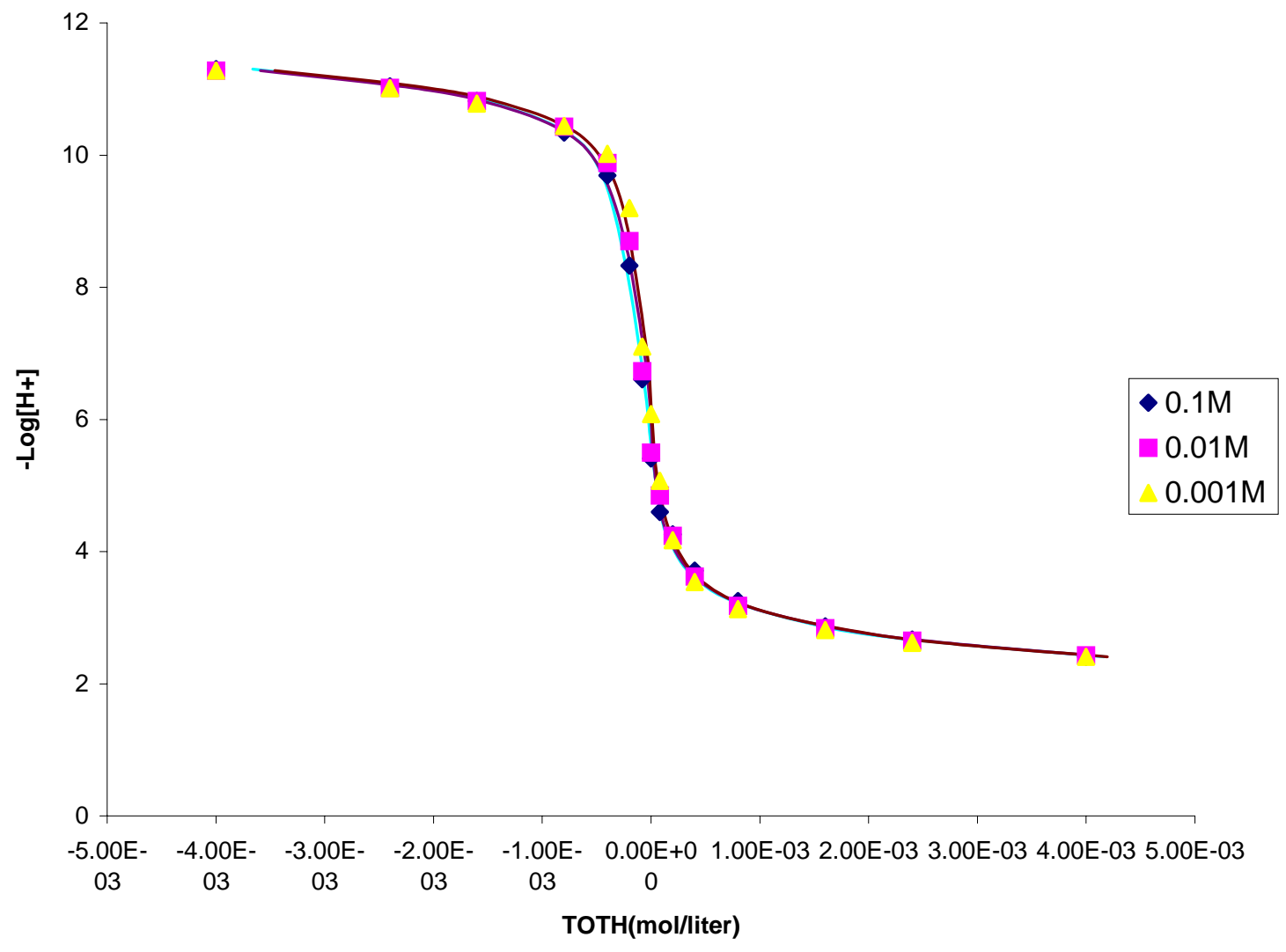

Figure 4.12: Constant capacitance model fits of titration data for suspension of pure kaolinite 
Sensitivity analysis for coated clay minerals: Better fits were observed for Fe coated clay minerals as compared to $\mathrm{Al}$ coated clay minerals (Tables 4.13-4.14, Figures 4.134.18).The reason for that is high reactivity of Fe oxide coatings as compared to $\mathrm{Al}$ oxide coatings (Hendershot and Lavkulich,1983) Lower F values were observed for Fe coated kaolinite as compared to all other clay minerals. Generally trends were similar to pure clay minerals in the sense that as the ionic strength increased the optimized value of log $\mathrm{K}^{+}$and $\log \mathrm{K}^{-}$decreased for both $\mathrm{Fe}$ and $\mathrm{Al}$ coated clays. Best fit $\mathrm{F}$ values were observed at $0.01 \mathrm{M}$ ionic strength for iron and aluminum coated kaolinite and illite.

Effect of coatings on CCM fit: Best fit F values were obtained for 0\% coated kaolinite as compared to $4 \%$ iron and aluminum coated kaolinite (Table 4.17). Optimized value of $\log \mathrm{K}^{+}$and $\log \mathrm{K}^{-}$are insensitive to changes in Ns (1 to 100$)$ and $\mathrm{C}(0.8$ to $1.2 \mathrm{~F} / \mathrm{m} 2)$. In case of attapulgite, illite and montmorillionite best fit $\mathrm{F}$ values are obtained at $4 \%$ iron coating as compared to $0 \%$ and $4 \% \mathrm{Al}$ coatings (Tables 4.15,4.16,4.18). Iron coated attapulgite and montmorilionite are insensitive to change in $\mathrm{Ns}$ and $\mathrm{C}_{1}$.

4.3.3 Triple layer model: The effects of changes of $\mathrm{Ns}_{\mathrm{s}}$ and $\mathrm{C}_{1}$ on the best fit values of the electrolyte surface reaction constants were evaluated.

Sensitivity analysis for pure clay minerals: Increasing the value of Ns resulted in decreasing values of $\log \mathrm{K}_{\mathrm{AN}}$ and $\log \mathrm{K}_{\mathrm{CA}}$ for kaolinite and illite at all the ionic strengths (Table 4.19, Figures 4.19-4.21) and the reason for that as explained in DLM and $\mathrm{CCM}$ is that in order for the computed number of proton released or consumed at a given $\mathrm{pH}$ to fit the titration data for different value of Ns, it is necessary that surface constants decrease as Ns increases. For attapulgite and montmorillonite, the titration data never converge for $\log \mathrm{K}_{\mathrm{AN}}$ and $\log \mathrm{K}_{\mathrm{CA}}$ all the ionic strengths, Ns (1 to 100 sites $/ \mathrm{nm}^{2}$ ) and $\mathrm{C}_{1}$ 
Table 4.13: Sensitivity of CCM to variation in total site density, ionic strength and capacitance for titration data of $4 \%$ iron coated clay minerals.

\begin{tabular}{|c|c|c|c|c|c|c|c|c|c|c|c|c|c|c|}
\hline & & & \multicolumn{4}{|c|}{ Attapulgite } & \multicolumn{3}{|c|}{ Illite } & \multicolumn{3}{|c|}{ Kaolnite } & \multicolumn{2}{|c|}{ Montmorillonite } \\
\hline IS & $\mathbf{N}_{\mathrm{S}}$ & C & $\log K^{+}$ & $\log K^{-}$ & $F$ & $\log K^{+}$ & $\log K^{-}$ & $\mathbf{F}$ & $\log ^{+}$ & $\log K^{-}$ & $\mathbf{F}$ & $\log ^{+}$ & $\log K^{-}$ & $\mathbf{F}$ \\
\hline 0.001 & 1 & 0.8 & 4.83 & -8.838 & 79.24 & 4.69 & -7.475 & 41.66 & 4.97 & -6.589 & 26.84 & 3.356 & -8.606 & 64.51 \\
\hline 0.001 & 1 & 1 & 4.7 & -8.958 & 141.97 & 4.55 & -7.663 & 60.22 & 4.711 & -6.9 & 25.2 & 3.307 & -8.76 & 79.984 \\
\hline 0.001 & 1 & 1.2 & 4.59 & -9.058 & 214.13 & 4.46 & -7.786 & 80.83 & 4.574 & -7.088 & 26.69 & 3.27 & -8.89 & 920.917 \\
\hline 0.001 & 10 & 0.8 & 3.76 & -9.904 & 111.55 & 3.58 & -8.667 & 73.23 & 3.75 & -7.87 & 29.19 & 2.32 & -9.717 & 750.49 \\
\hline 0.001 & 10 & 1 & 3.6 & -10.038 & 210.4 & 3.44 & -8.915 & 126.84 & 3.56 & -8.209 & 41.46 & 2.27 & -9.904 & 925.79 \\
\hline 0.001 & 10 & 1.2 & 3.46 & -10.146 & 321.08 & 3.34 & -9.109 & 190.6 & 3.42 & -8.453 & 61.68 & 2.23 & -10.05 & 105.7 \\
\hline 0.001 & 100 & 0.8 & 2.75 & -10.91 & 114.9 & 2.57 & -9.681 & 75.53 & 2.74 & -8.897 & 29.55 & 1.32 & -10.72 & 759.9 \\
\hline 0.001 & 100 & 1 & 2.59 & -11.045 & 217.05 & 2.43 & -9.931 & 131.14 & 2.53 & -9.23 & 42.82 & 1.26 & -10.91 & 936.97 \\
\hline 0.001 & 100 & 1.2 & 2.45 & -11.15 & 331.58 & 2.33 & -10.12 & 198.18 & 2.412 & -9.477 & 64.32 & 1.23 & -11.06 & 106.9 \\
\hline 0.01 & 1 & 0.8 & 4.91 & -8.381 & 68.28 & 4.568 & -6.728 & 35.7 & $\mathrm{NC}$ & & & 3.94 & -9.525 & 776.14 \\
\hline 0.01 & 1 & 1 & 4.77 & -8.523 & 148.68 & 4.39 & -6.938 & 44.033 & 5.53 & -6.01 & 43.25 & 3.88 & -9.72 & 926.6 \\
\hline 0.01 & 1 & 1.2 & 4.66 & -8.68 & 240.15 & 4.3 & -7.07 & 59.04 & 5.11 & -6.444 & 40.39 & 3.84 & -9.87 & 1048 \\
\hline 0.01 & 10 & 0.8 & 3.83 & -9.465 & 114.65 & 3.43 & -7.932 & 63.06 & 4.77 & -6.79 & 25.84 & 2.903 & -10.67 & 88.42 \\
\hline 0.01 & 10 & 1 & 3.675 & -9.628 & 245.12 & 3.27 & -8.181 & 128.71 & 4.05 & -7.526 & 22.46 & 2.83 & -10.9 & 106.5 \\
\hline 0.01 & 10 & 1.2 & 3.553 & -9.762 & 393.33 & 3.17 & -8.38 & 214.55 & 3.818 & -7.799 & 24.56 & 2.788 & -11.08 & 120.9 \\
\hline 0.01 & 100 & 0.8 & 2.823 & -10.472 & 119.15 & 2.42 & -8.946 & 68.64 & 3.69 & -7.875 & 25.75 & 1.9 & -11.68 & 893.79 \\
\hline 0.01 & 100 & 1 & 2.66 & -10.637 & 253.94 & 2.26 & -9.198 & 134.77 & 3.03 & -8.553 & 22.312 & 1.83 & -11.92 & 107.7 \\
\hline 0.01 & 100 & 1.2 & 2.54 & -10.773 & 406.85 & 2.17 & -9.401 & 225 & 2.8 & -8.822 & 25.46 & 1.78 & -12.103 & 122.3 \\
\hline 0.1 & 1 & 0.8 & 4.72 & -8.022 & 111.045 & 4.27 & -6.214 & 68.7 & & & NC & 4.55 & -9.743 & 47.39 \\
\hline 0.1 & 1 & 1 & 4.57 & -8.165 & 87.85 & 4.08 & -6.447 & 51.32 & 5.501 & -6.08 & 157.21 & 4.47 & -9.882 & 60.622 \\
\hline 0.1 & 1 & 1.2 & -4.47 & -8.27 & 154.23 & 3.97 & -6.578 & 44.99 & 5.16 & -6.409 & 153.8 & 4.41 & -9.983 & 72.563 \\
\hline 0.1 & 10 & 0.8 & -3.63 & -9.106 & 66.16 & 3.13 & -7.404 & 44.98 & 4.59 & -6.97 & 48.4 & 3.49 & -10.838 & 56.495 \\
\hline 0.1 & 10 & 1 & 3.488 & -9.272 & 161.95 & 2.95 & -7.644 & 58.46 & 4.058 & -7.517 & 31.2 & 3.41 & -10.99 & 74.3268 \\
\hline 0.1 & 10 & 1.2 & 3.37 & -9.407 & 288.64 & 2.84 & -7.819 & 104.48 & 3.85 & -7.74 & 22.2 & 3.33 & -11.1 & 90.887 \\
\hline 0.1 & 100 & 0.8 & 2.63 & -10.11 & 69.02 & 2.11 & -8.418 & 44.77 & 3.52 & -8.047 & 47.54 & 2.49 & -11.846 & 57.366 \\
\hline 0.1 & 100 & 1 & 2.48 & -10.28 & 164.02 & 1.94 & -8.659 & 61.09 & 4.06 & -7.51 & 49.84 & 2.4 & -12 & 75.616 \\
\hline 0.1 & 100 & 1.2 & 2.36 & -10.418 & 300.83 & 1.83 & -8.836 & 111.25 & 3.23 & -8.34 & 39.38 & 2.33 & -12.11 & 92.593 \\
\hline
\end{tabular}

$\mathrm{IS}=$ ionic strength in $\mathrm{mol} / \mathrm{lit}, \mathrm{Ns}=$ site density in sites per $\mathrm{nm}, \mathrm{C}=$ capacitance, $\mathrm{NC}=$ no convergence in numeric scheme 
Table 4.14: Sensitivity of CCM to variation in total site density, ionic strength and capacitance for titration data of $4 \%$ aluminum coated clay minerals.

\begin{tabular}{|c|c|c|c|c|c|c|c|c|c|c|c|c|c|c|}
\hline & & & \multicolumn{4}{|c|}{ Attapulgite } & \multicolumn{3}{|c|}{ Illite } & \multicolumn{3}{|c|}{ Kaolnite } & \multicolumn{2}{|c|}{ Montmorillonite } \\
\hline IS & $\mathbf{N}_{\mathbf{S}}$ & C & $\log K^{+}$ & $\log K^{-}$ & $F$ & $\log K^{+}$ & $\log K^{-}$ & $\mathbf{F}$ & $\log K^{+}$ & $\log K^{-}$ & $F$ & $\log K^{+}$ & $\log K^{-}$ & $F$ \\
\hline 0.001 & 1 & 0.8 & 4.74 & -7.58 & 70.4 & 6.55 & -5.11 & 69.4 & & & NC & 4.86 & -9.08 & 110.2 \\
\hline 0.001 & 1 & 1 & 4.44 & -7.72 & 64.1 & 5.16 & -6.488 & 69.8 & & & NC & 4.75 & -9.37 & 138.4 \\
\hline 0.001 & 1 & 1.2 & 4.38 & -7.816 & 61.4 & 4.92 & -6.755 & 68.4 & & & NC & 4.69 & -9.6 & 156.3 \\
\hline 0.001 & 10 & 0.8 & 3.48 & -8.69 & 65.4 & 4.37 & -7.29 & 60.3 & & & NC & 3.78 & -10.29 & 132.1 \\
\hline 0.001 & 10 & 1 & & & NC & 3.92 & -7.791 & 56.1 & & & NC & 3.68 & -10.64 & 159.8 \\
\hline 0.001 & 10 & 1.2 & 3.3 & -8.991 & 67.6 & 3.74 & -8.044 & 53.2 & 4.95 & -6.68 & 72.8 & 3.63 & -10.85 & 175.3 \\
\hline 0.001 & 100 & 0.8 & 2.47 & -9.644 & 65.2 & 3.33 & -8.336 & 6.01 & & & $\mathrm{NC}$ & 2.78 & -11.31 & 134 \\
\hline 0.001 & 100 & 1 & 2.37 & -9.867 & 63.8 & 2.9 & -8.815 & 55.8 & & & NC & 2.68 & -11.66 & 161.2 \\
\hline 0.001 & 100 & 1.2 & 2.29 & -10 & 68.3 & 2.72 & -9.067 & 53 & 3.37 & -7.762 & 70.7 & 2.62 & -11.87 & 176.8 \\
\hline 0.01 & 1 & 0.8 & 4.69 & -8.041 & 52.2 & & & NC & & & NC & 3.98 & -8.42 & 203.3 \\
\hline 0.01 & 1 & 1 & 4.59 & -8.172 & 46.5 & 6.01 & -5.399 & 55 & 6.023 & -5.08 & 19.3 & 3.9 & -8.86 & 236.9 \\
\hline 0.01 & 1 & 1.2 & 4.52 & -8.268 & 44.6 & 5.23 & -6.17 & 55.6 & 5.161 & -5.93 & 19.4 & 3.86 & -9.2 & 252 \\
\hline 0.01 & 10 & 0.8 & 3.62 & -9.138 & 46.9 & & & $\mathrm{NC}$ & 5.47 & -5.66 & 17.2 & 2.91 & -9.79 & 235.2 \\
\hline 0.01 & 10 & 1 & 3.52 & -9.296 & 44.7 & 4.19 & -7.246 & 42.2 & 3.99 & -7.169 & 17.4 & 2.866 & -10.31 & 257.3 \\
\hline 0.01 & 10 & 1.2 & 3.44 & -9.428 & 47.7 & 3.88 & -7.595 & 40.6 & & & NC & 2.85 & -10.6 & 261.9 \\
\hline 0.01 & 100 & 0.8 & 2.62 & -10.146 & 46.6 & & & NC & 4.08 & -7.048 & 17.2 & 1.9 & -10.82 & 236.9 \\
\hline 0.01 & 100 & 1 & 2.516 & -10.3 & 44.7 & 3.15 & -8.284 & 42.1 & 2.96 & -8.204 & 17.4 & 1.86 & -11.34 & 258.1 \\
\hline 0.01 & 100 & 1.2 & 2.44 & -10.441 & 48.2 & 2.86 & -8.622 & 40.5 & 2.7 & -8.561 & 18.3 & 1.84 & -11.65 & 262 \\
\hline 0.1 & 1 & 0.8 & 4.68 & -8.453 & 46.7 & & & NC & 5.34 & -5.7 & 14.5 & 3.18 & -7.75 & 251.3 \\
\hline 0.1 & 1 & 1 & 4.58 & -8.569 & 38.2 & & & NC & 4.87 & -6.22 & 14.6 & 3.1 & -8.38 & 298.3 \\
\hline 0.1 & 1 & 1.2 & 4.51 & -8.657 & 33.8 & 5.28 & -5.69 & 88.9 & 4.66 & -6.46 & 14.9 & 3.08 & -8.81 & 309.8 \\
\hline 0.1 & 10 & 0.8 & 3.62 & -9.53 & 38.2 & & & NC & 3.87 & -7.289 & 15.6 & 2.1 & -9.33 & 298.6 \\
\hline 0.1 & 10 & 1 & 3.519 & -9.665 & 30.8 & 4.17 & -6.82 & 75.8 & 3.56 & -7.744 & 17.4 & 2.08 & -9.92 & 314.6 \\
\hline 0.1 & 10 & 1.2 & 3.4 & -9.773 & 28.4 & 3.77 & -7.263 & 75.4 & 3.41 & -8.081 & 19.7 & 2.09 & -10.17 & 315.5 \\
\hline 0.1 & 100 & 0.8 & 2.61 & -10.53 & 37.7 & & & NC & 2.85 & -8.317 & 15.6 & 1.1 & -10.38 & 300.8 \\
\hline 0.1 & 100 & 1 & 2.51 & -10.674 & 30.5 & 3.12 & -7.879 & 75.8 & 2.54 & -8.772 & 17.6 & 1.08 & -10.95 & 314.8 \\
\hline 0.1 & 100 & 1.2 & 2.43 & -10.789 & 28.3 & 2.74 & -8.294 & 75.4 & 2.403 & -9.11 & 20 & 1.09 & -11.19 & 314.5 \\
\hline
\end{tabular}

$\mathrm{IS}=$ ionic strength in $\mathrm{mol} / \mathrm{lit}, \mathrm{Ns}=$ site density in sites per $\mathrm{nm}, \mathrm{C}=$ capacitance, $\mathrm{NC}=$ no convergence in numeric scheme 


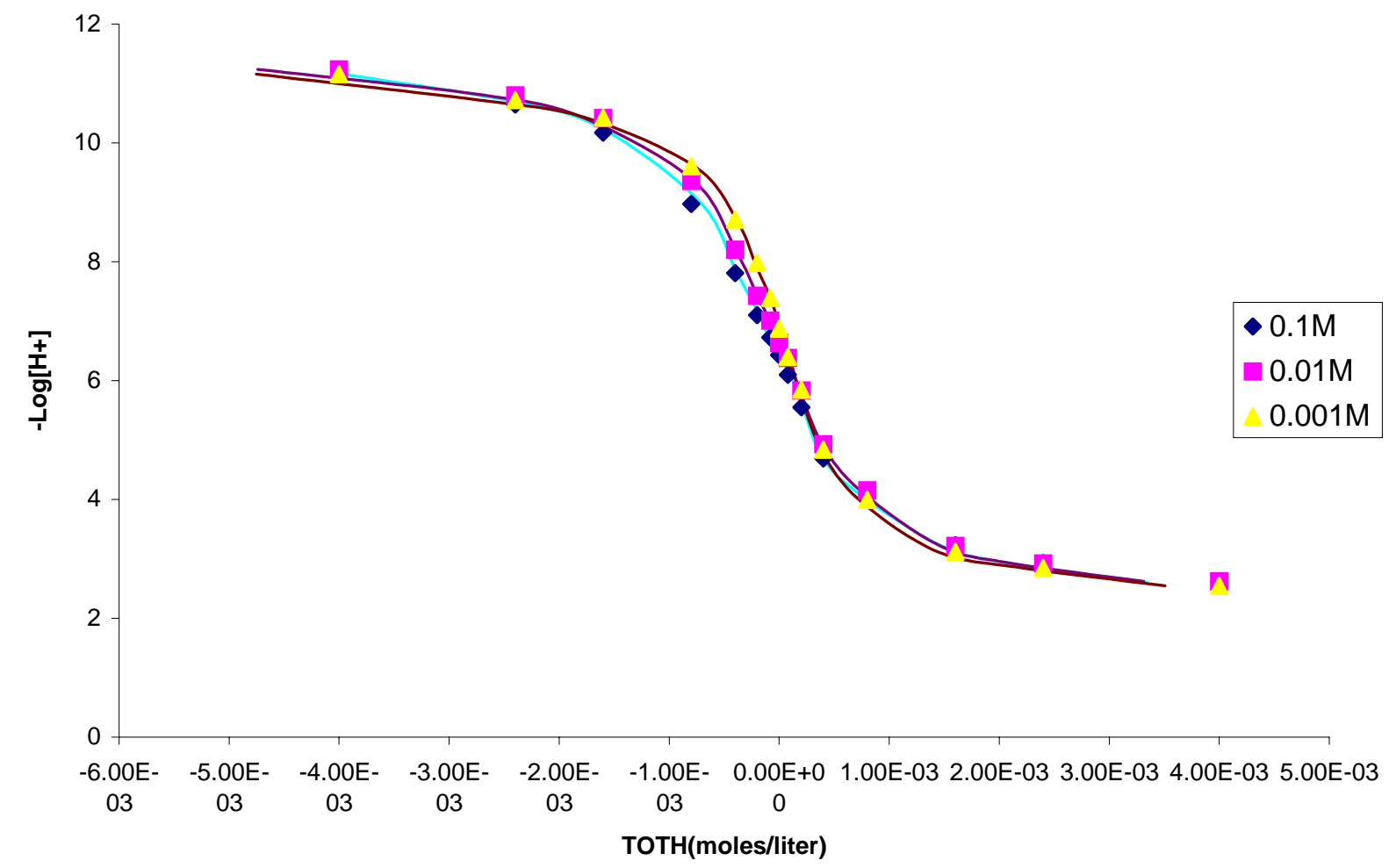

Figure 4.13: Constant capacitance model fit of titration data for suspension of $4 \%$ iron coated attapulgite 


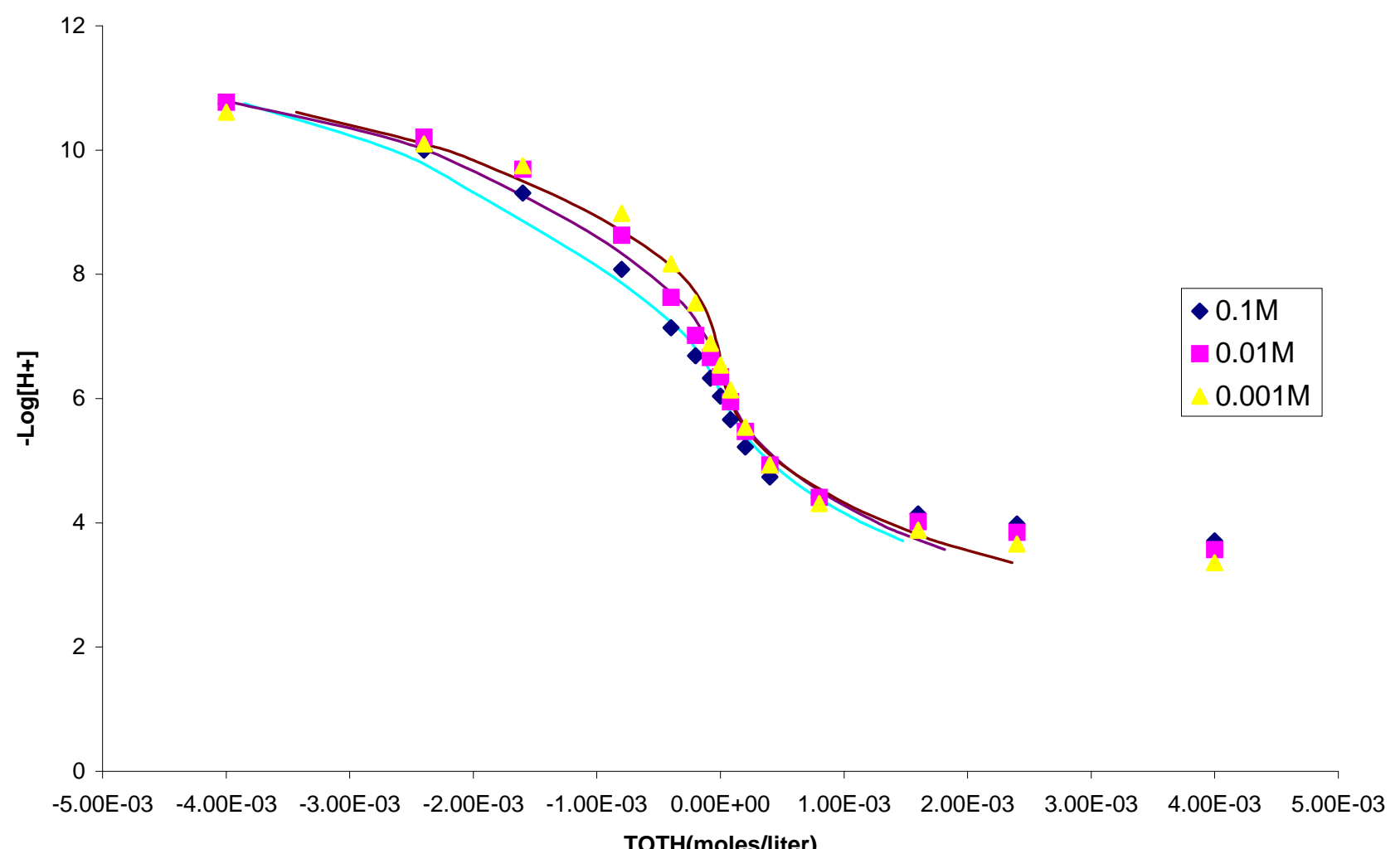

Figure 4.14: Constant capacitance model fit of titration data suspension of $4 \%$ aluminum coated attapulgite 


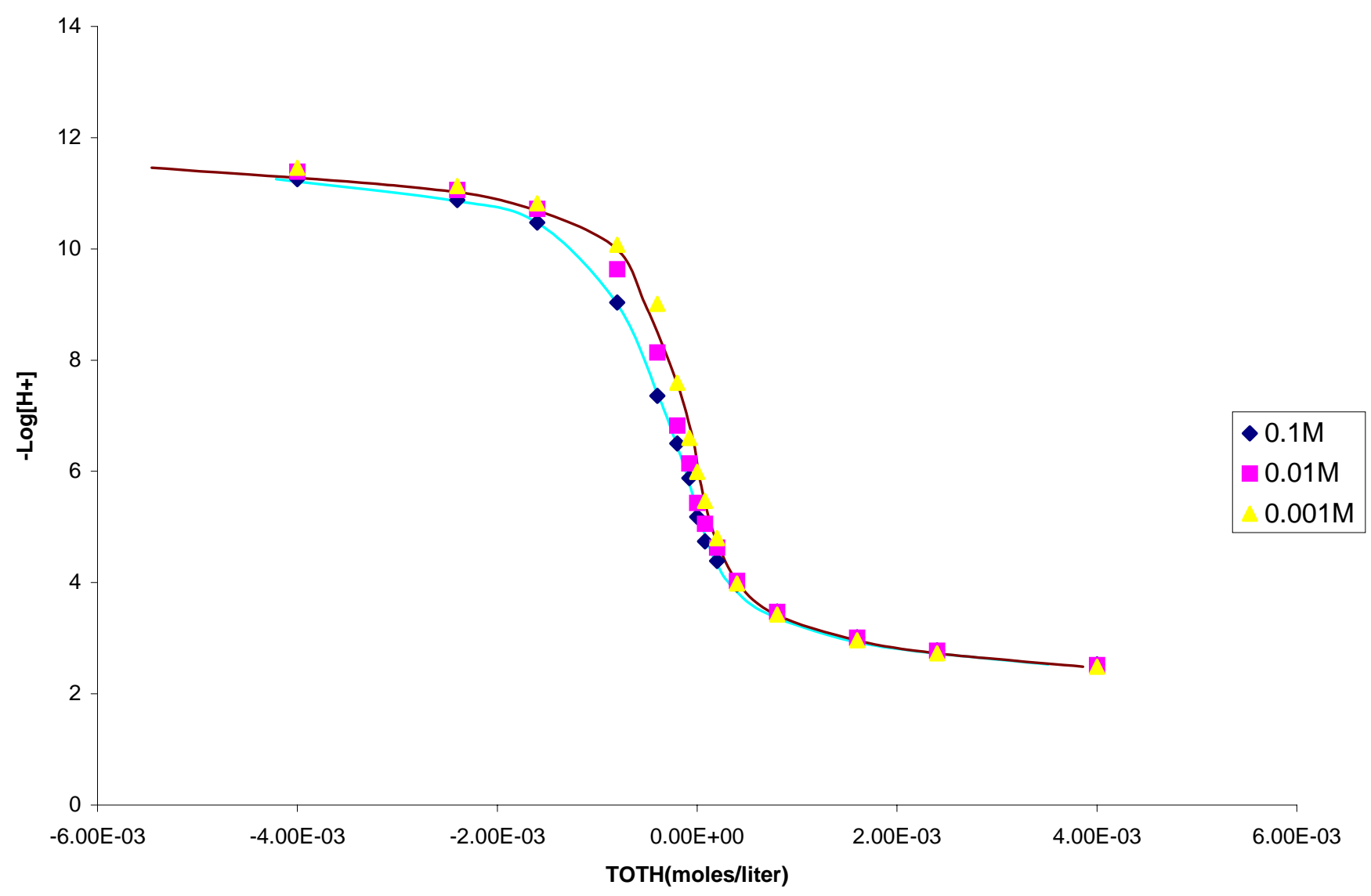

Figure 4.15: Constant capacitance model fit of titration data for suspension of $4 \%$ iron coated illite 


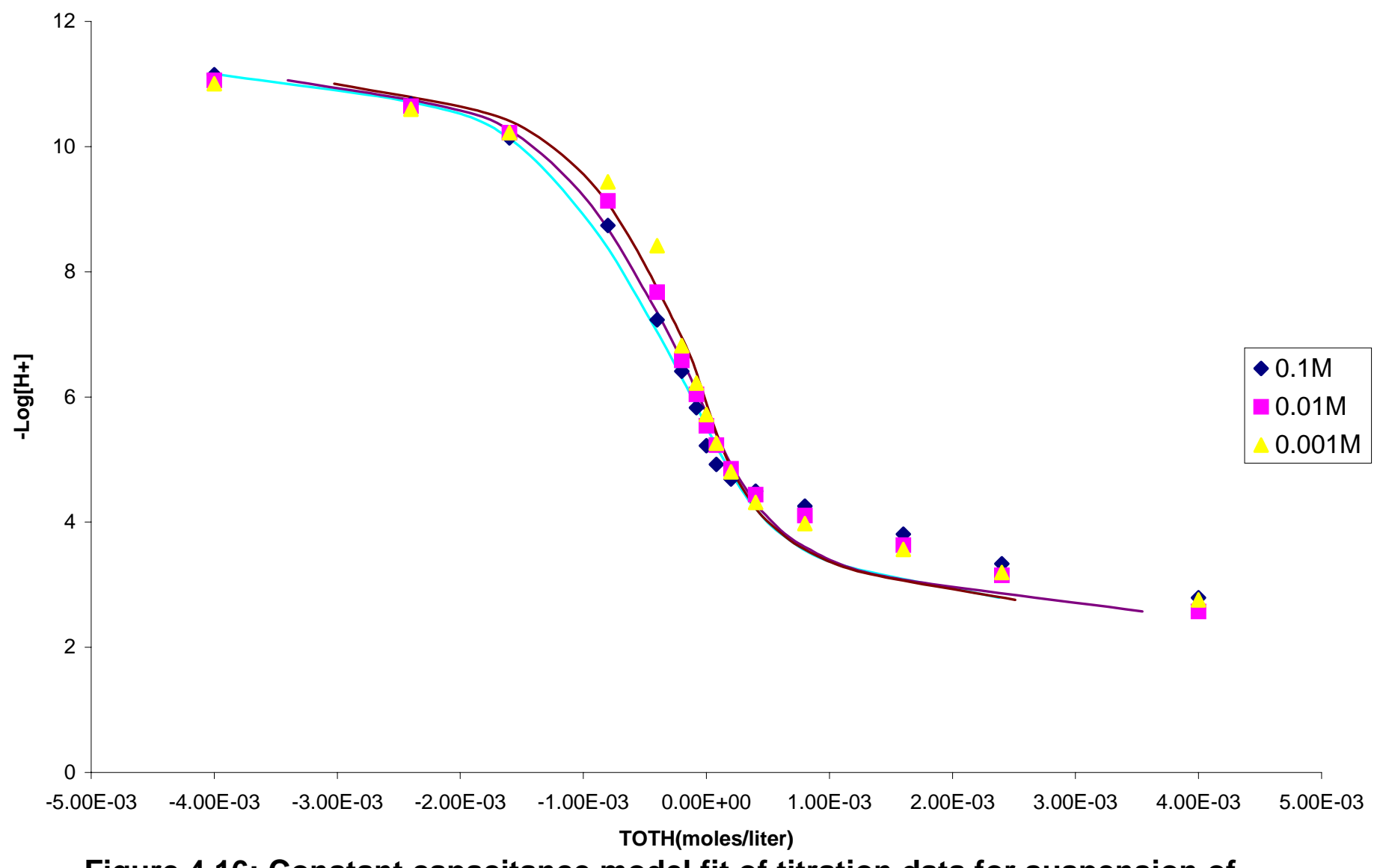

Figure 4.16: Constant capacitance model fit of titration data for suspension of

$4 \%$ aluminum coated illite 


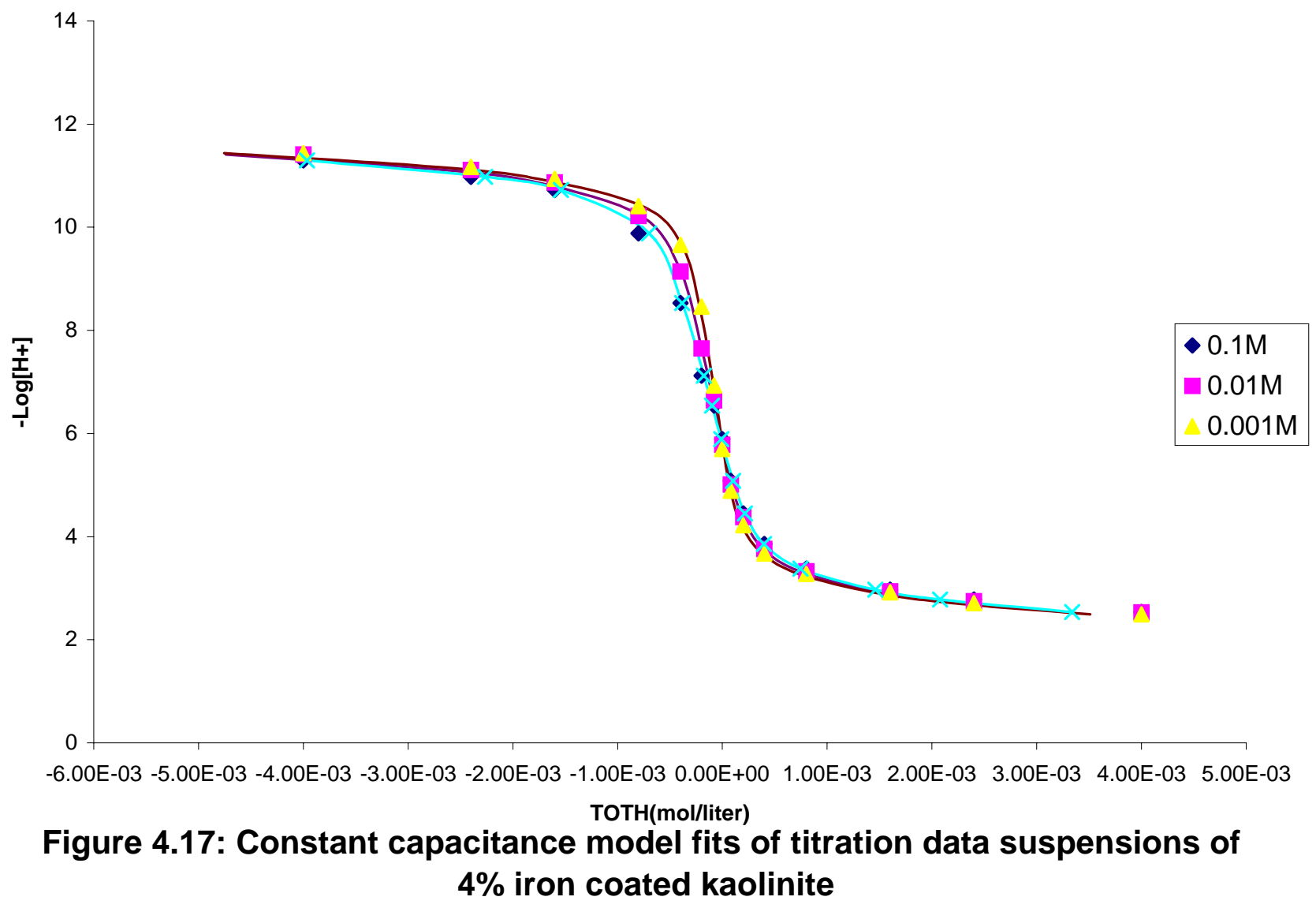




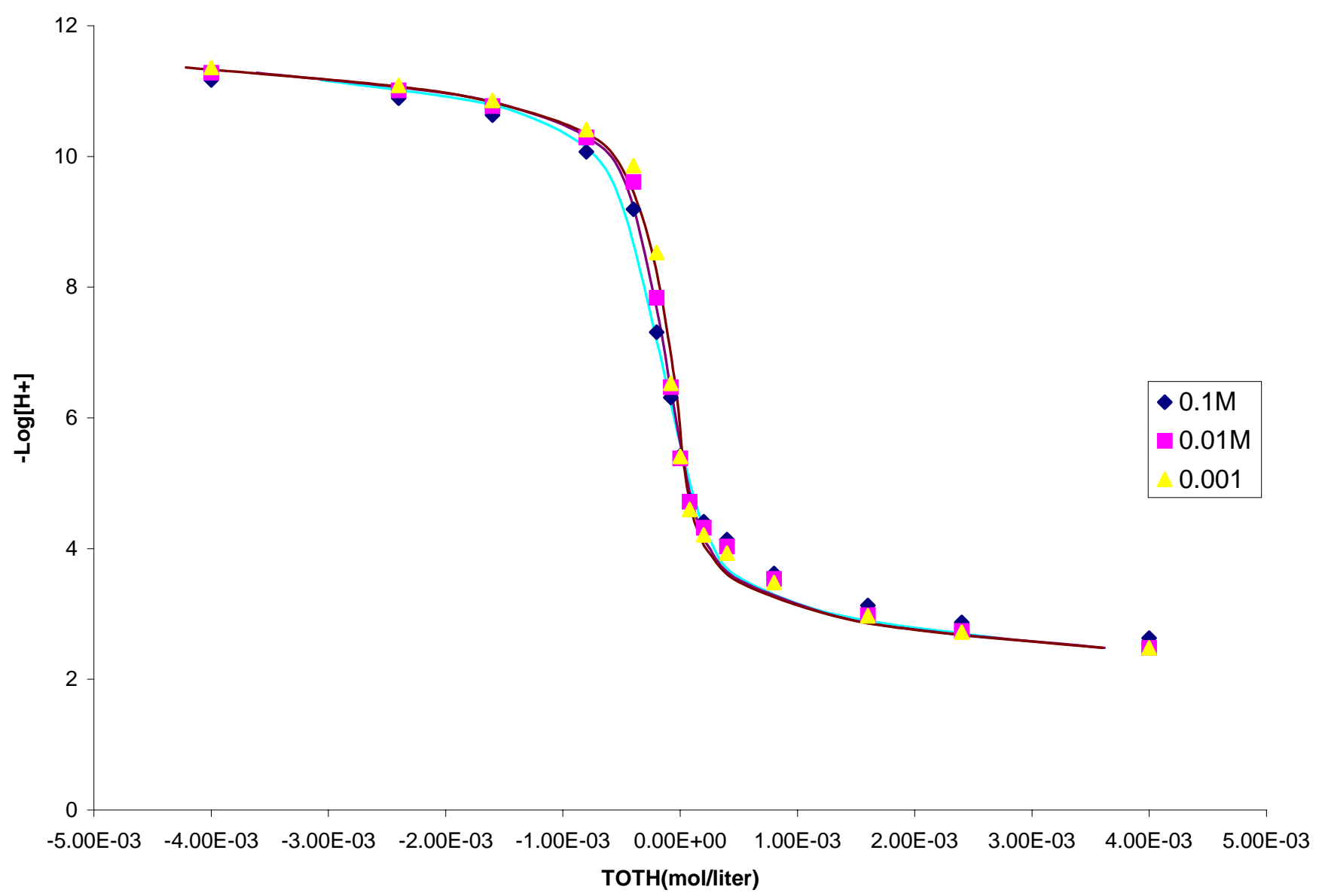

Figure 4.18: Constant capacitance model fits of titration data suspensions of $4 \%$ aluminum coated kaolinite

107 
Table 4.15: Effect of coatings on sensitivity of CCM to variation in total site density ionic, strength and capacitance for attapulgite titration data.

\begin{tabular}{|c|c|c|c|c|c|c|c|c|c|c|c|}
\hline & & & & \multicolumn{2}{|c|}{ Attapulgite(0\%) } & \multicolumn{4}{|c|}{ Attapulgite(4\% Fe) } & \multicolumn{2}{|c|}{ Attapulgite(4\% Al) } \\
\hline IS & $\mathbf{N}_{\mathrm{S}}$ & C & $\log K^{+}$ & $\log K^{-}$ & $\mathbf{F}$ & $\log ^{+}$ & $\log K^{-}$ & $\mathrm{F}$ & $\log ^{+}$ & $\log K^{-}$ & $\mathrm{F}$ \\
\hline 0.001 & 1 & 0.8 & 4.1 & -10.16 & 55.1 & 4.83 & -8.838 & 79.24 & 4.74 & -7.58 & 70.4 \\
\hline 0.001 & 1 & 1 & 3.98 & -10.31 & 66.8 & 4.7 & -8.958 & 141.97 & 4.44 & -7.72 & 64.1 \\
\hline 0.001 & 1 & 1.2 & 3.88 & -10.42 & 75.7 & 4.59 & -9.058 & 214.13 & 4.38 & -7.816 & 61.4 \\
\hline 0.001 & 10 & 0.8 & 3.01 & -11.2 & 63.2 & 3.76 & -9.904 & 111.55 & 3.48 & -8.69 & 65.4 \\
\hline 0.001 & 10 & 1 & 2.87 & -11.4 & 76.6 & 3.6 & -10.038 & 210.4 & & & \\
\hline 0.001 & 10 & 1.2 & 2.76 & -11.54 & 86.9 & 3.46 & -10.146 & 321.08 & 3.3 & -8.991 & 67.6 \\
\hline 0.001 & 100 & 0.8 & 2.01 & -12.27 & 63.9 & 2.75 & -10.91 & 114.9 & 2.47 & -9.644 & 65.2 \\
\hline 0.001 & 100 & 1 & 1.86 & -12.43 & 77.5 & 2.59 & -11.045 & 217.05 & 2.37 & -9.867 & 63.8 \\
\hline 0.001 & 100 & 1.2 & 1.75 & -12.55 & 87.9 & 2.45 & -11.15 & 331.58 & 2.29 & -10 & 68.3 \\
\hline 0.01 & 1 & 0.8 & 4.05 & -9.8 & 48.3 & 4.91 & -8.381 & 68.28 & 4.69 & -8.041 & 52.2 \\
\hline 0.01 & 1 & 1 & 3.96 & -9.972 & 58.9 & 4.77 & -8.523 & 148.68 & 4.59 & -8.172 & 46.5 \\
\hline 0.01 & 1 & 1.2 & 3.88 & -10 & 67 & 4.66 & -8.68 & 240.15 & 4.52 & -8.268 & 44.6 \\
\hline 0.01 & 10 & 0.8 & 2.99 & -10.92 & 55.7 & 3.83 & -9.465 & 114.65 & 3.62 & -9.138 & 46.9 \\
\hline 0.01 & 10 & 1 & 2.878 & -11.1 & 68 & 3.675 & -9.628 & 245.12 & 3.52 & -9.296 & 44.7 \\
\hline 0.01 & 10 & 1.2 & 2.78 & -11.8 & 77.9 & 3.553 & -9.762 & 393.33 & 3.44 & -9.428 & 47.7 \\
\hline 0.01 & 100 & 0.8 & 1.98 & -11.9 & 56.4 & 2.823 & -10.472 & 119.15 & 2.62 & -10.146 & 46.6 \\
\hline 0.01 & 100 & 1 & 1.87 & -12.11 & 66.8 & 2.66 & -10.637 & 253.94 & 2.516 & -10.3 & 44.7 \\
\hline 0.01 & 100 & 1.2 & 1.77 & -12.33 & 78.8 & 2.54 & -10.773 & 406.85 & 2.44 & -10.441 & 48.2 \\
\hline 0.1 & 1 & 0.8 & 3.86 & -9.42 & 46 & 4.72 & -8.022 & 111.045 & 4.68 & -8.453 & 46.7 \\
\hline 0.1 & 1 & 1 & 3.77 & -9.61 & 54.9 & 4.57 & -8.165 & 87.85 & 4.58 & -8.569 & 38.2 \\
\hline 0.1 & 1 & 1.2 & 3.71 & -9.76 & 61.5 & -4.47 & -8.27 & 154.23 & 4.51 & -8.657 & 33.8 \\
\hline 0.1 & 10 & 0.8 & 2.8 & -10.4 & 52.2 & -3.63 & -9.106 & 66.16 & 3.62 & -9.53 & 38.2 \\
\hline 0.1 & 10 & 1 & 2.71 & -10.74 & 62.3 & 3.488 & -9.272 & 161.95 & 3.519 & -9.665 & 30.8 \\
\hline 0.1 & 10 & 1.2 & 2.63 & -10.87 & 70.6 & 3.37 & -9.407 & 288.64 & 3.4 & -9.773 & 28.4 \\
\hline 0.1 & 100 & 0.8 & 1.8 & -11.56 & 52.8 & 2.63 & -10.11 & 69.02 & 2.61 & -10.53 & 37.7 \\
\hline 0.1 & 100 & 1 & 1.7 & -11.75 & 63 & 2.48 & -10.28 & 164.02 & 2.51 & -10.674 & 30.5 \\
\hline 0.1 & 100 & 1.2 & 1.62 & -11.88 & 71.5 & 2.36 & -10.418 & 300.83 & 2.43 & -10.789 & 28.3 \\
\hline
\end{tabular}

$\mathrm{IS}=$ ionic strength in $\mathrm{mol} / \mathrm{lit}, \mathrm{Ns}=$ site density in sites per $\mathrm{nm}, \mathrm{C}=$ capacitance, $\mathrm{NC}=$ no convergence in numeric scheme 
Table 4.16: Effect of coatings on sensitivity of CCM to variation in total site density, ionic strength and capacitance for illite titration data.

\begin{tabular}{|c|c|c|c|c|c|c|c|c|c|c|c|}
\hline & & & \multicolumn{3}{|c|}{ illite(0\%) } & \multicolumn{3}{|c|}{ Illite(4\%Fe) } & \multicolumn{3}{|c|}{ Illite(4\% Al) } \\
\hline IS & $\mathbf{N}_{\mathbf{S}}$ & C & $\log K^{+}$ & $\log K^{-}$ & $F$ & $\log K^{+}$ & $\log K^{-}$ & $F$ & $\log K^{+}$ & $\log K^{-}$ & $\mathbf{F}$ \\
\hline 0.001 & 1 & 0.8 & 4.08 & -7.98 & 30.2 & 4.69 & -7.475 & 41.66 & 6.55 & -5.11 & 69.4 \\
\hline 0.001 & 1 & 1 & 3.98 & -8.3 & 40.8 & 4.55 & -7.663 & 60.22 & 5.16 & -6.488 & 69.8 \\
\hline 0.001 & 1 & 1.2 & 3.92 & -8.6 & 48.9 & 4.46 & -7.786 & 80.83 & 4.92 & -6.755 & 68.4 \\
\hline 0.001 & 10 & 0.8 & 3 & -9.27 & 39.9 & 3.58 & -8.667 & 73.23 & 4.37 & -7.29 & 60.3 \\
\hline 0.001 & 10 & 1 & 2.92 & -975 & 52.1 & 3.44 & -8.915 & 126.84 & 3.92 & -7.791 & 56.1 \\
\hline 0.001 & 10 & 1.2 & 2.86 & -10.07 & 58.8 & 3.34 & -9.109 & 190.6 & 3.74 & -8.044 & 53.2 \\
\hline 0.001 & 100 & 0.8 & 2 & -10.29 & 40.6 & 2.57 & -9.681 & 75.53 & 3.33 & -8.336 & 6.01 \\
\hline 0.001 & 100 & 1 & 1.92 & -10.78 & 52.8 & 2.43 & -9.931 & 131.14 & 2.9 & -8.815 & 55.8 \\
\hline 0.001 & 100 & 1.2 & 1.85 & -11.09 & 59.4 & 2.33 & -10.12 & 198.18 & 2.72 & -9.067 & 53 \\
\hline 0.01 & 1 & 0.8 & 3.8 & -7.49 & 40.9 & 4.568 & -6.728 & 35.7 & & & $\mathrm{NC}$ \\
\hline 0.01 & 1 & 1 & 3.72 & -7.75 & 52.6 & 4.39 & -6.938 & 44.033 & 6.01 & -5.399 & 55 \\
\hline 0.01 & 1 & 1.2 & 3.67 & -7.99 & 62.1 & 4.3 & -7.07 & 59.04 & 5.23 & -6.17 & 55.6 \\
\hline 0.01 & 10 & 0.8 & 2.74 & -8.78 & 53.7 & 3.43 & -7.932 & 63.06 & & & $\mathrm{NC}$ \\
\hline 0.01 & 10 & 1 & 2.66 & -9.25 & 70.05 & 3.27 & -8.181 & 128.71 & 4.19 & -7.246 & 42.2 \\
\hline 0.01 & 10 & 1.2 & 2.611 & -9.62 & 80.14 & 3.17 & -8.38 & 214.55 & 3.88 & -7.595 & 40.6 \\
\hline 0.01 & 100 & 0.8 & 1.73 & -9.79 & 54.6 & 2.42 & -8.946 & 68.64 & & & $\mathrm{NC}$ \\
\hline 0.01 & 100 & 1 & 1.65 & -10.28 & 71 & 2.26 & -9.198 & 134.77 & 3.15 & -8.284 & 42.1 \\
\hline 0.01 & 100 & 1.2 & 1.6 & -10.64 & 80.9 & 2.17 & -9.401 & 225 & 2.86 & -8.622 & 40.5 \\
\hline 0.1 & 1 & 0.8 & 3.27 & -7.02 & 32.4 & 4.27 & -6.214 & 68.7 & & & $\mathrm{NC}$ \\
\hline 0.1 & 1 & 1 & 3.21 & -7.22 & 42.4 & 4.08 & -6.447 & 51.32 & & & $\mathrm{NC}$ \\
\hline 0.1 & 1 & 1.2 & 3.17 & -7.36 & 50.8 & 3.97 & -6.578 & 44.99 & 5.28 & -5.69 & 88.9 \\
\hline 0.1 & 10 & 0.8 & 2.21 & -8.28 & 47 & 3.13 & -7.404 & 44.98 & & & $\mathrm{NC}$ \\
\hline 0.1 & 10 & 1 & 2.14 & -8.63 & 65.5 & 2.95 & -7.644 & 58.46 & 4.17 & -6.82 & 75.8 \\
\hline 0.1 & 10 & 1.2 & 2.11 & -8.99 & 81.3 & 2.84 & -7.819 & 104.48 & 3.77 & -7.263 & 75.4 \\
\hline 0.1 & 100 & 0.8 & 1.2 & -9.29 & 47.9 & 2.11 & -8.418 & 44.77 & & & $\mathrm{NC}$ \\
\hline 0.1 & 100 & 1 & 1.14 & -9.66 & 66.8 & 1.94 & -8.659 & 61.09 & 3.12 & -7.879 & 75.8 \\
\hline 0.1 & 100 & 1.2 & 1.1 & -10.02 & 82.8 & 1.83 & -8.836 & 111.25 & 2.74 & -8.294 & 75.4 \\
\hline
\end{tabular}

$\mathrm{IS}=$ ionic strength in $\mathrm{mol} / \mathrm{lit}, \mathrm{Ns}=$ site density in sites per $\mathrm{nm}, \mathrm{C}=$ capacitance, $\mathrm{NC}=$ no convergence in numeric scheme 
Table 4.17: Effect of coatings on sensitivity of CCM to variation in total site density, ionic strength and capacitance for kaolinite titration data.

\begin{tabular}{|c|c|c|c|c|c|c|c|c|c|c|c|}
\hline & & & & $0 \%$ & & & $4 \% \mathrm{Fe}$ & & & $4 \% \mathrm{Al}$ & \\
\hline IS & $\mathbf{N}_{\mathbf{S}}$ & C & $\log K^{+}$ & $\log K^{-}$ & $F$ & $\log K^{+}$ & $\log K^{-}$ & $F$ & $\log K^{+}$ & $\log K^{-}$ & $\mathbf{F}$ \\
\hline 0.001 & 1 & 0.8 & 4.46 & -7.83 & 9.8 & 4.97 & -6.589 & 26.84 & & & $\mathrm{NC}$ \\
\hline 0.001 & 1 & 1 & 4.33 & -8.13 & 13.1 & 4.711 & -6.9 & 25.2 & & & $\mathrm{NC}$ \\
\hline 0.001 & 1 & 1.2 & 4.24 & -8.41 & 15.9 & 4.574 & -7.088 & 26.69 & & & $\mathrm{NC}$ \\
\hline 0.001 & 10 & 0.8 & 3.36 & -9.09 & 12.3 & 3.75 & -7.87 & 29.19 & & & $\mathrm{NC}$ \\
\hline 0.001 & 10 & 1 & 3.22 & -9.51 & 16.4 & 3.56 & -8.209 & 41.46 & & & $\mathrm{NC}$ \\
\hline 0.001 & 10 & 1.2 & 3.13 & -9.82 & 18.9 & 3.42 & -8.453 & 61.68 & 4.95 & -6.68 & 72.8 \\
\hline 0.001 & 100 & 0.8 & 2.35 & -10.11 & 12.6 & 2.74 & -8.897 & 29.55 & & & $\mathrm{NC}$ \\
\hline 0.001 & 100 & 1 & 2.21 & -10.54 & 16.6 & 2.53 & -9.23 & 42.82 & & & $\mathrm{NC}$ \\
\hline 0.001 & 100 & 1.2 & 2.12 & -10.85 & 19.1 & 2.412 & -9.477 & 64.32 & 3.37 & -7.762 & 70.7 \\
\hline 0.01 & 1 & 0.8 & 4.23 & -7.303 & 8.3 & & & $\mathrm{NC}$ & & & $\mathrm{NC}$ \\
\hline 0.01 & 1 & 1 & 4.11 & -7.59 & 10.8 & 5.53 & -6.01 & 43.25 & 6.023 & -5.08 & 19.3 \\
\hline 0.01 & 1 & 1.2 & 4.05 & -7.82 & 13.4 & 5.11 & -6.444 & 40.39 & 5.161 & -5.93 & 19.4 \\
\hline 0.01 & 10 & 0.8 & 3.14 & -8.582 & 10.7 & 4.77 & -6.79 & 25.84 & 5.47 & -5.66 & 17.2 \\
\hline 0.01 & 10 & 1 & 3.04 & -8.99 & 14.8 & 4.05 & -7.526 & 22.46 & 3.99 & -7.169 & 17.4 \\
\hline 0.01 & 10 & 1.2 & 2.98 & -9.31 & 17.8 & 3.818 & -7.799 & 24.56 & & & $\mathrm{NC}$ \\
\hline 0.01 & 100 & 0.8 & 2.13 & -9.06 & 10.9 & 3.69 & -7.875 & 25.75 & 4.08 & -7.048 & 17.2 \\
\hline 0.01 & 100 & 1 & 2.03 & -10.01 & 15.1 & 3.03 & -8.553 & 22.312 & 2.96 & -8.204 & 17.4 \\
\hline 0.01 & 100 & 1.2 & 1.97 & -10.35 & 18.1 & 2.8 & -8.822 & 25.46 & 2.7 & -8.561 & 18.3 \\
\hline 0.1 & 1 & 0.8 & 4.17 & -6.99 & 5.44 & & & $\mathrm{NC}$ & 5.34 & -5.7 & 14.5 \\
\hline 0.1 & 1 & 1 & 4.04 & -7.25 & 7.15 & 5.501 & -6.08 & 157.21 & 4.87 & -6.22 & 14.6 \\
\hline 0.1 & 1 & 1.2 & 3.97 & -7.44 & 8.96 & 5.16 & -6.409 & 153.8 & 4.66 & -6.46 & 14.9 \\
\hline 0.1 & 10 & 0.8 & 3.07 & -8.24 & 7.33 & 4.59 & -6.97 & 48.4 & 3.87 & -7.289 & 15.6 \\
\hline 0.1 & 10 & 1 & 2.96 & -8.59 & 10.96 & 4.058 & -7.517 & 31.2 & 3.56 & -7.744 & 17.4 \\
\hline 0.1 & 10 & 1.2 & 2.89 & -8.88 & 14.5 & 3.85 & -7.74 & 22.2 & 3.41 & -8.081 & 19.7 \\
\hline 0.1 & 100 & 0.8 & & & $\mathrm{NC}$ & 3.52 & -8.047 & 47.54 & 2.85 & -8.317 & 15.6 \\
\hline 0.1 & 100 & 1 & & & NC & 4.06 & -7.51 & 49.84 & 2.54 & -8.772 & 17.6 \\
\hline 0.1 & 100 & 1.2 & & & $\mathrm{NC}$ & 3.23 & -8.34 & 39.38 & 2.403 & -9.11 & 20 \\
\hline
\end{tabular}

$\mathrm{IS}=$ ionic strength in $\mathrm{mol} / \mathrm{lit}, \mathrm{Ns}=$ site density in sites per $\mathrm{nm}, \mathrm{C}=$ capacitance, $\mathrm{NC}=$ no convergence in numeric scheme 
Table 4.18: Effect of coatings on sensitivity of CCM to variation in total site density, ionic strength and capacitance for montmorillonite titration data.

\begin{tabular}{|c|c|c|c|c|c|c|c|c|c|c|c|}
\hline \multicolumn{6}{|c|}{ Montmorillonite (0\%) } & \multicolumn{3}{|c|}{ Montmorillonite (4\% Fe) } & \multicolumn{3}{|c|}{ Montmorillonite ( 4\% Al) } \\
\hline IS & $\mathbf{N}_{\mathbf{S}}$ & C & $\log K^{+}$ & $\log K^{-}$ & $\mathbf{F}$ & $\log \mathrm{K}^{+}$ & $\log K^{-}$ & $\mathbf{F}$ & $\log K^{+}$ & $\log K^{-}$ & $\mathbf{F}$ \\
\hline 0.001 & 1 & 0.8 & 4.12 & -10.35 & 76.7 & 3.356 & -8.606 & 64.51 & 4.86 & -9.08 & 110.2 \\
\hline 0.001 & 1 & 1 & 4.05 & -10.4 & 90.6 & 3.307 & -8.76 & 79.984 & 4.75 & -9.37 & 138.4 \\
\hline 0.001 & 1 & 1.2 & 3.99 & -10.54 & 102.3 & 3.27 & -8.89 & 920.917 & 4.69 & -9.6 & 156.3 \\
\hline 0.001 & 10 & 0.8 & 3.07 & -11.43 & 86.1 & 2.32 & -9.717 & 750.49 & 3.78 & -10.29 & 132.1 \\
\hline 0.001 & 10 & 1 & 2.98 & -11.54 & 103.4 & 2.27 & -9.904 & 925.79 & 3.68 & -10.64 & 159.8 \\
\hline 0.001 & 10 & 1.2 & 2.9 & -11.63 & 119.5 & 2.23 & -10.05 & 105.7 & 3.63 & -10.85 & 175.3 \\
\hline 0.001 & 100 & 0.8 & 2.07 & -12.44 & 87 & 1.32 & -10.72 & 759.9 & 2.78 & -11.31 & 134 \\
\hline 0.001 & 100 & 1 & 1.98 & -12.55 & 105.1 & 1.26 & -10.91 & 936.97 & 2.68 & -11.66 & 161.2 \\
\hline 0.001 & 100 & 1.2 & 1.89 & -12.64 & 121.1 & 1.23 & -11.06 & 106.9 & 2.62 & -11.87 & 176.8 \\
\hline 0.01 & 1 & 0.8 & 3.46 & -9.99 & 84.2 & 3.94 & -9.525 & 776.14 & 3.98 & -8.42 & 203.3 \\
\hline 0.01 & 1 & 1 & 3.42 & -10.14 & 93.1 & 3.88 & -9.72 & 926.6 & 3.9 & -8.86 & 236.9 \\
\hline 0.01 & 1 & 1.2 & 3.39 & -10.26 & 100.5 & 3.84 & -9.87 & 1048 & 3.86 & -9.2 & 252 \\
\hline 0.01 & 10 & 0.8 & 2.44 & -11.09 & 90.2 & 2.903 & -10.67 & 88.42 & 2.91 & -9.79 & 235.2 \\
\hline 0.01 & 10 & 1 & 2.39 & -11.27 & 101 & 2.83 & -10.9 & 106.5 & 2.866 & -10.31 & 257.3 \\
\hline 0.01 & 10 & 1.2 & 2.35 & -11.39 & 109.6 & 2.788 & -11.08 & 120.9 & 2.85 & -10.6 & 261.9 \\
\hline 0.01 & 100 & 0.8 & 1.44 & -12.1 & 90.7 & 1.9 & -11.68 & 893.79 & 1.9 & -10.82 & 236.9 \\
\hline 0.01 & 100 & 1 & 1.39 & -12.28 & 101.7 & 1.83 & -11.92 & 107.7 & 1.86 & -11.34 & 258.1 \\
\hline 0.01 & 100 & 1.2 & 1.359 & -12.4 & 110.4 & 1.78 & -12.103 & 122.3 & 1.84 & -11.65 & 262 \\
\hline 0.1 & 1 & 0.8 & 2.88 & -9.54 & 94.6 & 4.55 & -9.743 & 47.39 & 3.18 & -7.75 & 251.3 \\
\hline 0.1 & 1 & 1 & 2.86 & -9.727 & 101 & 4.47 & -9.882 & 60.622 & 3.1 & -8.38 & 298.3 \\
\hline 0.1 & 1 & 1.2 & 2.83 & -9.86 & 105.1 & 4.41 & -9.983 & 72.563 & 3.08 & -8.81 & 309.8 \\
\hline 0.1 & 10 & 0.8 & 1.86 & -10.67 & 99.2 & 3.49 & -10.838 & 56.495 & 2.1 & -9.33 & 298.6 \\
\hline 0.1 & 10 & 1 & 1.84 & -10.86 & 105.6 & 3.41 & -10.99 & 74.3268 & 2.08 & -9.92 & 314.6 \\
\hline 0.1 & 10 & 1.2 & 1.81 & -10.99 & 110.2 & 3.33 & -11.1 & 90.887 & 2.09 & -10.17 & 315.5 \\
\hline 0.1 & 100 & 0.8 & 0.86 & -11.6 & 99.6 & 2.49 & -11.846 & 57.366 & 1.1 & -10.38 & 300.8 \\
\hline 0.1 & 100 & 1 & 0.83 & -11.8 & 106 & 2.4 & -12 & 75.616 & 1.08 & -10.95 & 314.8 \\
\hline 0.1 & 100 & 1.2 & 0.82 & -12 & 110.6 & 2.33 & -12.11 & 92.593 & 1.09 & -11.19 & 314.5 \\
\hline
\end{tabular}

$\mathrm{IS}=$ ionic strength in $\mathrm{mol} / \mathrm{lit}, \mathrm{Ns}=$ site density in sites per n⿳⺈, $\mathrm{C}=$ capacitance, $\mathrm{NC}=$ no convergence in numeric sche 
Table 4.19: Representative sensitivity of TLM to variation in total site density and ionic strength using pure clay titration data.

\begin{tabular}{|c|c|c|c|c|c|c|c|c|c|c|c|c|}
\hline & & & Attapulgite. & & & Illite & & Kaolinite & & & Montmorillon & \\
\hline IS & $\mathbf{N}_{\mathbf{S}}$ & $\mathbf{C}$ & $\log K_{A N} \log K_{C A}$ & $\mathbf{F}$ & $\log K_{A N}$ & $\log K_{C A}$ & $\mathbf{F}$ & $\log K_{A N}$ & $\log K_{C A}$ & $\mathbf{F}$ & $\log K_{A N} \log K_{C A}$ & $\overline{\mathbf{F}}$ \\
\hline 0.001 & 1 & 0.8 & & $\mathrm{NC}$ & 5.6 & -8.12 & 57.9 & 5.71 & -7.22 & 75.5 & & $\mathrm{NC}$ \\
\hline 0.001 & 1 & 1 & & $\mathrm{NC}$ & 5.53 & -8.4 & 91.8 & 5.59 & -7.6 & 89.1 & & $\mathrm{NC}$ \\
\hline 0.001 & 1 & 1.2 & & $\mathrm{NC}$ & 5.48 & -8.62 & 127.6 & 5.51 & -7.85 & 99.4 & & $\mathrm{NC}$ \\
\hline 0.001 & 10 & 0.8 & & $\mathrm{NC}$ & 4.56 & -9.4 & 81 & 4.63 & -8.5 & 82.3 & & $\mathrm{NC}$ \\
\hline 0.001 & 10 & 1 & & $\mathrm{NC}$ & 4.48 & -9.76 & 137 & 4.5 & -8.87 & 96.9 & & $\mathrm{NC}$ \\
\hline 0.001 & 10 & 1.2 & & $\mathrm{NC}$ & 4.41 & -10 & 196 & 4.39 & -9.1 & 110.17 & & $\mathrm{NC}$ \\
\hline 0.001 & 100 & 0.8 & & $\mathrm{NC}$ & & & $\mathrm{NC}$ & & & $\mathrm{NC}$ & & $\mathrm{NC}$ \\
\hline 0.001 & 100 & 1 & & $\mathrm{NC}$ & & & $\mathrm{NC}$ & & & $\mathrm{NC}$ & & $\mathrm{NC}$ \\
\hline 0.001 & 100 & 1.2 & & $\mathrm{NC}$ & & & $\mathrm{NC}$ & & & $\mathrm{NC}$ & & $\mathrm{NC}$ \\
\hline 0.01 & 1 & 0.8 & & $\mathrm{NC}$ & 5.41 & -7.91 & 118 & 5.45 & -6.68 & 44.3 & & $\mathrm{NC}$ \\
\hline 0.01 & 1 & 1 & & $\mathrm{NC}$ & 5.36 & -8.35 & 138 & 5.37 & -7.08 & 47.3 & & $\mathrm{NC}$ \\
\hline 0.01 & 1 & 1.2 & & $\mathrm{NC}$ & 5.32 & -8.68 & 161 & 5.31 & -7.34 & 49.9 & & $\mathrm{NC}$ \\
\hline 0.01 & 10 & 0.8 & & $\mathrm{NC}$ & 4.38 & -9.48 & 133 & 4.4 & -8.01 & 43.8 & & $\mathrm{NC}$ \\
\hline 0.01 & 10 & 1 & & $\mathrm{NC}$ & 4.32 & -10.13 & 171 & 4.32 & -8.41 & 46.7 & & $\mathrm{NC}$ \\
\hline 0.01 & 10 & 1.2 & & $\mathrm{NC}$ & & & $\mathrm{NC}$ & 4.25 & -8.68 & 51.8 & & $\mathrm{NC}$ \\
\hline 0.01 & 100 & 0.8 & & $\mathrm{NC}$ & & & $\mathrm{NC}$ & & & $\mathrm{NC}$ & & $\mathrm{NC}$ \\
\hline 0.01 & 100 & 1 & & $\mathrm{NC}$ & & & $\mathrm{NC}$ & & & $\mathrm{NC}$ & & $\mathrm{NC}$ \\
\hline 0.01 & 100 & 1.2 & & $\mathrm{NC}$ & & & $\mathrm{NC}$ & & & $\mathrm{NC}$ & & $\mathrm{NC}$ \\
\hline 0.1 & 1 & 0.8 & & $\mathrm{NC}$ & 4.97 & -7.42 & 122 & 5.38 & -6.33 & 30.6 & & $\mathrm{NC}$ \\
\hline 0.1 & 1 & 1 & & $\mathrm{NC}$ & 4.93 & -7.88 & 142 & 5.29 & -6.69 & 27.4 & & $\mathrm{NC}$ \\
\hline 0.1 & 1 & 1.2 & & $\mathrm{NC}$ & 4.9 & -8.18 & 162 & 5.23 & -6.95 & 26.3 & & $\mathrm{NC}$ \\
\hline 0.1 & 10 & 0.8 & & $\mathrm{NC}$ & 3.96 & -8.99 & 148 & 4.33 & -7.64 & 25.6 & & $\mathrm{NC}$ \\
\hline 0.1 & 10 & 1 & & $\mathrm{NC}$ & 3.92 & -9.53 & 185 & 4.25 & -8.05 & 23.7 & & $\mathrm{NC}$ \\
\hline 0.1 & 10 & 1.2 & & $\mathrm{NC}$ & & & $\mathrm{NC}$ & 4.18 & -8.35 & 25.63 & & $\mathrm{NC}$ \\
\hline 0.1 & 100 & 0.8 & & $\mathrm{NC}$ & & & $\mathrm{NC}$ & & & $\mathrm{NC}$ & & $\mathrm{NC}$ \\
\hline 0.1 & 100 & 1 & & $\mathrm{NC}$ & & & $\mathrm{NC}$ & & & $\mathrm{NC}$ & & $\mathrm{NC}$ \\
\hline 0.1 & 100 & 1.2 & & $\mathrm{NC}$ & & & $\mathrm{NC}$ & & & $\mathrm{NC}$ & & $\mathrm{NC}$ \\
\hline
\end{tabular}

$\mathrm{IS}=$ ionic strength in $\mathrm{mol} / \mathrm{lit}, \mathrm{Ns}=$ site density in sites per $\mathrm{nm}^{2}, \mathrm{C}=$ capacitance, $\mathrm{NC}=$ no convergence in numeric scheme 


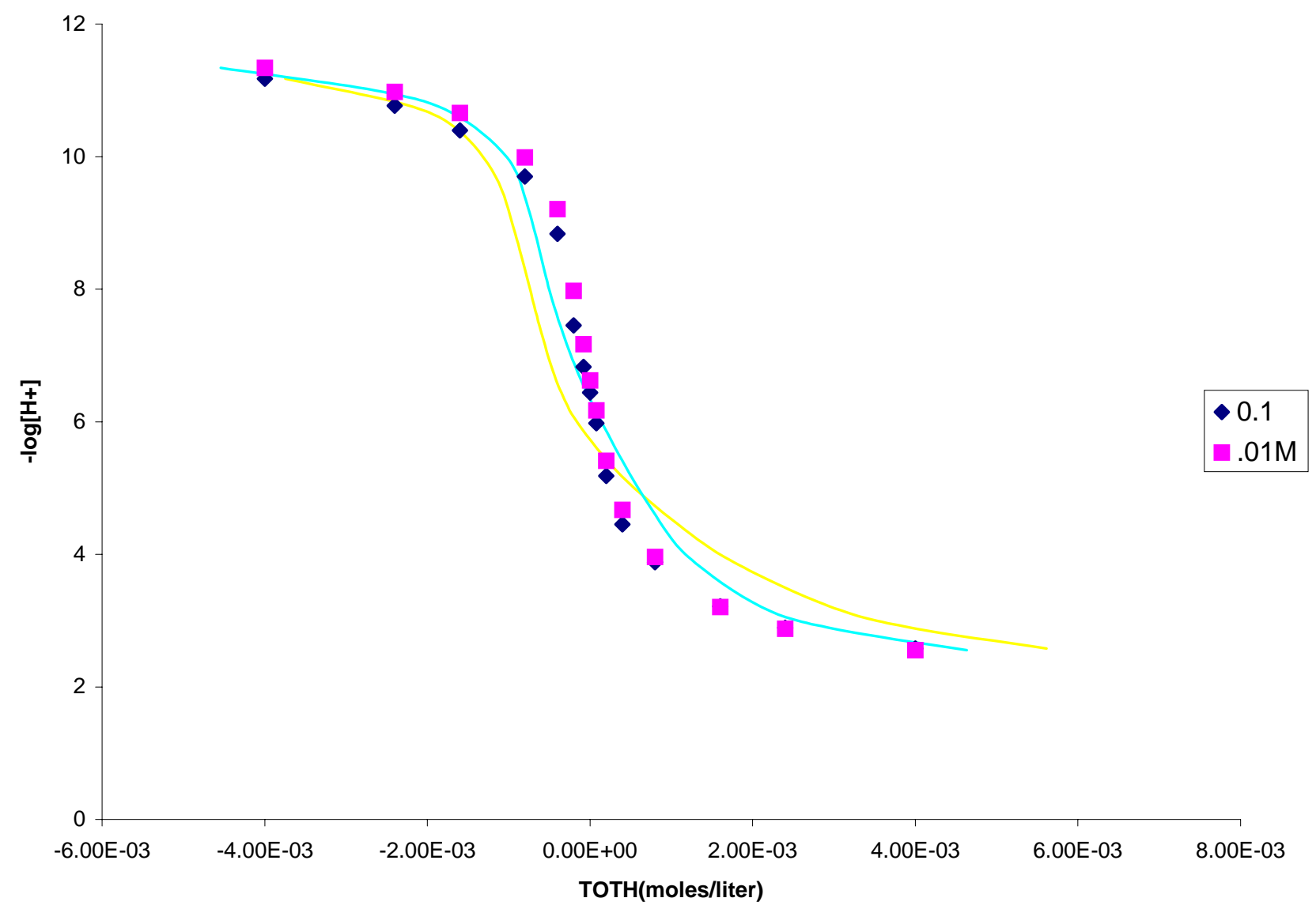

Figure 4.19: Triple layer model fits of titration data of pure attapulgite 


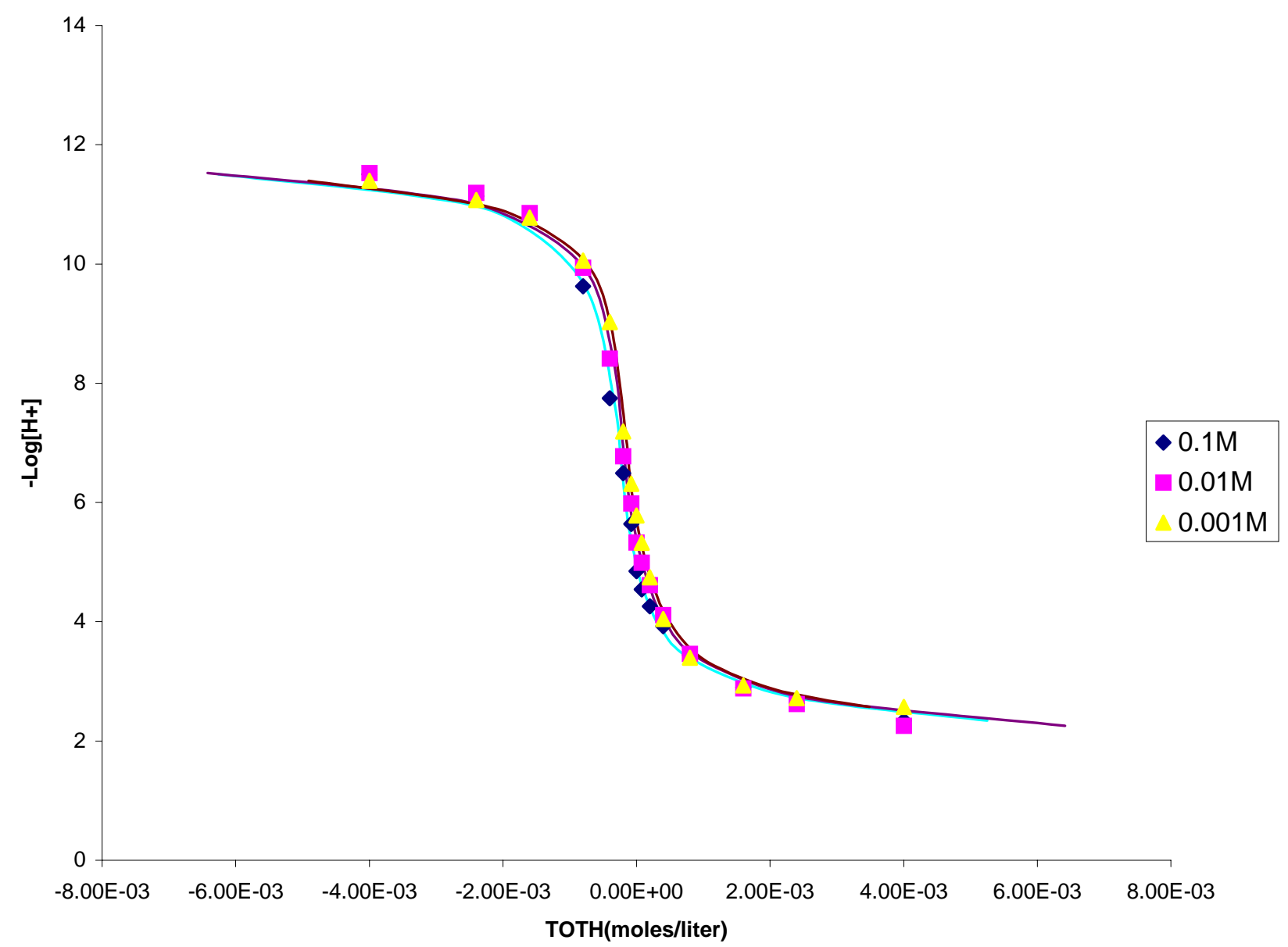

Figure 4.20: Triple-layer model fit of titration data for suspension of pure illite 


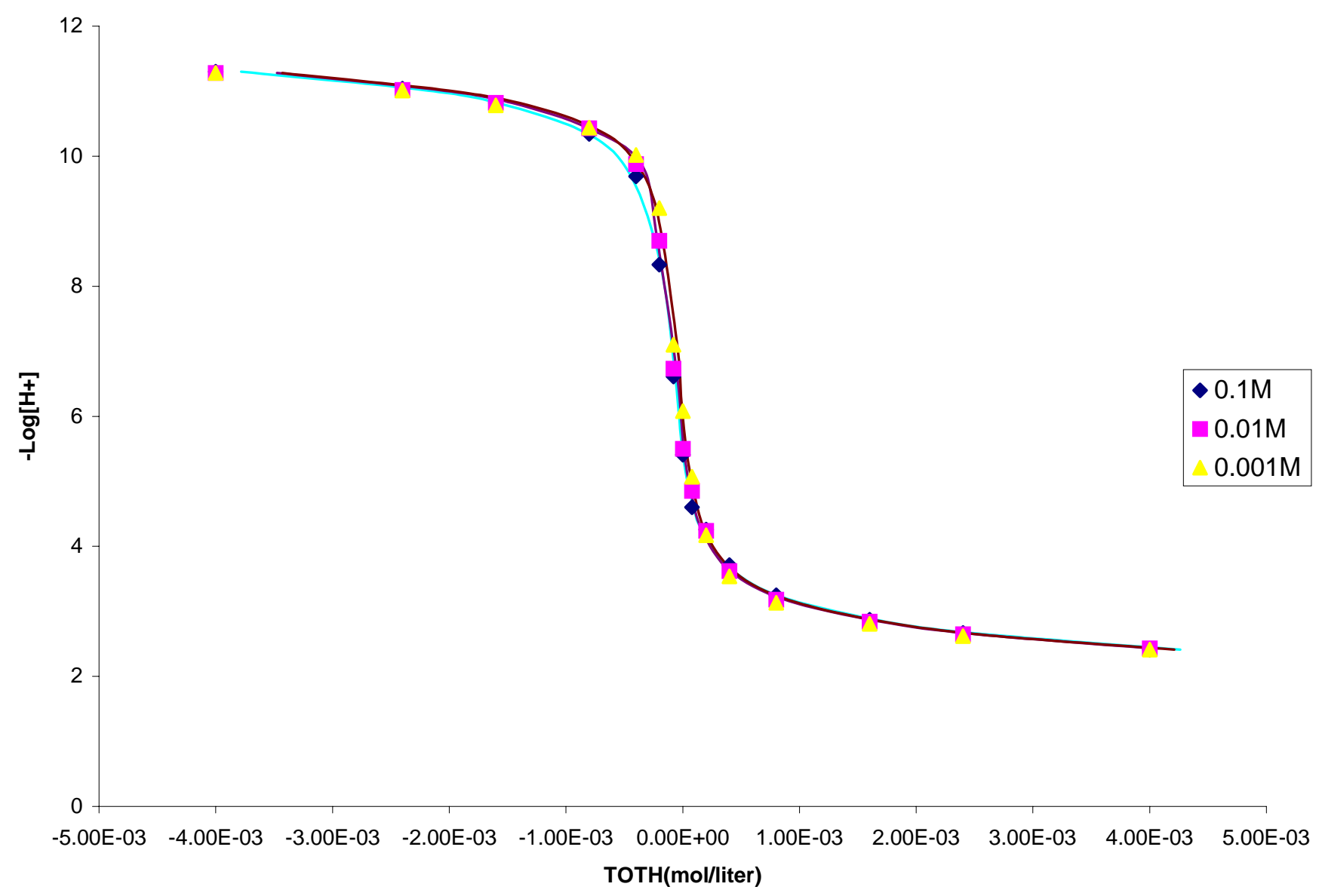

Figure 4.21: Triple-layer model fits of titration data for suspension of pure kaolinite 
( 0.6 to $1.2 \mathrm{~F} / \mathrm{m}^{2}$ )values. Generally better FITEQL fits were obtained for kaolinte as compared to illite. For kaolinite better fits was obtained at $0.1 \mathrm{M}$ ionic strength as compared to 0.01 and $0.001 \mathrm{M}$ ionic strength.

Sensitivity analysis for coated clay minerals: Similar trends of decreasing $\log$ Kan and $\log \mathrm{K}_{\mathrm{CA}}$ with increasing value of Ns were obtained for both iron and aluminum coated clay minerals (Tables 4.20, 4.21, Figures 4.22-4.27). Titration data for Ns (100 sites $/ \mathrm{nm}^{2}$ ) were converged for all $\mathrm{Fe}$ and Al coated clay minerals. Better FITEQL fits were obtained for both iron and aluminum coated illite and kaolinite as compared to attatpulgite and montmorillonite. Generally, better FITEQL fits for Fe and Al coated clay obtained at the ionic strength of $0.1 \mathrm{M}$. Better F value fits were obtained for kaolinite as compared to all other clay minerals.

Effect of Coating on TLM fits: For kaolinite, best fit values were obtained at (4\% Fe) coatings at 0.01 and $0.001 \mathrm{M}$ ionic strength as compare to $0 \%$ and $\mathrm{Al}$ coated kaolinite (Table 4.24). But at ionic strength $0.1 \mathrm{M}$ best fit value was obtained for $0 \%$ coating as compared to $\mathrm{Fe}$ and $\mathrm{Al}$ coated kaolinite. For attapulgite and illite, best fit values were obtained for $4 \%$ coatings as compared to $0 \%$ and $4 \% \mathrm{Al}$ coatings at all the ionic strength values (Tables 4.22, 4.23). For montmorillonite, the values of surface constants never converge.

\subsection{Summary and Conclusions}

For all the models evaluated, increase in the value of total number of sites resulted in a decrease in the FITEQL best fit equilibrium $\log \mathrm{K}$ value. Generally, better F value 
Table 4.20: Representative sensitivity of TLM to variation in total site density and ionic strength using $4 \%$ Fe coated clay titration data.

\begin{tabular}{|c|c|c|c|c|c|c|c|c|c|c|c|c|c|}
\hline & & & \multicolumn{3}{|c|}{ Attapulgite. } & \multicolumn{3}{|c|}{ Illite } & \multicolumn{3}{|c|}{ Kaolinite } & \multicolumn{2}{|c|}{ Montmorillonite. } \\
\hline IS & $\mathbf{N}_{\mathrm{S}}$ & $\mathrm{C}$ & $\log K_{A N}$ & $\log K_{C A}$ & $\mathbf{F}$ & $\log K_{A N}$ & $\log K_{C A}$ & $\mathbf{F}$ & $\log K_{A N}$ & $\log K_{C A}$ & $\mathbf{F}$ & $\log K_{A N} \log K_{C A}$ & $\bar{F}$ \\
\hline 0.001 & 1 & 0.8 & 6.32 & -8.39 & 379 & 5.87 & -6.73 & 37 & 6.4 & -4.67 & 145 & & $\mathrm{NC}$ \\
\hline 0.001 & 1 & 1 & 6.2 & -8.58 & 549 & 5.75 & -7.01 & 56 & 5.93 & -5.17 & 147 & & $\mathrm{NC}$ \\
\hline 0.001 & 1 & 1.2 & 6.11 & -8.72 & 712 & 5.68 & -7.21 & 78 & 5.72 & -5.43 & 150 & & $\mathrm{NC}$ \\
\hline 0.001 & 10 & 0.8 & 5.26 & -9.5 & 499 & 4.78 & -7.96 & 57 & 4.94 & -6.22 & 155 & & $\mathrm{NC}$ \\
\hline 0.001 & 10 & 1 & 5.12 & -9.71 & 740 & 4.67 & -8.32 & 94 & 4.63 & -6.7 & 173 & & $\mathrm{NC}$ \\
\hline 0.001 & 10 & 1.2 & 4.99 & -9.86 & 980 & 4.59 & -8.61 & 135 & 4.48 & -7.06 & 193 & & $\mathrm{NC}$ \\
\hline 0.001 & 100 & 0.8 & & & $\mathrm{NC}$ & & & $\mathrm{NC}$ & & & $\mathrm{NC}$ & & $\mathrm{NC}$ \\
\hline 0.001 & 100 & 1 & & & $\mathrm{NC}$ & & & $\mathrm{NC}$ & & & $\mathrm{NC}$ & & $\mathrm{NC}$ \\
\hline 0.001 & 100 & 1.2 & & & $\mathrm{NC}$ & & & $\mathrm{NC}$ & & & $\mathrm{NC}$ & & $\mathrm{NC}$ \\
\hline 0.01 & 1 & 0.8 & 6.44 & -8.05 & 200 & 5.62 & -5.8 & 41 & & & $\mathrm{NC}$ & & $\mathrm{NC}$ \\
\hline 0.01 & 1 & 1 & 5.35 & -8.327 & 350 & 5.49 & -6.14 & 36 & 7.05 & -4.05 & 193 & & $\mathrm{NC}$ \\
\hline 0.01 & 1 & 1.2 & 6.28 & -8.524 & 503 & 5.41 & -6.33 & 37 & 6.2 & -4.98 & 194 & & $\mathrm{NC}$ \\
\hline 0.01 & 10 & 0.8 & 5.39 & -9.22 & 298 & 4.51 & -7.11 & 52 & 6.55 & -4.85 & 172 & & $\mathrm{NC}$ \\
\hline 0.01 & 10 & 1 & 5.28 & -9.52 & 521 & 4.4 & -7.48 & 69 & 5.06 & -6.11 & 174 & & $\mathrm{NC}$ \\
\hline 0.01 & 10 & 1.2 & 5.19 & -9.75 & 755 & 4.32 & -7.79 & 96 & 4.78 & -6.49 & 180 & & $\mathrm{NC}$ \\
\hline 0.01 & 100 & 0.8 & & & $\mathrm{NC}$ & & & $\mathrm{NC}$ & & & $\mathrm{NC}$ & & $\mathrm{NC}$ \\
\hline 0.01 & 100 & 1 & & & $\mathrm{NC}$ & & & $\mathrm{NC}$ & & & $\mathrm{NC}$ & & $\mathrm{NC}$ \\
\hline 0.01 & 100 & 1.2 & & & $\mathrm{NC}$ & & & $\mathrm{NC}$ & & & $\mathrm{NC}$ & & $\mathrm{NC}$ \\
\hline 0.1 & 1 & 0.8 & 6.27 & -7.64 & 218 & 5.45 & -5.31 & 66 & & & $\mathrm{NC}$ & & $\mathrm{NC}$ \\
\hline 0.1 & 1 & 1 & 6.18 & -7.93 & 361 & 5.27 & -5.61 & 45 & & & $\mathrm{NC}$ & & $\mathrm{NC}$ \\
\hline 0.1 & 1 & 1.2 & 6.12 & -8.14 & 509 & 5.18 & -5.8 & 32 & 5.6 & -6.041 & 27.4 & & $\mathrm{NC}$ \\
\hline 0.1 & 10 & 0.8 & 5.23 & -8.82 & 311 & 4.32 & -6.52 & 38 & & & $\mathrm{NC}$ & & $\mathrm{NC}$ \\
\hline 0.1 & 10 & 1 & 5.13 & -9.14 & 526 & 4.18 & -6.87 & 30 & & & $\mathrm{NC}$ & & $\mathrm{NC}$ \\
\hline 0.1 & 10 & 1.2 & 5.04 & -9.38 & 752 & 4.1 & -7.14 & 42 & 5.35 & -5.81 & 393 & & $\mathrm{NC}$ \\
\hline 0.1 & 100 & 0.8 & & & $\mathrm{NC}$ & & & $\mathrm{NC}$ & & & $\mathrm{NC}$ & & $\mathrm{NC}$ \\
\hline 0.1 & 100 & 1 & & & $\mathrm{NC}$ & & & $\mathrm{NC}$ & & & $\mathrm{NC}$ & & $\mathrm{NC}$ \\
\hline 0.1 & 100 & 1.2 & & & $\mathrm{NC}$ & & & $\mathrm{NC}$ & & & $\mathrm{NC}$ & & $\mathrm{NC}$ \\
\hline
\end{tabular}

$\mathrm{IS}=$ ionic strength in $\mathrm{mol} / \mathrm{lit}, \mathrm{Ns}=$ site density in sites per $\mathrm{nm}, \mathrm{C}=$ capacitance, $\mathrm{NC}=$ no convergence in numeric schem 
Table 4.21: Representative sensitivity of TLM to variation in total site density and ionic strength using $4 \%$ Al coated clay titration data.

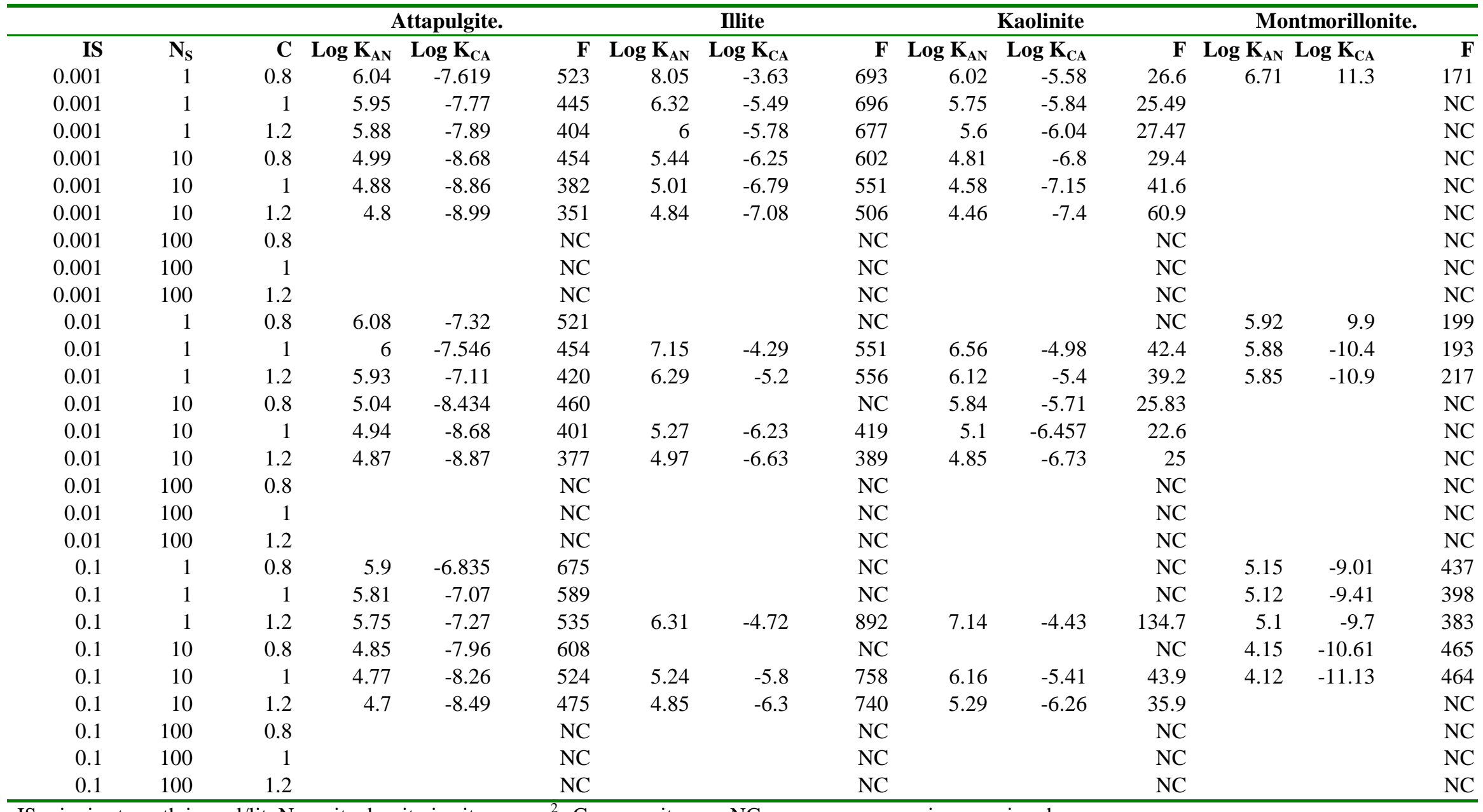

$\mathrm{IS}=$ ionic strength in $\mathrm{mol} / \mathrm{lit}, \mathrm{Ns}=$ site density in sites per $\mathrm{nm}^{2}, \mathrm{C}=$ capacitance, $\mathrm{NC}=$ no convergence in numeric scheme were obtained when the Ns value was between 1 to 10 sites $/ \mathrm{nm}^{2}$.In the case of DL 


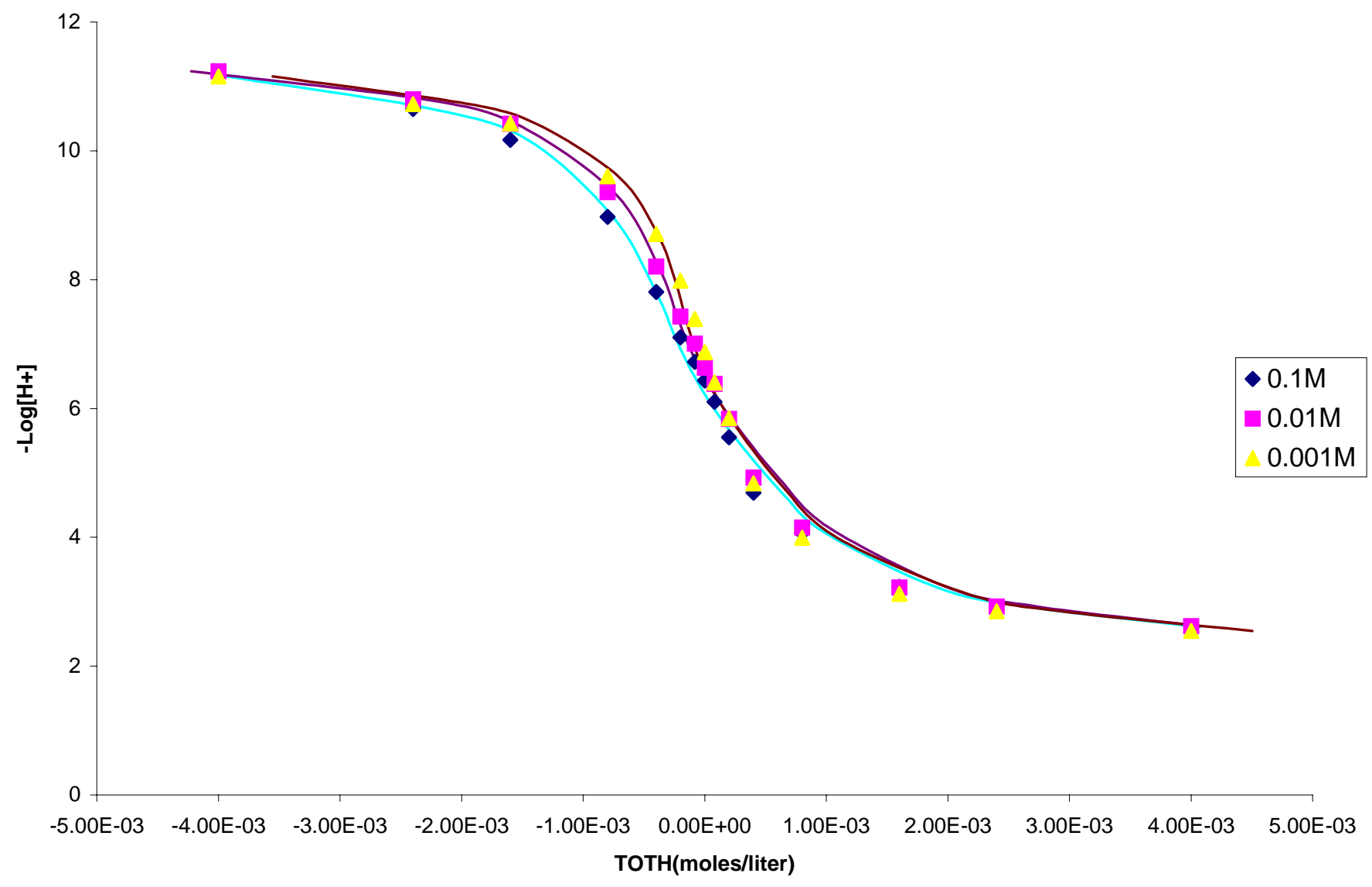

Figure 4.22: Triple-layer model fits of titration data for suspension of $4 \%$ iron coated attapulgite 


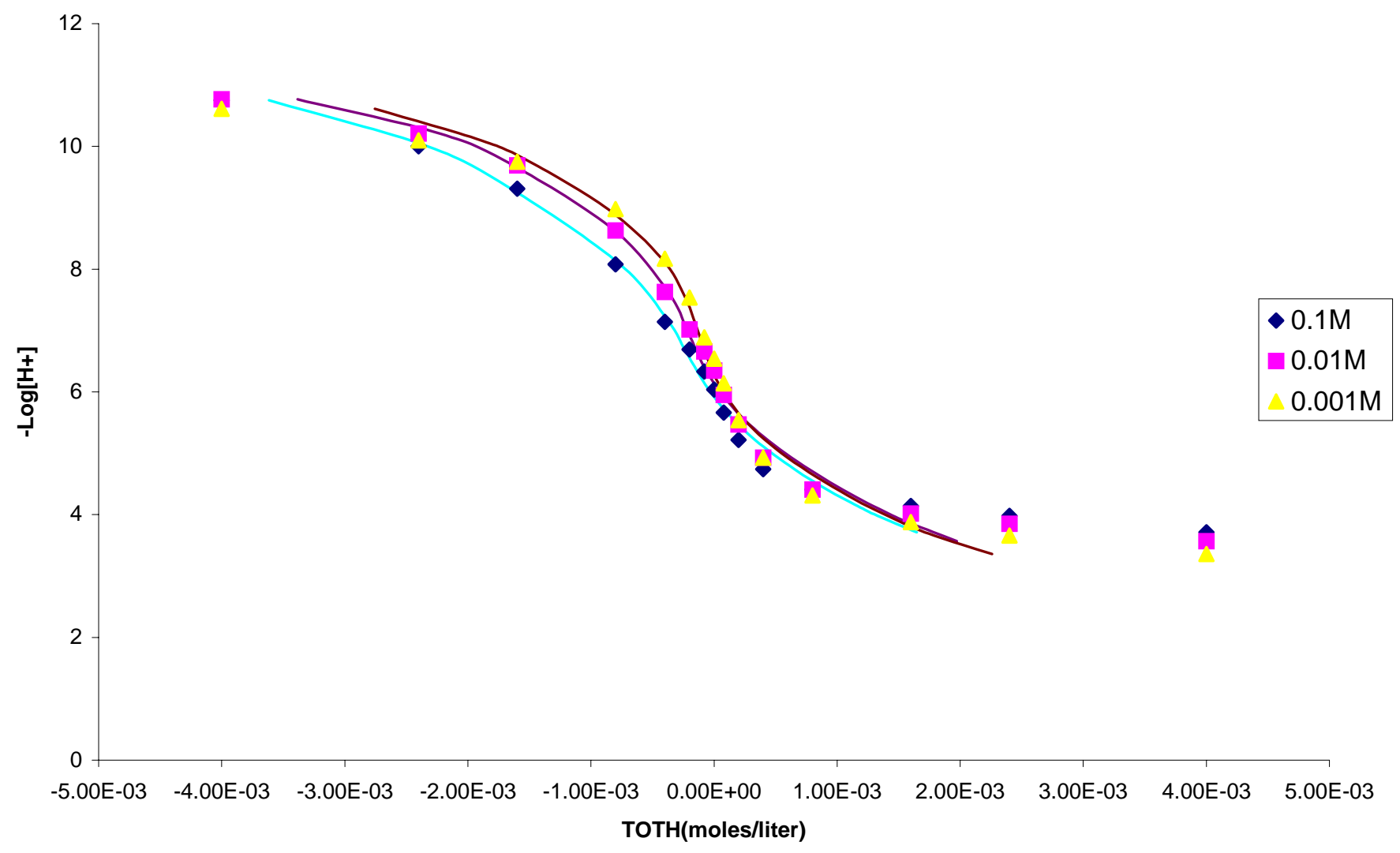

Figure 4.23: Triple-layer model fits of titration data for suspension of $4 \%$ aluminum coated attapulgite 


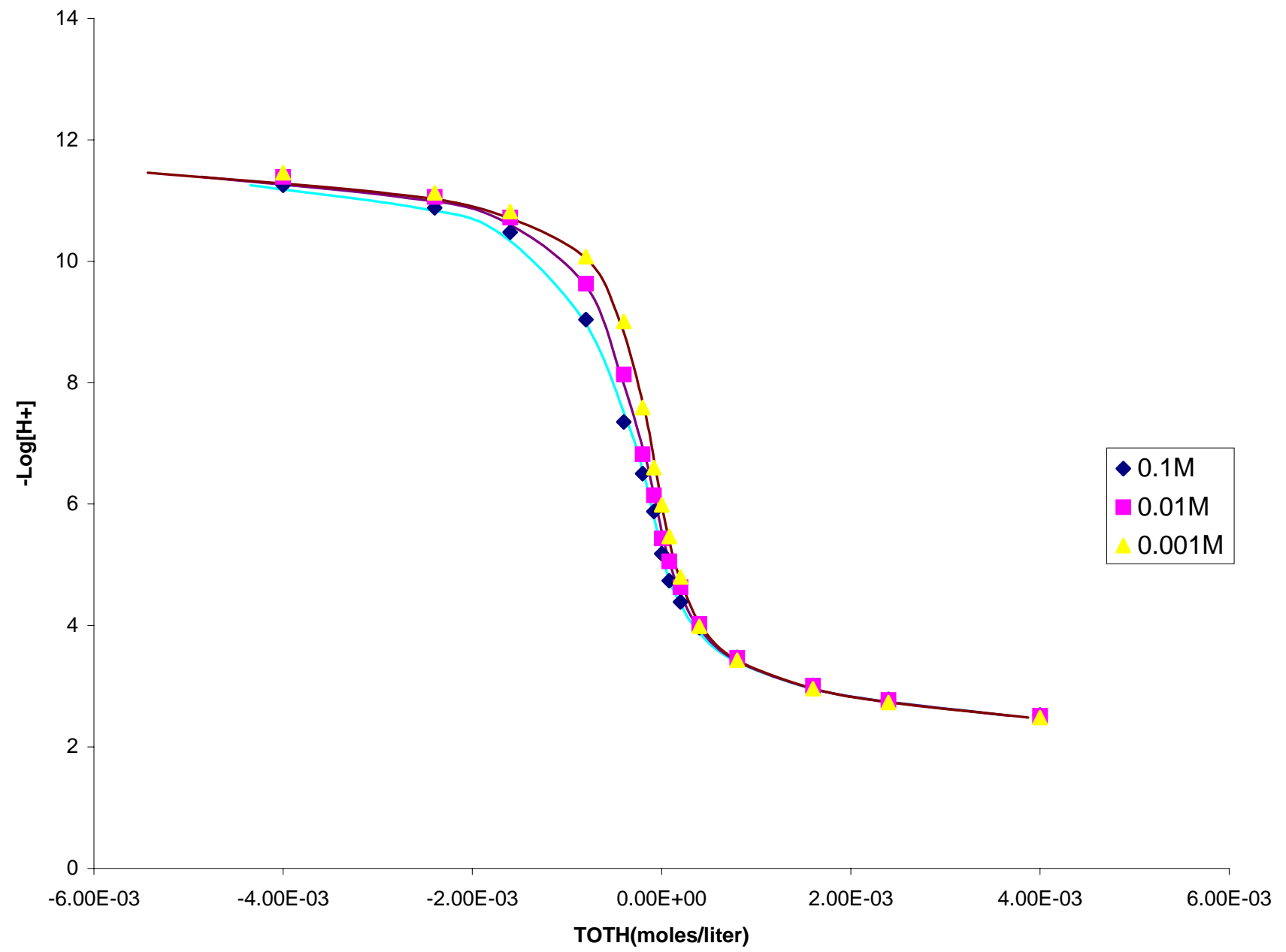

Figure 4.24: Triple layer model fit of titration data for suspension of $4 \%$ iron coated illite 


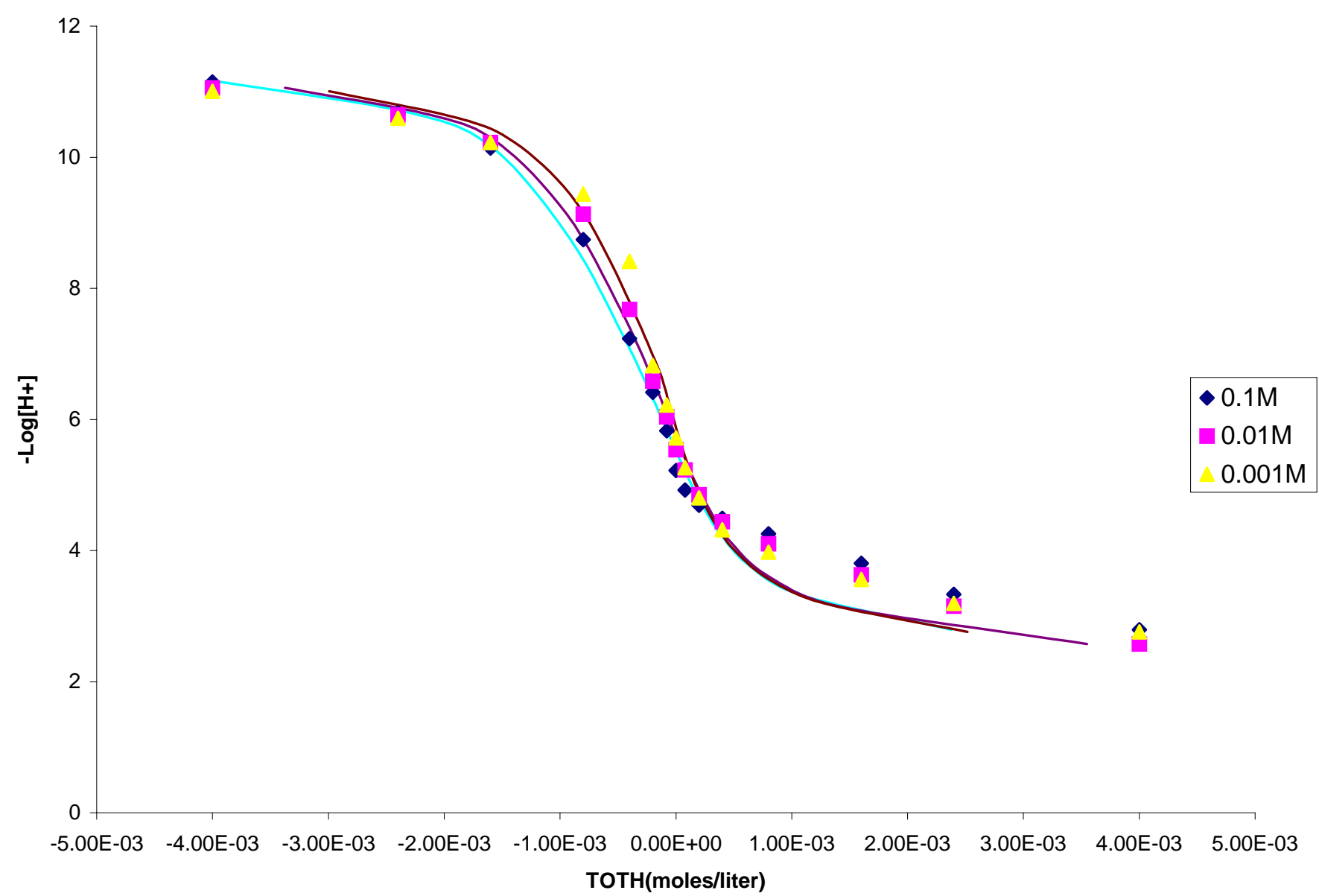

Figure 4.25: Triple-layer model fit of titration data for suspension of $4 \%$ aluminum coated illite 


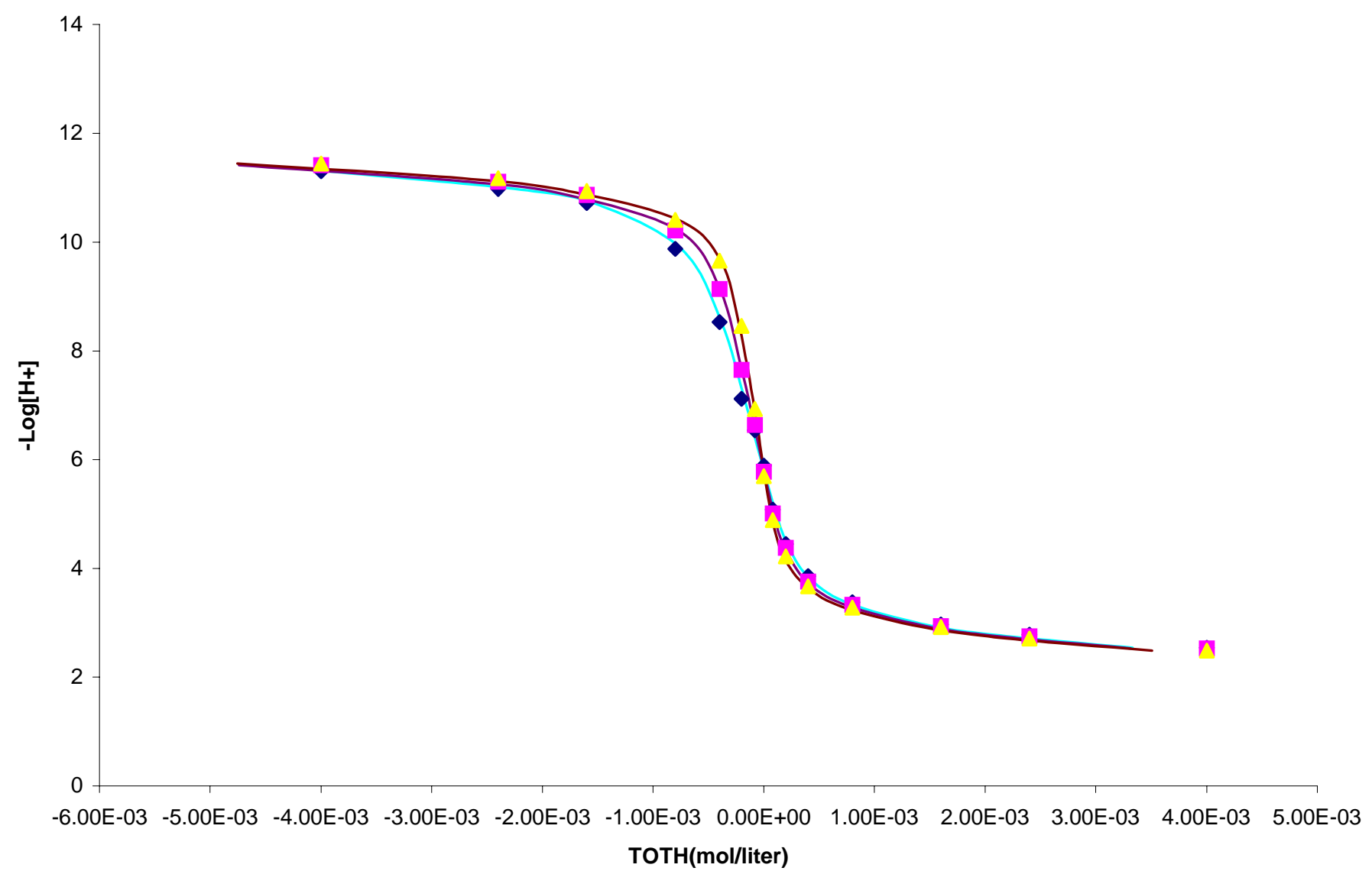

Figure 4.26: Triple-layer model fits of titration data for suspension of $4 \%$ iron coated kaolinite 


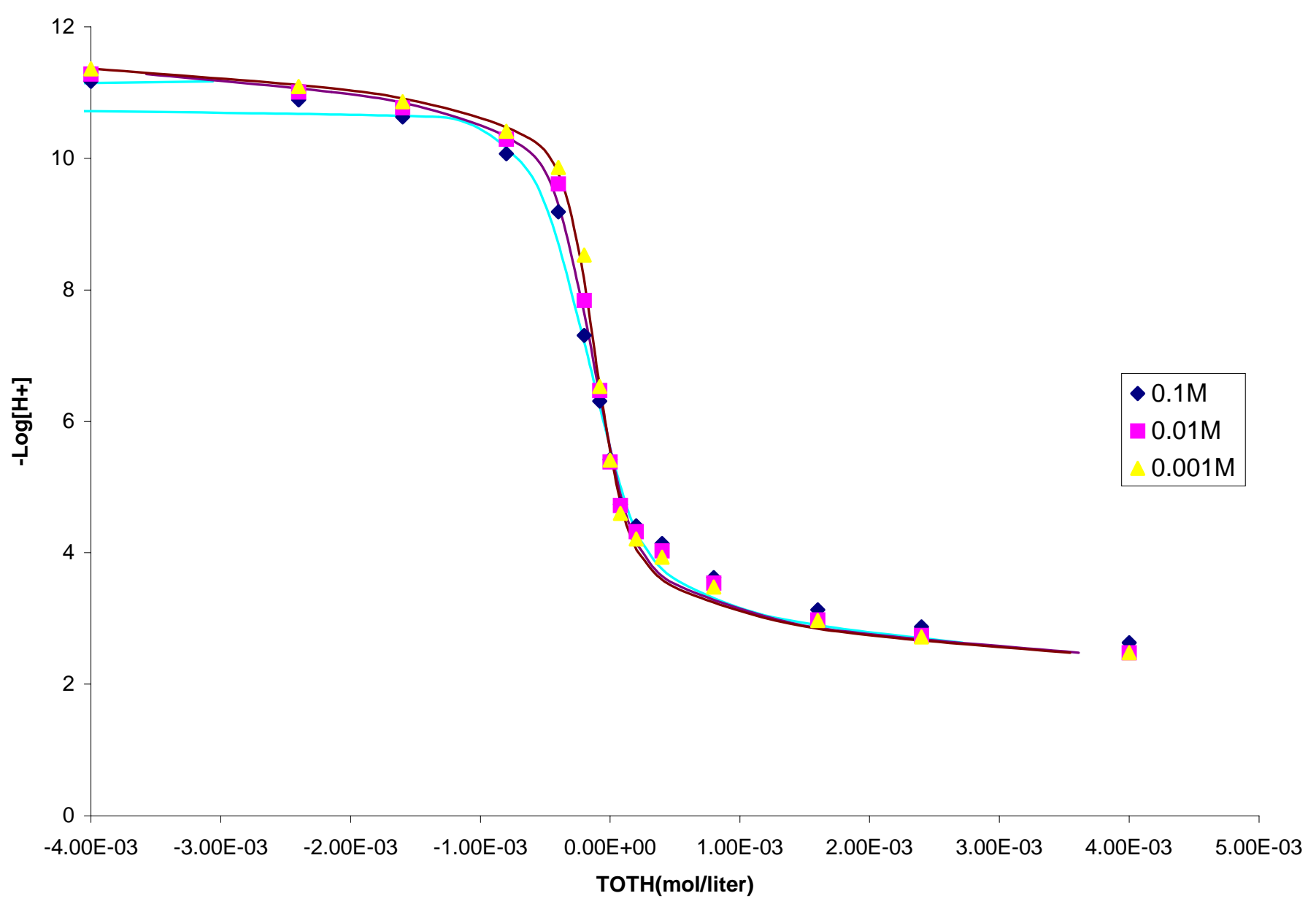

Figure 4.27:Triple layer model fits of titration data for suspensions of $4 \%$ aluminum coated kaolinite 
Table 4.22: Effect of different coatings on the sensitivity of TLM for attapulgite

\begin{tabular}{|c|c|c|c|c|c|c|c|c|c|c|}
\hline \multirow[b]{2}{*}{ IS } & \multirow[b]{2}{*}{$\mathbf{N}_{\mathrm{S}}$} & \multicolumn{3}{|c|}{$0 \%$} & \multicolumn{3}{|c|}{$4 \% \mathrm{Fe}$} & \multicolumn{3}{|c|}{$4 \% \mathrm{Al}$} \\
\hline & & $\mathbf{C}$ & $\log K_{A N} \log K_{C A}$ & $\mathbf{F}$ & $\log K_{A N}$ & $\log K_{C A}$ & $\mathbf{F}$ & $\log K_{A N}$ & $\log K_{C A}$ & $\mathbf{F}$ \\
\hline 0.001 & 1 & 0.8 & & $\mathrm{NC}$ & 6.32 & -8.39 & 379 & 6.04 & -7.619 & 523 \\
\hline 0.001 & 1 & 1 & & $\mathrm{NC}$ & 6.2 & -8.58 & 549 & 5.95 & -7.77 & 445 \\
\hline 0.001 & 1 & 1.2 & & $\mathrm{NC}$ & 6.11 & -8.72 & 712 & 5.88 & -7.89 & 404 \\
\hline 0.001 & 10 & 0.8 & & $\mathrm{NC}$ & 5.26 & -9.5 & 499 & 4.99 & -8.68 & 454 \\
\hline 0.001 & 10 & 1 & & $\mathrm{NC}$ & 5.12 & -9.71 & 740 & 4.88 & -8.86 & 382 \\
\hline 0.001 & 10 & 1.2 & & $\mathrm{NC}$ & 4.99 & -9.86 & 980 & 4.8 & -8.99 & 351 \\
\hline 0.001 & 100 & 0.8 & & $\mathrm{NC}$ & & & $\mathrm{NC}$ & & & $\mathrm{NC}$ \\
\hline 0.001 & 100 & 1 & & $\mathrm{NC}$ & & & $\mathrm{NC}$ & & & $\mathrm{NC}$ \\
\hline 0.001 & 100 & 1.2 & & $\mathrm{NC}$ & & & $\mathrm{NC}$ & & & $\mathrm{NC}$ \\
\hline 0.01 & 1 & 0.8 & & $\mathrm{NC}$ & 6.44 & -8.05 & 200 & 6.08 & -7.32 & 521 \\
\hline 0.01 & 1 & 1 & & $\mathrm{NC}$ & 5.35 & -8.327 & 350 & 6 & -7.546 & 454 \\
\hline 0.01 & 1 & 1.2 & & $\mathrm{NC}$ & 6.28 & -8.524 & 503 & 5.93 & -7.11 & 420 \\
\hline 0.01 & 10 & 0.8 & & $\mathrm{NC}$ & 5.39 & -9.22 & 298 & 5.04 & -8.434 & 460 \\
\hline 0.01 & 10 & 1 & & $\mathrm{NC}$ & 5.28 & -9.52 & 521 & 4.94 & -8.68 & 401 \\
\hline 0.01 & 10 & 1.2 & & $\mathrm{NC}$ & 5.19 & -9.75 & 755 & 4.87 & -8.87 & 377 \\
\hline 0.01 & 100 & 0.8 & & $\mathrm{NC}$ & & & $\mathrm{NC}$ & & & $\mathrm{NC}$ \\
\hline 0.01 & 100 & 1 & & $\mathrm{NC}$ & & & $\mathrm{NC}$ & & & $\mathrm{NC}$ \\
\hline 0.01 & 100 & 1.2 & & $\mathrm{NC}$ & & & $\mathrm{NC}$ & & & $\mathrm{NC}$ \\
\hline 0.1 & 1 & 0.8 & & $\mathrm{NC}$ & 6.27 & -7.64 & 218 & 5.9 & -6.835 & 675 \\
\hline 0.1 & 1 & 1 & & $\mathrm{NC}$ & 6.18 & -7.93 & 361 & 5.81 & -7.07 & 589 \\
\hline 0.1 & 1 & 1.2 & & $\mathrm{NC}$ & 6.12 & -8.14 & 509 & 5.75 & -7.27 & 535 \\
\hline 0.1 & 10 & 0.8 & & $\mathrm{NC}$ & 5.23 & -8.82 & 311 & 4.85 & -7.96 & 608 \\
\hline 0.1 & 10 & 1 & & $\mathrm{NC}$ & 5.13 & -9.14 & 526 & 4.77 & -8.26 & 524 \\
\hline 0.1 & 10 & 1.2 & & $\mathrm{NC}$ & 5.04 & -9.38 & 752 & 4.7 & -8.49 & 475 \\
\hline 0.1 & 100 & 0.8 & & $\mathrm{NC}$ & & & $\mathrm{NC}$ & & & $\mathrm{NC}$ \\
\hline 0.1 & 100 & 1 & & $\mathrm{NC}$ & & & $\mathrm{NC}$ & & & $\mathrm{NC}$ \\
\hline 0.1 & 100 & 1.2 & & $\mathrm{NC}$ & & & $\mathrm{NC}$ & & & $\mathrm{NC}$ \\
\hline
\end{tabular}

$\mathrm{IS}=$ ionic strength in $\mathrm{mol} / \mathrm{lit}, \mathrm{Ns}=$ site density in sites per $\mathrm{nm}, \mathrm{C}=$ capacitance, $\mathrm{NC}=$ no convergence in numeric scheme 
Table 4.23: Effect of different coatings on the sensitivity of TLM for illite

\begin{tabular}{|c|c|c|c|c|c|c|c|c|c|c|c|}
\hline & & \multicolumn{4}{|c|}{$0 \%$} & \multicolumn{3}{|c|}{$4 \% \mathrm{Fe}$} & \multicolumn{3}{|c|}{$4 \% \mathrm{Al}$} \\
\hline IS & $\mathbf{N}_{\mathbf{S}}$ & $\mathbf{C}$ & $\log K_{A N}$ & $\log K_{C A}$ & $\mathbf{F}$ & $\log K_{A N}$ & $\log K_{C A}$ & $\mathbf{F}$ & $\log K_{A N}$ & $\log K_{C A}$ & $\mathbf{F}$ \\
\hline 0.001 & 1 & 0.8 & 5.6 & -8.12 & 57.9 & 5.87 & -6.73 & 37 & 8.05 & -3.63 & 693 \\
\hline 0.001 & 1 & 1 & 5.53 & -8.4 & 91.8 & 5.75 & -7.01 & 56 & 6.32 & -5.49 & 696 \\
\hline 0.001 & 1 & 1.2 & 5.48 & -8.62 & 127.6 & 5.68 & -7.21 & 78 & 6 & -5.78 & 677 \\
\hline 0.001 & 10 & 0.8 & 4.56 & -9.4 & 81 & 4.78 & -7.96 & 57 & 5.44 & -6.25 & 602 \\
\hline 0.001 & 10 & 1 & 4.48 & -9.76 & 137 & 4.67 & -8.32 & 94 & 5.01 & -6.79 & 551 \\
\hline 0.001 & 10 & 1.2 & 4.41 & -10 & 196 & 4.59 & -8.61 & 135 & 4.84 & -7.08 & 506 \\
\hline 0.001 & 100 & 0.8 & & & $\mathrm{NC}$ & & & $\mathrm{NC}$ & & & $\mathrm{NC}$ \\
\hline 0.001 & 100 & 1 & & & $\mathrm{NC}$ & & & $\mathrm{NC}$ & & & $\mathrm{NC}$ \\
\hline 0.001 & 100 & 1.2 & & & $\mathrm{NC}$ & & & $\mathrm{NC}$ & & & $\mathrm{NC}$ \\
\hline 0.01 & 1 & 0.8 & 5.41 & -7.91 & 118 & 5.62 & -5.8 & 41 & & & $\mathrm{NC}$ \\
\hline 0.01 & 1 & 1 & 5.36 & -8.35 & 138 & 5.49 & -6.14 & 36 & 7.15 & -4.29 & 551 \\
\hline 0.01 & 1 & 1.2 & 5.32 & -8.68 & 161 & 5.41 & -6.33 & 37 & 6.29 & -5.2 & 556 \\
\hline 0.01 & 10 & 0.8 & 4.38 & -9.48 & 133 & 4.51 & -7.11 & 52 & & & $\mathrm{NC}$ \\
\hline 0.01 & 10 & 1 & 4.32 & -10.13 & 171 & 4.4 & -7.48 & 69 & 5.27 & -6.23 & 419 \\
\hline 0.01 & 10 & 1.2 & & & $\mathrm{NC}$ & 4.32 & -7.79 & 96 & 4.97 & -6.63 & 389 \\
\hline 0.01 & 100 & 0.8 & & & $\mathrm{NC}$ & & & $\mathrm{NC}$ & & & $\mathrm{NC}$ \\
\hline 0.01 & 100 & 1 & & & $\mathrm{NC}$ & & & $\mathrm{NC}$ & & & $\mathrm{NC}$ \\
\hline 0.01 & 100 & 1.2 & & & $\mathrm{NC}$ & & & $\mathrm{NC}$ & & & $\mathrm{NC}$ \\
\hline 0.1 & 1 & 0.8 & 4.97 & -7.42 & 122 & 5.45 & -5.31 & 66 & & & $\mathrm{NC}$ \\
\hline 0.1 & 1 & 1 & 4.93 & -7.88 & 142 & 5.27 & -5.61 & 45 & & & $\mathrm{NC}$ \\
\hline 0.1 & 1 & 1.2 & 4.9 & -8.18 & 162 & 5.18 & -5.8 & 32 & 6.31 & -4.72 & 892 \\
\hline 0.1 & 10 & 0.8 & 3.96 & -8.99 & 148 & 4.32 & -6.52 & 38 & & & $\mathrm{NC}$ \\
\hline 0.1 & 10 & 1 & 3.92 & -9.53 & 185 & 4.18 & -6.87 & 30 & 5.24 & -5.8 & 758 \\
\hline 0.1 & 10 & 1.2 & & & $\mathrm{NC}$ & 4.1 & -7.14 & 42 & 4.85 & -6.3 & 740 \\
\hline 0.1 & 100 & 0.8 & & & $\mathrm{NC}$ & & & $\mathrm{NC}$ & & & $\mathrm{NC}$ \\
\hline 0.1 & 100 & 1 & & & $\mathrm{NC}$ & & & $\mathrm{NC}$ & & & $\mathrm{NC}$ \\
\hline 0.1 & 100 & 1.2 & & & $\mathrm{NC}$ & & & $\mathrm{NC}$ & & & $\mathrm{NC}$ \\
\hline
\end{tabular}

$\mathrm{IS}=$ ionic strength in $\mathrm{mol} / \mathrm{lit}, \mathrm{Ns}=$ site density in sites per $\mathrm{nm}, \mathrm{C}=$ capacitance, $\mathrm{NC}=$ no convergence in numeric scheme 
Table 4.24: Effect of different coatings on the sensitivity of TLM for kaolinite

\begin{tabular}{|c|c|c|c|c|c|c|c|c|c|c|c|}
\hline \multirow[b]{2}{*}{ IS } & \multirow[b]{2}{*}{$\mathbf{N}_{\mathbf{S}}$} & \multicolumn{3}{|r|}{$0 \%$} & \multicolumn{3}{|r|}{$4 \% \mathrm{Fe}$} & \multicolumn{4}{|c|}{$4 \% \mathrm{Al}$} \\
\hline & & $\mathbf{C}$ & $\log K_{A N}$ & $\log K_{C A}$ & & $K_{\mathrm{AN}}$ & $\log K_{C A}$ & $\mathbf{F}$ & $\log K_{A N}$ & $\log K_{C A}$ & $\mathbf{F}$ \\
\hline 0.001 & 1 & 0.8 & 5.71 & -7.22 & 75.5 & 6.4 & -4.67 & 145 & 6.02 & -5.58 & 26.6 \\
\hline 0.001 & 1 & 1 & 5.59 & -7.6 & 89.1 & 5.93 & -5.17 & 147 & 5.75 & -5.84 & 25.49 \\
\hline 0.001 & 1 & 1.2 & 5.51 & -7.85 & 99.4 & 5.72 & -5.43 & 150 & 5.6 & -6.04 & 27.47 \\
\hline 0.001 & 10 & 0.8 & 4.63 & -8.5 & 82.3 & 4.94 & -6.22 & 155 & 4.81 & -6.8 & 29.4 \\
\hline 0.001 & 10 & 1 & 4.5 & -8.87 & 96.9 & 4.63 & -6.7 & 173 & 4.58 & -7.15 & 41.6 \\
\hline 0.001 & 10 & 1.2 & 4.39 & -9.1 & 110.17 & 4.48 & -7.06 & 193 & 4.46 & -7.4 & 60.9 \\
\hline 0.001 & 100 & 0.8 & & & $\mathrm{NC}$ & & & $\mathrm{NC}$ & & & $\mathrm{NC}$ \\
\hline 0.001 & 100 & 1 & & & $\mathrm{NC}$ & & & $\mathrm{NC}$ & & & $\mathrm{NC}$ \\
\hline 0.001 & 100 & 1.2 & & & $\mathrm{NC}$ & & & $\mathrm{NC}$ & & & $\mathrm{NC}$ \\
\hline 0.01 & 1 & 0.8 & 5.45 & -6.68 & 44.3 & & & $\mathrm{NC}$ & & & $\mathrm{NC}$ \\
\hline 0.01 & 1 & 1 & 5.37 & -7.08 & 47.3 & 7.05 & -4.05 & 193 & 6.56 & -4.98 & 42.4 \\
\hline 0.01 & 1 & 1.2 & 5.31 & -7.34 & 49.9 & 6.2 & -4.98 & 194 & 6.12 & -5.4 & 39.2 \\
\hline 0.01 & 10 & 0.8 & 4.4 & -8.01 & 43.8 & 6.55 & -4.85 & 172 & 5.84 & -5.71 & 25.83 \\
\hline 0.01 & 10 & 1 & 4.32 & -8.41 & 46.7 & 5.06 & -6.11 & 174 & 5.1 & -6.457 & 22.6 \\
\hline 0.01 & 10 & 1.2 & 4.25 & -8.68 & 51.8 & 4.78 & -6.49 & 180 & 4.85 & -6.73 & 25 \\
\hline 0.01 & 100 & 0.8 & & & $\mathrm{NC}$ & & & $\mathrm{NC}$ & & & $\mathrm{NC}$ \\
\hline 0.01 & 100 & 1 & & & $\mathrm{NC}$ & & & $\mathrm{NC}$ & & & $\mathrm{NC}$ \\
\hline 0.01 & 100 & 1.2 & & & $\mathrm{NC}$ & & & $\mathrm{NC}$ & & & $\mathrm{NC}$ \\
\hline 0.1 & 1 & 0.8 & 5.38 & -6.33 & 30.6 & & & $\mathrm{NC}$ & & & $\mathrm{NC}$ \\
\hline 0.1 & 1 & 1 & 5.29 & -6.69 & 27.4 & & & $\mathrm{NC}$ & & & $\mathrm{NC}$ \\
\hline 0.1 & 1 & 1.2 & 5.23 & -6.95 & 26.3 & 5.6 & -6.041 & 27.4 & 7.14 & -4.43 & 134.7 \\
\hline 0.1 & 10 & 0.8 & 4.33 & -7.64 & 25.6 & & $\mathrm{NC}$ & & & & $\mathrm{NC}$ \\
\hline 0.1 & 10 & 1 & 4.25 & -8.05 & 23.7 & & $\mathrm{NC}$ & & 6.16 & -5.41 & 43.9 \\
\hline 0.1 & 10 & 1.2 & 4.18 & -8.35 & 25.63 & 5.35 & -5.81 & 393 & 5.29 & -6.26 & 35.9 \\
\hline 0.1 & 100 & 0.8 & & & $\mathrm{NC}$ & & $\mathrm{NC}$ & & & & $\mathrm{NC}$ \\
\hline 0.1 & 100 & 1 & & & $\mathrm{NC}$ & & $\mathrm{NC}$ & & & & $\mathrm{NC}$ \\
\hline 0.1 & 100 & 1.2 & & & $\mathrm{NC}$ & & $\mathrm{NC}$ & & & & $\mathrm{NC}$ \\
\hline
\end{tabular}

$\mathrm{IS}=$ ionic strength in mol/lit, $\mathrm{Ns}=$ site density in sites per $\mathrm{nm}, \mathrm{C}=$ capacitance, $\mathrm{NC}=$ no convergence in numeric scheme 
Table 4.25: Effect of different coatings on sensitivity of TLM for montmorillonite

\begin{tabular}{|c|c|c|c|c|c|c|c|c|c|c|c|}
\hline & & & & $0 \%$ & & & $\% \mathrm{Fe}$ & & & $4 \% \mathrm{Al}$ & \\
\hline IS & $\mathbf{N}_{\mathrm{S}}$ & $\mathrm{C}$ & $\log K_{A N}$ & $\log K_{C A}$ & $\mathbf{F}$ & $\begin{array}{l}\log \\
K_{\text {AN }}\end{array}$ & $\begin{array}{l}\log \\
\mathbf{K}_{\mathrm{CA}}\end{array}$ & $\mathbf{F}$ & $\begin{array}{l}\log \\
\mathrm{K}_{\mathrm{AN}}\end{array}$ & $\begin{array}{l}\mathbf{L o g} \\
\mathbf{K}_{\mathrm{CA}}\end{array}$ & $\mathbf{F}$ \\
\hline 0.001 & 1 & 0.8 & & & $\mathrm{NC}$ & & & $\mathrm{NC}$ & 6.71 & 11.3 & 171 \\
\hline 0.001 & 1 & 1 & & & $\mathrm{NC}$ & & & $\mathrm{NC}$ & & & $\mathrm{NC}$ \\
\hline 0.001 & 1 & 1.2 & & & $\mathrm{NC}$ & & & $\mathrm{NC}$ & & & $\mathrm{NC}$ \\
\hline 0.001 & 10 & 0.8 & & & $\mathrm{NC}$ & & & $\mathrm{NC}$ & & & $\mathrm{NC}$ \\
\hline 0.001 & 10 & 1 & & & $\mathrm{NC}$ & & & $\mathrm{NC}$ & & & $\mathrm{NC}$ \\
\hline 0.001 & 10 & 1.2 & & & $\mathrm{NC}$ & & & $\mathrm{NC}$ & & & $\mathrm{NC}$ \\
\hline 0.001 & 100 & 0.8 & & & $\mathrm{NC}$ & & & $\mathrm{NC}$ & & & $\mathrm{NC}$ \\
\hline 0.001 & 100 & 1 & & & $\mathrm{NC}$ & & & $\mathrm{NC}$ & & & $\mathrm{NC}$ \\
\hline 0.001 & 100 & 1.2 & & & $\mathrm{NC}$ & & & $\mathrm{NC}$ & & & $\mathrm{NC}$ \\
\hline 0.01 & 1 & 0.8 & & & $\mathrm{NC}$ & & & $\mathrm{NC}$ & 5.92 & 9.9 & 199 \\
\hline 0.01 & 1 & 1 & & & $\mathrm{NC}$ & & & $\mathrm{NC}$ & 5.88 & -10.4 & 193 \\
\hline 0.01 & 1 & 1.2 & & & $\mathrm{NC}$ & & & $\mathrm{NC}$ & 5.85 & -10.9 & 217 \\
\hline 0.01 & 10 & 0.8 & & & $\mathrm{NC}$ & & & $\mathrm{NC}$ & & & $\mathrm{NC}$ \\
\hline 0.01 & 10 & 1 & & & $\mathrm{NC}$ & & & $\mathrm{NC}$ & & & $\mathrm{NC}$ \\
\hline 0.01 & 10 & 1.2 & & & $\mathrm{NC}$ & & & $\mathrm{NC}$ & & & $\mathrm{NC}$ \\
\hline 0.01 & 100 & 0.8 & & & $\mathrm{NC}$ & & & $\mathrm{NC}$ & & & $\mathrm{NC}$ \\
\hline 0.01 & 100 & 1 & & & $\mathrm{NC}$ & & & $\mathrm{NC}$ & & & $\mathrm{NC}$ \\
\hline 0.01 & 100 & 1.2 & & & $\mathrm{NC}$ & & & $\mathrm{NC}$ & & & $\mathrm{NC}$ \\
\hline 0.1 & 1 & 0.8 & & & $\mathrm{NC}$ & & & $\mathrm{NC}$ & 5.15 & -9.01 & 437 \\
\hline 0.1 & 1 & 1 & & & $\mathrm{NC}$ & & & $\mathrm{NC}$ & 5.12 & -9.41 & 398 \\
\hline 0.1 & 1 & 1.2 & & & $\mathrm{NC}$ & & & $\mathrm{NC}$ & 5.1 & -9.7 & 383 \\
\hline 0.1 & 10 & 0.8 & & & $\mathrm{NC}$ & & & $\mathrm{NC}$ & 4.15 & -10.61 & 465 \\
\hline 0.1 & 10 & 1 & & & $\mathrm{NC}$ & & & $\mathrm{NC}$ & 4.12 & -11.13 & 464 \\
\hline 0.1 & 10 & 1.2 & & & $\mathrm{NC}$ & & & $\mathrm{NC}$ & & & $\mathrm{NC}$ \\
\hline 0.1 & 100 & 0.8 & & & $\mathrm{NC}$ & & & $\mathrm{NC}$ & & & $\mathrm{NC}$ \\
\hline 0.1 & 100 & 1 & & & $\mathrm{NC}$ & & & $\mathrm{NC}$ & & & $\mathrm{NC}$ \\
\hline 0.1 & 100 & 1.2 & & & $\mathrm{NC}$ & & & $\mathrm{NC}$ & & & $\mathrm{NC}$ \\
\hline
\end{tabular}

$\mathrm{IS}=$ ionic strength in mol/lit, $\mathrm{Ns}=$ site density in sites per n⿳⺈, $\mathrm{C}=$ capacitance, $\mathrm{NC}=$ no convergence in numeric scheme 
iron coated clay minerals showed better F value fits compared to aluminum coated clay minerals. For kaolinite, best fit $\mathrm{F}$ values were obtained for $0 \%$ coatings, but for attapulgite, illite and montmorillonite best fit $\mathrm{F}$ values were obtained at $4 \%$ iron coatings.

In the case of the CCM, generally for all clay minerals the CCM did not converge for $\mathrm{C}_{1}$ below $0.6 \mathrm{~F} / \mathrm{m}^{2}$ and above $1.2 \mathrm{~F} / \mathrm{m}^{2}$. Reasonably good fits were obtained for kaolinite ( $0 \%$ coatings) at all the ionic strengths and Ns values. Better F value fits were obtained for iron coated clay minerals as compared to aluminium coated clay minerals. As similar to DLM, best fit F values were obtained at $0 \%$ coatings for kaolinite and at $4 \% \mathrm{Fe}$ coatings for attapulgite, illite and montmorillonite.

In the case of the TLM, data never converge for pure attapulgite and montmorillonite and better FITEQL fits were obtained for kaolinite as compared to illite. Better FITEQL fits were obtained for both iron and aluminum coated illite and kaolinite as compared to attapulgite and montmorillonite.

These studies focused on strategies for obtaining SCM parameters for complex natural system. As sorption of trace metals on clay and or oxide surface is a key element for better understanding transport of potentially toxic metals in the environment. It remains to be demonstrated that trace metal partitioning can be successfully modeled using the constants determined in the sensitivity analysis described above. 


\section{References}

Balistrieri, L.S., and J.W.Murray.1981.The surface chemistry of goethite $(\alpha-\mathrm{FeOOH})$ in major ion seawater. Am. J. Sci. 281:788-806.

Davis. J.A and J.O.Leckie.1978. Surface ionization and complexation at the oxide surface interface. II Surface properties of amorphous iron oxyhydroxide and adsorption of metal ions. J. Colloid Interface Sci.67:90-107.

Davis. J.A and J.O.Leckie.1980.Surface ionization and complexation at the oxide surface interface-adsorption of anions. J. Colloid Interface Sci.74:32-43.

Davis, J.A., R.O.James and J.O.Leckie.1978. Surface ionization and complexation at oxide/ water interface. I. Computation of electrical double layer properties in simple electrolyte. J. Colloid Interface Sci.63.480-499.

Davis, J.A. and K.F.Hayes.1986.Geochemical process at mineral surfaces. ACS Symposium Series, Vol 323. Amer. Chem. Soc. Washington, DC.

Dzombak, D.A. and F.M.M. Morel.1990.Surface complexation modeling-hydrous ferrous oxide. Wiley, New York.

Goldberg, S., and G.Sposito.1984a. A chemical model of phosphate adsorption by soils. I Reference oxide minerals. Soil Sci. Soc. Am. J. 48.772-778.

Goldberg, S.1985. Chemical modeling of anion competition on goethite using the constant capacitance model. Soil Sci. Soc. Am. J. 50:851-856.

Goldberg, S.1986a. Chemical modeling of arsenate adsorption on aluminum and iron oxide minerals. Soil Sci. Soc. Am. J.50.1154-1157.

Goldberg, S., and R.A.Glaubig.1988. Anion sorption on a calcareous, montmorillonite soil : arsenic. Soil Sci. Soc. Am. J.52.1297-1300.

Goldberg, S.1992.Use of surface complexation models in soil chemical systems. Adv. Agronomy.47.233-329.

Hayes,K.F.1987. Equilibrium, spectroscopic and kinetic studies of ion adsorption at the oxide/aqueous interface. Ph.D. Thesis. Stanford University, Stanford, California.

Hayes, K.F., and J.O.Leckie.1987.Modelling ionic strength effects on cation adsorption at hydrous oxide /solution interface. J. Colloid Interface Sci.115.564-572.

Hayes, K.F., C. Papelis and J.O.Leckie.1988.Modeling ionic strengths effects on anion 
adsorption at hydrous oxide solution interfaces. J. Colloid Interface Sci. 125.717726.

Hayes,K.F., G.Redden., W.Ela and J.O.Leckie.1991.Surface complexation models. An evaluation of model parameter estimation using FITEQL and oxide minerals titration data. J. Colloid. Interface Sci. 142. 448-469.

Hendershot, W.H., L.M.lavkulich.1983.Effect of sesquioxide coatings on the surface charge of standard and soil samples. Soil Sci. Soc. Am. J. 47:1252-1260.

Huang, C.P., and W.Stumn.1973. Specific adsorption of cation on hydrous $\gamma$ $\mathrm{Al}_{2} \mathrm{O}_{3}$. J.Collod Interface Sci.43.409-420.

Israelachvili, J.N.1985. Intermolecular and Surface Forces. Academic, Press. New York.

James,R.O., J.A.Davis and J.O.Leckie.1978. Computer simulation of the conductometric and potentiometric titrations of the surface groups on ionizable latexes. J. Colloid Interface Sci. 65.331-343.

James.R.O., and G.A.Parks.1982.Characterization of aqueous colloids by their electrical double layer and intrinsic surface chemical properties. Surf. Colloid Sci. 12.119216.

Kent, D.B., V.S.Tripathi, N.B. Ball and J.O.Leckie.1986. Progress Report Contract \# SNL-25-1891.Sandia National Laboratory.

Schindler, P.W., and W.Stumn.1987.The surface chemistry of oxide, hydroxide and oxide minerals. In Aquatic Surface Chemistry(W.Stumn ed.) pp 83-110. Wiley(interscience) New York.

Sigg, L.M.1979. Dic Wehselwirkung Von Anionen und Schwachen Sauren mit $\alpha$ FeOOH (Goethit) in Wassriger Losung. Ph.D. Thesis, Swiss Federal Institute of Technology, Zurich.

Stumn, W., R.Kummert and L.Sigg.1980. A ligand exchange model for the adsorption of inorganic and organic ligands at hydroxide interface. Croat. Chem. Acta 53.291312.

Sposito, G., J.C.M, deWit and R.H.Neal.1988.Selenite adsorption on alluvial soils. III Chemical modeling. Soil Sci. Soc. Am. J.52.947-950.

Westall, J.C.1982.FITEQL : A computer program for determination of equilibrium constants for experiment data. Rep 82-01. Department of Chemistry, Oregon State University. Corvallis. 
Westall, J.C and H.Hohl.1980.A comparison of electrostatic model for the oxide/ solution interface. Adv. Colloid Interface Sci 12.265-294.

Westall, J.C.1986.Reactions at the oxide solution interface chemical and electrostatic models. ACS Symp. Ser. 323:54-78. 


\section{Chapter 5}

\section{Pyromorphite Formation Artifact}

\subsection{Introduction}

Lead is the most common metal pollutant at hazardous sites in the USA. Lead is potentially toxic to humans and animals, especially to young children. The major pathways of lead exposure are ingestion, inhalation, and dermal contact. Lead is rarely translocated in plants so contamination of food chain through plant uptake is a minor concern for $\mathrm{Pb}$ exposure. Although most of the $\mathrm{Pb}$ exposure occurs through involuntary dust ingestion (McBride, 1994), its extensive use and widespread disposal in the environment results in numerous lead contaminated soils (Turjoman and Fuller, 1987). In these lead-contaminated sites, there are also concerns about the contamination of surface and subsurface waters by leaching of $\mathrm{Pb}$ from the contaminated fractions of soils.

Lead contamination is often observed in old smelting sites. Sources of $\mathrm{Pb}$ at these sites are old smelting process wastes and mine wastes contaminated due to atmospheric additions of high $\mathrm{Pb}$ dust particles. Although total $\mathrm{Pb}$ concentrations in contaminated media are often used to determine potential for $\mathrm{Pb}$ exposure to humans, bioavailability of $\mathrm{Pb}$ is determined by solid phase speciation of $\mathrm{Pb}$ (Freeman et al., 1992). Many investigators (Ma and Rao, 1997; Ruby et al. 1994) have used sequential extraction techniques to identify the solid phases most likely to contribute to bioavailable pool of $\mathrm{Pb}$.

Sequestering heavy metals in insoluble phosphate minerals has been suggested as an in situ remediation technique for heavy metals (Nriagu, 1973, 1974, and 1984). Lead sequestered in apatite minerals has great durability and leaching resistance, significantly exceeding other chemically stabilized forms. This is because the apatite mineral is very 
stable over a wide range of environmental conditions, such as from $\mathrm{pH} 2$ to 12 , temperature up to $1000{ }^{0} \mathrm{C}$, presence of aqueous and non aqueous phase liquids, and disturbance caused by earthquakes, ground subsidence or human intrusion for geologically long time periods, i.e. hundreds of millions of years. Therefore, the lead-enriched apatites are not source of groundwater contamination. Also because of the long term stability of metal-enriched apatite (Altschuler et al., 1967; Shaw and Wasserburg, 1985; Keto and Jacobsen, 1987), the effects of gravity, soil heterogeneity, hydrology and other properties of the subsurface do not affect the performance of the remediation treatment using apatites. The bioavailability of ingested metal apatite is also greatly reduced (Davis et al., 1992; Ruby et al., 1992), making animal and human intrusion less dangerous should the metal apatite phase be ingested, and making bioremediation more effective in mixed waste environment.

Low solubility and high stability of lead phosphate minerals has spurred investigations into the mechanisms of chemical fixation of $\mathrm{Pb}$ by reacting $\mathrm{Pb}-$ contaminated soils with phosphates. Both soluble phosphates i.e. potassium phosphate (Lambert et al., 1997) and slowly dissolving phosphate minerals, i.e. rock phosphates and hydroxy apatites (Ma et al., 1994 and Ma and Rao, 1997), have been used to immobilize $\mathrm{Pb}$. Amounts of phosphate application used in these studies were either empirically selected or were based on $\mathrm{Pb}$ concentrations in contaminated soils. Phosphate additions on the basis of level of contamination were often selected to give desired phosphate to $\mathrm{Pb}$ ratios. However, in soils contaminated with smelter wastes, high concentrations of iron oxides are often observed. These iron oxides become a major sink for added phosphates. Thus, all the phosphates added to remediate soils might not be available to react with $\mathrm{Pb}$. 
Sequential extractions of $\mathrm{Pb}$ have been used to determine the suitability of phosphates to immobilize $\mathrm{Pb}$. Lead in many $\mathrm{Pb}$-contaminated soils has been found to be associated with iron oxide phases (Xian, 1987). Phosphate additions have been reported to convert $\mathrm{Pb}$ associated with iron-oxide fractions of soils into pyromorphite (Ma and Rao, 1997). Pyromorphite is a very stable lead phosphate. However, there is a possibility that in the phosphate-treated lead-contaminated soils, pyromorphite does not form from reaction with $\mathrm{Pb}$ associated with iron oxides and the observed pyromorphite is only formed during solubilization of $\mathrm{Fe}$ during extraction. So it is likely that this assumption provides inaccurate information about immobilization of $\mathrm{Pb}$. Therefore this study was undertaken with the objective of investigating whether lead pyromorphites are formed in the soil prior to extraction or during extraction.

\subsection{Materials and Methods}

\subsubsection{Materials and Experimental Procedure}

Three soils were collected from an area contaminated with zinc smelter waste. Total $\mathrm{Pb}$ concentrations $(\mu \mathrm{g} / \mathrm{g}$ ) of these materials were 714 (Soil 1), 1662 (Soil 2), and 2369 (Soil 3). The sequential extraction procedure of Ma and Rao (1997) was used to fractionate $\mathrm{Pb}$ into six fractions namely: water soluble, exchangeable, carbonate bound, Fe-Mn oxide, organic and residual. These fractions were extracted with deionized water, 1 $\mathrm{M} \mathrm{MgCl}_{2}, 1 \mathrm{M} \mathrm{NaOAC}, 0.04 \mathrm{M} \mathrm{NH}_{2} \mathrm{OH} . \mathrm{HCl},\left(0.02 \mathrm{M} \mathrm{HNO}_{3}+30 \% \mathrm{H}_{2} \mathrm{O}_{2}+\mathrm{NH}_{2} \mathrm{OAC}\right)$ and $\mathrm{HF}$, respectively. A second portion of these soils was reacted with two concentrations of phosphates $(11,500 \mu \mathrm{g} / \mathrm{g}$ and $23,100 \mu \mathrm{g} / \mathrm{g})$. After reaction with phosphates, these soils 
were again fractionated by using the same extraction scheme to determine the formation of lead pyromorphite.

Synthetic amorphous iron oxides were prepared by neutralizing $0.1 \mathrm{M} \mathrm{FeCl}_{3}$ with $0.1 \mathrm{~N} \mathrm{NaOH}$. The precipitates were separated and dried to $35{ }^{0} \mathrm{C}$. Dried samples were characterized by using X-ray diffraction. Ground Fe oxide materials were used to adsorb various concentration of $\mathrm{Pb}$ and phosphates. Various concentrations of $\mathrm{Pb}$ (6000 (Sample 1), 3560 (Sample 2), 2340 (Sample 3) $\mu \mathrm{g} / \mathrm{g}$ ) and lead+phosphate (6000+8000 (Sample 4), 3560+6000 (Sample 5) , 2340+4000 (Sample 6) $\mu \mathrm{g} / \mathrm{g}$ ) were adsorbed on Fe oxide to get two sets of iron oxides, i.e. iron oxides with sorbed $\mathrm{Pb}$ and those containing both phosphates and $\mathrm{Pb}$ each set having three levels of $\mathrm{Pb}$ and lead+phosphate additions. Phosphates and $\mathrm{Pb}$ were extracted from these oxides by hydroxylamine hydrochloride.

\subsubsection{Analytical Method:}

In this investigation, acid washed $\left(5 \% \mathrm{HNO}_{3}\right)$ polycarbonate labware, analytical grade chemicals and double de-ionized water were used. Total $\mathrm{Pb}$ concentrations of supernatant after each extraction step were analyzed using Inductively Coupled Plasma Spectrophotometer (for $\mathrm{Pb}>100 \mu \mathrm{g} / \mathrm{L}$ ) and Graphite Furnace Atomic Absorption Spectrophotometer (for $\mathrm{Pb}<100 \mu \mathrm{g} / \mathrm{L}$ ). Separate $\mathrm{Pb}$ standards were prepared for each extraction step in the same matrix as the extracting reagent to minimize matrix effect. During analysis, standard samples were run after every 20 samples to check the accuracy of analysis. 


\subsection{Results and Discussions}

Sequential extractions of $\mathrm{Pb}$ contaminated soils from a smelter site showed that most of the non-residual $\mathrm{Pb}$ was associated with oxide phases of the soils (Table 5.1). Exchangeable and water-soluble extractions constituted a small fraction of the total $\mathrm{Pb}$ in these soils. Although the water-soluble fraction was only a small fraction of the total $\mathrm{Pb}$, $\mathrm{Pb}$ concentration in the water extracts exceeded drinking water standards (Maximum Contamination Limit (MCL) $<15 \mu \mathrm{gL}^{-1}$ ). Although treatment of these soils with phosphates $(11,550 \mu \mathrm{g} / \mathrm{g})$ significantly reduced $\mathrm{Pb}$ concentration. However, $\mathrm{Pb}$ concentrations exceeded MCL ( Table 5.2). Similar results were found when phosphate concentration was $23,100 \mu \mathrm{g} / \mathrm{g}$ ( Table 5.3). Most of the non-residual $\mathrm{Pb}$ in these soils was in metal oxide fractions; this observation is consistent with the reports that $\mathrm{Pb}$ is predominantly associated with this fraction (Chlopeka, 1993; Jordao and Nickless, 1989; Ramos et al., 1994). Phosphate treatment of these soils reduced extractable $\mathrm{Pb}$ in all the fractions, including the metal oxide fraction( Table 5.2 and Table 5.3). The reason for this reduction as reported by many researchers (Ma and Rao, 1997; Davis et al., 1992) is the dissolution of phosphate minerals and the precipitation of $\mathrm{Pb}$ with the dissolved phosphate to form pyromorphite.

The proposed reaction suite for this mechanism the following (Lindsay,1979).

$$
\begin{aligned}
& \mathrm{Ca}_{10}\left(\mathrm{PO}_{4}\right)_{6}(\mathrm{OH})_{2}+14 \mathrm{H}^{+} \stackrel{\text { dissolution }}{\longrightarrow} 10 \mathrm{Ca}^{2+}+6 \mathrm{H}_{2} \mathrm{PO}_{4}^{-}+2 \mathrm{H}_{2} \mathrm{O} \\
& \text { apatite } \\
& \text { precipitation } \\
& 10 \mathrm{~Pb}^{2+}+6 \mathrm{H}_{2} \mathrm{PO}_{4}{ }^{-}+2 \mathrm{H}_{2} \mathrm{O} \longrightarrow \mathrm{Pb}_{10}\left(\mathrm{PO}_{4}\right)_{6}(\mathrm{OH})_{2}+14 \mathrm{H}^{+} \\
& \text {pyromorphite }
\end{aligned}
$$




\section{Table 5.1: Lead Concentration $(\mu \mathrm{g} / \mathrm{g})$ in different fractions of the original soils}

\begin{tabular}{|l|r|c|c|}
\hline Fractions & Soil-1 & Soil-2 & Soil-3 \\
\hline Water soluble & 1.4 & 1.0 & 9.8 \\
\hline Exchangeable & 9.5 & 12.8 & 71.4 \\
\hline Carbonate & 44.4 & 97.5 & 383.2 \\
\hline Fe-Mn oxide & 153.8 & 532.4 & 1180.8 \\
\hline Organic & 50.6 & 167.6 & 184.3 \\
\hline Residual & 459.2 & 779.0 & 985.3 \\
\hline
\end{tabular}

Table 5.2 : Lead Concentration $(\mu \mathrm{g} / \mathrm{g})$ in different fractions of the soils treated with $(11,550(\mu \mathrm{g} / \mathrm{g})) \mathbf{P}$

\begin{tabular}{|l|r|r|r|}
\hline Fractions & Soil-1 & Soil-2 & Soil-3 \\
\hline Water soluble & 0.3 & 0.2 & 0.2 \\
\hline Exchangeable & 0.4 & 0.9 & 0.5 \\
\hline Carbonate & 6.1 & 92.5 & 142.5 \\
\hline Fe-Mn oxide & 68.3 & 499.2 & 573.0 \\
\hline Organic & 30.1 & 17.4 & 14.2 \\
\hline Residual & 543.3 & 943.0 & 1479.7 \\
\hline
\end{tabular}

\section{Table 5.3: Lead Concentration $(\mu \mathrm{g} / \mathrm{g})$ in different fractions of the soils treated with $(23,100(\mu \mathrm{g} / \mathrm{g})) \mathbf{P}$}

\begin{tabular}{|l|r|r|r|}
\hline Fractions & Soil-1 & \multicolumn{1}{|c|}{ Soil-2 } & Soil-3 \\
\hline Water soluble & 0.3 & 0.3 & 0.8 \\
\hline Exchangeable & 0.4 & 0.8 & 0.4 \\
\hline Carbonate & 3.5 & 60.6 & 119.1 \\
\hline Fe-Mn oxide & 51.6 & 408.6 & 514.3 \\
\hline Organic & 38.7 & 16.6 & 19.2 \\
\hline Residual & 545.2 & 1180.2 & 1572.3 \\
\hline
\end{tabular}


It was hypothesized that the precipitation (reaction 2) is affected during extraction procedure; it does not actually take place in soil environment. This hypothesis was confirmed by studying $\mathrm{Pb}$ and lead+phosphate adsorption on synthetic iron oxides.

In synthetic iron oxides, the fact that all of the sorbed $\mathrm{Pb}$ could be extracted by dissolution with hydroxylamine hydrochloride (Figure 5.1) means that all the $\mathrm{Pb}$ was associated with $\mathrm{Fe}$ oxides. When iron oxides had both $\mathrm{Pb}$ and phosphates sorbed, there should be formation of pyromorphite to support the argument of different researchers (Nriagu, 1973; Davis et al., 1992; and Ruby et al. 1994), that addition of phosphate to $\mathrm{Pb}$ contaminated soils results in the formation of pyromorphite. But in our study, no pyromorphite was found by X-ray diffraction (Figure 5.2). Moreover, when iron oxides with sorbed phosphates and $\mathrm{Pb}$ were extracted with hydroxylamine hydrochloride, a significant fraction of $\mathrm{Pb}$ could not be extracted (Figure 5.3). These results suggest that in the sequential extraction procedure when a soil has both $\mathrm{Pb}$ and phosphate sorbed, $\mathrm{Pb}$ may be lost from the solution by reactions with other constituents in the extracts. Since, our system was pure, the probable cause of $\mathrm{Pb}$ loss was the precipitation reaction of pyromorphite. So we can conclude that there is always decrease in $\mathrm{Pb}$ concentration in $\mathrm{Fe}$ -oxide after the addition of phosphates which may not be due to the formation of pyromorphite but due to the artifact of the extraction procedure. 


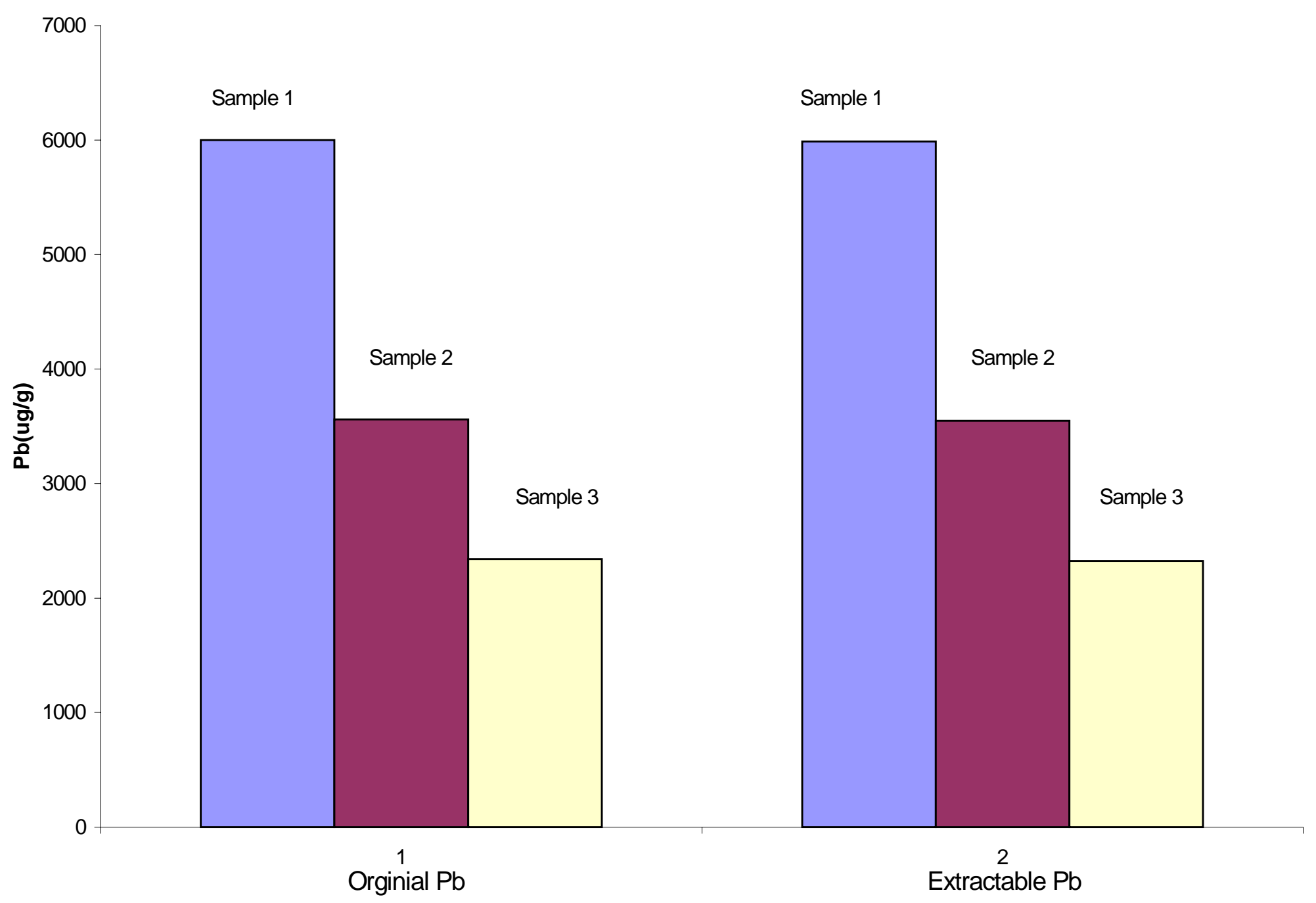

Figure 5.1: Extractable lead without phosphorus from iron-oxides 


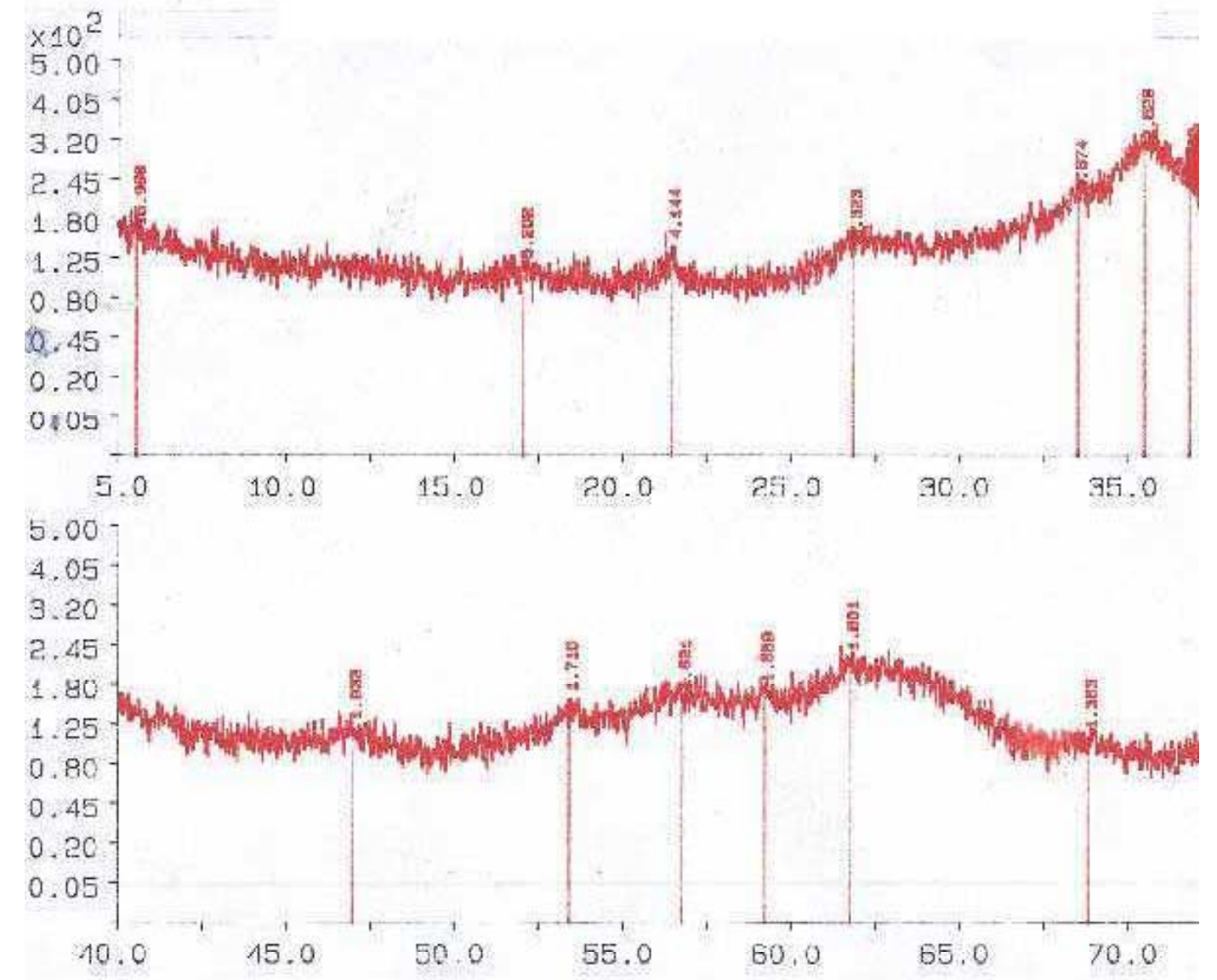

Figure 5.2: X-ray diffraction of iron oxides sorbes with lead and phosphate 


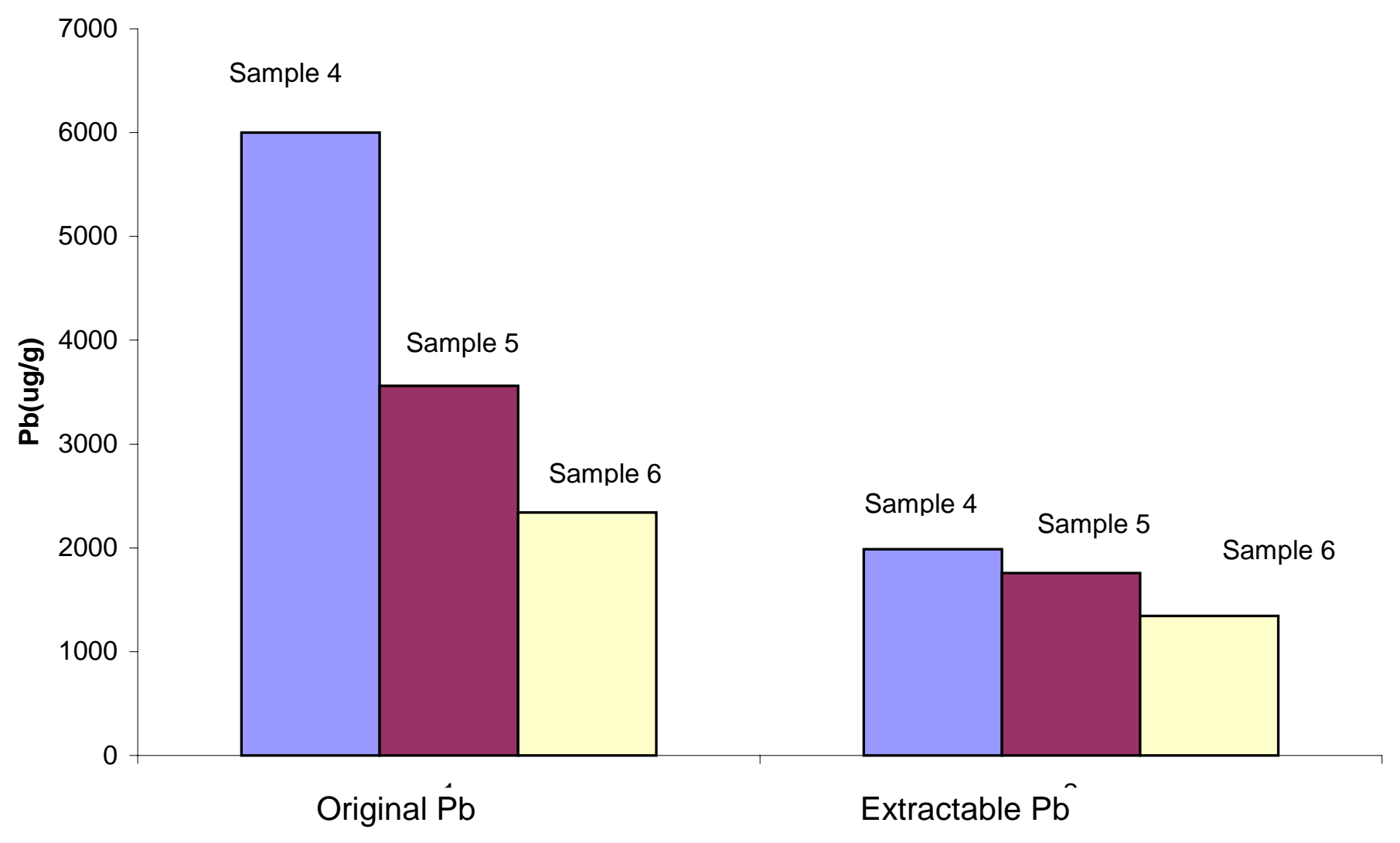

Figure 5.3: Extractable lead with phosprous from the iron-oxides 


\section{References:}

Altschuler, Z.S., C.K.Berman and F.Cuttita. 1967: Rare earth in phosphorites geochemistry and potential recovery. U.S. Geol. Survey. Paper 575B, Denver.

Chlopeka, A.1993. Forms of trace metals from inorganic sources of soil and amounts found in spring barley. Water Air Soil Pollut. 69:1-2.

Davis, A., M.V. Ruby and P.D. Bergstrom.1992. Bioavaliability of arsenic and lead in soils from the Butte, Montana, Mining District. Environ. Sci. Technol. 26:461-468.

Freeman, G.B., J.D.Johnson , J.M. Killinger, S.C.Liao and P.I. Feder.1992. Relative bio availability of lead from mining waste soil in rats. Fund. Appl. Toxicol.19:388398.

Jordao, C.P., and G. Nickless.1989. Chemical association of $\mathrm{Zn}, \mathrm{Cd}, \mathrm{Pb}$ and $\mathrm{Cu}$ in soils and sediments determined by sequential extraction technique. Environ. Technol. Lett. 10:743-752.

Keto, L.S. and S.B. Jacobsen.1987. Nd and Sr isotopic variation of early Paleozoic oceans. Earth and Planetary Science letters.84:27-41.

Lindsay, W.L.1979. Chemical equilibrium in soils. John Wiley and Sons, New York.

Ma Q.L and G.N.Rao.1997.Effect of phosphate rock on sequential chemical extraction of lead in contaminated soils. J. Environ. Qual. 26:788-794.

McBride, M.B.1994. Environmental Chemistry of Soils. Oxford Univ. Press, Oxford.

Nriagu,J. 1973. Lead Orthophosphates-I. Stability of chloropyromorphite at $25^{\circ} \mathrm{C}$. Geochim. et. Cosmochim. Acta. 37: 367-377.

Nriagu, J. 1974. Lead Orthophosphates-IV. Formation and stability in the environment. Geochim. et. Cosmochim. Acta 38:887-902.

Nriagu, J.1984. Formation and stability of base metal phosphates in soils and sediments. In Nriagu and P.Moore(eds.) Phosphate Minerals. p 318.

Ramos, L., L.M.Hernandez, and J.J.Gonzalez.1994. Sequential fraction of copper, lead , cadmium and zinc in soils from or near Donana National Park. J. Environ. Qual.23:50-57.

Ruby, M., A. Davis and A.Nicholson.1994. In situ formation of lead phosphates in soils as a method to immobilize lead. Environ. Sci. Technol. 28:646-654. 
Shaw, H.F. and G.J. Wasserburg.1985. Sm-Nd in marine carbonates and phosphates: implication for Nd isotopes in seawater and crustal ages. Geochim. et Cosmochim. Acta. 49:503-518.

Turjaoman. A.M., and W.H.Filler.1987. Behavior of lead as a migrating pollutant in Saudi Arabian soils. Arid Soil Res. Rehabilitation. 1:31:45

Xian. X. 1987. Chemical partitioning of cadmium, zinc, lead and copper in soils near smelters. J. Environ. Sci. Health 6:527-541. 


\section{Chapter 6}

\section{Effectiveness of Phosphate to Remediate Lead and Arsenic Contaminated Soils}

\subsection{Rationale and Scope for Research}

Contamination of soils with toxic trace elements such as lead $(\mathrm{Pb})$ and arsenic $(\mathrm{As})$ represents a significant environmental threat due to their high toxicity. Excessive exposure to $\mathrm{Pb}$ and $\mathrm{As}$ is toxic to many organisms, from microbes to higher animals. Lead is the most common contaminant found at the USEPA designated superfund sites. Lead additions to the environment predate the industrial revolution. However, $\mathrm{Pb}$ and $\mathrm{As}$ contamination of the environment increased over the last century due to the extensive mining of $\mathrm{Pb}$ and $\mathrm{As}$ containing ores, use of $\mathrm{Pb}$ and $\mathrm{As}$ in industrial and agricultural products. There are many industrial and agricultural sites that are contaminated with both $\mathrm{Pb}$ and As.

Lead arsenate was the preferred pesticide for insect control in deciduous fruit trees before the production of DDT. Frequent application at high rates led to significant $\mathrm{Pb}$ and As accumulations in orchard soils (Pereyea, 1991). Lead in these soils was relatively immobile and non-phytotoxic whereas the As could be mobile and phytotoxic (Davenport and Peryea, 1991). In addition to the concerns about phytotoxicity of these two elements, there are risks of direct exposure to these toxic elements when house are constructed on soils contaminated with these elements.

Sphalerite $(\mathrm{ZnS})$ is the most common ore of zinc. Galena $(\mathrm{PbS})$ and arsenopyrites (FeAsS) are the most common contaminants found associated with sphalerite and 
consequently, $\mathrm{Pb}$ and $\mathrm{As}$ are common contaminants of zinc ores. During the smelting process, significant amounts of both $\mathrm{Pb}$ and $\mathrm{As}$ are concentrated in the silicate slag that is rich in oxides of iron and aluminum. Since $\mathrm{Pb}$ and $\mathrm{As}$ are associated with oxides of iron and aluminum, many zinc ore tailings and smelting waste disposal sites are contaminated with $\mathrm{Pb}$ and $\mathrm{As}$. Boiling points of both $\mathrm{Pb}$ and $\mathrm{As}$ are much lower than that of $\mathrm{Zn}$. During the smelting process significant amounts of both $\mathrm{Pb}$ and $\mathrm{As}$ are lost to the environment through flue gases. Because of the atmospheric additions of $\mathrm{As}$ and $\mathrm{Pb}$, soils on the downwind direction from smelting plants often have elevated concentrations of both $\mathrm{Pb}$ and As.

Ingestion and inhalation are the predominant means of $\mathrm{Pb}$ and As contamination in humans and other animals. Ingestion is common in infants who eat contaminated soils by frequent hand to mouth activity and the subsequent ingestion of soil containing metals and other contaminants. Young children may also be exposed to these contaminants by playing on contaminated soils. Children also have the ability to absorb higher percentages of metals through the digestive system into the blood stream than adults, which may leave them susceptible to adverse health effects (Hamel et al., 1998). The incomplete development of the blood-brain barrier in very young children (up to 3 years of age) increases the risk of lead' s entry into the developing nervous system, which can result in prolonged neurobehavioral disorders. Contamination of the food chain can also occur by bioconcentrations of these elements in plants grown on contaminated soils and from animals or human eating those plants. 
Both $\mathrm{Pb}$ and $\mathrm{As}$ in soils exist as aqueous species, adsorbed components on charged surfaces, and structural components of soil materials. Lead and As are ubiquitous in the environment; however, their concentrations in uncontaminated soils are much smaller than those observed at contaminated sites. The average concentrations of $\mathrm{Pb}$ and $\mathrm{As}$ in soils around the world are estimated to be $15 \mathrm{mg} \mathrm{kg}^{-1}$ and $5 \mathrm{mg} \mathrm{kg}^{-1}$, respectively (Zimdahl and Skogerboe, 1977). Lead and As concentrations are much higher in sites that are contaminated with smelting wastes, lead ores, or lead arsenate pesticides. In the United States, $\mathrm{Pb}$ contamination has been observed on 635 out of 1177 sites on the National Priorities List of Hazardous Sites (Reed and Cline, 1994). The USEPA has declared that there is a great need for remedial technologies for treating metals that are found at hazardous waste sites. In the USA, remediation is usually required when total $\mathrm{Pb}$ concentrations in soils exceed 300 to $500 \mathrm{mg} \mathrm{kg}^{-1}$ in residential soils, or $2000 \mathrm{mg} \mathrm{kg}^{-1}$ in soils used for industrial purposes (USEPA, 1996).

Remediation methods for contaminated soils attempt to reduce volume, toxicity, or mobility of contaminants in the environment. In metal contaminated sites the major thrust of remediation technologies is to reduce mobility or bioavailability of toxic trace elements. However, current remediation methods for soils contaminated with trace elements are often expensive and disruptive to the site. There are many technologies employed to clean up contaminated soils and wastes including thermal, microbiological, and physical/chemical (Ma et al., 1993). Both thermal and microbiological treatments are ineffective in removing trace elements from contaminated sites. Physical stabilization (e.g., mixing soils with cements or other solidifying agent or installation of soil or asphalt caps) is often costly and destructive. In recent years there have been a number of research 
reports that suggest that $\mathrm{Pb}$ contaminated sites can be treated with phosphates to reduce solubility and consequently, bioavailability of $\mathrm{Pb}$ (Ma 1996; Ma et al., 1993). Nriagu (1973) was the first to suggest that phosphate minerals have a potential to immobilize $\mathrm{Pb}$ in lead-contaminated soils and wastes due to low solubility of lead orthophosphates. Numerous reports from Japan suggested that hydroxy-apatite (HA) could be used to remove $\mathrm{Pb}$ form aqueous solutions. They suggested that apatite minerals could be used as ion exchangers for removing $\mathrm{Pb}$ from aqueous solutions (Ma et al., 1995). These authors provided little evidence that exchange reactions were responsible for the removal of $\mathrm{Pb}$ by hydroxy apatite (HA) minerals. Their results, however, showed that more $\mathrm{Pb}$ was removed by HA from a solution when soil $\mathrm{pH}$ was lowered. If exchange reactions on the surface of $\mathrm{HA}$ were responsible for removal of $\mathrm{Pb}$, then lower $\mathrm{pH}$ would result in less $\mathrm{Pb}$ being adsorbed, as HA-surface will have less negative charge. However, the results of Takeuchi and Arai (1990) can be explained alternatively by a precipitation mechanism. More HA dissolved at low $\mathrm{pH}$, and thus there was more $\mathrm{P}$ reacting with $\mathrm{Pb}$ to form hydroxypyromorphite (HP). Ma and coworkers (1993) conclusively proved that $\mathrm{Pb}$ was immobilized by dissolution of $\mathrm{HA}$ and precipitation of lead phosphate (hydroxypyromorphite).

It has been suggested that the bioavailability of soil $\mathrm{Pb}$ can be reduced by amending lead-contaminated soils with solid orthophosphate minerals or by adding soluble phosphates and producing $\mathrm{Pb}$ (II) phosphate mineral, pyromorphite $\left(\mathrm{Pb}_{10}\left(\mathrm{PO}_{4}\right)_{6}\right.$ $\left.(\mathrm{OH})_{2}\right)$. It has also been shown that formation of pyromorphite results in equilibrium $\mathrm{Pb}$ concentration approximately equal to EPA drinking water limits $\left(15 \mu \mathrm{g} \mathrm{L}^{-1}\right)$ ( Laperche et al., 1997). The hydrous oxides of $\mathrm{Fe}, \mathrm{Al}$, and $\mathrm{Mn}$ control, to a great extent the 
concentration and transport of many trace elements in soils and natural water through mechanisms of sorption and co-precipitation (Stumn and Morgan (1981). Hydrous oxides of $\mathrm{Fe}$ and $\mathrm{Al}$ can scavenge heavy metals and, thus, are believed to play an important role in retention and release of heavy metals in polluted soils. A number of $\mathrm{Pb}$ chemical speciation studies have shown that adsorbed $\mathrm{Pb}$ is the major $\mathrm{Pb}$ retaining solid phase in contaminated soils. Goethite is usually the dominant hydrous iron oxide mineral in soils. Interactions between goethite and $\mathrm{Pb}$ have been extensively investigated because they represent a common soil constituent and a typical pollutant and, therefore, are ideal candidates with which to establish a model that describes the relationship between soil matrices and pollutant for monitoring purposes and also to predict transport of metals in soils and natural waters. Zhang and Ryan (1999) observed that when stoichiometric concentrations of soluble phosphates were added directly to the suspension of $\mathrm{Pb}$-adsorbed goethite, the thermodynamically stable lead phosphate mineral, chloropyromorphite, was rapidly precipitated. In their experiments approximately $60-70$ percent of the adsorbed$\mathrm{Pb}$ was extractable with $1.0 \mathrm{M} \mathrm{MgCl}_{2}$. However, additions of stoichiometric concentrations of phosphates reduced exchangeable $\mathrm{Pb}$ to $0.3-2.8 \%$. By contrast, when the same goethite suspension was reacted with HA, the formation of chloropyromorphite was slow and was apparently controlled by the rate of dissolution of HA. These results showed that $\mathrm{Pb}$-adsorbed on oxides of $\mathrm{Fe}$ and $\mathrm{Al}$ can be desorbed from the mineral surfaces and converted into a more thermodynamically stable solid phase by reacting it with phosphates. 
Arsenic exhibits varying oxidation states in natural systems; in oxidized systems As may occur As $(+3)$ and $\mathrm{As}(+5)$. In smelter wastes and in orchard soils treated with lead arsenates the most common form of arsenic is As (+5). Both As (+3) and As (+5) are adsorbed to Fe oxide surfaces through inner-sphere complexation mechanisms (Jain et al., 1999). Arsenate adsorption on oxides of iron and aluminum increases when $\mathrm{pH}$ is decreased below 7.0. Extended x-ray absorption fine structure (EXAFS) studies have provided evidence that As $(+5)$ adsorbs to the iron oxide and hydroxide minerals by an inner-sphere complexation mechanism. Variably charged surfaces in general, and the oxy-hydroxides of $\mathrm{Fe}, \mathrm{Al}$, and $\mathrm{Mn}$ in particular, are the primary solid phases that control As solubility in soils. Arsenic is retained on these clay minerals by a ligand exchange reaction where As replaces an $\mathrm{OH}^{-1}$ or an aqua group from the mineral surface. This ligand exchange adsorption is reversible such that both phosphates and $\mathrm{OH}^{-}$have been used to effect the ligand displacement reactions (Chao and Salazone, 1989; Gustafsson and Jacks, 1995). Lead solubility in soils decreases with increasing soil $\mathrm{pH}$. Liming is often recommended for reducing the bioavailability of $\mathrm{Pb}$. However, liming an As contaminated soil may increase As concentrations in soil solution by a ligand exchange reaction. Similarly, additions of phosphate ions to solutions can displace arsenate ions from the soil solids into the soil solution, thereby increasing As solubility and bioavailability. Thus when phosphates are used to remediate soils that are contaminated with $\mathrm{Pb}$ and $\mathrm{As}$, they may reduce bioavailability of $\mathrm{Pb}$, but at the same time increase the bioavailability of As. So the objectives of this study were: 
1. to conduct greenhouse investigations on the effect of treatments with iron oxides and phosphate on As concentrations in red clover grown on As contaminated soils

2. to investigate the effect of phosphate treatments on As and $\mathrm{Pb}$ concentrations in Japanese millet and red clover grown on soil contaminated with both $\mathrm{Pb}$ and As

3. to conduct laboratory investigations to determine mechanism for P induced decline in As concentrations in soil contaminated with both $\mathrm{Pb}$ and $\mathrm{As}$.

\subsection{Materials and Methods}

\subsubsection{Effect of Iron hydroxides and phosphate treatments on As bio-} availability to red clover.

\subsubsection{Green House Experiment 1}

A bulk soil sample from a mine site in Preston County, West Virginia was collected for this experiment. The physico-chemical properties of the soil are listed in Table 6.1. Soils were limed with $\mathrm{Ca}(\mathrm{OH})_{2}$ to a target $\mathrm{pH}$ of 6.5. After addition of lime, soils were incubated for 2 weeks. During that incubation period soils went through two wetting and drying cycles. After $\mathrm{pH}$ adjustment, soils were divided into three subsamples. The first subsamples of soil did not receive any treatment, the second subsamples of soil was treated with $\mathrm{Fe}(\mathrm{OH})_{3}$ that was prepared by neutralizing $\mathrm{Fe}(\mathrm{NO})_{3}$ with $\mathrm{NaOH}$ to $\mathrm{pH}$ 6.5. Total Fe concentration in the second subsamples of soil was adjusted to $10 \mathrm{~g} \mathrm{~kg}^{-1}$ soil. After adjustment of Fe concentration this soil was designated 
Table 6.1. Physico- chemical properties of the soil-1 used in the Greenhouse

\section{Experiment-1}

\section{Physical Properties}

Particle size Analysis

Sand

Silt

Clay
$\%$

$\%$

$\%$
37

39

24

\section{Chemical Properties}

Soil pH (1:1)

Organic carbon

Cation exchange capacity

Total Phosphorus

Total Arsenic

Total $\mathrm{Pb}$

DCB Fe
4.55

$\mathrm{g} \mathrm{kg}^{-1} \quad 9.5$

$\mathrm{cmol}_{\mathrm{c}} \mathrm{kg}^{-1} \quad 10.1$

$\mathrm{g} \mathrm{kg}^{-1} \quad 0.50$

$\mathrm{mg} \mathrm{kg}^{-1} \quad 12.5$

$\mathrm{mg} \mathrm{kg}^{-1} \quad 22.7$

$\mathrm{g} \mathrm{kg}^{-1} \quad 4.5$ 
as Soil-2 The third subsample of the soil was amended with $\mathrm{Fe}(\mathrm{OH})_{3}$ to give a total $\mathrm{Fe}$ concentration of $20 \mathrm{~g} \mathrm{~kg}^{-1}$. This soil was called Soil-3. Each of these soils were further divided into 3 parts each and each part was treated with $\mathrm{NaAsO}_{4}$ to give As concentrations of 0,125 and $250 \mathrm{mg} \mathrm{kg}^{-1}$. Initial soil samples (approximately $500 \mathrm{~g} /$ arsenic-treatment) were collected for laboratory extraction experiments. These 9 different types of soil $(550 \mathrm{~g} / \mathrm{pot})$ were mixed with phosphate treatments in 3 replications. The amounts of $\mathrm{P}$ added were $0,125,250$, and $375 \mathrm{mg} \mathrm{kg}^{-1}$. Five red clover seeds were planted in each pot and after germination, two plants of red clover were retained in each pot. Above ground plant parts were harvested 60 days after sowing. Plant samples were washed with distilled de-ionized water and after washing they were dried at $60^{\circ} \mathrm{C}$ in a forced air oven. Samples were ground with a cyclone grinder and ground samples were digested with concentrated nitric acid in a CEM (MDS-2000) microwave oven. Digested plant samples were analyzed for As on an electrothermal atomic absorption spectrophotometer.

6.2.1.2 Effect of Phosphate Concentrations on As Extraction: One-gram samples (in 12 replicates) for each As contaminated soil were transferred to 50-ml polyethylene centrifuge tubes. These soils were extracted with distilled water and $\mathrm{KH}_{2} \mathrm{PO}_{4}$ solutions with the following P concentrations:125, 250, and $375 \mathrm{mg} \mathrm{kg}^{-1}$. Soil to solution ratio was 1:10 and equilibration time was $18 \mathrm{hrs}$. After $18 \mathrm{hrs}$ of extraction, soil suspensions were centrifuged@12,000 rpm and the supernatant solution was filtered through a glass fiber filter paper of $0.45 \mu \mathrm{m}$ nominal pore size. Filtered samples were analyzed for As on an electrothermal AAS. 


\subsubsection{Effect of Phosphate Applications on As and $\mathrm{Pb}$ Availability in Soils Contaminated with Both $\mathrm{Pb}$ and $\mathrm{As}$}

\subsubsection{Green House experiment 2}

In the second greenhouse experiment, thirteen soils were initially collected from a smelter waste disposal site. Soils were analyzed for chemical properties and three soils were selected on the basis of variation in As concentrations (Table 6.2). These soils had similar total $\mathrm{Pb}$ concentrations ranging from 2228 to $2485 \mathrm{mg} / \mathrm{kg}$. Total As

concentration in soil-A was $52 \mathrm{mg} \mathrm{kg}^{-1}$, Soil -B was 238 , and soil-C was $489 \mathrm{mg} \mathrm{kg}^{-1}$ (Table 6.2). These soils had very high $\mathrm{P}$ fixation capacity. $\mathrm{P}$ adsorption capacity of these soils ranged from 1250 to $1432 \mu \mathrm{g} \mathrm{P} \mathrm{g}^{-1}$ soil. Soil material had 3.75 to $4.22 \%$ organic carbon. Since the site did not support any vegetation, most of the organic carbon in these soils apparently came from unburned fuel that was used during the smelting process. These soils had a soil CEC of 16 to $18 \mathrm{cmol}_{\mathrm{c}} \mathrm{kg}^{-1}$. A significant fraction of soil CEC in these waste streams originated from soil organic carbon. These soils were collected from different depths as $0-30 \mathrm{~cm}, 30-60 \mathrm{~cm}, 60-90 \mathrm{~cm}, 90-120 \mathrm{~cm}, 120-150 \mathrm{~cm}, 150-200 \mathrm{~cm}$, $200-250 \mathrm{~cm}, 250-300 \mathrm{~cm}, 300-350 \mathrm{~cm}, 350-400 \mathrm{~cm}, 400-500 \mathrm{~cm}, 500-600 \mathrm{~cm}$ and $600-$ $700 \mathrm{~cm}$. Soils were air dried and sieved for obtaining $\leq 2 \mathrm{~mm}$ fraction. Lime was used to raise the soil $\mathrm{pH}$ to 6.5 . For equilibration, the soils were passed through three wetting and drying cycles. 
Table 6.2 Chemical properties of soils used in the Greenhouse Experiment -2

\begin{tabular}{|l|l|l|l|l|}
\hline Soil Property & Units & Soil-A & Soil-B & Soil-C \\
\hline Total Pb & $\mathrm{mg} \mathrm{kg}^{-1}$ & 2228 & 2485 & 2196 \\
\hline Total As & $\mathrm{mg} \mathrm{kg}^{-1}$ & 52 & 238 & 489 \\
\hline Soil $\mathrm{pH}$ & & 4.3 & 4.8 & 4.6 \\
\hline Organic Carbon & $\mathrm{g} \mathrm{kg}^{-1}$ & 42.2 & 38.4 & 37.5 \\
\hline CEC(pH 7.0) & $\mathrm{cmol}_{\mathrm{c}} \mathrm{kg}^{-1}$ & 18.0 & 17.5 & 16.1 \\
\hline Exchangeable & $\mathrm{cmol}_{\mathrm{c}} \mathrm{kg}^{-1}$ & 7.2 & 5.9 & 7.8 \\
\hline Ca & & & & \\
\hline Mg & & & 1.21 & 0.01 \\
\hline Na & $\mathrm{cmol}_{\mathrm{c}} \mathrm{kg}^{-1}$ & 1.2 & & \\
\hline DCB & $\mathrm{cmol}_{\mathrm{c}} \mathrm{kg}^{-1}$ & 0.02 & 58 & \\
\hline
\end{tabular}


Japanese millet( Echinochloa crusgalli) and red clover ( Trifolium pratense) were grown in pots under green house conditions. These crops were chosen for their ability to accumulate metals and grow easily under greenhouse conditions. Seeds of these crops were germinated and grown in pots containing $500 \mathrm{~g}$ of acid washed sand. The bottom of each pot was removed and cheesecloth was inserted instead for facilitating root growth. Each pot was irrigated upon need. When a mat of roots had developed at the bottom, the pots were put back on other pots containing experimental plant growth medium described below.

Subsamples ( in three replicates) of soil $(500 \mathrm{~g} / \mathrm{pot}$ ) were mixed with phosphate materials. The amounts of phosphate were based upon the $\mathrm{Pb}$ content of the soil; four molar ratios $(\mathrm{Pb} / \mathrm{P})$ of $0,0.33,0.66$, and 1.00 were used for the experiment. Aboveground plant parts were harvested 60 days after sowing and were oven dried at $60^{\circ} \mathrm{C}$. Two grams of each material were digested in CEM (MDS-2000) microwave apparatus using EPA 3051 method. The extracts were analyzed for P, As, and Pb on Perkin - Elmer Inductively Coupled Plasma Spectrophotometer and/or graphite furnace atomic absorption spectrophotometer.

\subsubsection{Arsenic and P Co-precipitation Reactions (Laboratory Studies) Lead} phosphates with entrained As were prepared by reacting $0.1 \mathrm{M} \mathrm{Na}_{3}\left(\mathrm{PO}_{4}\right)(250 \mathrm{~mL})$ contaiaining 0.0001 to $0.01 \mathrm{M}$ As with $250 \mathrm{ml}$ of $\mathrm{O} .1 \mathrm{M} \mathrm{Pb}\left(\mathrm{NO}_{3}\right)_{2}$. Suspensions were filtered after 18 hrs through 0.2 um membrane filter paper. Filtered samples were analyzed for $\mathrm{As}$ and $\mathrm{Pb}$ on an electro-thermal AAS. Solid samples were also analyzed by 
Philips X-ray diffractometer for X-ray diffraction. A second set of precipitates was prepared by reacting the following mixtures of $\mathrm{P}$ and As with $0.1 \mathrm{M} \mathrm{Pb}\left(\mathrm{NO}_{3}\right)_{2}$ :

\begin{tabular}{|l|l|}
\hline Molar Concentration of AS & Molar concentration of P \\
\hline 0.1 & 0.0 \\
\hline 0.075 & 0.025 \\
\hline 0.050 & 0.050 \\
\hline 0.025 & 0.075 \\
\hline 0.018 & 0.082 \\
\hline
\end{tabular}

Solid precipitates were analyzed for their crystal structures by an X-ray diffraction spectrophotometer.

\subsubsection{Basic Soil Analysis :}

Soil $\mathrm{pH}$ : Soil $\mathrm{pH}$ was determined in soil samples(1:1 soil water w/v) allowing one hour equilibration using glass electrode with double junction $\mathrm{Ag} / \mathrm{AgCl}$ reference electrode(McLean,1982).

Cation Exchange Capacity (CEC): Cation exchange capacity of soil was determined following the ammonium acetate method given by Soil Survey Staff (1984).

Organic Carbon(OC): A rapid titration procedure of Walkey and Black (1934) as outlined by Soil Survey Staff (1984) was used to determine Organic C.

Total Analysis: Total Analysis was done by following a procedure developed by HF digestion procedure modified from CEM corporation (CEM, 1991). Elements in digested samples were analyzed by ICP-AES (Perkin Elmer Model 400) 
Exchangeable $\mathrm{Ca}, \mathrm{Mg}, \mathrm{Na}$ and DCB Extractable Fe: Exchangeable $\mathrm{Ca}, \mathrm{Mg}, \mathrm{Na}$ and $\mathrm{Fe}$ were determined using the standard procedures (ammonium acetate method) mentioned in Methods of Soil analysis (Sparks et al., 1996).

Particle Size Analysis: Particle size analysis was performed by pipette method proposed by Gee and Bausder (1986).

\subsection{Results and Discussions}

\subsubsection{Effect of Iron hydroxides and phosphate treatments on As bio-availability to red clover (Greenhouse experiment -1)}

In all soils increasing levels of As contamination resulted in elevated As concentrations in red clover that was grown in this pot culture experiment (Table 6.3). Arsenic concentrations of plant grown in uncontaminated soils were extremely low $\left(<0.14 \mathrm{mg} \mathrm{kg}^{-}\right.$

$\left.{ }^{1}\right)$. In soil-1 when As concentrations were increased to 125 and $250 \mathrm{mg} \mathrm{kg}^{-1}$ corresponding As concentrations in the plant tissues were approximately 10 to 20 times larger than those observed in plants grown in uncontaminated soils. When soils contaminated with As were treated with phosphates, a significant increase in As concentrations in plant tissue were observed with increasing concentrations of P. In solution culture experiments, increasing phosphorus concentrations in nutrient solutions have been known to suppress As uptake. These results have been explained by fact that As and P have very similar chemical behavior and a single carrier facilitates uptake of these ions, consequently, high concentrations of $\mathrm{P}$ out-compete for sites on soil thereby making the available As for plant uptake. In our experiments, in a soil growth media, $\mathrm{P}$ applications enhanced As concentrations in plants. Both As and P form inner sphere 
Table 6.3. Effect of four rates of phosphate treatments on As concentrations $\left(\mathrm{mg} \mathrm{kg}^{-1}\right)$ in red clover plants grown on three soils that have been contaminated with 0,125 and 250 $\mathrm{mg} \mathrm{kg}^{-1}$ As.

\begin{tabular}{|c|c|c|c|c|c|c|}
\hline \multirow[b]{2}{*}{ Soil-1 } & \multirow[t]{2}{*}{$\begin{array}{l}\text { Soil } \\
\text { Arsenic(mg/kg) }\end{array}$} & \multicolumn{5}{|c|}{$\begin{array}{l}\text { Arsenic concentrations in plant tissue }\left(\mathrm{mg} \mathrm{kg}^{-1}\right) \text { in } \\
\text { soils treated with various concentrations of calcium } \\
\text { phosphates }\end{array}$} \\
\hline & & P0 & P125 & P250 & P375 & \\
\hline & 0 & 0.13 & 0.09 & 0.10 & 0.14 & \\
\hline & 125 & 1.22 & 1.65 & 1.93 & 2.11 & \\
\hline & 250 & 2.45 & 2.85 & 3.10 & 2.96 & \\
\hline $\operatorname{LSD}(0.05)$ & & 0.19 & 0.25 & 0.37 & 0.39 & \\
\hline \multirow[t]{3}{*}{ Soil-2 } & 0 & 0.09 & 0.07 & 0.10 & 0.08 & \\
\hline & 125 & 0.45 & 0.62 & 0.85 & 0.96 & \\
\hline & 250 & 1.36 & 1.84 & 2.10 & 2.05 & \\
\hline LSD 0.05) & & 0.26 & 0.34 & 0.21 & 0.33 & \\
\hline \multirow[t]{3}{*}{ Soil-3 } & 0 & 0.0 .7 & 0.08 & 0.05 & 0.08 & \\
\hline & 125 & 0.39 & 0.45 & 0.55 & 0.65 & \\
\hline & 250 & 0.77 & 0.69 & 0.82 & 0.84 & \\
\hline $\mathrm{LSD}(0.05)$ & & 0.22 & 0.35 & 0.29 & 0.23 & \\
\hline
\end{tabular}

Note: P125, P250, P 375 refer to P concentrations of $0,125,250$, and $375 \mathrm{mg} \mathrm{L}^{-1}$ in the soil. 
complexes with metal oxides in soils. When $\mathrm{P}$ was added to a soil a significant amount of $\mathrm{P}$ participated in ligand exchange reactions that resulted in As removal from the soil surface and moving into soil solution. This transfer of As from the soil surface to the soil solution resulted in enhanced bioavailability of As. When these soils were extracted with orthophosphate solutions, As concentrations in extracts increased with increasing $\mathrm{P}$ concentrations of up to $250 \mathrm{~g} \mathrm{~mL}^{-1}$ (Table 6.4). These data support the hypothesis that amendment of soil with $\mathrm{P}$ increased bioavailability and potential mobility of As in the environment.

Both As uptake by plants and As extraction by phosphate containing extracting solutions decreased with increasing iron oxide concentrations in soils (Tables 6.3 and 6.4). Iron oxide concentrations in soils were: Soil-3 > Soil-2 > Soil-1. Arsenic concentrations in red clover tissue decreased from $2.45 \mathrm{mg} \mathrm{kg}^{-1}$ (Soil-1 contaminated with $250 \mathrm{mg} \mathrm{kg}{ }^{-1}$ As) to $0.77 \mathrm{mg} \mathrm{kg}^{-1}$ (Soil-3 contaminated with $250 \mathrm{mg} \mathrm{kg}^{-1} \mathrm{As}$ ). These results suggest that iron oxides in soils not only impart As sorption capacity to soil, but they also reduce As extracting capacity of the phosphate ions. There are two possible mechanisms for these observations: 1) iron oxides may have some high energy sites where As is adsorbed so strongly that it can not be easily replaced; 2) high iron oxide concentrations in soils provide new sites for the adsorption of both As and $\mathrm{P}$ such that a significant fraction of orthophosphate ions in the extracting solution get adsorbed on the iron oxide surfaces thus phosphate ions are not available for extracting As. 
Table 6.4. Effect of phosphate concentrations in extracting solutions on As extractions from three soils contaminated with three levels of As.

\begin{tabular}{|l|l|l|l|l|l|l|}
\hline & Soil & \multicolumn{5}{|c|}{ Arsenic extracted mg kg ${ }^{-1}$ Soil } \\
& & Nrsenic(mg/kg) & \multicolumn{5}{|c|}{} \\
\hline & & Water & P125 & P250 & P375 & \\
\hline Soil 1 & 0 & ND* & ND & ND & ND & \\
\hline & 125 & ND & 26.2 & 28.6 & 32.1 & \\
\hline & 250 & 0.19 & 48.3 & 62.5 & 68.7 & \\
\hline Soil 2 & 0 & ND & ND & ND & ND & \\
\hline & 125 & ND & 14.2 & 18.7 & 18.2 & \\
\hline & 250 & ND & 21.2 & 34.5 & 36.0 & \\
\hline Soil 3 & 0 & ND & ND & ND & ND & \\
\hline & 125 & ND & 12.6 & 11.2 & 11.7 & \\
\hline & 250 & ND & 19.7 & 21.2 & 21.4 & \\
\hline
\end{tabular}

* Non determined

Note: P125, P250, P 375 refer to P concentrations of $0,125,250$, and $375 \mathrm{mg} \mathrm{L}^{-1}$ in the extracting solution. 


\subsubsection{Effect of phosphate treatments on As bio-availability to red clover and Japenese millet (JM) from soils contaminated with both As and Pb (Greenhouse experiment -2)}

Phosphorus concentrations in Japanese millet did not increase when P was applied @ $\mathrm{Pb} / \mathrm{P}$ molar ratio 0.33 . In some treatments there was a significant decline in $\mathrm{P}$ concentration in plant tissue when $\mathrm{P}$ was applied @ Pb/P Molar ratio of 0.3. This decline in $\mathrm{P}$ concentration was due to higher crop yield with $\mathrm{P}$ compared to the treatments where no $\mathrm{P}$ was applied. Phosphorus in JM tissue increased with fertilizer $\mathrm{P}$ application when $\mathrm{P}$ was applied @ Pb/P molar ratio of 0.66 or 1.0 (Table 6.5 ). Total As concentrations in the soil had no effect on the P concentrations in the JM. Lead concentrations in the JM were not affected by low application rates of $\mathrm{P}$, but there were significantly lower $\mathrm{Pb}$ concentrations in the plants grown in pots that were treated with P application rates of @ $\mathrm{Pb} / \mathrm{P}$ molar ratio of 1 . There are a number of reports in the literature that indicate that $\mathrm{P}$ can reduce $\mathrm{Pb}$ availability by converting bioavailable $\mathrm{Pb}$ to a highly insoluble $\mathrm{Pb}$ phosphate mineral pyromorphite. Lead concentrations were very high in these soils and at high rates of application of water soluble P sources it is very likely that in our systems pyromorphite was formed and thus, it reduced the availability of $\mathrm{Pb}$. Unlike the green house experiment-1, high rates of application of $\mathrm{P}$ also resulted in reduced As concentrations in the plant tissue of the crops grown on soil-B and soil-C. Thus, when soils were contaminated with both $\mathrm{Pb}$ and $\mathrm{As}$, application of phosphate reduced plant availability of $\mathrm{Pb}$. 
Table 6.5. Effect of application rates of phosphates on $\mathrm{Pb}$ and As concentrations in Japanese millet grown on three soils contaminated with both $\mathrm{Pb}$ and $\mathrm{As}$

\begin{tabular}{|c|c|c|c|c|}
\hline Soil & $\begin{array}{l}\text { Phosphate } \\
\text { Treatments } \\
\mathrm{Pb} / \mathrm{P} \text { molar } \\
\text { ratios }\end{array}$ & $\begin{array}{l}\text { Phosphorus } \\
\text { Concentrations } \\
\text { in Plant Tissue } \\
\left(\mathrm{mg} \mathrm{kg}^{-1} \text { dry }\right. \\
\text { matter) }\end{array}$ & $\begin{array}{l}\text { Lead } \\
\text { Concentrations } \\
\left(\mathrm{mg} \mathrm{kg}^{-1} \text { dry }\right. \\
\text { matter) }\end{array}$ & $\begin{array}{l}\text { Arsenic } \\
\text { Concentrations } \\
\left(\mathrm{mg} \mathrm{kg}^{-1} \text { dry }\right. \\
\text { matter) }\end{array}$ \\
\hline \multirow[t]{4}{*}{ Soil 1} & 0.00 & 0.12 & 1.20 & 0.21 \\
\hline & 0.33 & .09 & 1.15 & 0.27 \\
\hline & 0.66 & 0.17 & 0.83 & 0.25 \\
\hline & 1.00 & 0.19 & 0.45 & 0.21 \\
\hline $\mathrm{LSD}(0.05)$ & & 0.04 & 0.12 & $\mathrm{NS}$ \\
\hline \multirow[t]{4}{*}{ Soil 2} & 0.00 & $0 . .11$ & 1.18 & 0.89 \\
\hline & 0.33 & 0.08 & 1.19 & 0.85 \\
\hline & 0.66 & 0.15 & 0.75 & 0.71 \\
\hline & 1.00 & 0.18 & 0.82 & 0.35 \\
\hline $\operatorname{LSD}(0.05)$ & & 0.03 & 0.14 & 0.15 \\
\hline \multirow[t]{4}{*}{ Soil 3} & 0.00 & 0.11 & 0.98 & 1.15 \\
\hline & 0.33 & 0.13 & 0.95 & 1.06 \\
\hline & 0.66 & 0.17 & 0.58 & 0.85 \\
\hline & 1.00 & 0.16 & 0.51 & 0.78 \\
\hline LSD & & 0.05 & 0.13 & 0.21 \\
\hline
\end{tabular}


In red clover tissue $\mathrm{Pb}$ and $\mathrm{As}$ concentration were much higher than those observed for JM grown on soils with same P treatment( Table 6.6 ). Even in this crop at high application rates of $\mathrm{P}$ both $\mathrm{Pb}$ and $\mathrm{As}$ concentrations in plant tissue declined. Decline in $\mathrm{Pb}$ concentration was expected, but no known explanation could sufficiently describe the observed antagonistic relationship between $\mathrm{P}$ and As. Based on the chemical structure of $\mathrm{P}$ and As atoms, it is possible that As and $\mathrm{P}$ can coprecipitate in a pyromorphite crystal where As substitutes for $\mathrm{P}$ atoms in the structure of a pyromorphite crystal. Soil and plant data collected from the greenhouse experiments was insufficient to conclusively prove this possibility.

\subsubsection{Arsenic and P Co-precipitation Reactions (Laboratory Experiments)}

When equimolar ratios of $\mathrm{Pb}$ and $\mathrm{P}$ were reacted, $\mathrm{Pb}$ concentrations in the equilibrium solution were less than the method detection limit for the electrothermal atomic absorption spectrophotomer of $2 \mathrm{~g} \mathrm{~L}^{-1}$. When As was added along with the $\mathrm{P}$, no arsenic could be detected in the equilibrium solution even when the reacting solution contained As concentrations of approximately $75 \mathrm{mg} \mathrm{L}^{-1}(0.001 \mathrm{M} \mathrm{As})$ (Table 6.7). Even when As concentrations of $750 \mathrm{mg} \mathrm{L}^{-1}$ were present almost all As was incorporated into the structure of the precipitates. These experiments clearly indicated that As was removed from the solution when $\mathrm{Pb}$ and $\mathrm{P}$ reacted to form pyromorphite. Loss of a solute from a solution can occur by any of the following mechanism: 1) sorption of the solute on the surface of solid by formation of inner or outer sphere complexes; 2) surface precipitation of one solute on the surface of the solid; 3) co-precipitation of the solute with another precipitating compound. Reaction kinetics for precipitation of pyromorphite 
Table 6.6. Effect of application rates of phosphates on $\mathrm{Pb}$ and As concentrations in red clover grown on three soils contaminated with both $\mathrm{Pb}$ and $\mathrm{As}$

\begin{tabular}{|c|c|c|c|c|}
\hline Soil & $\begin{array}{l}\text { Phosphate } \\
\text { Treatments } \\
\mathrm{Pb} / \mathrm{P} \text { molar } \\
\text { ratios }\end{array}$ & $\begin{array}{l}\text { Phosphorus } \\
\text { Concentrations } \\
\text { in Plant } \\
\text { Tissue(mg kg-1 } \\
\text { dry matter) }\end{array}$ & $\begin{array}{l}\text { Lead } \\
\text { Concentrations } \\
\text { (mg kg }{ }^{-1} \text { Dry } \\
\text { matter) }\end{array}$ & $\begin{array}{l}\text { Arsenic } \\
\text { Concentrations } \\
\left(\mathrm{mg} \mathrm{kg}^{-1} \text { Dry }\right. \\
\text { matter) }\end{array}$ \\
\hline \multirow[t]{4}{*}{ Soil-A } & 0.00 & 0.14 & 3.15 & 0.31 \\
\hline & 0.33 & .09 & 2.78 & 0.32 \\
\hline & 0.66 & 0.21 & 1.9 & 0.28 \\
\hline & 1.00 & 0.25 & 0.85 & 0.31 \\
\hline $\operatorname{LSD}(0.05)$ & & 0.07 & 0.26 & NS \\
\hline \multirow[t]{4}{*}{ Soil-B } & 0.00 & $0 . .16$ & 2.75 & 1.13 \\
\hline & 0.33 & 0.15 & 1.84 & 1.16 \\
\hline & 0.66 & 0.22 & 1.18 & 0.44 \\
\hline & 1.00 & 0.23 & 0.78 & 0.25 \\
\hline $\operatorname{LSD}(0.05)$ & & 0.05 & 0.27 & 0.21 \\
\hline \multirow[t]{4}{*}{ Soil-C } & 0.00 & 0.11 & 2.71 & 1.55 \\
\hline & 0.33 & 0.13 & 2.22 & 1.59 \\
\hline & 0.66 & 0.21 & 1.69 & 0.92 \\
\hline & 1.00 & 0.25 & 1.16 & 0.42 \\
\hline LSD & & 0.07 & 0.41 & 0.25 \\
\hline
\end{tabular}


Table 6.7 Lead and As concentrations in equilibrium solutions when $0.1 \mathrm{M}$ $\mathrm{Pb}\left(\mathrm{NO}_{3}\right)_{2}$ were reacted with $0.1 \mathrm{M}$ phosphate solution that contained 0.0001 to $0.01 \mathrm{M} \mathrm{Na}\left(\mathrm{AsO}_{4}\right)_{2}$

\begin{tabular}{|l|l|l|l|l|}
\hline \multicolumn{2}{|l|}{ Molar Concentrations of Reactants } & \multicolumn{2}{|}{$\begin{array}{l}\text { Equilibrium Concentrations } \\
\left(\mathrm{g} \mathrm{L}^{-1}\right)\end{array}$} \\
\hline $\mathrm{Pb}$ & $\mathrm{P}$ & As & $\mathrm{Pb}$ & As \\
\hline 0.1 & 0.1 & 0.0 & $<2$ & $\mathrm{ND}$ \\
\hline 0.1 & 0.1 & 0.0001 & $<2$ & $\mathrm{ND}$ \\
\hline 0.1 & 0.2 & 0.0002 & $<2$ & $\mathrm{ND}$ \\
\hline 0.1 & 0.1 & 0.001 & 4.5 & $\mathrm{ND}$ \\
\hline 0.1 & 0.1 & 0.01 & $<2.0$ & 6 \\
\hline
\end{tabular}

* Non determined 
are extremely rapid (Ma et al., 1993). Thus, in our experiments As could be removed from the solution by any of the reactions. Homogeneous inclusions of As by co-precipitation in pyromorphite can $\mathrm{Pb}$ to crystal distortions that can be measured by x-ray diffraction. Xray diffraction analysis was conducted for pure pyromorphite and lead arsenate minerals . X-ray diffraction pattern showed that " $\mathrm{d}$ " value for 113 line was $3.34 \mathrm{~nm}$ for pyromorphite and it shifted to $3.38 \mathrm{~nm}$ when $\mathrm{Pb}$ was precipitated as lead arsenate (Figure 6.1). There was a linear increase in " $d$ " value with increasing fractions of As in the precipitate. These results clearly demonstrate that As is incorporated into the crystal structure of pyromorphite and, consequently there is a distortion in the crystal structure of this mineral. Our results suggest that use of phosphates for remediation of sites that are contaminated with both $\mathrm{Pb}$ and $\mathrm{As}$ is feasible. 


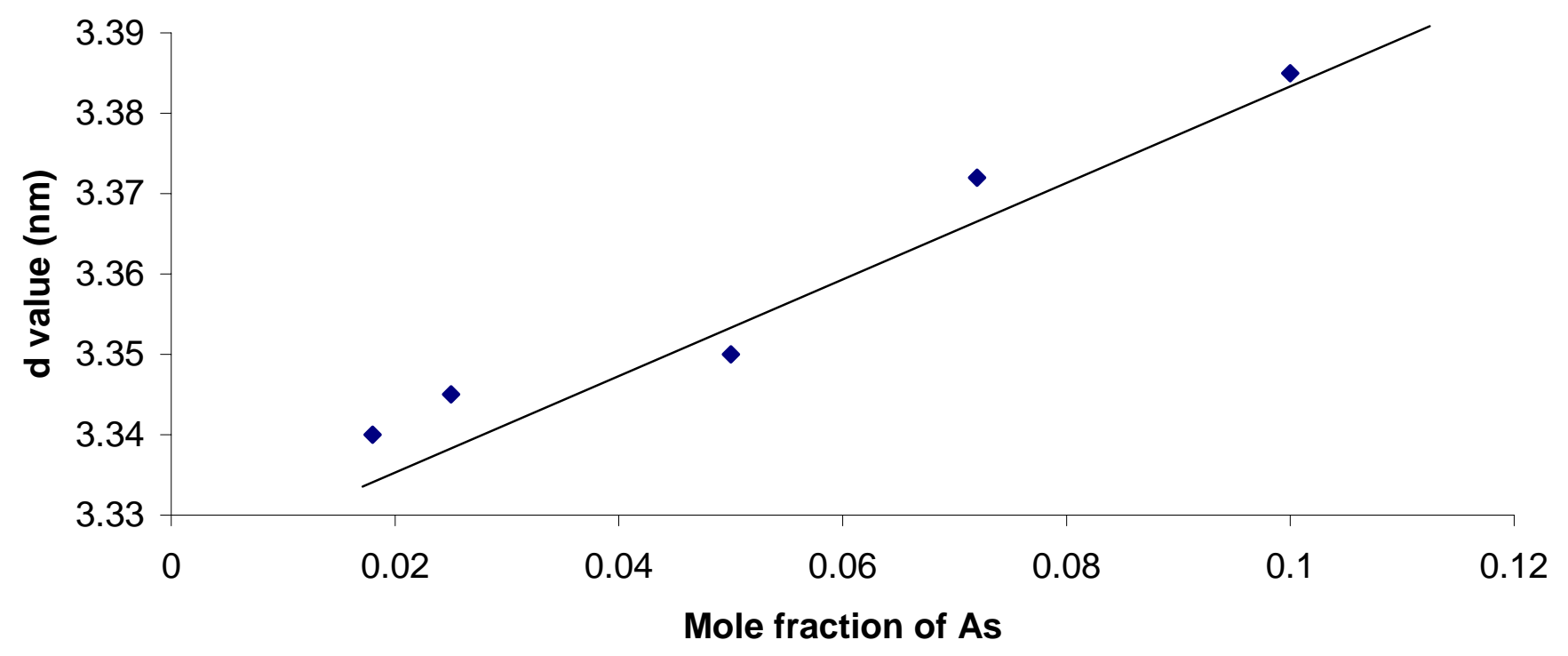

Figure 6.1: Effect of mole fraction of As in P soluton on (113) d spacing of pyromorphite crystal 


\section{References}

Chao, T.T. and R.S. Salazone. 1989. Fractionation of soil selenium by partial dissolution. Soil Sci. Soc. Am. J. 53: 385-392.

Davenport, J.R., and F.J. Peryea. 1991. Phosphate fertilizers influence leaching of lead and arsenic in soil contaminated with lead arsenate. Water, Air and Soil Pollution 57/58: 101-110.

Gee, G.W ., and J.W.Bauder.1986. Particle size analysis.p383-411.In A.Kulte(ed). Methods of soil analysis,part1. $2^{\text {nd }}$ ed. Agron Monogr.9. ASA and SSSA, Madison, WI.

Gustafsson, J.P., and G. Jacks. 1995. Arsenic geochemistry in forested soil profiles as revealed by solid phase studies. Appl. Geochem. 10: 307-315.

Hamel, S.C., B. Buckely and P.J.Paul.1998. Bioaccessibilty of metals in soils for different liquid to solid ratios in synthetic gastric fluid.Environ. Sci. Technol.32:358-362.

Jain, A., K.P. Raven, and R.H. Loeppert. 1997. Arsenite and arsenate adsorption on ferrihydrite: surface charge reduction and net $\mathrm{OH}^{-}$release stoichiometry. Environ. Sci. Technol. 33: 1179-1184.

Laperche, V., S.J. Triana, P. Gaddam, and T.J. Logan. 1996. Chemical and mineralogical characterization of $\mathrm{Pb}$ in a contaminated soil: reaction with synthetic apatite. Environ. Sci. Technol. 30: 3321-3326.

Ma, Q.Y. 1996. Factor of influencing the effectiveness and stability of aqueous lead immobilization by hydroxyapatite. J. Environ. Qual. 25: 1420-1429.

Ma, Q.Y., T.J. Logan, and S.J. Triana. 1995. Lead immobilization from aqueous solution and contaminated soils using phosphate rock. Environ. Sci. Technol. 29: 11181126.

Ma, Q.Y., S.J. Triana, T.J. Logan, and J.A. Ryan. 1993. In situ Pb immobilization by apatite. Environ. Sci. Technol. 27: 1803-1810.

McLean, E.O.1982. Soil pH and lime requirement.pp199-223. In A.L.Page, R.H. Miller, and D.R.Keeney(ed) Methods of Soil Analysis. Part2. Am. Soc. Agron., Madison, WI.

Nriagu, J.1973. Lead orthophosphates. I. Stability of chloropyromorphite at $25^{\circ} \mathrm{C}$. Geochim. et Cosmochim. Acta 37: 367-377. 
Peryea, F.J. 1991. Phosphate induced release of arsenic from soils contaminated with lead arsenate. Soil Sci. Soc. Am. J. 55: 1301-1306.

Reed, B.E. and S.R. Cline. 1994. Retention and release of lead by a very fine sandy loam. I. Isotherm modeling. Separation Sci. Technol. 29: 1529-1551.

Soil Survey Staff.1984. Procedure for collecting soil samples and methods of analysis for soil survey. In Soil Survey investigations. Report No. 1. USDA Soil Conversation Service, Washington, D.C.

Sparks,D.L.,A.L.Page.,P.A.Helmke., R.H.Loeppert., P.N. Soltanpour.,M.A. Tabatabai., C.T.Johnston., and M.E. Sumner.1996. Methods in soil analysis part 3- chemical method.Stumm, W. and J.J. Morgan. 1981. Aquatic Chemistry. John Wiley \& Sons, New York.ASA and SSSA, Madison, WI.

Takeuchi, Y., H. Arai.1990. Removal of lead by synthesized hydroxapatite. J Chem. Eng. Jpn.23:75-80.

U.S. Environment Protection Agency. 1996. Soil screening guidance. Tech. Background Doc. USEPA Rep. 540/R-95/ 128. U.S. Gov. Print Office, Washington, D.C.

Walkley, A., and I.A. Black.1934. An examination of the Degtjareff method for determining soil organic matter and a proposed modification of the chromic acid titration method. Soil Sci. 37:29-38.

Zhang, P. and J.A. Ryan. 1999. Transformation of $\mathrm{Pb}$ from cerrusite to chloropyromorphite in the presence of hydroxyapatite under varying conditions of pH. Environ. Sci. Technol. 33: 625-630.

Zimdahl, R.L. and R.K. Skogube. 1997. Behavior of lead in soil. Environ. Sci. Technol. 11: $1202-1207$. 